\title{
Catálogo de los procesos inquisitoriales del Tribunal del Santo Oficio de Barcelona
}

Juan Blázquez Miguel

Considero que es prácticamente imposible pretender hacer estudios serios, exhaustivos, sin contar con unos imprescindibles instrumentos de trabajo, que en estas arduas labores de investigación histórica de cuanto fue y supuso el Tribunal del Santo Oficio de la Inquisición son los catálogos. Pionero de los mismos fue el publicado por Vignau en 1903: "Catálogo de las Causas de Fe seguidas ante el Tribunal del Santo Oficio de Toledo". Hubieron de transcurrir sesenta y dos años para que otra obra de similares características viese la luz. Se trata de "Registros de los documentos del Santo Oficio de Cuenca y Sigüenza", de S. Cirac Estopañán, ampliada en 1982 por D. Pérez Ramírez, con el título "Catálogo del Archivo de la Inquisición de Cuenca». En 1977, N. Moreno Garbayo publicó su "Catálogo de alegaciones fiscales", que sirve para esbozar someramente la inextricable selva de la documentación inquisitorial conservada en el Archivo Histórico Nacional.

A esto se reducía, prácticamente, cuanto al tema había escrito, hasta que 1987, y aprovechando el exhaustivo estudio que llevé a cabo para escribir mi libro El Tribunal de la Inquisición en Murcia, publiqué: "Catálogo de procesos inquisitoriales del Tribunal del Santo Oficio de Murcia». Al margen de esta obra, algunos otros trabajos relativos a este tema también he publicado en diversas revistas: "Algunas precisiones sobre estadistica inquisitorial: el ejemplo de la actividad antijudía del Tribunal de Granada en el siglo XVII" y "Judaizantes en Almazán, Berlanga y 
Medinaceli» (en prensa), que dan al traste con mucho de cuanto referente a cifras se había escrito.

Se barajan números, se ofrecen estadísticas, más o menos cercanas a la realidad, basadas en relaciones de causas, pero con eso no es suficiente. Son precisos catálogos como los anteriormente citados, en los que figuren los máximos datos posibles y que recojan lo más minuciosamente que se pueda todos los procesos existentes, incluso aquellos de los que no tenemos otra noticia que una escueta referencia que ni siquiera nos sirva para conocer de qué delito se trata, pero que nos sirve para saber que hubo un delito más que añadir a la estadística.

El Tribunal de Barcelona no era muy conocido. Los historiadores catalanes no parecen haber sentido un especial interés por esta Institución, bien porque la relacionaban con un poder extraño, que nada tenía que ver con su mundo, bien porque su actividad no gozó de interés especifico. Con todo, hay que tener en cuenta que, al margen de su poco simpática labor, macabra en muchas ocasiones, los datos que los vetustos documentos nos ofrecen no se circunscriben completamente al delito juzgado. En ellos se nos abre un mundo fascinante en el que como manantial inagotable van fluyendo datos de todo tipo relacionados con la economía, con las costumbres - muchas de ellas perdidas-, con la religión, con la sociedad, con las guerras, con las miserias, hambres y plagas, etc., como perfectamente puede comprobarse en el libro que sobre este Tribunal he escrito.

He procurado reflejar en este Catálogo cuantos documentos han pasado por mis manos; no obstante, lagunas debidas a pérdidas de documentos son inevitables, a las que hay que añadir las que a mí se me hayan pasado por descuido, pues ante todo hay que tener presente que éste ha sido un trabajo realizado personalmente, sin ningún tipo de colaboración, con las deficiencias que ello puede conllevar, y sin utilizar ninguno de esos elementos que la moderna cibernética nos ha impuesto.

Para una mejor comprensión de este Catálogo considero imprescindible dar unas normas con las cuales el investigador no tendrá problema alguno para saber a qué atenerse.

En primer lugar, consta de dos partes: en la primera se encuentran los estrictos procesos de causas de fe, divididos por delitos. En la segunda, los procesos por causas civiles y criminales de las que fueron protagonistas los propios familiares o ministros del Santo Oficio o quienes contra ellos se enfrentaron de palabra o hecho.

La mayoría de los documentos se hallan en el Archivo Histórico Nacional, Sección de Inquisición, y de ellos únicamente especifico el libro o legajo donde se encuentran. En los libros sólo especifico el año, pero 
como en ellos los procesos están escritos siguiendo un orden cronológico, fácil será encontrar lo deseado. Los legajos, por su parte, no suelen tener numerada su documentación, por lo que es imprescindible mirar los documentos uno por uno.

En alguna ocasión, sobre todo en el primer capitulo dedicado al criptojudaísmo, figura un autor o un libro impreso, del que se da la oportuna referencia en nota a pie de página. 


\section{ABREVIATURAS}

\section{NACIONALIDADES}

$\begin{array}{ll}\text { (a) } & \text { alemán } \\ \text { (d) } & \text { danés } \\ \text { (e) } & \text { escocés } \\ \text { (f) } & \text { francés } \\ \text { (fl) } & \text { flamenco } \\ \text { (g) } & \text { griego } \\ \text { (h) } & \text { holandés } \\ \text { (hu) } & \text { húngaro } \\ \text { (i) } & \text { italiano } \\ \text { (in) } & \text { inglés } \\ \text { (ir) } & \text { irlandés } \\ \text { (m) } & \text { moro } \\ \text { (ma) } & \text { maltés } \\ \text { (mo) } & \text { morisco } \\ \text { (p) } & \text { portugués } \\ \text { (po) } & \text { polaco } \\ \text { (r) } & \text { ruso } \\ \text { (s) } & \text { suizo } \\ \text { (su) } & \text { sueco } \\ \text { (t) } & \text { turco } \\ \text { (y) } & \text { yugoslavo }\end{array}$

ESTAMENTO RELIGIOSO

$\begin{array}{ll}\text { (ber) } & \text { bernardino } \\ \text { (cap) } & \text { capuchino } \\ \text { (cart) } & \text { cartujo } \\ \text { (cist) } & \text { cisterciense } \\ \text { (cm) } & \text { paul } \\ \text { (cr) } & \text { teatino } \\ \text { (csb) } & \text { San Basilio } \\ \text { (er) } & \text { ermitaño } \\ \text { (esc) } & \text { escolapio } \\ \text { (jer) } & \text { jerónimo }\end{array}$




$\begin{array}{ll}\text { (oc) } & \text { carmelita } \\ \text { (ocso) } & \text { trapense } \\ \text { (of) } & \text { franciscano } \\ \text { (om) } & \text { mercedario } \\ \text { (omi) } & \text { mínimo } \\ \text { (op) } & \text { dominico } \\ \text { (osa) } & \text { agustino } \\ \text { (osb) } & \text { benedictino } \\ \text { (osm) } & \text { servita } \\ \text { (osst) } & \text { trinitario } \\ \text { (s) } & \text { sacerdote secular }\end{array}$

\section{MONJAS}

(cla) clarisa

(cmi) carmelita

(conc) concepcionista

(dom) dominica

(o.min) minima 
INDICE

\section{PROCESOS DE CAUSAS DE FE}

1. Criptojudaísmo

2. Islamismo

3. Luteranismo

4. Bigamia

5. Fornicarios

6. Solicitación

7. Sodomía

8. Bestialidad

9. Proposiciones

10. Palabras

11. Blasfemias

12. Misticismo heterodoxo

13. Superstición

14. Masonería

15. Fautoría. Oposición al Santo Oficio

16. Falsas testificaciones

17. Irreverencias y sacrilegios

18. Censura

19. Religiosos casados

20. Celebrantes de misa sin estar autorizados

21. Delitos en la confesión y comunión

22. Bautizos múltiples

23. Comer carne en días prohibidos

24. Delitos varios

25. Delitos desconocidos

\section{PROCESOS CIVILES Y CRIMINALES}

1. Bandolerismo

2. Pasar caballos a Francia

3. Portar armas prohibidas

4. Usura. Moneda falsa

5. Riñas. Insultos

6. Incontinencia sexual 
7. Asesinatos

8. Delitos varios de familiares y ministros

9. Robos a familiares y ministros

10. Desacatos

11. Fingimiento de cargo inquisitorial

12. Detenciones indebidas y fugas

13. Quebrantamiento de destierro

14. Delitos varios 
Catálogo de los procesos inquisitoriales del Tribunal del...

\section{PROCESOS DE CAUSAS DE FE}

Apellidos y nombre; profesión Localidad Fecha Fuente * Sentencia

\section{CRIPTOJUDAÍSMO}

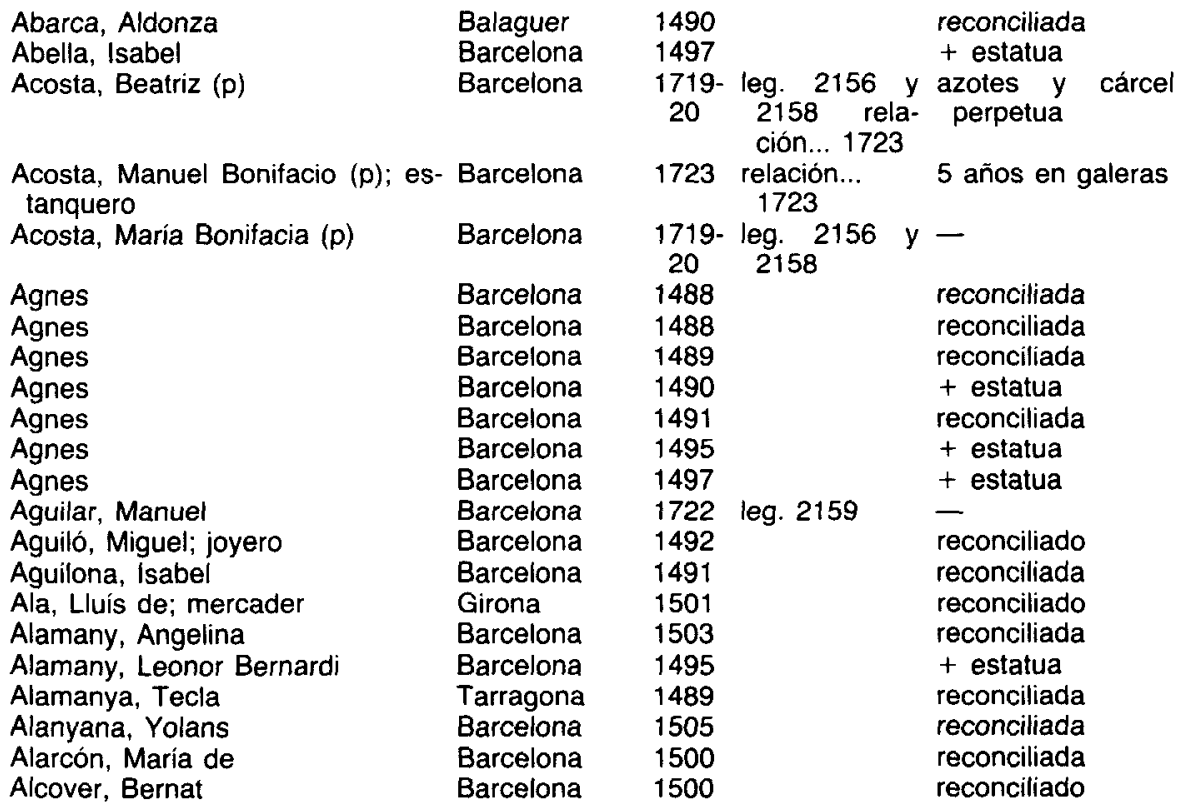

* Se observará que en la mayor parte de los procesos reseñados no figura dato alguno. Ello es debido a que están basados en el libro de P.M. Carbonell: Liber descripcionis, y para su comprobación no es preciso más que recurrir al año correspondiente, ya que en dicha obra vienen reseñados cronológicamente.

Las otras fuentes son los dos libros de Relaciones de Autos de Fe, de los años 1723 y 1726, y los legajos o libros del Archivo Histórico Nacional, Sección Inquisición, que se indican. 
JUAN BLÁZQUEZ MIGUEL

\begin{tabular}{|c|c|c|c|}
\hline Apellidos y nombre; profesión & Localidad & Fecha Fuente * & Sentencia \\
\hline Alcovera, Serena & Barcelona & 1500 & reconciliada \\
\hline Alenya, Gabriel (y esposa) & Montblanc & 1489 & reconciliados \\
\hline Aldonza & Barcelona & 1487 & reconciliada \\
\hline Aldonza & Barcelona & 1488 & + estatua \\
\hline Aldonza & Barcelona & 1488 & + estatua \\
\hline Aldonza & Barcelona & 1488 & reconciliada \\
\hline Aldonza & Barcelona & 1488 & reconciliada \\
\hline Aldonza & Tarragona & 1489 & reconciliada \\
\hline Aldonza & Barcelona & 1490 & + estatua \\
\hline Aldonza & Barcelona & 1490 & + estatua \\
\hline Aldonza & Barcelona & 1490 & + estatua \\
\hline Aldonza & Barcelona & 1490 & + estatua \\
\hline Aldonza & Barcelona & 1490 & + estatua \\
\hline Aldonza & Barcelona & 1490 & + estatua \\
\hline Aldonza & Balaguer & 1490 & reconciliada \\
\hline Aldonza & Balaguer & 1490 & reconciliada \\
\hline Aldonza & Barcelona & 1491 & + estatua \\
\hline Aldonza & Barcelona & 1491 & + estatua \\
\hline Aldonza & Barcelona & 1491 & reconciliada \\
\hline Aldonza & Barcelona & 1491 & reconciliada \\
\hline Aldonza & Barcelona & 1491 & reconciliada \\
\hline Aldonza & Barcelona & 1491 & + estatua \\
\hline Aldonza & Barcelona & 1492 & reconciliada \\
\hline Aldonza & Barcelona & 1492 & reconciliada \\
\hline Aldonza & Barcelona & 1492 & reconciliada \\
\hline Aldonza & $\begin{array}{l}\text { Castello } \\
\text { d'Empuries }\end{array}$ & 1495 & + estatua \\
\hline Aldonza & Girona & 1495 & reconciliada \\
\hline Aldonza & Perpignan & 1495 & reconciliada \\
\hline Aldonza & Barcelona & 1496 & reconciliada \\
\hline Aldonza & Barcelona & 1497 & + estatua \\
\hline Aldonza & Barcelona & 1497 & + estatua \\
\hline Aldonza & Barcelona & 1504 & + estatua \\
\hline Aldonza & Barcelona & 1505 & reconciliada \\
\hline Alenya, Luis & Barcelona & 1489 & reconciliado \\
\hline Amada & Barcelona & 1488 & reconciliada \\
\hline Amat, Pere (y su esposa) & Barcelona & 1491 & + estatua \\
\hline Amoros, Agusti & Barcelona & 1504 & + estatua \\
\hline Amorós, Andreas; curtidor & Barcelona & 1487 & reconciliado \\
\hline Amorós, Andreas; curtidor & Barcelona & 1504 & reconciliado \\
\hline Amoros, Baltasar & Barcelona & 1488 & reconciliado \\
\hline Amorosa, Violant & Barcelona & 1487 & reconciliada \\
\hline Andrade, Félix Duarte de; cirujano & Barcelona & $\begin{array}{l}\text { relación... } \\
1726\end{array}$ & + persona \\
\hline Andreas, Francesc & Barcelona & 1489 & + estatua \\
\hline Andreas, Joan & Barcelona & 1489 & + estatua \\
\hline Andreas, Joan; mercader & Barcelona & 1491 & + estatua \\
\hline Andreas, Llorenc & Barcelona & 1491 & + estatua \\
\hline Andreas, Marc, esposa de & Girona & 1491 & + estatua \\
\hline Andreas, Miquel & $\begin{array}{l}\text { Castello } \\
\text { d'Empuries }\end{array}$ & 1495 & + estatua \\
\hline Andreas, Rafael (y su esposa) & Barcelona & 1488 & + estatua \\
\hline Andreu, Guillem & Girona & 1491 & + estatua \\
\hline Ángel & Barcelona & 1490 & + estatua \\
\hline Angelina & Barcelona & 1487 & reconciliada \\
\hline Angelina & Barcelona & 1488 & reconciliada \\
\hline
\end{tabular}


Catálogo de los procesos inquisitoriales del Tribunal del...

\begin{tabular}{|c|c|c|c|}
\hline Apellidos y nombre; profesión & Localidad & Fecha Fuente & Sentencia \\
\hline Angelina & Barcelona & 1488 & reconciliada \\
\hline Angelina & Barcelona & 1488 & reconciliada \\
\hline Angelina & Barcelona & 1488 & reconciliada \\
\hline Angelina & Barcelona & 1488 & reconciliada \\
\hline Angelina & Barcelona & 1488 & reconciliada \\
\hline Angelina & Tarragona & 1489 & reconciliada \\
\hline Angelina & Balaguer & 1490 & reconciliada \\
\hline Angelina & Barcelona & 1491 & + estatua \\
\hline Angelina & Barcelona & 1491 & reconciliada \\
\hline Angelina & Barcelona & 1492 & reconciliada \\
\hline Angelina & Barcelona & 1492 & reconciliada \\
\hline Angelina & Balaguer & 1493 & + estatua \\
\hline Angelina & Barcelona & 1495 & + estatua \\
\hline Angelina & Barcelona & 1497 & reconciliada \\
\hline Angelina & Barcelona & 1505 & reconciliada \\
\hline Angelini, Juan (i); soldado & - & leg. 2170 & ¿huido? \\
\hline Ángelo & Barcelona & 1490 & + estatua \\
\hline Antonia & Barcelona & 1488 & reconciliada \\
\hline Antonia (y su hija) & Barcelona & 1490 & + estatua (2) \\
\hline Antonia & Barcelona & 1495 & + estatua \\
\hline Antonia & $\begin{array}{l}\text { Castello } \\
\text { d'Empuries }\end{array}$ & 1495 & + estatua \\
\hline Antonia & Barcelona & 1497 & + estatua \\
\hline Arenas de Écija, Pedro; galeote & - & libro 731 & azotes y galeras \\
\hline Arguens, Gabriel & Barcelona & 1488 & + estatua \\
\hline $\begin{array}{l}\text { Arguens, Gabriel (y madre, } \\
\text { esposa e hija); tintorero }\end{array}$ & Barcelona & 1489 & + estatua (4) \\
\hline Arguens, Leonor & Barcelona & 1491 & + estatua \\
\hline Avinio; tendero & Barcelona & 1491 & + estatua \\
\hline Avinyona, Violant & Barcelona & 1502 & reconciliada \\
\hline Aymeric, Pau; tejedor de velos & Barcelona & 1487 & reconciliada \\
\hline Aymeric, Violant & Barcelona & 1503 & reconciliada \\
\hline Badía, Eduardo & Barcelona & 1495 & + estatua \\
\hline $\begin{array}{l}\text { Badía, Francesc (y su esposa); } \\
\text { tejedor }\end{array}$ & Barcelona & 1490 & + estatua (2) \\
\hline Badia, Francesc; tejedor & Barcelona & 1491 & reconciliado \\
\hline Badía, Gaspar; mercader & Barcelona & 1487 & reconciliado \\
\hline Badía, Joan; coralero & Barcelona & 1490 & + estatua \\
\hline $\begin{array}{l}\text { Badía, Melcior (y su esposa); } \\
\text { tendero }\end{array}$ & Barcelona & 1491 & + estatua (2) \\
\hline Badía, Melcior & Barcelona & 1491 & + estatua \\
\hline Badía, Salvador; tejedor & Barcelona & 1497 & + estatua \\
\hline Badorch, Pere & Barcelona & 1488 & reconciliado \\
\hline Baes de Acevedo, Manuel (p) & Barcelona & libro 733 & - \\
\hline Bages, Beatriu & Barcelona & 1488 & reconciliada \\
\hline Bages, Violant & Barcelona & 1503 & reconciliada \\
\hline Baidofer, Lluís & Barcelona & 1487 & reconciliado \\
\hline Balerna; roparejero & Barcelona & 1491 & + estatua \\
\hline Balle, Joan & Barcelona & 1489 & + estatua \\
\hline Balle, Joan; mercader & Barcelona & 1495 & + estatua \\
\hline Balle, Joan & Barcelona & 1497 & + estatua \\
\hline Balle, Mandina & Barcelona & 1495 & + estatua \\
\hline Balle, Simo & Barcelona & 1489 & + estatua \\
\hline Ballester, Francesc; tejedor & Barcelona & 1488 & reconciliado \\
\hline Ballester, Gabriel & Barcelona & 1497 & reconciliado \\
\hline
\end{tabular}


JUAN BLAZQUEZ MIGUEL

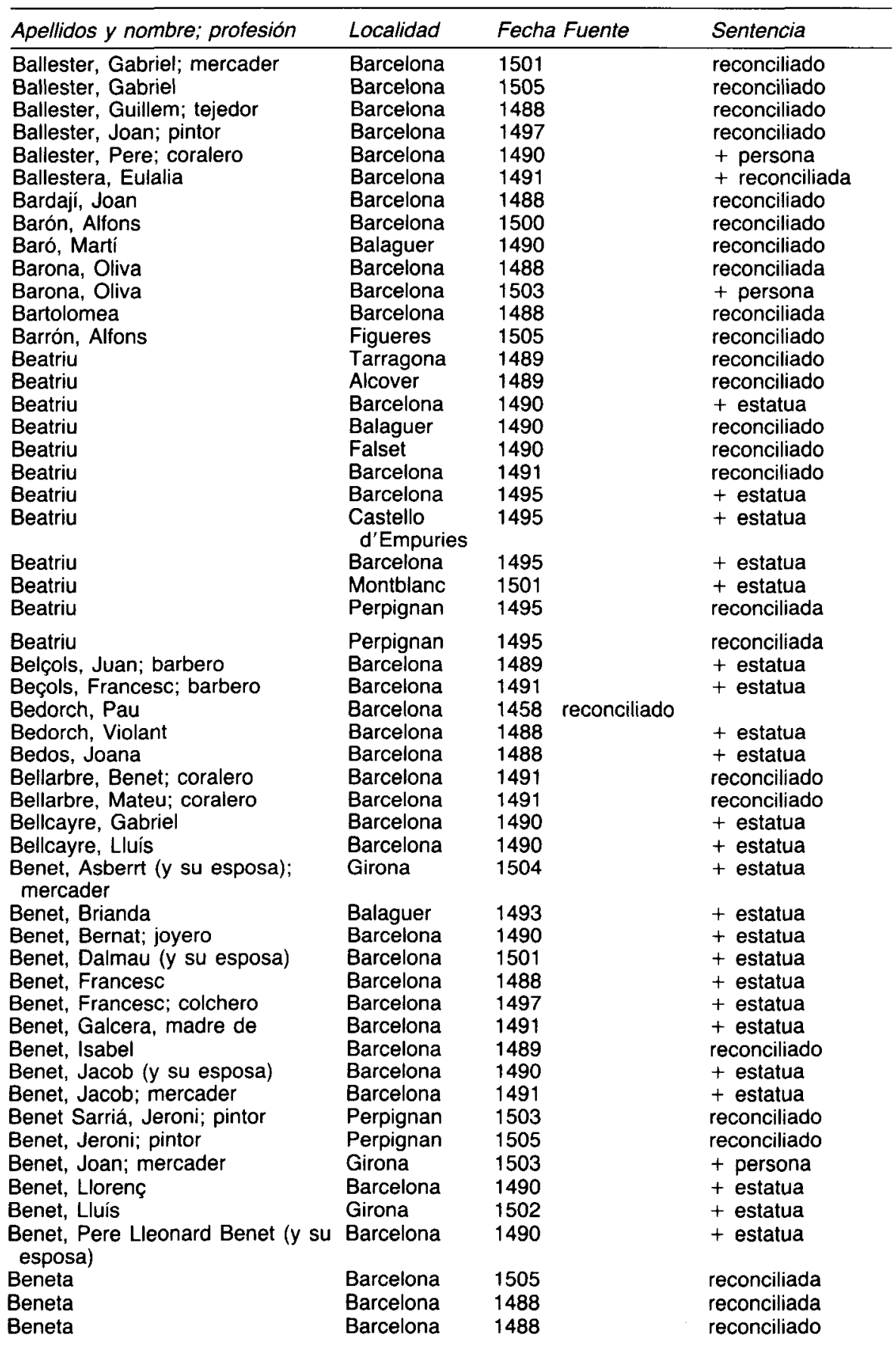


Catálogo de los procesos inquisitoriales del Tribunal del...

\begin{tabular}{|c|c|c|c|}
\hline Apellidos y nombre; profesión & Localidad & Fecha Fuente & Sentencia \\
\hline Beneta, Isabel & Balaguer & 1490 & reconciliada \\
\hline Bernardo Geraldo; tejedor & Barcelona & 1495 & + estatua \\
\hline Bernardo Guillem & Girona & 1491 & + estatua \\
\hline Bernardo, Jacob; mercader & Barcelona & 1490 & + estatua \\
\hline Bernsch, Bonanatus; coralero & Barcelona & 1492 & reconciliado \\
\hline Bertrán, Francesc & Barcelona & 1491 & + estatua \\
\hline Bertrán, Francesc & Barcelona & 1502 & reconciliado \\
\hline Bertrán, Joan; mercader & Barcelona & 1491 & + estatua \\
\hline Besalu, Francesc & Barcelona & 1490 & + estatua \\
\hline Besalu, Rafael & Barcelona & 1490 & + estatua \\
\hline Besaluna, Joana & Barcelona & 1490 & + estatua \\
\hline Besaluna, Violant & Barcelona & 1488 & reconciliada \\
\hline Blanca & Barcelona & 1497 & + estatua \\
\hline Blanca & Barcelona & 1505 & + persona \\
\hline Blanca & Barcelona & 1505 & + persona \\
\hline Blanquina & Barcelona & 1487 & reconciliada \\
\hline Blanquina & Barcelona & 1487 & reconciliada \\
\hline Blanquina & Barcelona & 1488 & reconciliada \\
\hline Blanquina & Barcelona & 1488 & reconciliada \\
\hline Blanquina & Barcelona & 1489 & + estatua \\
\hline Blanquina & Tarragona & 1489 & reconciliada \\
\hline Blanquina & Barcelona & 1490 & + estatua \\
\hline Blanquina & Barcelona & 1490 & + estatua \\
\hline Blanquina & Barcelona & 1490 & + estatua \\
\hline Blanquina & Balaguer & 1490 & reconciliada \\
\hline Blanquina & Barcelona & 1491 & + estatua \\
\hline Blanquina & Barcelona & 1491 & reconciliada \\
\hline Blanquina & Barcelona & 1491 & reconciliada \\
\hline Blanquina & Barcelona & 1491 & reconciliada \\
\hline Blanquina & Girona & 1491 & + estatua \\
\hline Blanquina & Balaguer & 1493 & + estatua \\
\hline Blanquina & Barcelona & 1495 & + estatua \\
\hline Blanquina & Barcelona & 1495 & + estatua \\
\hline Blanquina & Barcelona & 1495 & + estatua \\
\hline Blanquina & $\begin{array}{l}\text { Castello } \\
\text { d'Empuries }\end{array}$ & 1495 & + estatua \\
\hline Blanquina & Girona & 1495 & + estatua \\
\hline Blanquina & Barcelona & 1497 & + estatua \\
\hline Blanquina & Barcelona & 1497 & + estatua \\
\hline Blanquina & Barcelona & 1499 & + estatua \\
\hline Blanquina & Barcelona & 1500 & + estatua \\
\hline Blanquina & Barcelona & 1502 & reconciliada \\
\hline Bonanat, Gabriel; mercader & Barcelona & 1491 & + estatua \\
\hline Bonanat Amorós, Agustí & Barcelona & $\begin{array}{c}1488 y \\
1504\end{array}$ & + estatua \\
\hline Bonanatus & Barcelona & 1490 & + estatua \\
\hline Bonanatus, Jacob; joyero & Barcelona & 1490 & + estatua \\
\hline $\begin{array}{l}\text { Bonanatus, Joan; cuidador de } \\
\text { juegos }\end{array}$ & Barcelona & 1491 & + estatua \\
\hline Bonet, Pere (y su esposa) & Barcelona & 1488 & + estatua \\
\hline Boneta, Beatriu & Barcelona & 1492 & reconciliada \\
\hline Bonsenyor, viuda de & Barcelona & 1490 & + estatua \\
\hline Bosca, Clara & Barcelona & 1497 & + estatua \\
\hline Bosch, Aldonza & Barcelona & 1488 & + estatua \\
\hline Bosch, Baltasar & Barcelona & 1497 & + estatua \\
\hline Bosch, Berenguer & Barcelona & 1497 & + estatua \\
\hline
\end{tabular}


JUAN BLÁZQUEZ MIGUEL

\begin{tabular}{|c|c|c|c|}
\hline Apellidos y nombre; profesión & Localidad & Fecha Fuente & Sentencia \\
\hline Bosch, Clara & Barcelona & 1490 & + estatua \\
\hline Bosch, Francesc & Barcelona & 1491 & + estatua \\
\hline Bosch, Joan & Barcelona & 1490 & + estatua \\
\hline Bosch, Joan & Barcelona & 1490 & + estatua \\
\hline Bosch, Mandina & Barcelona & 1503 & + persona \\
\hline Bosch, Pere; sedero & Barcelona & 1497 & + estatua \\
\hline Bosch, Pere (y su esposa) & Barcelona & 1501 & + estatua \\
\hline Brianda & Barcelona & 1487 & reconciliada \\
\hline Brigida & Barcelona & 1487 & reconciliada \\
\hline Brígida & Barcelona & 1488 & reconciliada \\
\hline Brigida & Barcelona & 1495 & + estatua \\
\hline Brígida & Barcelona & 1497 & + estatua \\
\hline Brigida & Barcelona & 1501 & + estatua \\
\hline Brígida & Barcelona & 1505 & reconciliada \\
\hline Bronto, Gaspar & Barcelona & 1490 & + estatua \\
\hline Bruch, Llorenc; tendero & Perpignan & 1495 & reconciliado \\
\hline Burguera, Eulalia & Barcelona & 1488 & reconciliada \\
\hline Busot, Pere & Barcelona & 1491 & + estatua \\
\hline Buzota, Joana & Barcelona & 1488 & reconciliada \\
\hline Buzota, Gabriela & Barcelona & 1488 & + estatua \\
\hline Cabaçer, Gabriel; sastre & Barcelona & 1496 & reconciliado \\
\hline Cabestany & Barcelona & 1489 & + estatua \\
\hline Cabebera, Leonor & Barcelona & 1500 & absuelta \\
\hline Cabrida, Gabriela & Barcelona & 1492 & reconciliada \\
\hline Cabrit, Joana & Barcelona & 1491 & reconciliada \\
\hline Cabut, Bernat & Barcelona & 1504 & + estatua \\
\hline Caderona, Joan; azucarero & Barcelona & 1491 & + estatua \\
\hline $\begin{array}{l}\text { Calatayud, Antoni (y su madre, } \\
\text { esposa y suegra); zapatero }\end{array}$ & Barcelona & 1501 & + estatua \\
\hline $\begin{array}{l}\text { Calces, Nicolau (y su esposa); } \\
\text { curtidor }\end{array}$ & & 1988 & +estatua \\
\hline Callar, Ponç; joyero & Perpignan & 1495 & reconciliado \\
\hline Camp-Ells, esposa de & Barcelona & 1491 & + estatua \\
\hline Camp-Ells, Bernat; mercader & Barcelona & 1492 & reconciliado \\
\hline Campos, Melcior; tejedor & Barcelona & libro 730 & absuelto \\
\hline Cantí, Joan; mercader & Barcelona & 1495 & + estatua \\
\hline Cantó, Esteve & Barcelona & 1497 & + estatua \\
\hline Cantó, Llorenç; tejedor & Barcelona & 1492 & reconciliado \\
\hline Cantó, Pau; tornero & Barcelona & 1491 & reconciliado \\
\hline Capreti, Angelo (i) & - & libro 735 & destierro \\
\hline Casasages, Pere; coralero & Barcelona & 1488 & reconciliado \\
\hline Carcasona & Barcelona & 1490 & + estatua \\
\hline Carcason, Joana & Barcelona & 1488 & + estatua \\
\hline Cardona, Violant & Barcelona & 1500 & absuelta \\
\hline Cartella, Gaspar & Barcelona & 1491 & + estatua \\
\hline Cartella, Galceran & Barcelona & 1491 & + estatua \\
\hline Cartella, Jacob & Barcelona & 1490 & + estatua \\
\hline Cartella, Jacob & Barcelona & 1491 & + estatua \\
\hline Cartellana, esposa de & Barcelona & 1490 & + estatua \\
\hline $\begin{array}{l}\text { Cartellón, Dalmau (su esposa y } \\
\text { su madre); mercader }\end{array}$ & Barcelona & 1489 & + estatua \\
\hline Casafranca, Jaume & Balaguer & 1490 & reconciliado \\
\hline $\begin{array}{l}\text { Casafranca, Jacob; lugarteniente } \\
\text { del tesoro }\end{array}$ & Barcelona & 1505 & + persona \\
\hline Casaldáguila, Baltasar de & Pons & 1490 & reconciliado \\
\hline Casanyes, Jacob; mercader & Perpignan & 1495 & reconciliado \\
\hline
\end{tabular}


Catálogo de los procesos inquisitoriales del Tribunal del...

\begin{tabular}{|c|c|c|c|}
\hline Apellidos y nombre; profesión & Localidad & Fecha Fuente & Sentencia \\
\hline $\begin{array}{l}\text { Casas, Llorenç; joyero } \\
\text { Castanyer, Joan } \\
\text { Castanyera, Clara } \\
\text { Castanyera, Constança } \\
\text { Castell, Galceran; coralero } \\
\text { Castell, Gabriel (y su esposa); } \\
\text { mercader }\end{array}$ & $\begin{array}{l}\text { Barcelona } \\
\text { Barcelona } \\
\text { Barcelona } \\
\text { Barcelona } \\
\text { Barcelona } \\
\text { Barcelona }\end{array}$ & $\begin{array}{l}1667 \\
1499 \\
1503 \\
1488 \\
1490 \\
1488\end{array}$ & $\begin{array}{l}\text { suspenso } \\
\text { absuelto } \\
\text { reconciliado } \\
\text { reconciliada } \\
+ \text { estatua } \\
\text { reconciliados }\end{array}$ \\
\hline Castelló, Joan; joyero & Barcelona & 1492 & reconciliado \\
\hline Castelló, Joan & Barcelona & 1502 & reconciliado \\
\hline Castellona, Aldonza & Barcelona & 1492 & reconciliada \\
\hline Castellana, Florencia & Barcelona & 1497 & + estatua \\
\hline Castelló de Mallorca & Barcelona & 1501 & + estatua \\
\hline Catalín, Pe (y su hijo); mercader & Barcelona & libro 242 & reconciliados \\
\hline Caterina & Barcelona & 1487 & reconciliada \\
\hline Caterina & Balaguer & 1490 & reconciliada \\
\hline Caterina & Barcelona & 1491 & + estatua \\
\hline Caterina & Barcelona & 1491 & + estatua \\
\hline Caterina & Barcelona & 1491 & + estatua \\
\hline Caterina & Barcelona & 1495 & + estatua \\
\hline Caterina & Barcelona & 1495 & + estatua \\
\hline Caterina & Barcelona & 1496 & reconciliada \\
\hline Caterina & Barcelona & 1500 & reconciliada \\
\hline Caterina & Barcelona & 1501 & reconciliada \\
\hline Caterina & Barcelona & 1504 & reconciliada \\
\hline Caterina & Barcelona & 1505 & reconciliada \\
\hline Cavaller, Rafael & Barcelona & 1500 & absuelto \\
\hline $\begin{array}{l}\text { Cavalleria, Gaspar de la (y su } \\
\text { esposa) }\end{array}$ & Barcelona & 1490 & + estatua \\
\hline Celestina & Barcelona & 1497 & reconciliada \\
\hline $\begin{array}{l}\text { Cerdo, Funes (y su esposa) } \\
\text { Cerquosa, Aldonza }\end{array}$ & $\begin{array}{l}\text { Barcelona } \\
\text { Barcelona }\end{array}$ & $\begin{array}{c}1491 \\
1502 y \\
1489\end{array}$ & $\begin{array}{l}+ \text { estatua } \\
\text { reconciliada }\end{array}$ \\
\hline Cenvello, Guerao & Balaguer & 1493 & + estatua \\
\hline Cervello, Guerao & Balaguer & 1493 & + estatua \\
\hline Cervello, Joan & Barcelona & 1490 & + estatua \\
\hline Cirera, Dalmau; curtidor & Barcelona & 1488 & reconciliado \\
\hline $\begin{array}{l}\text { Cicera, Dalmau (y su esposa); } \\
\text { variopola }\end{array}$ & Barcelona & 1504 & $\begin{array}{l}\text { + persona } y+\text { en } \\
\text { estatua }\end{array}$ \\
\hline Cirera, Juan; roparejero & Barcelona & 1488 & reconciliado \\
\hline Clara & Barcelona & 1487 & reconciliada \\
\hline Clara & Barcelona & 1487 & reconciliada \\
\hline Clara & Barcelona & 1488 & reconciliada \\
\hline Clara & Barcelona & 1488 & reconciliada \\
\hline Clara & Barcelona & 1488 & reconciliada \\
\hline Clara & Barcelona & 1488 & + estatua \\
\hline Clara & Barcelona & 1489 & + estatua \\
\hline Clara & Barcelona & 1490 & + estatua \\
\hline Clara & Balaguer & 1490 & reconciliada \\
\hline Clara & Barcelona & 1491 & reconciliada \\
\hline Clara & Barcelona & 1492 & reconciliada \\
\hline Clara & Barcelona & 1492 & reconciliada \\
\hline Clara & Barcelona & 1492 & reconciliada \\
\hline Clara & Balaguer & 1493 & + estatua \\
\hline Clara & Barcelona & 1495 & + estatua \\
\hline Clara & Barcelona & 1497 & reconciliada \\
\hline Clara & Barcelona & 1497 & + estatua \\
\hline
\end{tabular}


JUAN BLAZQUEZ MIGUEL

\begin{tabular}{|c|c|c|c|}
\hline Apellidos y nombre; profesión & Localidad & Fecha Fuente & Sentencia \\
\hline Clara & Barcelona & 1499 & reconciliada \\
\hline Clara & Barcelona & 1504 & + estatua \\
\hline Clara & Barcelona & 1505 & + persona \\
\hline Claver, Guillem & Barcelona & 1488 & reconciliado \\
\hline Claverol, Juan & Balaguer & 1490 & reconciliado \\
\hline Claverola, Gracia & Balaguer & 1490 & reconciliada \\
\hline Clemens, Domenec; tejedor & Barcelona & 1488 & reconciliado \\
\hline $\begin{array}{l}\text { Colell, Ferrer ( y su esposa); } \\
\text { tejedor }\end{array}$ & Tarragona & 1490 & reconciliados \\
\hline Colom, Andreas (y su esposa) & Tarragona & 1489 & reconciliados \\
\hline Colom, Andreas (y su esposa) & Barcelona & 1502 & reconciliados \\
\hline Colom, Francina & Tarragona & 1489 & reconciliada \\
\hline Coloma & Barcelona & 1488 & reconciliado \\
\hline Coloma & Barcelona & 1495 & + estatua \\
\hline Colomer, Galceran; curtidor & Barcelona & 1487 & reconciliado \\
\hline Colomer, Galceran & Barcelona & 1505 & reconciliado \\
\hline Colomer, Galceran; curtidor & Barcelona & 1503 & reconciliado \\
\hline Colomera, Eulalia & Barcelona & 1490 & + estatua \\
\hline Colomba & Barcelona & 1488 & reconciliada \\
\hline Colomba & Barcelona & 1488 & reconciliada \\
\hline Colomba & Barcelona & 1490 & + estatua \\
\hline Colomba & Barcelona & 1490 & + estatua \\
\hline Colomba & Barcelona & 1490 & + estatua \\
\hline Colomba & $\begin{array}{l}\text { Castello } \\
\text { d'Empuries }\end{array}$ & 1495 & + estatua \\
\hline Colomba & Perpignan & 1495 & reconciliado \\
\hline Coll, Pau & Balaguer & 1493 & + estatua \\
\hline Coll, Violant & Barcélona & $\begin{array}{c}1504 y \\
1488\end{array}$ & reconciliada \\
\hline Comte, Bartolomeu & $\begin{array}{l}\text { Castello } \\
\text { D'Empuries }\end{array}$ & 1495 & + estatua \\
\hline Comte, Gabriel, esposa de & Barcelona & 1498 & + estatua \\
\hline Conques, Joan & Barcelona & 1488 & reconciliado \\
\hline Conques, Joan; jubonero & Barcelona & 1488 & reconciliado \\
\hline Constança & Barcelona & 1488 & reconciliada \\
\hline Constança & Barcelona & 1488 & reconciliada \\
\hline Constança & Barcelona & 1488 & reconciliada \\
\hline Constança & Barcelona & 1490 & + estatua \\
\hline Constança & Falset & 1490 & + persona \\
\hline Constança & Barcelona & 1490 & + estatua \\
\hline Constança & Barcelona & 1491 & + estatua \\
\hline Constança & Girona & 1495 & + estatua \\
\hline Constança & Perpignan & 1495 & reconciliada \\
\hline Constança & Barcelona & 1495 & reconciliada \\
\hline Constança & Barcelona & 1497 & reconciliada \\
\hline $\begin{array}{l}\text { Corteyll, Jacob (y su esposa); } \\
\text { comerciante }\end{array}$ & Barcelona & 1489 & reconciliados \\
\hline Corro, Joan; librero & Barcelona & 1489 & reconciliado \\
\hline Corro, Antoni Raimond; librero & Barcelona & 1489 & reconciliado \\
\hline Costa, Bernar, esposa de & Girona & 1491 & + estatua \\
\hline Costa, Guillem & Barcelona & 1491 & + estatua \\
\hline Costa, Jacob & Barcelona & 1491 & + estatua \\
\hline Costa, Joan & Barcelona & 1491 & + estatua \\
\hline Costa, Joana & Barcelona & 1487 & reconciliada \\
\hline Costa, Llorenç; jubonero & Barcelona & 1487 & reconciliado \\
\hline Coyta, Guillem; joyero & Barcelona & 1489 & + estatua \\
\hline
\end{tabular}


Catálogo de los procesos inquisitoriales del Tribunal del...

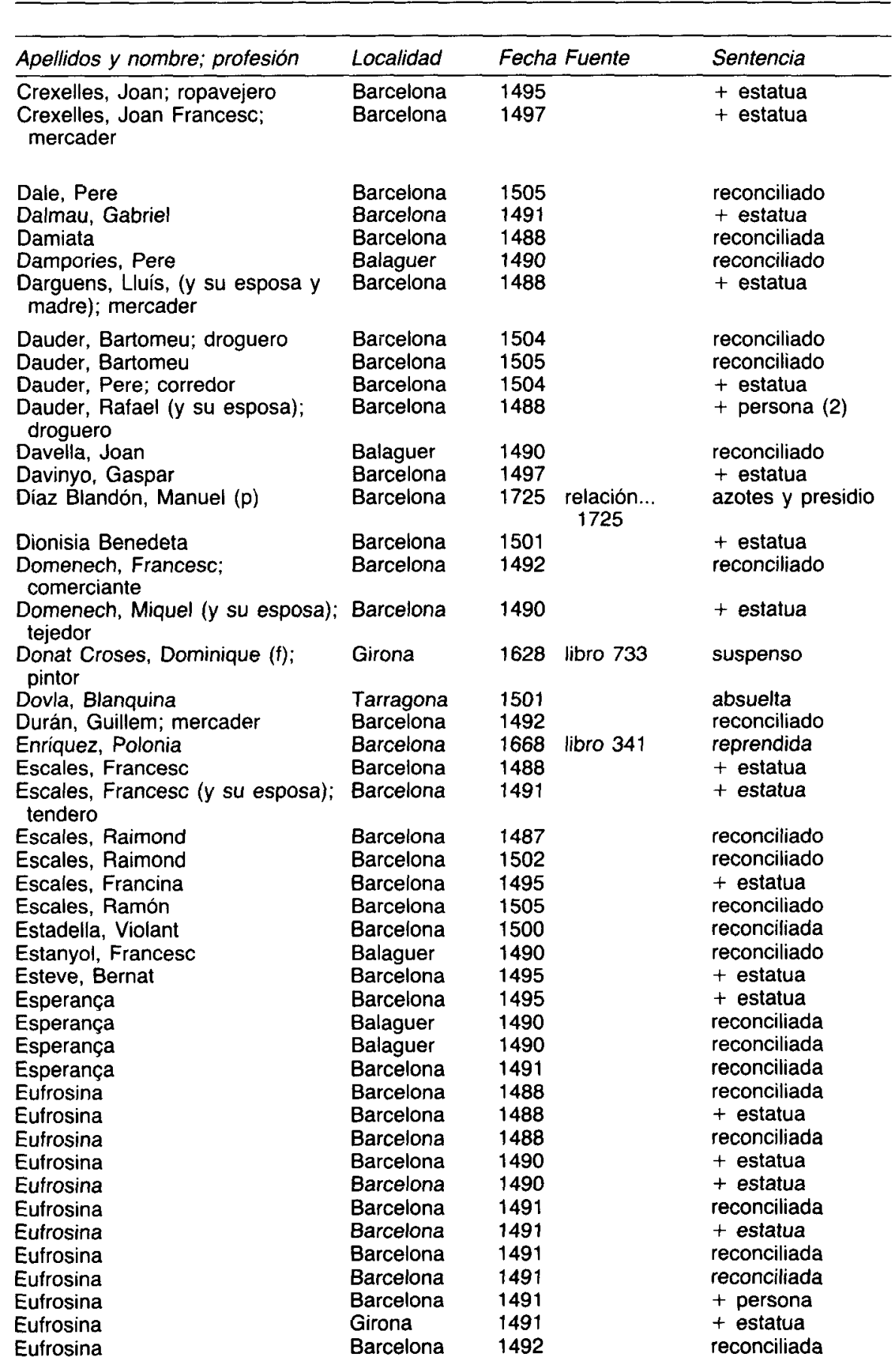


JUAN BLÁZQUEZ MIGUEL

\begin{tabular}{|c|c|c|c|}
\hline Apellidos y nombre; profesión & Localidad & Fecha Fuente & Sentencia \\
\hline Eufrosina & Barcelona & 1495 & + estatua \\
\hline Eufrosina & Barcelona & 1495 & + estatua \\
\hline Eufrosina & Perpignan & 1495 & reconciliada \\
\hline Eufrosina & Barcelona & 1497 & + estatua \\
\hline Eufrosina & Barcelona & 1497 & + estatua \\
\hline Eufrosina & Barcelona & 1487 & + estatua \\
\hline Eufrosina & Barcelona & 1505 & reconciliada \\
\hline Eulalia & Barcelona & 1487 & reconciliada \\
\hline Eulalia & Barcelona & 1487 & reconciliada \\
\hline Eulalia & Barcelona & 1488 & reconciliada \\
\hline Eulalia & Barcelona & 1488 & reconciliada \\
\hline Eulalia & Barcelona & 1488 & reconciliada \\
\hline Eulalia & Barcelona & 1488 & reconciliada \\
\hline Eulalia & Barcelona & 1489 & reconciliada \\
\hline Eulalia & Barcelona & 1490 & + estatua \\
\hline Eulalia & Barcelona & 1490 & + estatua \\
\hline Eulalia & Balaguer & 1490 & reconciliada \\
\hline Eulalia & Falset & 1490 & + persona \\
\hline Eulalia (y su madre) & Barcelona & 1491 & + estatua \\
\hline Eulalia & Barcelona & 1491 & reconciliada \\
\hline Eulalia & Barcelona & 1491 & reconciliada \\
\hline Eulalia & Barcelona & 1495 & + estatua \\
\hline Eulalia (y su hija) & Barcelona & 1497 & reconciliadas \\
\hline Eulalia & Barcelona & 1504 & + estatua \\
\hline Eulalia & Barcelona & 1505 & reconciliada \\
\hline Fabra, viuda de & Barcelona & 1491 & + estatua \\
\hline Fabra, Francina & Barcelona & 1502 & reconciliada \\
\hline Fabra, Guillem; joyero & Barcelona & 1495 & + estatua \\
\hline Fabra, Violant & Barcelona & 1488 & reconciliada \\
\hline Fabra, Violant & Barcelona & 1490 & + estatua \\
\hline Fabra Pertusa, Joan; mercader & Barcelona & 1491 & reconciliado \\
\hline $\begin{array}{l}\text { Fabregues, Bernat (y su esposa); } \\
\text { mercader }\end{array}$ & Barcelona & 1491 & + estatua \\
\hline Fagoll, Manuel (y su esposa) & Barcelona & 1488 & reconciliados \\
\hline Falcó, Blanquina & Girona & 1491 & + estatua \\
\hline Falcó, Caterina & Tarragona & 1501 & reconciliado \\
\hline Falcó, Francesc; mercader & Barcelona & 1490 & + estatua \\
\hline $\begin{array}{l}\text { Falcó, Francesc \& (y su esposa); } \\
\text { mercader }\end{array}$ & Girona & 1491 & + estatua \\
\hline Falcó, Gabriel & Tarragona & 1484 & reconciliado \\
\hline Falcó, Pau; curtidor & Barcelona & 1487 & reconciliado \\
\hline Falcó, Pau & Barcelona & 1501 & + estatua \\
\hline Falcó, Pau (y su esposa) & Girona & 1491 & + estatua \\
\hline $\begin{array}{l}\text { Falcó, Raimond (y su madre y } \\
\text { esposa) }\end{array}$ & Barcelona & $\begin{array}{l}1490- \\
91\end{array}$ & + estatua \\
\hline Fanyas, Joan; comerciante & Perpignan & 1495 & reconciliado \\
\hline Fanera, Francina & Falset & 1501 & reconciliada \\
\hline Far, Antoni; sastre & Barcelona & 1487 & reconciliado \\
\hline Felipa & Barcelona & 1501 & + estatua \\
\hline Far, Franci & Barcelona & 1504 & + estatua \\
\hline $\begin{array}{l}\text { Far, Galceran de (y su esposa); } \\
\text { zapatero }\end{array}$ & Barcelona & $\begin{array}{c}1488- \\
91\end{array}$ & $\begin{array}{l}\text { reconciliado y }+ \\
\text { en estatua }\end{array}$ \\
\hline Far, Joan & Barcelona & 1495 & + estatua \\
\hline
\end{tabular}


Catálogo de los procesos inquisitoriales del Tribunal del...

\begin{tabular}{|c|c|c|c|}
\hline Apellidos y nombre; profesión & Localidad & Fecha Fuente & Sentencia \\
\hline $\begin{array}{l}\text { Feliz Cubienchi, Adam (i); } \\
\text { soldado }\end{array}$ & Tremp & 1721 leg. 2.159 & 一 \\
\hline Fernández, Francisco; soldado & - & 1722 leg. 2.159 & - \\
\hline Fernández, Luis & - & libro 731 & reconciliado \\
\hline Ferrer, Bernat (s) & Barcelona & 1499 & + estatua \\
\hline Ferrera, Joana & Barcelona & 1492 & reconciliada \\
\hline Ferrer, Pere & Barcelona & 1497 & + estatua \\
\hline Ferreres, Bernat & Barcelona & 1497 & reconciliado \\
\hline Ferreres, Isabel de & Barcelona & 1497 & + estatua \\
\hline Ferreres, Benet, madre de & Barcelona & 1491 & + estatua \\
\hline Florencia & $\begin{array}{l}\text { Castello } \\
\text { d'Empuries }\end{array}$ & 1495 & + estatua \\
\hline Florencia & Barcelona & 1495 & + estatua \\
\hline Florencia & Barcelona & 1497 & + estatua \\
\hline Florencia & Barcelona & 1497 & + estatua \\
\hline Foguet, Baltasar; barbero & Barcelona & 1487 & reconciliado \\
\hline Foguet, Gabriel, tejedor & Barcelona & 1488 & reconciliado \\
\hline Foix, Francesquina de & Balaguer & 1493 & + estatua \\
\hline Foix, Francesc de & Balaguer & 1490 & reconciliado \\
\hline Foix, Miquel de & Balaguer & 1490 & reconciliado \\
\hline Font & Barcelona & 1491 & + estatua \\
\hline Font; coralero & Barcelona & 1491 & + estatua \\
\hline $\begin{array}{l}\text { Font, Miquel (y su esposa); } \\
\text { coralero }\end{array}$ & Barcelona & $\begin{array}{c}1490- \\
91\end{array}$ & + estatua \\
\hline Florentina & Barcelona & 1491 & reconciliada \\
\hline Florentina & Perpignan & 1495 & reconciliada \\
\hline Florentina & Perpignan & 1495 & reconciliada \\
\hline Forte, Francesc & Barcelona & 1490 & + estatua \\
\hline Forte, Juan; mercader & Barcelona & 1488 & + estatua \\
\hline Forte, Marc & Barcelona & 1491 & + estatua \\
\hline Forte, Rafael (y su esposa) & Barcelona & 1490 & + estatua \\
\hline Francesca & Barcelona & 1488 & reconciliada \\
\hline Francecs, Juan & Barcelona & 1491 & + estatua \\
\hline Francina & Barcelona & 1487 & reconciliada \\
\hline Francina & Barcelona & 1488 & reconciliada \\
\hline Francina & Barcelona & 1488 & reconciliada \\
\hline Francina & Barcelona & 1488 & reconciliada \\
\hline Francina & Barcelona & 1488 & reconciliada \\
\hline Francina & Barcelona & 1488 & reconciliada \\
\hline Francina & Barcelona & 1488 & reconciliada \\
\hline Francina & Barcelona & 1488 & + estatua \\
\hline Francina & Barcelona & 1489 & reconciliada \\
\hline Francina & Barcelona & 1490 & + estatua \\
\hline Francina & Barcelona & 1490 & + estatua \\
\hline Francina (y su hija) & Barcelona & 1490 & + estatua \\
\hline Francina & Barcelona & 1490 & + estatua \\
\hline Francina (y sus dos hijas) & Barcelona & 1490 & + estatua \\
\hline Francina & Barcelona & 1490 & + estatua \\
\hline Francina & Barcelona & 1490 & + estatua \\
\hline Francina & Balaguer & 1490 & reconciliada \\
\hline Francina & Barcelona & 1490 & reconciliada \\
\hline Francina & Barcelona & 1491 & + estatua \\
\hline Francina & Barcelona & 1491 & + estatua \\
\hline Francina & Barcelona & 1491 & reconciliada \\
\hline Francina & Barcelona & 1491 & reconciliada \\
\hline Francina & Barcelona & 1492 & reconciliada \\
\hline
\end{tabular}


JUAN BLAZQUEZ MIGUEL

\begin{tabular}{|c|c|c|c|}
\hline Apellidos y nombre; profesión & Localidad & Fecha Fuente & Sentencia \\
\hline Francina & $\begin{array}{l}\text { Castello } \\
\text { d'Empuries }\end{array}$ & 1495 & + estatua \\
\hline $\begin{array}{l}\text { Francina } \\
\text { Francina } \\
\text { Francina } \\
\text { Francina } \\
\text { Francina } \\
\text { Francina } \\
\text { Francina } \\
\text { Francina (y su hija) } \\
\text { Francina } \\
\text { Francina (y su hija) } \\
\text { Francina } \\
\text { Francina } \\
\text { Francina } \\
\text { Francina } \\
\text { Francina }\end{array}$ & $\begin{array}{l}\text { Barcelona } \\
\text { Barcelona } \\
\text { Barcelona } \\
\text { Barcelona } \\
\text { Barcelona } \\
\text { Barcelona } \\
\text { Barcelona } \\
\text { Barcelona } \\
\text { Barcelona } \\
\text { Barcelona } \\
\text { Barcelona } \\
\text { Montblanc } \\
\text { Valls } \\
\text { Barcelona } \\
\text { Barcelona }\end{array}$ & $\begin{array}{l}1495 \\
1495 \\
1495 \\
1495 \\
1495 \\
1495 \\
1497 \\
1497 \\
1499 \\
1499 \\
1499 \\
1501 \\
1502 \\
1504 \\
1505\end{array}$ & $\begin{array}{l}\text { + estatua } \\
\text { + estatua } \\
\text { + estatua } \\
\text { + estatua } \\
\text { + estatua } \\
\text { + estatua } \\
\text { reconciliada } \\
\text { + estatua } \\
\text { + estatua } \\
\text { reconciliadas } \\
\text { + persona } \\
\text { + estatua } \\
\text { reconciliada } \\
\text { + persona } \\
\text { + persona }\end{array}$ \\
\hline Frances, Pere & $\begin{array}{l}\text { Castello } \\
\text { d'Empuries }\end{array}$ & 1495 & + estatua \\
\hline $\begin{array}{l}\text { Francesc, Salvador; sastre } \\
\text { Francoya } \\
\text { Funes, Leonor } \\
\text { Funes, Pere Lluís; variopola } \\
\text { Funes Zabater, Gabriel }\end{array}$ & $\begin{array}{l}\text { Barcelona } \\
\text { Barcelona } \\
\text { Riudoms } \\
\text { Barcelona } \\
\text { Barcelona }\end{array}$ & $\begin{array}{l}1491 \\
1497 \\
1490 \\
1491 \\
1497\end{array}$ & $\begin{array}{l}\text { reconciliado } \\
+ \text { estatua } \\
+ \text { persona } \\
\text { reconciliado } \\
+ \text { estatua }\end{array}$ \\
\hline $\begin{array}{l}\text { Gabriel, Jacob (y su esposa); } \\
\text { tendero }\end{array}$ & Barcelona & 1490 & + estatua \\
\hline Gabriel, Pere; mercader & Barcelona & 1490 & + estatua \\
\hline Galceran, Baltasar & Balaguer & 1493 & + estatua \\
\hline Galceran, Manuel (cist) & Poblet & 1501 & reconciliado \\
\hline García, Señora & Barcelona & $\begin{array}{l}1495 \\
1488\end{array}$ & + estatua \\
\hline $\begin{array}{l}\text { Garret, rrancesc } \\
\text { Garret, Pere (su madre y tres } \\
\text { hermanas) }\end{array}$ & $\begin{array}{l}\text { Barcelona } \\
\text { Barcelona }\end{array}$ & $\begin{array}{l}1488 \\
1491\end{array}$ & + estatua \\
\hline Garridella, Violant & Barcelona & 1497 & + estatua \\
\hline Garriga & Barcelona & 1490 & + estatua \\
\hline Garriga, Angelina & Tarragona & 1490 & + persona \\
\hline Garriga, Francesc & Tarragona & 1489 & reconciliado \\
\hline Gaspar & Barcelona & 1490 & + estatua \\
\hline Gaspar Benet (y su hijo) & Balaguer & 1493 & + estatua \\
\hline Gempere, Señora & Barcelona & 1490 & + estatua \\
\hline Gil, Joan; peletero & Barcelona & 1504 & + estatua \\
\hline $\begin{array}{l}\text { Girgos, Joan ( y su esposa); } \\
\text { escribano }\end{array}$ & Barcelona & 1489 & + estatua \\
\hline Goltara, Gabriela Joana & Tarragona & 1501 & reconciliada \\
\hline Gómez, Cristina $(p)$ & Barcelona & 1624 libro 733 & absuelta \\
\hline Gómez, Maria (p) & Barcelona & 1624 libro 733 & absuelta \\
\hline Gomis, Joan (y su esposa) & Tarragona & 1489 & reconciliados \\
\hline Gomis, Margarida & Barcelona & 1495 & + estatua \\
\hline Gomis, Nicolau; coralero & Barcelona & 1488 & reconciliado \\
\hline González, Joao (p); galeote & & libro 734 & se ahorcó \\
\hline Gracia & Barcelona & 1492 & reconciliado \\
\hline Graciosa & Barcelona & 1490 & + estatua \\
\hline Graciosa & Barcelona & 1491 & + estatua \\
\hline Gralla, Señora & Barcelona & 1491 & + estatua \\
\hline
\end{tabular}


Catálogo de los procesos inquisitoriales del Tribunal del...

\begin{tabular}{|c|c|c|c|}
\hline Apellidos y nombre; profesión & Localidad & Fecha Fuente & Sentencia \\
\hline Gri, Joao (p); galeote & - & 1667 libro 735 & ¿reconciliado? \\
\hline Gual, Señora & Barcelona & 1490 & + estatua \\
\hline Gual, Antoni, esposa de & Barcelona & 1491 & + estatua \\
\hline Gual, Berengario & Barcelona & 1489 & + estatua \\
\hline $\begin{array}{l}\text { Guardiola, Benet (y esposa); } \\
\text { sedero }\end{array}$ & Barcelona & 1491 & + estatua \\
\hline Guardiola, Benet & Barcelona & 1491 & + estatua \\
\hline Guardiola, Francesc & Barcelona & 1487 & reconciliado \\
\hline Guasch, Manuel; tintorero & Barcelona & 1488 & reconciliado \\
\hline $\begin{array}{l}\text { Guillem, Jacob (y esposa); } \\
\text { tendero }\end{array}$ & Barcelona & 1491 & + estatua \\
\hline Guillem, Nicolau; tejedor & Tarragona & $\begin{array}{c}1488 y \\
1501\end{array}$ & reconciliado \\
\hline Guillén, Nicolau & Barcelona & 1500 & absuelto \\
\hline Guillén, Nicolau & Barcelona & 1505 & reconciliado \\
\hline Guillera, Joan; joyero & Barcelona & 1491 & + estatua \\
\hline Guimera & Barcelona & 1490 & + estatua \\
\hline Guimera, Gabriel & Barcelona & 1491 & + estatua \\
\hline Guimerana & Barcelona & 1497 & + estatua \\
\hline Guiselda & Barcelona & 1488 & reconciliada \\
\hline Guiselda & Barcelona & 1504 & reconciliada \\
\hline Hipólita & Barcelona & 1495 & + estatua \\
\hline Heredia, Juan de; sastre & Barcelona & 1491 & + estatua \\
\hline Hugo Bertrán & Barcelona & 1490 & + estatua \\
\hline Huquet, Arnald; portero & Barcelona & 1487 & reconciliado \\
\hline Huguet, Francesc (y su esposa) & Barcelona & 1501 & + estatua \\
\hline Huguet, Jacob; comerciante & Barcelona & 1490 & + estatua \\
\hline Huguet, Joan & Barcelona & 1495 & + estatua \\
\hline Isabel & Barcelona & 1487 & reconciliada \\
\hline Isabel & Barcelona & 1487 & reconciliada \\
\hline Isabel & Barcelona & 1487 & reconciliada \\
\hline Isabel & Barcelona & 1487 & reconciliada \\
\hline Isabel & Barcelona & 1488 & reconciliada \\
\hline Isabel & Barcelona & 1488 & reconciliada \\
\hline Isabel & Barcelona & 1488 & reconciliada \\
\hline Isabel & Barcelona & 1488 & reconciliada \\
\hline Isabel & Barcelona & 1488 & reconciliada \\
\hline Isabel & Barcelona & 1488 & + estatua \\
\hline Isabel & Barcelona & 1489 & reconciliada \\
\hline Isabel & Barcelona & 1489 & reconciliada \\
\hline Isabel & Barcelona & 1489 & reconciliada \\
\hline Isabel & Barcelona & 1489 & + estatua \\
\hline Isabel & Tarragona & 1489 & reconciliada \\
\hline Isabel & Tarragona & 1489 & reconciliada \\
\hline Isabel & Barcelona & 1490 & + persona \\
\hline Isabel (y su madre) & Barcelona & 1490 & + estatua \\
\hline Isabel & Barcelona & 1490 & + estatua \\
\hline Isabel & Barcelona & 1490 & + estatua \\
\hline Isabel & Barcelona & 1490 & + estatua \\
\hline Isabel & Tarragona & 1490 & reconciliada \\
\hline Isabel & Tarragona & 1490 & + persona \\
\hline Isabel & Barcelona & 1491 & + estatua \\
\hline Isabel & Barcelona & 1491 & + estatua \\
\hline Isabel & Barcelona & 1491 & + estatua \\
\hline Isabel & Barcelona & 1491 & + estatua \\
\hline
\end{tabular}


JUAN BLÁZQUEZ MIGUEL

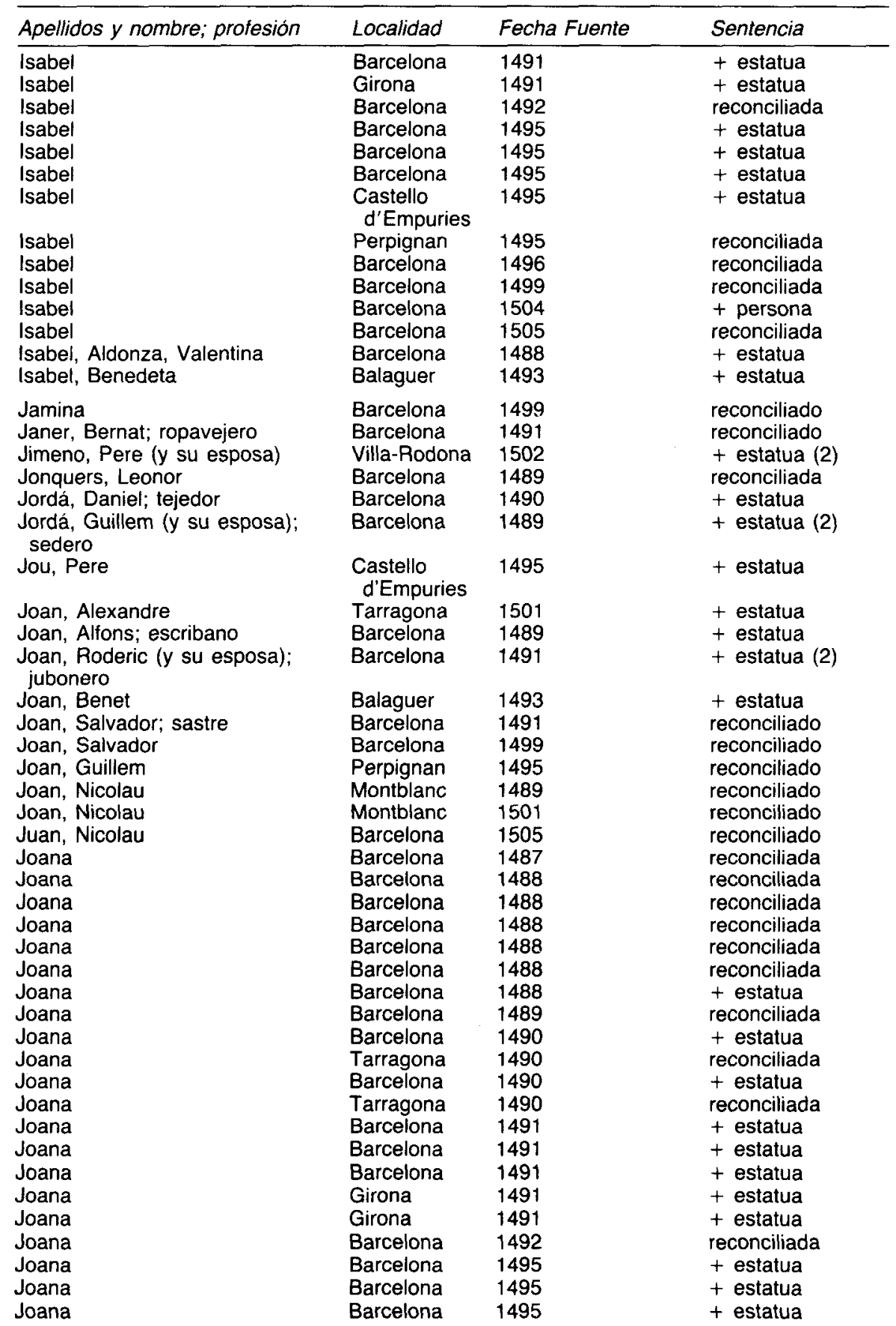


Catálogo de los procesos inquisitoriales del Tribunal del...

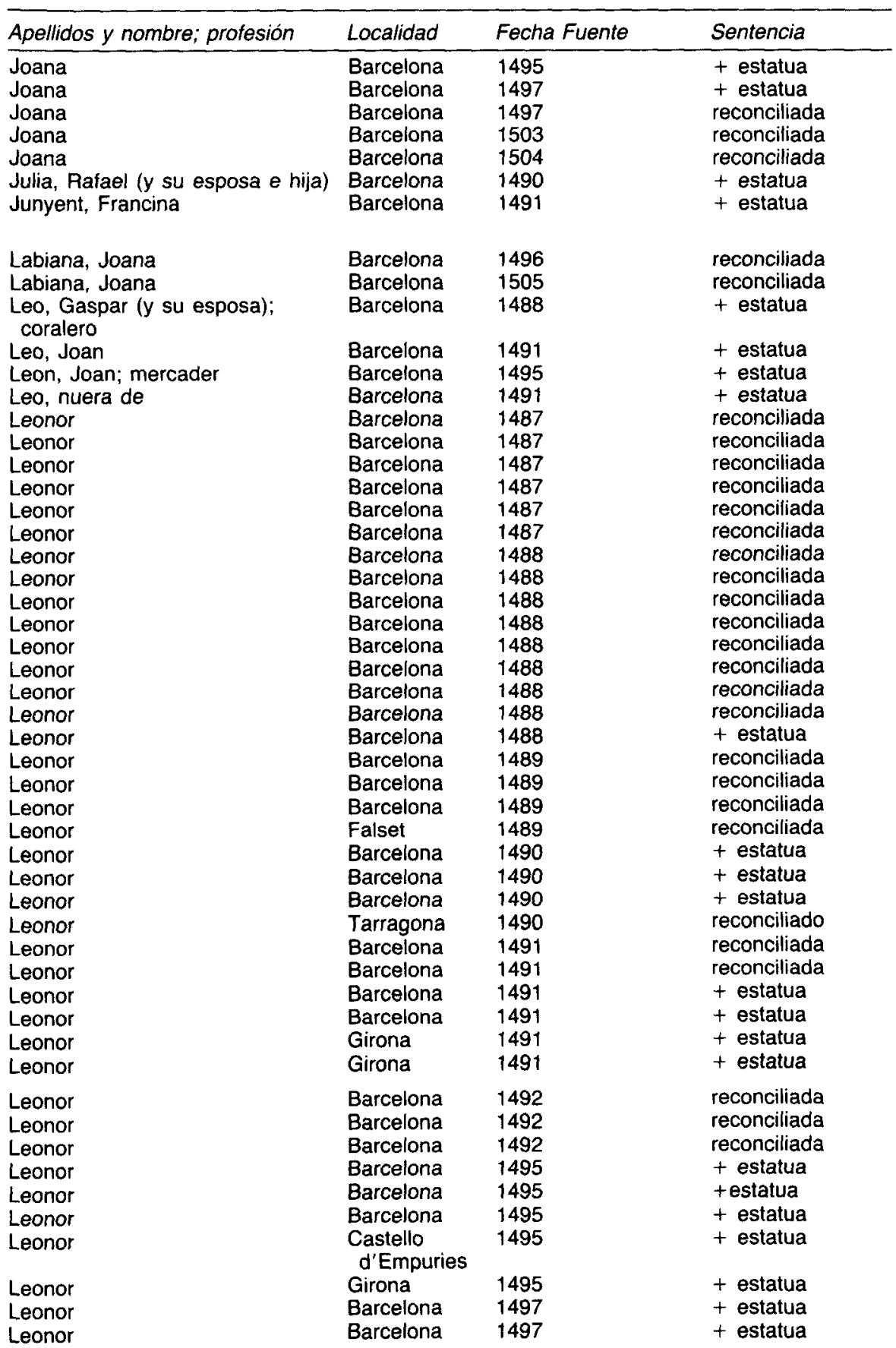


JUAN BLÁZQUEZ MIGUEL

\begin{tabular}{|c|c|c|c|}
\hline Apellidos y nombre; profesión & Localidad & Fecha Fuente & Sentencia \\
\hline Leonor & Barcelona & 1497 & + estatua \\
\hline Leonor & Barcelona & 1498 & + estatua \\
\hline Leonor & Barcelona & 1499 & reconciliada \\
\hline Leonor & Barcelona & 1499 & reconciliada \\
\hline Leonor & Girona & 1503 & reconciliada \\
\hline Leonor & Barcelona & 1504 & reconciliada \\
\hline Leonor & Barcelona & 1504 & + persona \\
\hline Leonor & Barcelona & 1501 & + en estatua \\
\hline Leonor & Montblanc & 1501 & reconciliada \\
\hline Leonor & Barcelona & 1504 & reconciliada \\
\hline Leonor Graciana & Barcelona & 1500 & reconciliada \\
\hline Libia, Joan & Barcelona & 1489 & + estatua \\
\hline $\begin{array}{l}\text { Libia, Nicolau (y su esposa } \\
\text { e hija); mercader }\end{array}$ & Barcelona & 1489 & + estatua \\
\hline $\begin{array}{l}\text { Linas (su esposa e hijo); } \\
\text { jubonero }\end{array}$ & Barcelona & 1497 & + estatua \\
\hline López, Abraham & Barcelona & 1789 leg. 2.174 & reconciliado \\
\hline Lopez, Manuel $(p)$ & Barcelona & $\begin{array}{l}1703-\operatorname{leg} \cdot 2.157 \\
15\end{array}$ & reconciliado \\
\hline Lunella, Grabiela & Tarragona & 1501 & + estatua \\
\hline Lunes, Gabriel; curtidor & Barcelona & 1487 & reconciliado \\
\hline Llebres, Gertrudis & Barcelona & 1773 leg. 2.169 & - \\
\hline Macip, Bernat, esposa de & Girona & 1491 & + estatua \\
\hline Macip, Guillem; médico & Barcelona & 1505 & reconciliado \\
\hline Maestres, Margarida & Barcelona & 1495 & + estatua \\
\hline Malart, Eufrosina & Barcelona & 1487 & reconciliada \\
\hline Marlat, Joan; tintorero & Barcelona & 1487 & reconciliado \\
\hline Mandina & Barcelona & 1488 & reconciliada \\
\hline Mandina & Barcelona & 1489 & reconciliada \\
\hline Mandina & Barcelona & 1491 & reconciliada \\
\hline Mandina & Girona & 1495 & + estatua \\
\hline Mandina & Barcelona & 1505 & reconciliada \\
\hline Marc, Jacob; comerciante & Barcelona & 1492 & reconciliado \\
\hline Marco, Antoni; zapatero & Barcelona & 1488 & reconciliado \\
\hline March, Gabriel (y sus hijas) & Falset & 1501 & + estatua \\
\hline Margarida & Barcelona & 1488 & reconciliada \\
\hline Margarida & Barcelona & 1490 & + estatua \\
\hline Margarida (y su hija) & Barcelona & 1490 & + estatua \\
\hline Margarida & Balaguer & 1490 & reconciliada \\
\hline Margarida & Balaguer & 1490 & reconciliada \\
\hline Margarida & Barcelona & 1491 & reconciliada \\
\hline Margarida & Barcelona & 1491 & reconciliada \\
\hline Margarida & Barcelona & 1495 & + estatua \\
\hline Margarida & $\begin{array}{l}\text { Castello } \\
\text { d'Empuries }\end{array}$ & 1495 & + estatua \\
\hline Margarida & $\begin{array}{l}\text { Castello } \\
\text { d'Empuries }^{\prime} \text { Empla }\end{array}$ & 1495 & + estatua \\
\hline Margarida & Perpignan & 1495 & reconciliada \\
\hline Margarida & Barcelona & 1504 & + estatua \\
\hline Maria & Barcelona & 1490 & + estatua \\
\hline María & Barcelona & 1491 & + estatua \\
\hline Maria & Barcelona & 1501 & + estatua \\
\hline María & Barcelona & 1501 & + estatua \\
\hline Marimón, Aldonza & Barcelona & 1489 & reconciliada \\
\hline Marimón del Pla, Pere (y su hijo) & Barcelona & 1489 & reconciliado \\
\hline
\end{tabular}


Catálogo de los procesos inquisitoriales del Tribunal del...

\begin{tabular}{|c|c|c|c|c|}
\hline Apellidos y nombre; profesión & Localidad & Fecha & Fuente & Sentencia \\
\hline Marquesa & Barcelona & 1488 & & reconciliada \\
\hline Marquesa & Barcelona & 1490 & & + estatua \\
\hline Marquesa & Barcelona & 1492 & & reconciliada \\
\hline Marquesa & Barcelona & 1496 & & reconciliada \\
\hline Marquesa & Barcelona & 1504 & & + estatua \\
\hline Marquesa & Barcelona & 1505 & & reconciliada \\
\hline Marquesa & Barcelona & 1505 & & reconciliada \\
\hline Marqueta, Constança & Barcelona & 1500 & & + estatua \\
\hline Marta & Balaguer & 1490 & & reconciliada \\
\hline Marti, Benet; notario & Barcelona & 1500 & & reconciliado \\
\hline Martínez, Constança & Barcelona & 1490 & & reconciliado \\
\hline $\begin{array}{l}\text { Mascaró, dos hijas de, y su } \\
\text { esposa }\end{array}$ & Barcelona & 1491 & & + estatua \\
\hline Matamala, Leonor & Barcelona & 1489 & & reconciliada \\
\hline Matiana & Barcelona & 1491 & & reconciliada \\
\hline Maya, Bonanat & Balaguer & 1490 & & reconciliada \\
\hline Maya, Marquesa & Balaguer & 1492 & & reconciliada \\
\hline Mayans, Antoni & Barcelona & 1499 & & + estatua \\
\hline Mayans, Joan & Barcelona & 1499 & & + estatua \\
\hline Mayols, Joan; joyero & Barcelona & 1488 & & reconciliado \\
\hline Mazana; mercader & Barcelona & 1491 & & + estatua \\
\hline Méndez, Catalina $(p)$ & Barcelona & 1667 & libro 735 & suspenso \\
\hline Méndez, Pedro $(p)$; lencero & Barcelona & 1682 & libro 735 & suspenso \\
\hline Menescal, Jacob; hornero & Barcelona & 1488 & & reconciliado \\
\hline Meneses, María & Montblanc & 1717 & $\begin{array}{l}\text { leg. } 2.158 \text { y } \\
3.724 / 127\end{array}$ & cárcel perpetua \\
\hline Mercader (y su esposa) & Barcelona & 1490 & & + estatua \\
\hline Mercader, Bernat & Girona & 1491 & & + estatua \\
\hline $\begin{array}{l}\text { Mercader, Gabriel; lugarteniente } \\
\text { del tesoro }\end{array}$ & Barcelona & 1490 & & + estatua \\
\hline Mercader, Dalmau & Girona & 1491 & & + estatua \\
\hline $\begin{array}{l}\text { Mercader, Daniel, (y su esposa e } \\
\text { hija) }\end{array}$ & Girona & 1491 & & + estatua \\
\hline Mercader, Ramón & Girona & 1497 & & reconciliado \\
\hline Micaela & Barcelona & 1498 & & reconciliada \\
\hline Micaela & Barcelona & 1491 & & reconciliada \\
\hline Mestres, Pere; curtidor & Barcelona & 1487 & & reconciliado \\
\hline Miguel, Pere & $\begin{array}{l}\text { Castello } \\
\text { d'Empuries }\end{array}$ & 1495 & & + estatua \\
\hline Miguel, Narcis & Barcelona & 1488 & & reconciliado \\
\hline Miguel, Bernat & Barcelona & 1504 & & + estatua \\
\hline Mir, Gaspar; curtidor & Barcelona & 1488 & & reconciliado \\
\hline Mir, Gaspar; curtidor & Barcelona & 1505 & & + persona \\
\hline $\begin{array}{l}\text { Miró, Gabriel (y su esposa); } \\
\text { médico }\end{array}$ & Barcelona & 1490 & & + estatua \\
\hline Miró, Joan & $\begin{array}{l}\text { Castello } \\
\text { d'Empuries }\end{array}$ & 1495 & & + estatua \\
\hline Miró, Pere & Barcelona & 1491 & & + estatua \\
\hline Mo, Narcís & Barcelona & 1504 & & + estatua \\
\hline Molés, hijo de & Barcelona & 1491 & & + estatua \\
\hline $\begin{array}{l}\text { Molins, Pere (y su esposa); } \\
\text { tejedor }\end{array}$ & Barcelona & 1488 & & reconciliados \\
\hline Montfort, Aldonza & Barcelona & 1499 & & + estatua \\
\hline Montalbán, Isabel & Barcelona & 1497 & & reconciliada \\
\hline Monrós, Miata de & Balaguer & 1493 & & + estatua \\
\hline Montoya, Juan de; galeote & - & 1723 & leg. 2.159 & \\
\hline
\end{tabular}




\begin{tabular}{|c|c|c|c|c|}
\hline Apellidos y nombre; profesión & Localidad & Fecha & Fuente & Sentencia \\
\hline $\begin{array}{l}\text { Montpeller, Joan } \\
\text { Monzo, Gabriel } \\
\text { Morachs, Eufrosina } \\
\text { Morato, Luis (y su esposa) } \\
\text { Morato, Lluis } \\
\text { Morato, Lluis (y su esposa) } \\
\text { Morell, Joan; cotamellero } \\
\text { Morell, Pere; cotamallero } \\
\text { Mos, Benet (y su esposa) } \\
\text { Mujer, Una } \\
\text { Mundina } \\
\text { Mur, Gaspar de } \\
\text { Mur, Gaspar de }\end{array}$ & $\begin{array}{l}\text { Girona } \\
\text { Barcelona } \\
\text { Solsona } \\
\text { Montblanc } \\
\text { Montblanc } \\
\text { Tarragona } \\
\text { Barcelona } \\
\text { Barcelona } \\
\text { Barcelona } \\
\text { Montblanc } \\
\text { Barcelona } \\
\text { Barcelona } \\
\text { Barcelona }\end{array}$ & $\begin{array}{l}1491 \\
1491 \\
1500 \\
1502 \\
1505 \\
1489 \\
1491 \\
1489 \\
1491 \\
1489 \\
1489 \\
1497 \\
1502\end{array}$ & . & $\begin{array}{l}\text { + estatua } \\
\text { reconciliado } \\
\text { reconciliada } \\
\text { reconciliados (2) } \\
\text { reconciliado } \\
\text { reconciliado } \\
\text { + persona } \\
\text { reconciliado } \\
\text { + estatua } \\
\text { reconciliada } \\
\text { reconciliada } \\
\text { reconciliado }\end{array}$ \\
\hline $\begin{array}{l}\text { Nadal (y su esposa e hija); } \\
\text { tendero }\end{array}$ & Barcelona & 1491 & & + estatua \\
\hline $\begin{array}{l}\text { Narcisa } \\
\text { Navarro (y su esposa); } \\
\text { comerciante }\end{array}$ & $\begin{array}{l}\text { Barcelona } \\
\text { Barcelona }\end{array}$ & $\begin{array}{l}1487 \\
1490\end{array}$ & & $\begin{array}{l}\text { reconciliada } \\
+ \text { estatua }\end{array}$ \\
\hline $\begin{array}{l}\text { Navarro, Joan; corredor } \\
\text { Navarro, Joan } \\
\text { Naves, Gaspar de } \\
\text { Naves, Joan; jugador } \\
\text { Naves, Manuel; sedero } \\
\text { Naves, Pau de }\end{array}$ & $\begin{array}{l}\text { Girona } \\
\text { Girona } \\
\text { Balaguer } \\
\text { Barcelona } \\
\text { Barcelona } \\
\text { Balaguer }\end{array}$ & $\begin{array}{l}1503 \\
1505 \\
1493 \\
1489 \\
1489 \\
1490\end{array}$ & reconciliado & $\begin{array}{l}\text { reconciliado } \\
+ \text { estatua } \\
+ \text { estatua } \\
+ \text { estatua } \\
\text { reconciliado }\end{array}$ \\
\hline $\begin{array}{l}\text { Olers, Beatriu } \\
\text { Olivares, Gabriel } \\
\text { Olivares, Manuel } \\
\text { Oliver, Joan (y su esposa y } \\
\text { cuñada) }\end{array}$ & $\begin{array}{l}\text { Barcelona } \\
\text { Barcelona } \\
\text { Barcelona } \\
\text { Barcelona }\end{array}$ & $\begin{array}{l}1488 \\
1491 \\
1487 \\
1491\end{array}$ & & $\begin{array}{l}\text { reconciliada } \\
+ \text { estatua } \\
\text { reconciliado } \\
+ \text { estatua }\end{array}$ \\
\hline $\begin{array}{l}\text { Olivera, Leonor } \\
\text { Oluja, Paula } \\
\text { Ortiz, Pere }\end{array}$ & $\begin{array}{l}\text { Barcelona } \\
\text { Barcelona } \\
\text { Girona }\end{array}$ & $\begin{array}{c}1497 \\
1491 \\
1574- \\
78\end{array}$ & libro 730 & $\begin{array}{l}\text { reconciliada } \\
\text { reconciliada } \\
-\end{array}$ \\
\hline Oller, esposa de & Barcelona & 1491 & & + estatua \\
\hline $\begin{array}{l}\text { Paladar (y su esposa); tendero } \\
\text { Paladara, señora } \\
\text { Paladara, Clara } \\
\text { Paladara, Eulalia } \\
\text { Paladara, Leonor } \\
\text { Palau, Joan (y su esposa) }\end{array}$ & $\begin{array}{l}\text { Barcelona } \\
\text { Barcelona } \\
\text { Barcelona } \\
\text { Barcelona } \\
\text { Barcelona } \\
\text { Barcelona }\end{array}$ & $\begin{array}{l}1490 \\
1490 \\
1490 \\
1490 \\
1490 \\
1503\end{array}$ & & $\begin{array}{l}\text { + estatua } \\
+ \text { estatua } \\
+ \text { estatua } \\
+ \text { estatua } \\
+ \text { estatua } \\
+ \text { persona } \\
\text { (ambos) }\end{array}$ \\
\hline $\begin{array}{l}\text { Palou; lanero } \\
\text { Palau, Galcera; comerciante } \\
\text { Palou, Lluís } \\
\text { Pallas, esposa de } \\
\text { Pallas, Esperança de }\end{array}$ & $\begin{array}{l}\text { Barcelona } \\
\text { Barcelona } \\
\text { Barcelona } \\
\text { Barcelona } \\
\text { Balaguer }\end{array}$ & $\begin{array}{l}1490 \\
1488 \\
1499 \\
1490 \\
1490\end{array}$ & & $\begin{array}{l}\text { + estatua } \\
\text { reconciliado } \\
\text { absuelto } \\
+ \text { estatua } \\
\text { reconciliada }\end{array}$ \\
\hline $\begin{array}{l}\text { Parets, Marc de; mercader } \\
\text { Palau, Joan; variopola } \\
\text { Pau, Bernat de } \\
\text { Pau, Francina de } \\
\text { Pau, Francesc de (y su esposa) }\end{array}$ & $\begin{array}{l}\text { Barcelona } \\
\text { Barcelona } \\
\text { Barcelona } \\
\text { Barcelona } \\
\text { Barcelona }\end{array}$ & $\begin{array}{r}1490 \\
1488 \\
1490 \\
1492 \\
1490\end{array}$ & & $\begin{array}{l}\text { + estatua } \\
\text { reconciliado } \\
+ \text { estatua } \\
\text { reconciliada } \\
+ \text { estatua }\end{array}$ \\
\hline
\end{tabular}


Catálogo de los procesos inquisitoriales del Tribunal del...

\begin{tabular}{|c|c|c|c|c|}
\hline Apellidos y nombre; profesión & Localidad & Fecha & Fuente & Sentencia \\
\hline Pau, Jacob (y su esposa) & Barcelona & 1491 & & + estatua \\
\hline Paula & Barcelona & 1495 & & + estatua \\
\hline Paula & Barcelona & 1497 & & + estatua \\
\hline Paulina & Balaguer & 1493 & & + estatua \\
\hline Pere Pau & Barcelona & 1491 & & + estatua \\
\hline Pere Antoni, esposa de & Barcelona & 1491 & & + estatua \\
\hline Penán, Judá & - & 1663 & libro 341 & ¿absuelto? \\
\hline Pesavi, Judá & Barcelona & 1664 & libro 735 & absuelto \\
\hline Pi, Clara (y su hija) & Barcelona & 1497 & & + estatua \\
\hline $\mathrm{Pi}$, Aldonza & Barcelona & 1497 & & + estatua \\
\hline Piera, Francesc; coralero & Barcelona & 1495 & & + estatua \\
\hline Piera, Pere & Barcelona & 1495 & & + estatua \\
\hline Pla, Bernat; correo & Barcelona & 1491 & & + persona \\
\hline Pla, Joan del, esposa de & Barcelona & 1490 & & + estatua \\
\hline Placentia & Perpignan & 1495 & & reconciliada \\
\hline Planella, Jacob; tejedor & Perpignan & 1495 & & reconciliado \\
\hline Ponc, Pau; chatarrero & Barcelona & 1497 & & reconciliado \\
\hline Porneta, Eufrosina & Sitges & 1499 & & absuelta \\
\hline Porta, Bernat, tejedor & Barcelona & 1495 & & + estatua \\
\hline Portapa, Gabriel, tejedor & Barcelona & 1492 & & reconciliado \\
\hline Portugués, Pere & Barcelona & 1497 & & + estatua \\
\hline Pou, Micaela & Barcelona & 1503 & & + persona \\
\hline $\begin{array}{l}\text { Prats, Francesc (y su esposa y } \\
\text { madre) }\end{array}$ & Barcelona & 1488 & & + estatua \\
\hline Prats, Magdalena & Figueres & 1500 & & reconciliado \\
\hline Puigmija, Francesc & Barcelona & 1490 & & + estatua \\
\hline $\begin{array}{l}\text { Puigmija, Joan (y su esposa); } \\
\text { escribano }\end{array}$ & Barcelona & 1488 & & + estatua \\
\hline Puigmija, Manuel & Barcelona & 1491 & & + estatua \\
\hline Puigmija, Manuel de; notario & Barcelona & 1499 & & reconciliado \\
\hline Pujol, Pere & Barcelona & 1497 & & + estatua \\
\hline $\begin{array}{l}\text { Queralt, Dalmau (y su esposa y } \\
\text { madre); mercader }\end{array}$ & Barcelona & 1489 & & + estatua \\
\hline Queralt, Francesc; coralero & Barcelona & 1488 & & reconciliado \\
\hline Queralt, Jaufrudis (y su esposa) & Barcelona & 1490 & & + estatua \\
\hline Queralt, Violant & Barcelona & 1495 & & + estatua \\
\hline $\begin{array}{l}\text { Quot, Pere (y su esposa); } \\
\text { boticario }\end{array}$ & Barcelona & 1488 & & + estatua \\
\hline Rabacera, Bartomeu & Barcelona & 1503 & & reconciliado \\
\hline Rabacer, Bernat; revendedor & Barcelona & 1487 & & reconciliado \\
\hline Rabacer, Eufrosina & Barcelona & 1503 & & reconciliada \\
\hline Rabacer, Gabriel; sastre & Barcelona & 1505 & & reconciliado \\
\hline Rafaela & Barcelona & 1488 & & reconciliada \\
\hline Rafaela & Barcelona & 1488 & & reconciliada \\
\hline Rafaela & Barcelona & 1495 & & + estatua \\
\hline Rafaela & Barcelona & $\{504$ & & + estatua \\
\hline Raillo, Gregori & - & 1690 & $\begin{array}{l}\text { leg. } 2.155 / 2 \\
\text { y libro } 735\end{array}$ & - \\
\hline Raimat, Baltasar; coralero & Barcelona & 1491 & & reconciliado \\
\hline Ram, Joan (y su esposa) & Barcelona & 1488 & & + estatua \\
\hline Ramírez, Tomás (cist) & Poblet & 1501 & & reconciliado \\
\hline Rens, Manuel & Barcelona & 1491 & & + estatua \\
\hline Requesens, Francesc; droguero & Barcelona & 1487 & & reconciliado \\
\hline Requesens, Francesc & Barcelona & 1491 & & + estatua \\
\hline Requesens, Francesc; médico & Barcelona & 1490 & & + estatua \\
\hline
\end{tabular}




\begin{tabular}{|c|c|c|c|c|}
\hline Apellidos y nombre; profesión & Localidad & \multicolumn{2}{|c|}{ Fecha Fuente } & Sentencia \\
\hline Requesens, Francesc; droguero & Barcelona & 1500 & & reconciliado \\
\hline Requesens, Francesc & Barcelona & 1505 & & reconciliado \\
\hline Res, Joan de & Balaguer & 1490 & & reconciliado \\
\hline Res, Leonor de & Balaguer & 1490 & & reconciliado \\
\hline Res, Pau de; tendero & Balaguer & 1490 & & reconciliado \\
\hline Riasti, Ignacio María (i) (osm) & Barcelona & 1682 & leg. $2.155 / 1$ & reconciliado \\
\hline Ribas, Bartomeu; chapinero & Barcelona & 1505 & & reconciliado \\
\hline Ribes, Brianda & Barcelona & 1500 & & absuelta \\
\hline $\begin{array}{l}\text { Ribelles, Francesc (y su esposa } \\
\text { y suegra) }\end{array}$ & Falset & 1501 & & + estatua \\
\hline Ribelles, Francesc (y su esposa) & Barcelona & 1504 & & reconciliados \\
\hline Ribelles, Francesc; curtidor & Barcelona & 1505 & & reconciliado \\
\hline Ribelles, Gabriel; barbero & Tarragona & 1490 & & reconciliado \\
\hline Ribelles, Lluís; médico & Falset & 1490 & & reconciliado \\
\hline $\begin{array}{l}\text { Ribelles, Lluís (y sus tres hijos); } \\
\text { abogado }\end{array}$ & $\begin{array}{l}\text { Vilafranca del } \\
\text { Penedes }\end{array}$ & 1490 & & reconciliados \\
\hline Ribesaltes, Bartomeu; chapinero & Barcelona & 1504 & & reconciliado \\
\hline Ribesaltes, Joan & Barcelona & 1497 & & absuelto \\
\hline Ricsen & Perpignan & 1495 & & reconciliada \\
\hline Riera, Margarida de & Balaguer & 1490 & & reconciliada \\
\hline Ripoll, Lluís; jabonero & Barcelona & 1490 & & + estatua \\
\hline Ripoll, Lluís; sastre & Barcelona & 1491 & & + estatua \\
\hline Roca, Falcona & Gerona & 1491 & & + estatua \\
\hline Roca, Miquel; tendero & $\begin{array}{l}\text { Castello } \\
\text { d'Empuries }\end{array}$ & 1495 & & + estatua \\
\hline Rodes, Francesc, joyero & Barcelona & 1488 & & reconciliado \\
\hline Rodó, Francesc; tendero & Barcelona & 1491 & & + estatua \\
\hline Rodó, Guillem (y su esposa) & Barcelona & 1491 & & + estatua \\
\hline Rodo, Pere; variopola & Barcelona & 1492 & & reconciliado \\
\hline Roja, Blanquina & Tarragona & 1489 & & + persona \\
\hline Rovira, Eulalia & Barcelona & 1491 & & reconciliada \\
\hline Rodríguez, Bartolomé & Barcelona & 1488 & & + estatua \\
\hline Rodríguez, Simón $(p)$; mercader & Barcelona & 1624 & libro 733 & absuelto \\
\hline $\begin{array}{l}\text { Rodríguez Arellano, } \\
\text { Antón (p.) (op) }\end{array}$ & - & 1594 & libro 731 & reconciliado \\
\hline Rodríguez Tomás, Manuel & - & 1683 & $\operatorname{leg} .2155 / 1$ & reconciliado \\
\hline Rodríguez Vidal, Juan & - & 1668 & libro 735 & reconciliado \\
\hline Roger (y su hijo); escribano & Barcelona & 1491 & & + estatua \\
\hline $\begin{array}{l}\text { Roger, Joan (y su esposa); } \\
\text { variopola }\end{array}$ & Barcelona & 1488 & & reconciliado \\
\hline Roger, Joan; trapero & Barcelona & 1504 & & reconciliado \\
\hline Roger, Joan & Barcelona & 1505 & & reconciliado \\
\hline Roia, Blanquina & Valls & 1501 & & reconciliada \\
\hline Roig, Bernat (y su esposa e hijo) & Valls & 1502 & & + estatua \\
\hline Roig Zabata, Miquel & Barcelona & 1488 & & reconciliado \\
\hline Rosanos, Bonanatus & Barcelona & 1495 & & + estatua \\
\hline Rosas, Jeroni; zapatero & Barcelona & 1488 & & reconciliado \\
\hline Rosas, Jeroni (y su esposa) & Barcelona & 1503 & & $\begin{array}{l}+ \text { persona } \\
\text { (ambos) }\end{array}$ \\
\hline Rossel, Francina & Barcelona & 1487 & & reconciliada \\
\hline Rubert, Joan & Barcelona & 1491 & & + estatua \\
\hline Sahanua, Esperança & Barcelona & 1499 & & reconciliada \\
\hline Sala, Isabel & Barcelona & 1504 & & reconciliada \\
\hline Salabert, Joana & Balaguer & 1490 & & reconciliada \\
\hline
\end{tabular}


Catálogo de los procesos inquisitoriales del Tribunal del...

\begin{tabular}{|c|c|c|c|}
\hline Apellidos y nombre; profesión & Localidad & Fecha Fuente & Sentencia \\
\hline Salabert, Pere & Balaguer & 1490 & reconciliado \\
\hline Salestina & Barcelona & 1488 & reconciliada \\
\hline Salmons, Francina & Barcelona & 1488 & + estatua \\
\hline Salmons, Macià & Barcelona & 1488 & + estatua \\
\hline Salt, Llorenç (y su esposa) & Barcelona & 1490 & + estatua \\
\hline Salvador, Gabriel; sastre & Barcelona & 1491 & reconciliado \\
\hline Salvat, Joan & Barcelona & 1500 & + estatua \\
\hline Samso, Bernat & Girona & 1495 & + estatua \\
\hline Samso, Mateu (y su esposa) & Girona & 1491 & + estatua \\
\hline Sanat, Pere Joan; escribano & Barcelona & 1491 & reconciliado \\
\hline Sanctes, Gonçal, esposa de & Barcelona & 1491 & + estatua \\
\hline Sant Climent, Francina & Barcelona & 1488 & reconciliada \\
\hline Sant Climent, Joan; notario & $\begin{array}{l}\text { Castello } \\
\text { D'Empuries }\end{array}$ & 1495 & + estatua \\
\hline Sant Jacob, Benet; coralero & Barcelona & 1492 & reconciliado \\
\hline $\begin{array}{l}\text { Sant Jordi, Joan (y su esposa y } \\
\text { madre) }\end{array}$ & Barcelona & 1488 & + estatua \\
\hline Sant Jordi, T.; curtidor & Barcelona & 1487 & reconciliado \\
\hline Sant Marti, Rolando; abogado & Barcelona & 1490 & + estatua \\
\hline Santa Romana, Gabriel & Balaguer & 1490 & reconciliado \\
\hline Santafé, Gisbert & Falset & 1490 & reconciliado \\
\hline Santafé, Joan & Barcelona & 1488 & reconciliado \\
\hline Santafe, Raimond & Barcelona & 1488 & reconciliado \\
\hline $\begin{array}{l}\text { Santafé, Ramón (y su esposa); } \\
\text { zapatero }\end{array}$ & Barcelona & 1488 & reconciliado \\
\hline Santángel, Galcera; mercader & Perpignan & 1495 & reconciliado \\
\hline Santo, Pau & Tarragona & 1489 & reconciliado \\
\hline Santos, Gundisalvo de & Barcelona & 1501 & + estatua \\
\hline Sanz, Pere; jubonero & Barcelona & 1488 & reconciliado \\
\hline Sart, Pere; sastre & Barcelona & 1488 & reconciliado \\
\hline Sartre, Bartomeu; librero & Barcelona & 1488 & reconciliado \\
\hline Sartre, Bartomeu; librero & Barcelona & 1504 & + estatua \\
\hline Sartre, Gabriel; jubonero & Barcelona & 1488 & reconciliado \\
\hline Sartre, Gabriel; jubonero & Barcelona & 1490 & + estatua \\
\hline Sartre, Joan; coralero & Barcelona & 1489 & reconciliado \\
\hline Sartre, Linas (y su mujer e hija) & Montblanc & 1501 & + estatua \\
\hline Sarria, Pere & Barcelona & 1504 & + estatua \\
\hline Sarriana, Blanquina & Barcelona & 1503 & + persona \\
\hline Sauri, Gabriel (y su esposa) & Barcelona & 1488 & + estatua \\
\hline Saurí, Gabriel & Barcelona & 1490 & reconciliado \\
\hline Sauri, Joan (y su esposa) & Barcelona & 1488 & + estatua \\
\hline Seguerra, Joan; calcetero & Balaguer & 1490 & reconciliado \\
\hline Sener, Beatriu & Barcelona & 1499 & + estatua \\
\hline Serena & Barcelona & 1488 & reconciliada \\
\hline Serena & Barcelona & 1488 & reconciliada \\
\hline Serena & Barcelona & 1491 & reconciliada \\
\hline Servent, Gaspar (y su madre) & $\begin{array}{l}\text { Castello } \\
\text { D'Empuries }\end{array}$ & 1495 & + estatua \\
\hline Servent, Pere & $\begin{array}{l}\text { Castello } \\
\text { D'Empuries }\end{array}$ & 1495 & + estatua \\
\hline Serra, Antoni (y su esposa) & Barcelona & 1490 & + estatua \\
\hline Serra, Antón (p) & Barceloa & 1495 & + estatua \\
\hline $\begin{array}{l}\text { Setmenat, Francesc (y su } \\
\text { esposa) }\end{array}$ & Barcelona & 1488 & + estatua \\
\hline Sever, Bonanatus & Barcelona & 1501 & + estatua \\
\hline Sever, Joan & Barcelona & 1501 & + estatua \\
\hline
\end{tabular}


JUAN BLÁZQUEZ MIGUEL

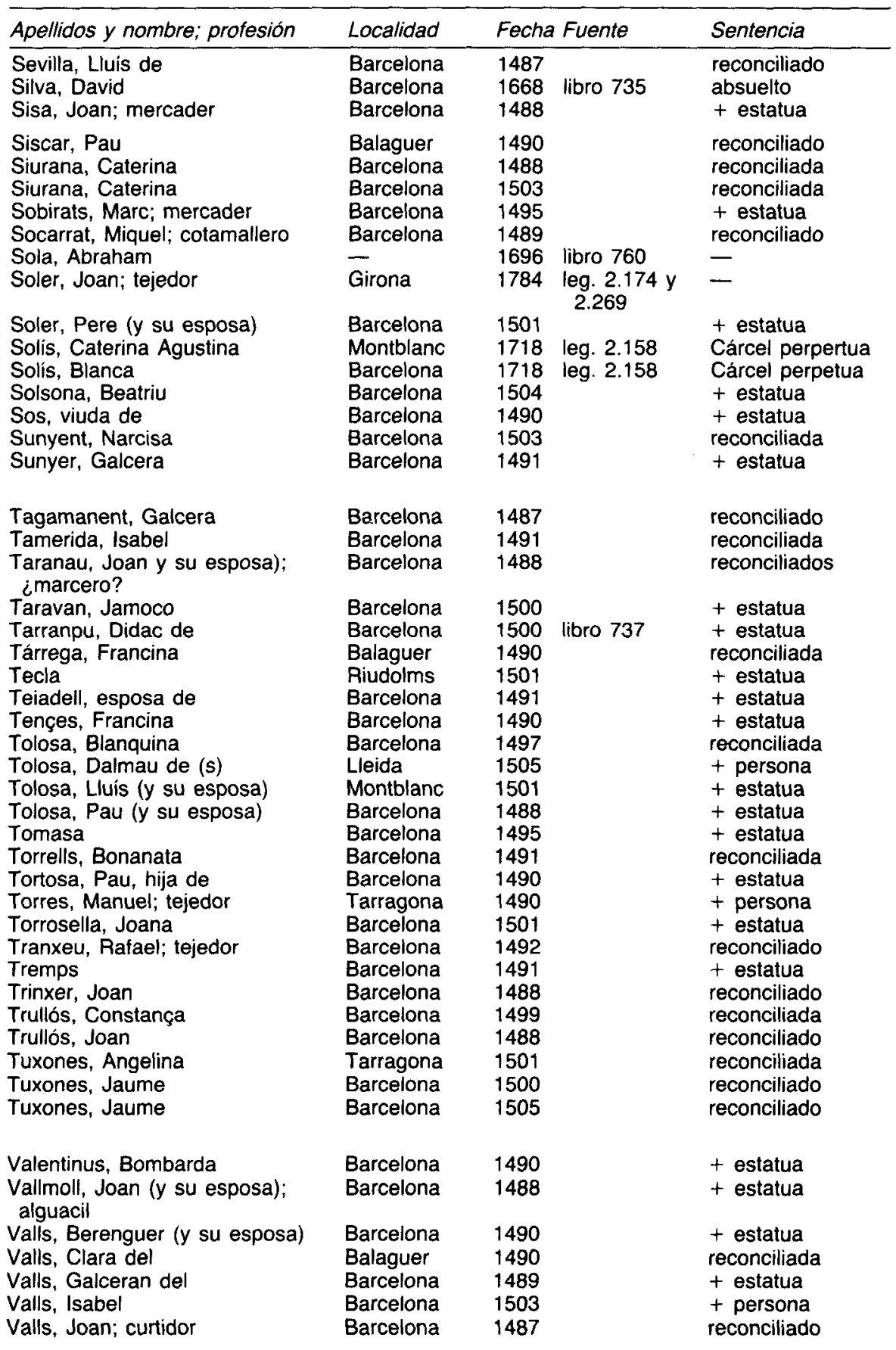


Catálogo de los procesos inquisitoriales del Tribunal del...

\begin{tabular}{|c|c|c|c|c|}
\hline Apellidos y nombre; profesión & Localidad & Fecha & Fuente & Sentencia \\
\hline Valls, Joan; mercader & Balaguer & 1490 & \multirow{12}{*}{$\begin{array}{l}\text { libro } 735 \\
\text { leg. 2.155 } \\
\text { libro 735; } \\
\text { leg. 2.155 } \\
\text { libro } 735 ; \\
\text { leg. } 2.155\end{array}$} & reconciliado \\
\hline Valls, Joan; tendero & Balaguer & 1490 & & reconciliado \\
\hline Valls, Joan & Barcelona & 1495 & & + estatua \\
\hline Valls, Joan; curtidor & Barcelona & 1505 & & reconciliado \\
\hline Valls, Joan, (y su esposa) & Barcelona & 1505 & & reconciliado \\
\hline Valls, Miquel; tendero & Barcelona & 1503 & & reconciliado \\
\hline Valls, Miquel & Barcelona & 1505 & & reconciliado \\
\hline Vázquez, Polonia & Barcelona & 1667 & & Cárcel perpetua \\
\hline Vázquez, Joana & Barcelona & 1667 & & Cárcel perpetua \\
\hline Vázquez, Manuel & Barcelona & 1667 & & 6 meses de cárcel \\
\hline Ventesa, Agnes & Perpignan & 1495 & & reconciliada \\
\hline $\begin{array}{l}\text { Vergueta, Melcior (y su madre); } \\
\text { tejedor }\end{array}$ & Barcelona & 1491 & & + estatua \\
\hline Via Camps, Joana & Balaguer & 1493 & & + estatua \\
\hline Vidente, Guillem; tejedor & Barcelona & 1491 & & reconciliado \\
\hline Vidal, Francesc; joyero & Barcelona & 1488 & & reconciliado \\
\hline Vidal, Miquel; escribano & Barcelona & 1501 & & + estatua \\
\hline Vidal, Leonor & Barcelona & 1491 & & + estatua \\
\hline Vidal, Raimond, esposa de & Barcelona & 1491 & & + estatua \\
\hline Vidua (y sus hijas) & Barcelona & 1489 & & + estatua \\
\hline Viladecans, Francina & Barcelona & 1495 & & + estatua \\
\hline Viladecans, Francina & Barcelona & 1497 & & + estatua \\
\hline Viladecans; tejedor & Barcelona & 1490 & & + estatua \\
\hline Vilafranca, Isabel & Barcelona & 1488 & & reconciliada \\
\hline Vilafranca, Joana & Barcelona & 1492 & & reconciliada \\
\hline Vilagut, Franci & Tarragona & 1505 & & reconciliado \\
\hline Vilagut, Francesc & Tarragona & 1489 & & reconciliado \\
\hline Vilagut, Francesc, (y su esposa) & Barcelona & 1502 & & reconciliados \\
\hline Vilagut, Raimond (y su esposa) & Tarragona & 1502 & & + estatua \\
\hline Vilamari, Bernat & Barcelona & 1495 & & + estatua \\
\hline Vilanova, Blanquina & Barcelona & 1492 & & reconciliada \\
\hline Vilanova, Gabriel; coralero & Barcelona & 1492 & & reconciliado \\
\hline Vilanova, Gaspar; jubonero & Barcelona & 1487 & & reconciliado \\
\hline Vilarasa, Juana & Perpignan & 1495 & & «reconciliada \\
\hline Vilella & Barcelona & 1497 & & + estatua \\
\hline Vinyes, Gaspar; mercader & Barcelona & 1490 & & + estatua \\
\hline Vinyes, Pau; mercader & Barcelona & 1490 & & + estatua \\
\hline Violant & Barcelona & 1487 & & reconciliada \\
\hline Violant & Barcelona & 1487 & & reconciliada \\
\hline Violant & Barcelona & 1488 & & reconciliada \\
\hline Violant & Barcelona & 1488 & & reconciliada \\
\hline Violant & Barcelona & 1488 & & reconciliada \\
\hline Violant (y sus dos hijas) & Barcelona & 1488 & & + estatua \\
\hline Violant & Barcelona & 1489 & & + estatua \\
\hline Violant & Perpignan & 1489 & & + estatua \\
\hline Violant & Tarragona & 1489 & & reconciliada \\
\hline Violant & Tarragona & 1489 & & reconciliada \\
\hline Violant & Barcelona & 1490 & & + estatua \\
\hline Violant & Barcelona & 1490 & & + estatua \\
\hline Violant & Barcelona & 1490 & & + estatua \\
\hline Violant & Barcelona & 1490 & & + estatua \\
\hline Violant & Balaguer & 1490 & & reconciliada \\
\hline Violant & Falset & 1490 & & reconciliada \\
\hline
\end{tabular}


JUAN BLÁZQUEZ MIGUEL

\begin{tabular}{|c|c|c|c|}
\hline Apellidos y nombre; profesión & Localidad & Fecha Fuente & Sentencia \\
\hline $\begin{array}{l}\text { Violant } \\
\text { Violant } \\
\text { Violant } \\
\text { Violant } \\
\text { Violant } \\
\text { Violant } \\
\text { Violant } \\
\text { Violant } \\
\text { Violant } \\
\text { Violant } \\
\text { Violant } \\
\text { Violant } \\
\text { Violant } \\
\text { Violant (y sus dos hijas) } \\
\text { Violant } \\
\text { Violant } \\
\text { Violant } \\
\text { Violant } \\
\text { Violant } \\
\text { Vital, Miquel } \\
\text { Vitalis, Francesc } \\
\text { Vitalis, Francesc } \\
\text { Vitalis, Lluís; mercader } \\
\text { Vitalis, Raimond, esposa de } \\
\text { Vitalis Samso, Joan (y su } \\
\text { esposa) }\end{array}$ & $\begin{array}{l}\text { Barcelona } \\
\text { Barcelona } \\
\text { Girona } \\
\text { Girona } \\
\text { Girona } \\
\text { Barcelona } \\
\text { Barcelona } \\
\text { Balaguer } \\
\text { Barcelona } \\
\text { Barcelona } \\
\text { Barcelona } \\
\text { Barcelona } \\
\text { Perpignan } \\
\text { Barcelona } \\
\text { Barcelona } \\
\text { Barcelona } \\
\text { Barcelona } \\
\text { Barcelona } \\
\text { Tarragona } \\
\text { Barcelona } \\
\text { Barcelona } \\
\text { Barcelona } \\
\text { Barcelona } \\
\text { Barcelona } \\
\text { Girona }\end{array}$ & $\begin{array}{l}1491 \\
1491 \\
1491 \\
1491 \\
1491 \\
1492 \\
1492 \\
1492 \\
1495 \\
1495 \\
1495 \\
1495 \\
1495 \\
1497 \\
1497 \\
1499 \\
1504 \\
1504 \\
1505 \\
1495 \\
1488 \\
1490 \\
1490 \\
1490 \\
1491\end{array}$ & $\begin{array}{l}\text { reconciliada } \\
\text { + estatua } \\
\text { + estatua } \\
\text { + estatua } \\
\text { + estatua } \\
\text { reconciliada } \\
\text { reconciliada } \\
\text { reconciliada } \\
\text { + estatua } \\
\text { + estatua } \\
\text { + estatua } \\
\text { + estatua } \\
\text { reconciliada } \\
\text { + estatua } \\
\text { + estatua } \\
\text { + estatua } \\
\text { + estatua } \\
\text { + estatua } \\
\text { reconciliada } \\
\text { + estatua } \\
\text { + estatua } \\
\text { + estatua } \\
\text { + estatua } \\
\text { + estatua } \\
\text { + estatua }\end{array}$ \\
\hline $\begin{array}{l}\text { Xercano, Clara } \\
\text { Xorcano }\end{array}$ & $\begin{array}{l}\text { Barcelona } \\
\text { Barcelona }\end{array}$ & $\begin{array}{l}1503 \\
1490\end{array}$ & $\begin{array}{l}+ \text { persona } \\
+ \text { estatua }\end{array}$ \\
\hline $\begin{array}{l}\text { Zabatera, Francina } \\
\text { Zabuda, Rafaela } \\
\text { Zacam (y su esposa); mercader } \\
\text { Zacoma, Blanquina } \\
\text { Zacoma, Joan; librero } \\
\text { Zalón, Luis (y su esposa); sastre } \\
\text { Zaportella, Galcera } \\
\text { Zarriera, Joan; curtidor } \\
\text { Zatorre, Gabriel } \\
\text { Zatorre, Gracia } \\
\text { Zatorre, Joan } \\
\text { Zatrillas, Lluisa } \\
\text { Zatrillas, Francina, hija de } \\
\text { Zavall, Melcior (y su esposa) }\end{array}$ & $\begin{array}{l}\text { Barcelona } \\
\text { Barcelona } \\
\text { Barcelona } \\
\text { Barcelona } \\
\text { Barcelona } \\
\text { Barcelona } \\
\text { Montblanc } \\
\text { Barcelona } \\
\text { Balaguer } \\
\text { Balaguer } \\
\text { Balaguer } \\
\text { Barcelona } \\
\text { Barcelona } \\
\text { Barcelona }\end{array}$ & $\begin{array}{l}1488 \\
1503 \\
1501 \\
1491 \\
1495 \\
1490 \\
1501 \\
1497 \\
1490 \\
1493 \\
1490 \\
1500 \\
1491 \\
1500\end{array}$ & $\begin{array}{l}\text { reconciliada } \\
\text { reconciliada } \\
\text { + estatua } \\
\text { + estatua } \\
\text { + estatua } \\
\text { + estatua } \\
\text { + estatua } \\
\text { + estatua } \\
\text { reconciliado } \\
\text { + estatua } \\
\text { reconciliado } \\
\text { absuelta } \\
\text { + estatua } \\
\text { + estatua }\end{array}$ \\
\hline
\end{tabular}

\section{ISLAMISMO}

Acasio, Jeronimo; galeote

Aguirre, Juan de (of)

1634 libro 733

1602 libro 731 absuelto

azotado y 8 años de galeras 
Catálogo de los procesos inquisitoriales del Tribunal del...

\begin{tabular}{|c|c|c|c|c|}
\hline Apellidos y nombre; profesión & Localidad & Fecha & Fuente & Sentencia \\
\hline $\begin{array}{l}\text { Alagarah, Miguel (mo) } \\
\text { Alarcós. Felipe de }\end{array}$ & & 1606 & $\begin{array}{l}\text { libro } 732 \\
\text { leg. } 1.593\end{array}$ & destierro y multa \\
\hline Alabaizin, Francisco de; esclavo & & 1658 & libro 734 & reconciliado \\
\hline Alejo, Jerónimo (mo) & & 1606 & libro 732 & destierro y multa \\
\hline Alfaro, Francisco Artonio & & 1670 & libro 754 & ¿reconciliado? \\
\hline Amar $(m)$ & & 1675 & libro 735 & $\begin{array}{l}\text { azotado y } 6 \text { años } \\
\text { en galeras }\end{array}$ \\
\hline Amburgo, Johannes (a); galeote & & 1628 & libro 733 & absuelto \\
\hline Amete; galeote & & 1623 & libro, 733 & reconciliado \\
\hline Andars, Carnels (in); galeote & & 1626 & libro 732 & absuelto \\
\hline Andrea, Antonio (i); marinero & & 1563 & libro 730 & $\begin{array}{l}\text { azotado y } 7 \text { años } \\
\text { en galeras }\end{array}$ \\
\hline $\begin{array}{l}\text { Ansunos, Pierre (f); galeote } \\
\text { Antonio: esclavo }\end{array}$ & & $\begin{array}{l}1626 \\
1596\end{array}$ & libro 732 & $\begin{array}{l}\text { absuelto } \\
\text { reconciliado }\end{array}$ \\
\hline Aranda, Felipe de; militar & Barcelona & 1734 & leg. 2162 & ¿reconciliado? \\
\hline Aragonesa, Maria (mo) & Segorbe & 1569 & libro 730 & reclusión \\
\hline $\begin{array}{l}\text { Arbori, Guillem } \\
\text { Arévalo, Francisco }\end{array}$ & & 1562 & libro 730 & $\begin{array}{l}\text { reconciliado } \\
\text { reconciliado }\end{array}$ \\
\hline $\begin{array}{l}\text { Arevalo, Francisco } \\
\text { Arráez, Jaban (m?) }\end{array}$ & & $\begin{array}{l}150< \\
1626\end{array}$ & libro 732 & - \\
\hline Azmill, Jaime (mo) & Benavit & 1569 & libro 730 & - \\
\hline Babre, Montserrat ( $¿ f ?)$ & & 1607 & libro 732 & - \\
\hline Baloles, Antón; galeote & & 1654 & libro 734 & suspenso \\
\hline Barbastro, Francisco & & 1562 & libro 730 & absuelto \\
\hline Baszia, Esteban & & 1600 & libro 731 & huyó \\
\hline Baszia, Ramón & & 1600 & libro 731 & huyó \\
\hline Baudu, Giovanni (i); galeote & & 1661 & libro 734 & reprendido \\
\hline Belito, Francisco (mo) & & 1606 & libro 732 & destierro y multa \\
\hline Belito, Jerónimo (mo) & & 1606 & libro 732 & destierro y multa \\
\hline $\begin{array}{l}\text { Bella, Alarcós (mo) } \\
\text { Beneqas, Gabriel }\end{array}$ & & 1633 & libro 733 & absuelto \\
\hline Benegas, Gabriel & & 1565 & libro 730 & reconciliado \\
\hline Berenys, Mateo & & 1491 & Carbonell & reconciliado \\
\hline Berton, Jean (f) & & 1664 & libro 735 & absuelto \\
\hline Beth, Sansón (a); galeote & & 1626 & libro 732 & absuelto \\
\hline Blanch, Luis; galeote & & 1615 & libro 732 & absuelto \\
\hline Blanch, Tomas; marinero & & 1569 & libro 730 & reconcilado \\
\hline Bonin, Clemente & Barcelona & 1562 & libro 730 & reconciliado \\
\hline $\begin{array}{l}\text { Boyfis, Jean (f) } \\
\text { Bretell Guillaume }(f) \text {. galeote }\end{array}$ & & 1609 & libro 732 & absuelto \\
\hline Burme, Ambrogio (i) & & $\begin{array}{l}1004 \\
1574\end{array}$ & libro 730 & reconciliado \\
\hline $\begin{array}{l}\text { Cáceres, Juan Bautista de; galeo- } \\
\text { te }\end{array}$ & & 1613 & libro 732 & \\
\hline Cadena, Alvaro; galeote & & 1578 & libro 730 & $\begin{array}{l}\text { azotado y galeras } \\
\text { a perpetuidad }\end{array}$ \\
\hline Cafar, Francisco (mo) & & 1605 & libro 731 & reconciliado \\
\hline Calanda, Lope & & 1615 & libro 732 & $\begin{array}{l}\text { azotado y galeras } \\
\text { a perpetuidad }\end{array}$ \\
\hline Calavera, Manuel (mo) & & 1606 & libro 732 & destierro y multa \\
\hline Candia, Mohamed (mo) & & 1691 & libro 735 & \\
\hline Cara, Joseph de la $(f)$; galeote & & 1629 & libro 733 & absuelto \\
\hline Carmel, Noel $(f)$ & & 1627 & libro 733 & reconciliado \\
\hline Carretero, Johannes (a); galeote & & 1624 & libro 733 & absuelto \\
\hline Caso, Juan del; galeote & & 1600 & libro 731 & huyó \\
\hline Castillo, Ana del (mo?) & & 1562 & libro 730 & absuelta \\
\hline Cato, Baltasar (mo) & & 1606 & libro 732 & destierro y multa \\
\hline Cerdá, Sebastian; marinero & Barcelona & 1569 & libro 730 & penitenciado \\
\hline
\end{tabular}




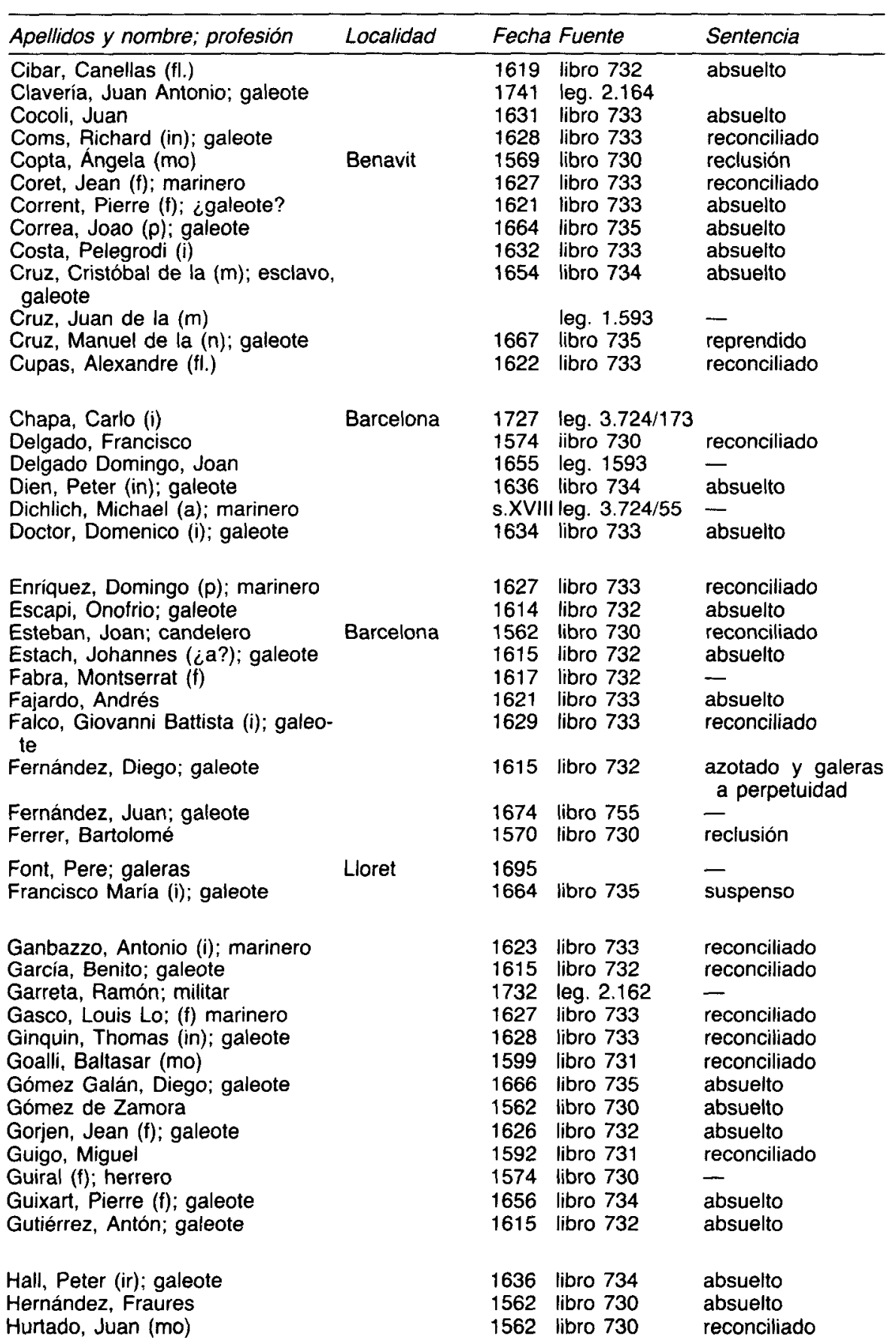


Catálogo de los procesos inquisitoriales del Tribunal del...

\begin{tabular}{|c|c|c|c|c|}
\hline Apellidos y nombre; profesión & Localidad & Fecha & Fuente & Sentencia \\
\hline $\begin{array}{l}\text { Ibarra, Domingo de; galeote } \\
\text { Insaustre, Francisco; candelero } \\
\text { Irigoy, Pedro de; galeote }\end{array}$ & Barcelona & $\begin{array}{l}1634 \\
1571 \\
1615\end{array}$ & $\begin{array}{l}\text { libro } 733 \\
\text { libro } 730 \\
\text { libro } 732\end{array}$ & $\begin{array}{l}\text { absuelto } \\
\text { reconciliado } \\
\text { absuelto }\end{array}$ \\
\hline $\begin{array}{l}\text { Jean Baptiste (f); tundidor } \\
\text { Jiménez, Francisco; galeote } \\
\text { Jonas (in); galeote } \\
\text { Jorge Balthesar (g); galeote } \\
\text { Juan (m?); ¿galeote? } \\
\text { Juan (m); esclavo } \\
\text { Juan (po) } \\
\text { Juan Bautista; galeote } \\
\text { Juan Francisco (p) } \\
\text { Juan Francisco } \\
\text { Juan María (mo) } \\
\text { Juan Miguel de Santa Maria (m) } \\
\text { Juan Ramón (mo) } \\
\text { Juana (mo) }\end{array}$ & $\begin{array}{l}\text { Barcelona } \\
\text { Barcelona } \\
\text { Segorbe } \\
\text { Segorbe }\end{array}$ & $\begin{array}{l}1562 \\
1635 \\
1636 \\
1634 \\
1562 \\
1573 \\
1624 \\
1615 \\
1562 \\
1668 \\
1609 \\
1638 \\
1569 \\
1569\end{array}$ & $\begin{array}{l}\text { libro } 730 \\
\text { libro } 733 \\
\text { libro } 734 \\
\text { libro } 733 \\
\text { libro } 730 \\
\text { libro } 737 \\
\text { libro } 733 \\
\text { libro } 732 \\
\text { libro } 730 \\
\text { libro } 735 \\
\text { libro } 732 \\
\text { libro } 734 \\
\text { libro } 730 \\
\text { libro } 730\end{array}$ & $\begin{array}{l}\text { absuelto } \\
\text { absuelto } \\
\text { absuelto } \\
\text { reconciliado } \\
\text { reclusión } \\
\text { reprendido } \\
\text { absuelto } \\
\text { reconciliado } \\
\text { suspenso } \\
\text { multado } \\
\text { falleció } \\
\text { reclusión } \\
\text { absuelta }\end{array}$ \\
\hline $\begin{array}{l}\text { Lamberti, Francesco (i); milítar } \\
\text { Lancero, Jerónimo (mo) } \\
\text { Lanoz, Benoit (f); galeote } \\
\text { Lebrero, Jerónimo (mo) } \\
\text { Lecoh, Louis (f); galeote } \\
\text { Lepp, Peter von (¿a?); galeote } \\
\text { López, Diego; ¿galeote? } \\
\text { López, Miguel; ¿galeote? } \\
\text { López, Ventura; militar }\end{array}$ & & $\begin{array}{l}1735 \\
1606 \\
1628 \\
1606 \\
1636 \\
1574 \\
1562 \\
1674 \\
1737\end{array}$ & $\begin{array}{l}\text { leg. } 2.162 \\
\text { libro } 732 \\
\text { libro } 733 \\
\text { libro } 732 \\
\text { libro } 734 \\
\text { libro } 730 \\
\text { libro } 730 \\
\text { libro } 735 \\
\text { leg. } 3.724 / \\
150\end{array}$ & $\begin{array}{l}\text { - destierro y multa } \\
\text { absuelto } \\
\text { destierro y multa } \\
\text { absuelto } \\
\text { reconciliado } \\
\text { reconciliado } \\
\text { absuelto } \\
\text { - }\end{array}$ \\
\hline $\begin{array}{l}\text { Maltés, Onofre; galeote } \\
\text { Mallol, Felipe }\end{array}$ & Cadaqués & $\begin{array}{l}1611 \\
1569\end{array}$ & $\begin{array}{l}\text { libro } 732 \\
\text { libro } 730\end{array}$ & $\begin{array}{l}\text { absuelto } \\
\text { penitencias } \\
\text { espirituales }\end{array}$ \\
\hline $\begin{array}{l}\text { Mallos, Guillaume (f); galeote } \\
\text { Mami (m); galeote } \\
\text { Mami (es); galeote } \\
\text { Maulenque, Pere } \\
\text { Manuel Jorge }(p) \\
\text { Marcos Jorge }(p) ; \text { galeote } \\
\text { Marin, Jordi de; galeote } \\
\text { Marquete, Laurente (f); en } \\
\text { galeote }\end{array}$ & Montroig & $\begin{array}{l}1626 \\
1636 \\
1627 \\
1602 \\
1629 \\
1634 \\
1615 \\
1635\end{array}$ & $\begin{array}{l}\text { libro } 732 \\
\text { libro } 734 \\
\text { libro } 733 \\
\text { libro } 731 \\
\text { libro } 733 \\
\text { libro } 733 \\
\text { libro } 732 \\
\text { libro } 733\end{array}$ & $\begin{array}{l}\text { absuelto } \\
\text { absuelto } \\
\text { absuelto } \\
+ \text { estatua } \\
\text { absuelto } \\
\text { absuelto } \\
\text { absuelto } \\
\text { absuelto }\end{array}$ \\
\hline $\begin{array}{l}\text { Marquina, Isabel (mo) } \\
\text { Martin, Etienne (f) } \\
\text { Martínez, Bartolomé; galeote } \\
\text { Martínez, Gregorio; escopetero } \\
\text { Martinez, Pedro } \\
\text { Martre, Simón; apotecario } \\
\text { Mas, Juan del }\end{array}$ & Barcelona & $\begin{array}{l}1612 \\
1627 \\
1562 \\
1569 \\
1562 \\
1602 \\
1578\end{array}$ & $\begin{array}{l}\text { libro } 732 \\
\text { libro } 733 \\
\text { libro } 730 \\
\text { libro } 730 \\
\text { libro } 730 \\
\text { libro } 731 \\
\text { libro } 730\end{array}$ & $\begin{array}{l}\text { reconciliada } \\
+ \text { persona } \\
\text { reconciliado } \\
\text { reconciliado } \\
\text { reconciliado } \\
\text { ¿reconciliado? } \\
\text { azotado y } \\
\text { entregado a la } \\
\text { justicia seglar }\end{array}$ \\
\hline $\begin{array}{l}\text { Matera, Jean (f); galeote } \\
\text { Maurí, Luis (mo); herrero }\end{array}$ & Tivica & $\begin{array}{l}1636 \\
1575\end{array}$ & $\begin{array}{l}\text { libro } 734 \\
\text { libro } 730\end{array}$ & $\begin{array}{l}\text { absuelto } \\
\text { azotado y galeras } \\
\text { a perpetuidad }\end{array}$ \\
\hline Medina, Isabel de (mo) & & 1562 & libro 730 & absuelta \\
\hline
\end{tabular}


JUAN BLÁZQUEZ MIGUEL

\begin{tabular}{|c|c|c|c|c|}
\hline Apellidos y nombre; profesión & Localidad & Fecha & Fuente & Sentencia \\
\hline Mendoza, Jerónimo $(\mathrm{mo})$ & & 1606 & libro 732 & destierro y multa \\
\hline Mendoza, Jerónimo, su hijo (ma) & & 1606 & libro 732 & destierro y multa \\
\hline Mendoza, Luis de; esclavo & & 1639 & libro 734 & absuelto \\
\hline Metali, Juan & & 1557 & leg. $1.592 / 23$ & - \\
\hline Micino, Francesco (i); galeote & & 1629 & libro 733 & reconciliado \\
\hline Michel Honorat (f); galeote & & 1615 & libro 732 & absuelto \\
\hline Molina, Juan de & & 1562 & libro 730 & reconciliado \\
\hline Mon Luc $(f)$; galeote & & 1626 & libro 732 & absuelto \\
\hline Montoya, Alonso de; marinero & & 1561 & libro 730 & reconciliado \\
\hline Morales, Francisco; galeote & & 1626 & libro 732 & absuelto \\
\hline Moreno, Gregorio & & 1562 & libro 730 & absuelto \\
\hline Moro, Jacob Le (f?) & & 1574 & libro 730 & multado \\
\hline Mustafá $(m)$; galeote & & 1578 & libro 730 & $\begin{array}{l}\text { azotado y galeras } \\
\text { a perpetuidad }\end{array}$ \\
\hline Mustafá (m) & c. & 1554 & libro 736 & + persona \\
\hline $\begin{array}{l}\text { Mustier, Honoré }(f) \text {; marinero } \\
\text { Moral }\end{array}$ & & $\begin{array}{l}1627 \\
1626\end{array}$ & $\begin{array}{l}\text { libro } 733 \\
\text { libro } 732\end{array}$ & absuelto \\
\hline Navarro, Juan; ¿galeote? & & 1562 & libro 730 & reconciliado \\
\hline Nemur, Jean $(f)$; galeote & & 1626 & libro 732 & absuelto \\
\hline Ocar, Robert (in); galeote & & 1626 & libro 732 & absuelto \\
\hline Ojeda, Juan de; galeote & & 1636 & libro 734 & absuelto \\
\hline Oliver, Louis (f); galeote & & 1623 & libro 733 & reconciliado \\
\hline Orán, Diego de & & 1569 & libro 730 & $\begin{array}{l}20 \text { años en } \\
\text { galeras }\end{array}$ \\
\hline Ortencia, Francesco (i) & & 1623 & libro 733 & reconciliado \\
\hline Oseya, Ausany (i) & & 1591 & libro 731 & reconciliado \\
\hline Par, Guiseppe (i); marinero & Barcelona & 1725 & leg. 2.161 & $\begin{array}{l}\text { azotado y } 5 \text { años } \\
\text { en galeras }\end{array}$ \\
\hline Parascopla, Juan (g); galeote & & 1626 & libro 732 & absuelto \\
\hline Pedrosa, Felipe; galeote & & 1619 & libro 732 & absuelto \\
\hline Peire, Miguel & & 1565 & libro 730 & reconciliado \\
\hline Perbas, Antón de; ¿galeote? & & 1562 & libro 730 & reconciliado \\
\hline Pérez, Andrés (mo) & & 1624 & libro 733 & absuelto \\
\hline Pérez, Damián; galeote & & 1615 & libro 732 & absuelto \\
\hline Petre, Nicolás (fl); galeote & & 1629 & libro 733 & absuelto \\
\hline Polo Jerónimo & & 1565 & libro 730 & reconciliado \\
\hline $\begin{array}{l}\text { Ponce, Luis (mo); labrador } \\
\text { Ponz, Simón }\end{array}$ & Miravet & $\begin{array}{l}1569 \\
1570\end{array}$ & $\begin{array}{l}\text { libro } 730 \\
\text { libro } 730\end{array}$ & $\begin{array}{l}\text { Reclusión } \\
\text { azotado } 3 \text { años en } \\
\text { galeras }\end{array}$ \\
\hline Portes, Michel (f); galeote & & 1618 & libro 732 & absuelto \\
\hline Prats, Joan; médico & $\begin{array}{l}\text { Castello } \\
d^{\prime} \text { Empuries }\end{array}$ & 1662 & libro 752 & \\
\hline Prats, Pere & Montalbán & 1503 & Carbonell & $\begin{array}{l}\text { condenado en } \\
\text { ausencia }\end{array}$ \\
\hline $\begin{array}{l}\text { Prohesin, Giovanni (i); cocinero, } \\
\text { Proto, Bonifacio; galeote }\end{array}$ & Barcelona & $\begin{array}{l}1592 \\
1615\end{array}$ & $\begin{array}{l}\text { libro } 731 \\
\text { libro } 732\end{array}$ & $\begin{array}{l}\text { absuelto } \\
\text { absuelto }\end{array}$ \\
\hline Quesada, Juan de; galeote & & 1629 & libro 733 & absuelto \\
\hline Radih, Georgio (fl); galeote & & 1613 & libro 732 & - \\
\hline
\end{tabular}


Catálogo de los procesos inquisitoriales del Tribunal del...

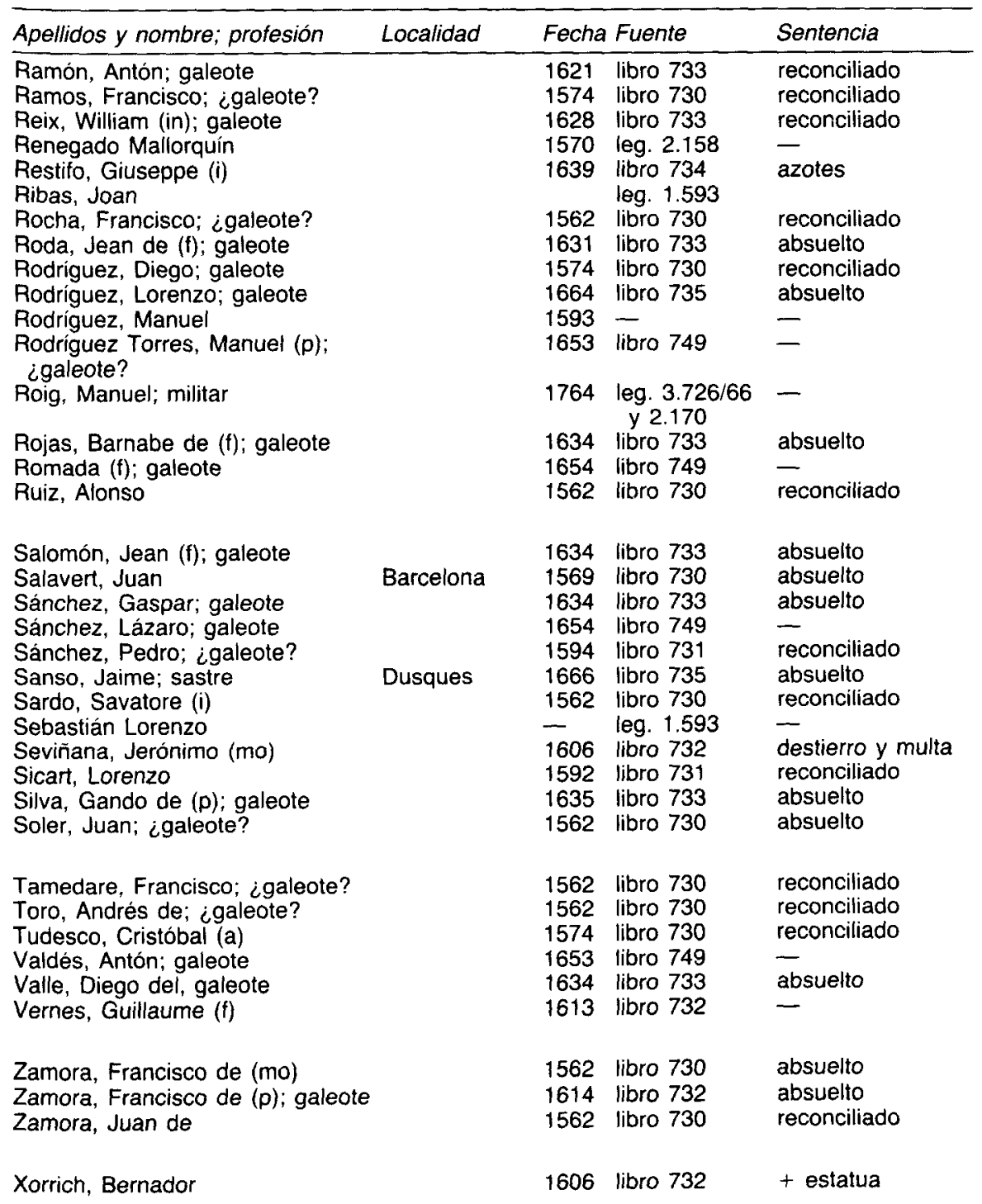

\section{LUTERANISMO}

Abat, Edward (in); galeote

1628 libro 733 reconciliado

Abdeu, Pierre ( $f$ )

1573 libro 737

reclusión 
JUAN BLAZZUEZ MIGUEL

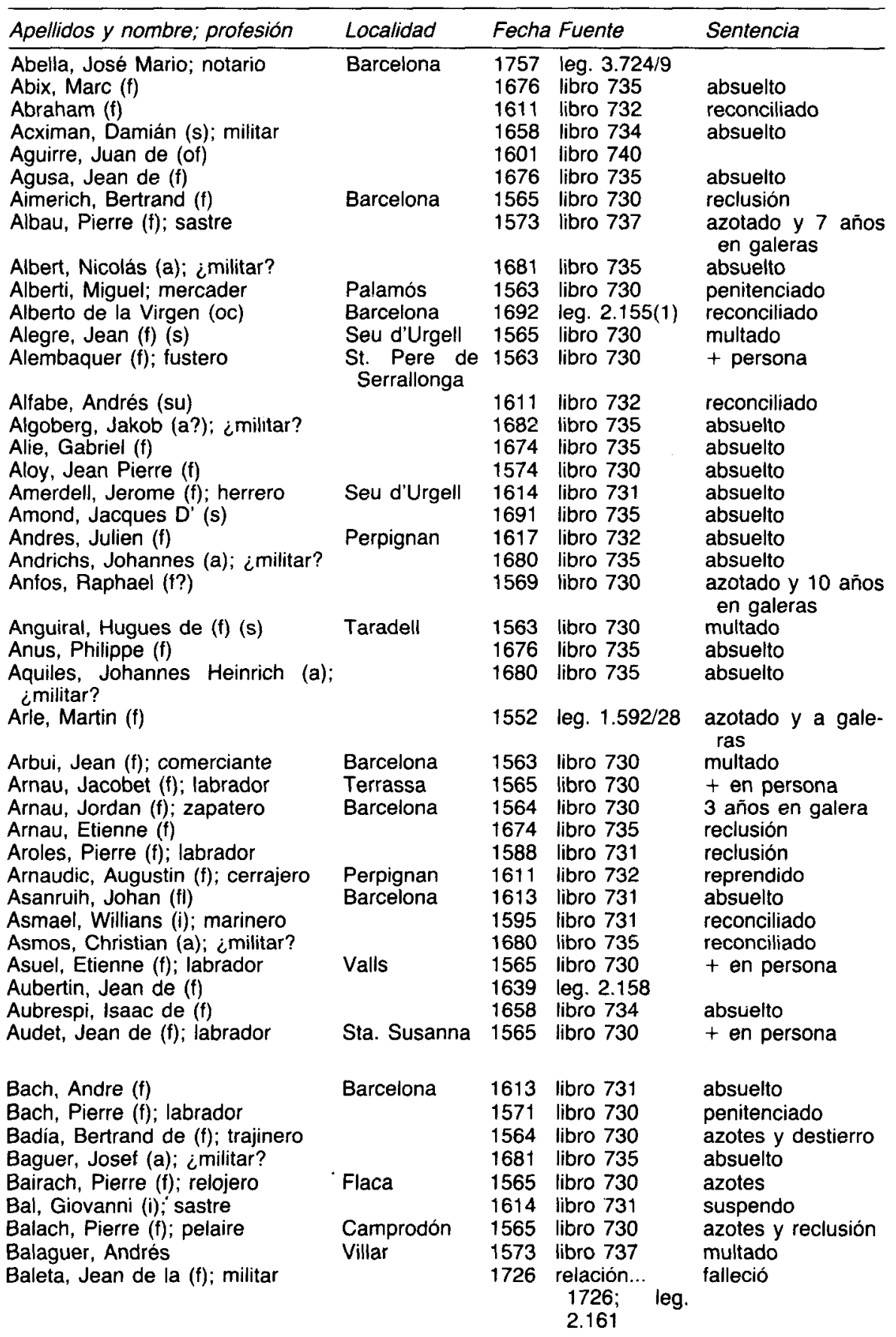


Catálogo de los procesos inquisitoriales del Tribunal del...

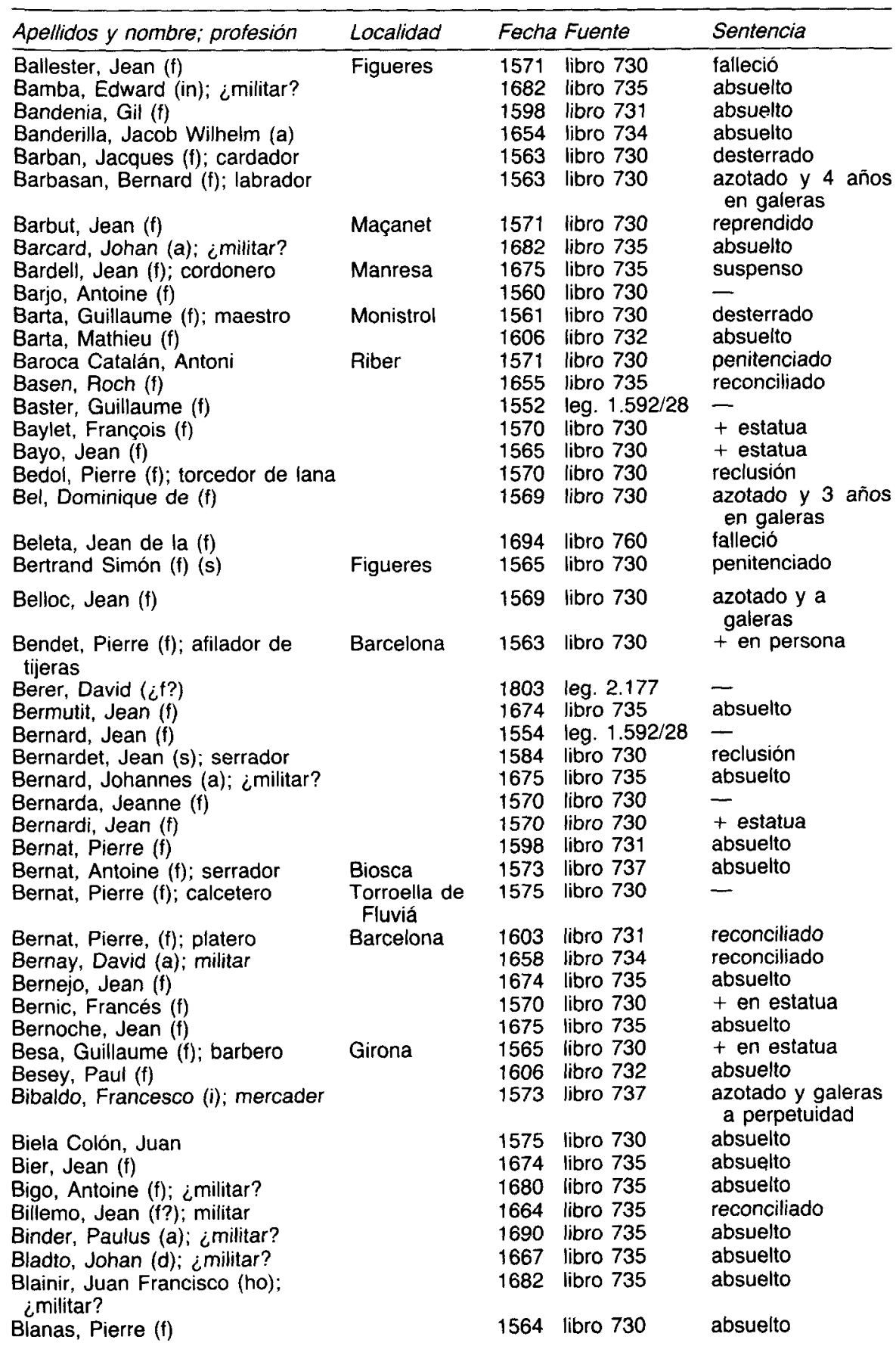




\begin{tabular}{|c|c|c|c|c|}
\hline Apellidos y nombre; profesión & Localidad & Fecha & Fuente & Sentencia \\
\hline Blanc, Joannot (f) & & 1573 & libro 737 & reclusión \\
\hline Blanco, Etienne (f) & & 1680 & libro 735 & absuelto \\
\hline Blanch, Pierre (f) & & 1617 & libro 732 & absuelto \\
\hline Blanche, Hotvene $(f)$ & & 1691 & libro 735 & absuelto \\
\hline Blanchart, Jean (f); labrador & & 1624 & libro 733 & absuelto \\
\hline Boart, Nicholas (fl) & & 1560 & libro 730 & - \\
\hline Boisen, Jean (f) & & 1674 & libro 735 & absuelto \\
\hline Boldu, Antoni (s) & Vimbodí & 1571 & libro 730 & reprendido \\
\hline Bon, Thomas (in); marinero & & 1595 & libro 731 & reconciliado \\
\hline Bonafont, Guillaume (f) & & 1573 & libro 737 & reconciliado \\
\hline Bonafont, Jean de (f); labrador & Olesa & 1594 & libro 731 & reclusión \\
\hline Bonet, Nicolás (f); cerrajero & Vic & 1564 & libro 730 & azotes y destierro \\
\hline Bonte, Jean de la (f) & & 1560 & libro 730 & \\
\hline Boquer Frederick (a); ¿militar? & & 1676 & libro 735 & absuelto \\
\hline $\begin{array}{l}\text { Borchet, Balthazar (f) } \\
\text { Bordas, Jean }(f) \text {; pastor }\end{array}$ & & 1617 & libro 732 & + en estatua \\
\hline Bordas, Jean (f); pastor & & 1563 & libro 730 & + en estatua \\
\hline Bordons, Pierre $(f)$; músico & Perpignan & 1571 & libro 730 & reclusión \\
\hline $\begin{array}{l}\text { Borguyno, Claude (s); ¿militar? } \\
\text { Bordan, Joseph (s); ¿militar? }\end{array}$ & & $\begin{array}{l}1667 \\
1676\end{array}$ & $\begin{array}{l}\text { libro } 735 \\
\text { libro } 735\end{array}$ & $\begin{array}{l}\text { absuelto } \\
\text { absuelto }\end{array}$ \\
\hline Bosch, Guillaume (f); labrador & & 1578 & libro 730 & \\
\hline Bosch, Guillaume (f) & Valls & 1622 & libro 733 & reprendido \\
\hline Bosch, Leonard $(f)$ & & 1560 & libro 730 & - \\
\hline Bossas, Jacques $(f)$; curtidor & & 1654 & libro 734 & absuelto \\
\hline Bouta, Jean de la $(f)$ & & 1565 & libro 730 & + en estatua \\
\hline Braun, Abraham (a); ¿militar? & & 1688 & libro 735 & absuelto \\
\hline $\begin{array}{l}\text { Braun, Johannes Jacob (a); } \\
\text { militar }\end{array}$ & & 1690 & libro 735 & absuelto \\
\hline Brebonethes, Jean (f); zapatero & Constanti & 1565 & libro 730 & $\begin{array}{l}\text { azotado y } 6 \text { años } \\
\text { en galeras }\end{array}$ \\
\hline Breis, Johannes Georg (a) & & 1803 & leg. 2.177 & - \\
\hline Bresola, Jean (f); boyero & & 1571 & libro 730 & penitenciado \\
\hline Brey, José de (om) & & 1601 & libro 740 & - \\
\hline Briesa, Jacques (f) & & 1560 & libro 730 & - \\
\hline Brindeis, Jaime $(s)$ & & 1676 & libro 735 & absuelto \\
\hline Bron, Johan Jorge $(h)$; ¿militar? & & $\begin{array}{l}1681 \\
1675\end{array}$ & $\begin{array}{l}\text { libro } 735 \\
\text { libro } 735\end{array}$ & absuelto \\
\hline $\begin{array}{l}\text { Brosus, Antolne }(\mathfrak{f}) \\
\text { Bru, Antoine }(\mathfrak{f}) ; \text { criado }\end{array}$ & Barcelona & $\begin{array}{l}16 / 5 \\
1564\end{array}$ & $\begin{array}{l}\text { libro } 735 \\
\text { libro } 730\end{array}$ & $\begin{array}{l}\text { absuelto } \\
\text { penitenciado }\end{array}$ \\
\hline Brudera, Abraham (a); militar & & 1682 & libro 735 & absuelto \\
\hline Buret, Pierre (f); cerrajero & & 1571 & libro 730 & reclusión \\
\hline Brugrave, Jaime (a); militar & & 1676 & libro 735 & absuelto \\
\hline Brunell, Jacques (f) & & 1610 & libro 732 & reconciliado \\
\hline Brunet, Jean (f); criado & & 1573 & libro 737 & $\begin{array}{l}\text { reclusión } \\
\text { absuelto }\end{array}$ \\
\hline $\begin{array}{l}\text { Brunet, Jean ( } f \text { ) } \\
\text { Bruno, Jaime (su); ¿militar? }\end{array}$ & & $\begin{array}{l}1674 \\
1676\end{array}$ & $\begin{array}{l}\text { libro } 735 \\
\text { libro } 735\end{array}$ & $\begin{array}{l}\text { absuelto } \\
\text { absuelto }\end{array}$ \\
\hline Brusu, Raphael (f); naipero & Barcelona & 1575 & libro 730 & $\begin{array}{l}\text { azotado y galeras } \\
\text { a perpetuidad }\end{array}$ \\
\hline Budet, Jean (f) & & 1675 & libro 735 & absuelto \\
\hline Bugia, Samson (f) & & 1674 & libro 735 & absuelto \\
\hline Bulf (Wolf), Johannes (a); militar & & 1658 & libro 734 & absuelto \\
\hline Buman, Albert (a); militar & & 1688 & libro 735 & absuelto \\
\hline Burget, Balthazar (f); estampero & Barcelona & 1602 & libro 731 & reclusión \\
\hline Burgada, Pierre (f) & & 1564 & libro 730 & $\begin{array}{l}\text { azotado y } 3 \text { años } \\
\text { en galeras }\end{array}$ \\
\hline Burgasen, Jean (¿f?) & & 1574 & libro 730 & azotado \\
\hline Burriana, Jacques (f) & Vic & 1603 & libro 731 & $\begin{array}{l}\text { azotado y } 4 \text { años } \\
\text { en galeras }\end{array}$ \\
\hline
\end{tabular}


Catálogo de los procesos inquisitoriales del Tribunal del...

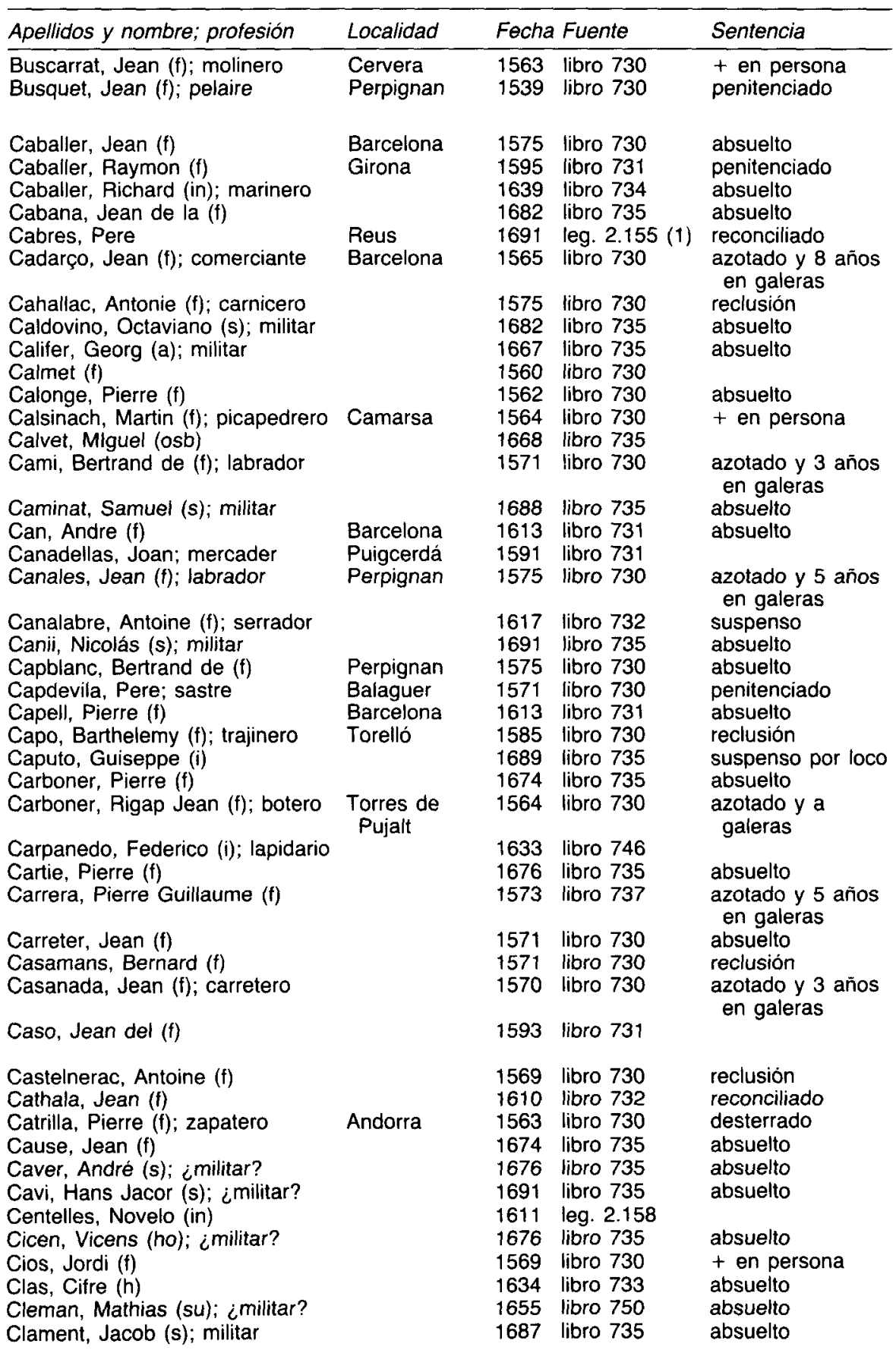




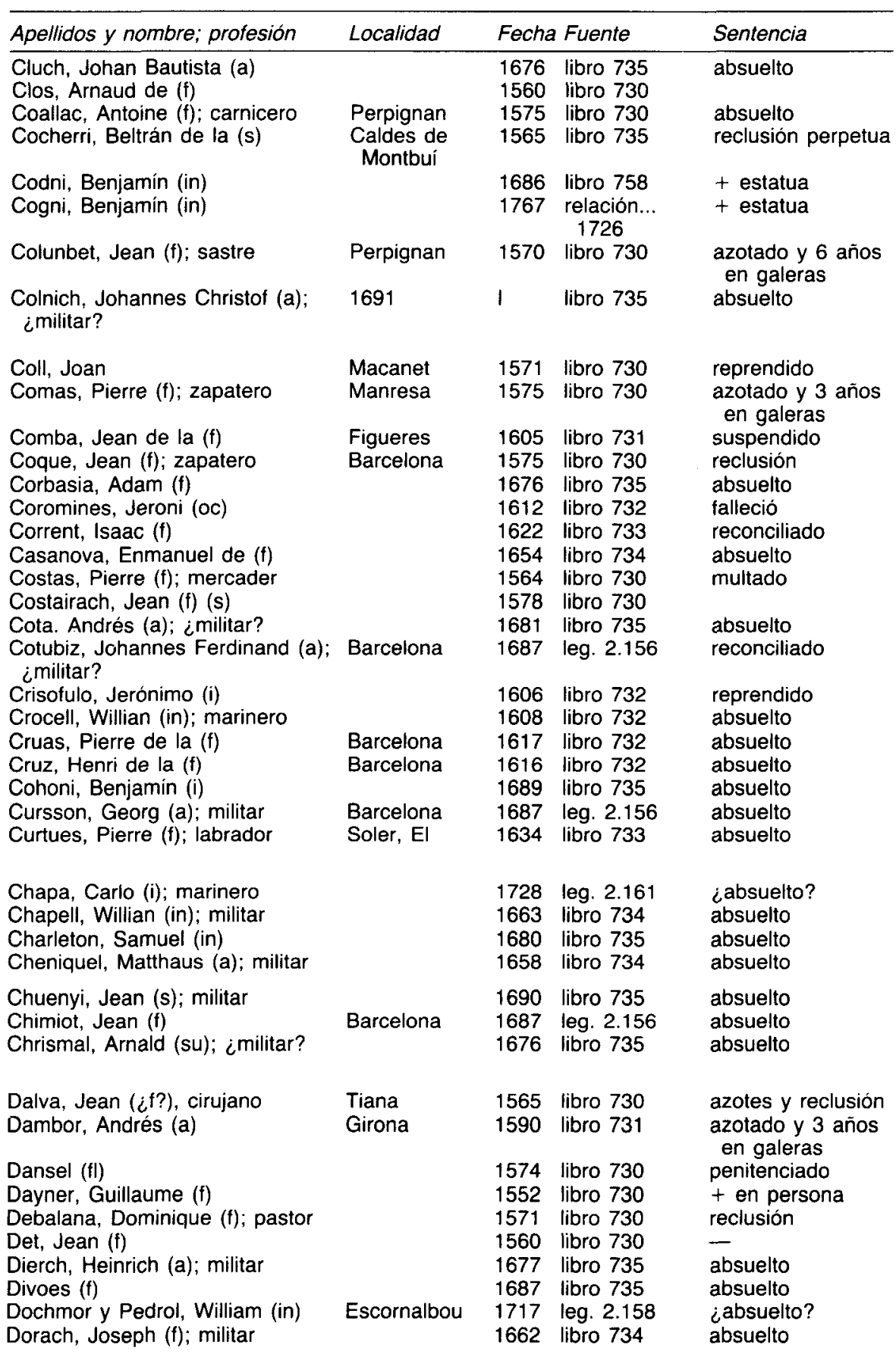


Catálogo de los procesos inquisitoriales del Tribunal del...

\begin{tabular}{|c|c|c|c|c|}
\hline Apellidos y nombre; profesión & Localidad & Fecha & Fuente & Sentencia \\
\hline Drull, Vicent $(\mathrm{f})$; vidriero & Vilassar & 1583 & libro 730 & $\begin{array}{l}\text { azotado y } 10 \text { años } \\
\text { en galeras }\end{array}$ \\
\hline $\begin{array}{l}\text { Dugat, Blaise (f); zapatero } \\
\text { Dulcet, Benoit (f) }\end{array}$ & Girona & $\begin{array}{l}1583 \\
1571\end{array}$ & $\begin{array}{l}\text { libro } 730 \\
\text { libro } 730\end{array}$ & $\begin{array}{l}\text { reclusión } \\
\text { azotado } 3 \text { años en } \\
\text { galeras }\end{array}$ \\
\hline Dueron, Jean François (s); militar & & 1667 & libro 735 & absuelto \\
\hline Dumas, Jean (s) & & 1621 & libro 733 & absuelto \\
\hline Duran Claude (f); galeote & & 1654 & libro 734 & absuelto \\
\hline Duran, Jean (f) & & 1571 & libro 730 & recluido \\
\hline Duran, Louis $(f)$ & & 1680 & libro 735 & absuelto \\
\hline Ebran, Marc (f) & & 1573 & libro 737 & $\begin{array}{l}\text { azotado y } 7 \text { años } \\
\text { en galeras }\end{array}$ \\
\hline Ebran, Bernard $(f)$ & & 1563 & libro 730 & destierro \\
\hline $\begin{array}{l}\text { Echtermeyer, Christof (a); } \\
\text { ¿militar? }\end{array}$ & & 1667 & libro 735 & absuelto \\
\hline Einkhenp, Johannes (a); militar & & 1691 & libro 735 & absuelto \\
\hline Eles, Herry (in); marinero & & 1595 & libro 731 & reconciliado \\
\hline Eller, Gerard (h) & & 1688 & libro 735 & absuelto \\
\hline Encausi, Jeanne D' (f) & Fonollosa & 1575 & libro 730 & reclusión \\
\hline Endrich, Johannes (a) & & 1667 & libro 735 & absuelto \\
\hline Enrique, Simón (f); sombrerero & Barcelona & 1565 & libro 730 & reclusión \\
\hline $\begin{array}{l}\text { Erich, Johan (s); ¿militar? } \\
\text { Escar, Pierre }(f)\end{array}$ & & $\begin{array}{l}1676 \\
1675\end{array}$ & $\begin{array}{l}\text { libro } 735 \\
\text { libro } 735\end{array}$ & $\begin{array}{l}\text { absuelto } \\
\text { absuelto }\end{array}$ \\
\hline Escuder, Jean $(f)$ & & c. 1619 & 9libro 743 & + en persona \\
\hline Escuderete, Jean (f) & Ripoll & 1571 & libro 730 & + en estatua \\
\hline Esperanza, Jaime $(f)$ & & 1676 & libro 735 & absuelto \\
\hline Esplachin, Lawrence (in); militar & & 1633 & libro 733 & absuelto \\
\hline Esportela, Louise (s) & & 1667 & libro 735 & absuelta \\
\hline Espuche, Jean de (f); sastre & Banyoles & 1570 & libro 730 & reclusión \\
\hline Estany, Johannes Friedrich (a) & & 1681 & libro 735 & absuelto \\
\hline Estarria, Jacques ( $f$ ); naipero & Barcelona & 1575 & libro 730 & absuelto \\
\hline Esteanuz, Johannes Christof (a) & & 1676 & libro 735 & absuelto \\
\hline Estefaneus, Jules $(f)$ & Terrassa & 1575 & libro 730 & reclusión \\
\hline Esterleis, Nicolás (a); militar & & 1663 & libro 734 & absuelto \\
\hline Esteumf, Martín (a); ¿militar? & & 1681 & libro 735 & absuelto \\
\hline Estibes, John (in); marinero & & 1595 & libro 731 & reconciliado \\
\hline Estiller, Martín (a); militar & & 1680 & libro 735 & absuelto \\
\hline Estuva, Jean de (f); labrador & Comabella & 1564 & libro 730 & $\begin{array}{l}\text { azotado y } 5 \text { años } \\
\text { en galeras }\end{array}$ \\
\hline Exalambre, Antoine (f); mercader & & 1564 & libro 730 & multado \\
\hline Fabra, François ( $\mathfrak{f})$ & & 1676 & libro 735 & absuelto \\
\hline Falaix, William (in) & & 1680 & libro 735 & absuelto \\
\hline Fangier, Pons (f); boticario & Tarragona & 1594 & libro 731 & reconciliado \\
\hline Faura, Giralda (f) & Barcelona & 1565 & libro 730 & penintenciada \\
\hline Faura, Jean la (f) & Vila-Sacra & 1594 & libro 731 & desterrado \\
\hline Fauria, Pierre $(f)$; tejedor de lino & Banyoles & 1575 & libro 730 & reclusión \\
\hline Faves, Pove & Girona & 1552 & libro 730 & reconciliado \\
\hline $\begin{array}{l}\text { Faxile, Francis (in) } \\
\text { Fava, Jean de la (f): serrador }\end{array}$ & Tordera & $\begin{array}{l}1676 \\
1575\end{array}$ & $\begin{array}{l}\text { libro } 735 \\
\text { libro } 730\end{array}$ & $\begin{array}{l}\text { absuelto } \\
\text { azotado y } 5 \text { años }\end{array}$ \\
\hline raya, Jean de la (i), setradur & Tulueta & & & en galera \\
\hline $\begin{array}{l}\text { Fayet, Jordi du (f) (s) } \\
\text { Ferrari, Nicolao di (i); militar } \\
\text { Ferrer, Guillaume Francois (f) }\end{array}$ & Cardona & $\begin{array}{l}1564 \\
1682 \\
1569\end{array}$ & $\begin{array}{l}\text { libro } 730 \\
\text { libro } 735 \\
\text { libro } 730\end{array}$ & $\begin{array}{l}\text { + en persona } \\
\text { suspenso } \\
\text { penitenciado }\end{array}$ \\
\hline
\end{tabular}




\begin{tabular}{|c|c|c|c|c|}
\hline Apellidos y nombre; profesión & Localidad & Fecha & Fuente & Sentencia \\
\hline $\begin{array}{l}\text { Fillons, Jean Guillaume (f) } \\
\text { Final, Jacques (f) } \\
\text { Fitor Pou, Jean (s); ¿militar? } \\
\text { Flat, Magnus Estefanus (a); } \\
\text { militar }\end{array}$ & & $\begin{array}{l}1602 \\
1674 \\
1690 \\
1687\end{array}$ & $\begin{array}{l}\text { libro } 731 \\
\text { libro } 735 \\
\text { libro } 735 \\
\text { libro } 735\end{array}$ & $\begin{array}{l}+ \text { en estatua } \\
\text { absuelto } \\
\text { absuelto } \\
\text { absuelto }\end{array}$ \\
\hline Flixo, Guillaume (f); labrador & Perpignan & 1575 & libro 730 & $\begin{array}{l}\text { azotado y } 7 \text { años } \\
\text { en galera }\end{array}$ \\
\hline $\begin{array}{l}\text { Floide, Thimoty (in) } \\
\text { Florante, Jean ( } f \text { ) } \\
\text { Florau, Jean }(f) \text {; mesonero } \\
\text { Foch, Johannes (a); ¿militar? }\end{array}$ & Puigcerdá & $\begin{array}{l}1680 \\
1603 \\
1602 \\
1681\end{array}$ & $\begin{array}{l}\text { libro } 735 \\
\text { libro } 731 \\
\text { libro } 731 \\
\text { libro } 735\end{array}$ & $\begin{array}{l}\text { absuelto } \\
\text { absuelto } \\
\text { absuelto }\end{array}$ \\
\hline Folguet, Guillaume (f); blanquero & Barcelona & 1563 & libro 730 & $\begin{array}{l}\text { azotado y } 7 \text { años } \\
\text { en galeras }\end{array}$ \\
\hline $\begin{array}{l}\text { Font, Catherine }(f) \\
\text { Fontana, Giuseppe (i); militar } \\
\text { Font, Jacques ( } f \text { ); sastre } \\
\text { Font, Jean }(f) ; \text { pastor } \\
\text { Fontaine, Etienne }(f) \\
\text { Forga, Paule }(f)\end{array}$ & $\begin{array}{l}\text { Cardona } \\
\text { Sant Celoni }\end{array}$ & $\begin{array}{l}1565 \\
1726 \\
1571 \\
1563 \\
1753 \\
1571\end{array}$ & $\begin{array}{l}\text { libro } 730 \\
\text { leg. } 2.161 \\
\text { libro } 730 \\
\text { libro } 730 \\
\text { leg. } 2.167 \\
\text { libro } 730\end{array}$ & $\begin{array}{l}\text { absuelta } \\
\text { reprendido } \\
\text { penitenciado } \\
\text { multado } \\
\text { ¿absuelto? } \\
\text { penitenciada }\end{array}$ \\
\hline Fornat, Antoine $(f)$; labrador & Martorell & 1585 & libro 730 & $\begin{array}{l}\text { azotado y } 3 \text { años } \\
\text { en galeras }\end{array}$ \\
\hline $\begin{array}{l}\text { Foyas, Jerome (f) } \\
\text { Fradsan, Thomas (in) }\end{array}$ & & $\begin{array}{l}1610 \\
1680\end{array}$ & $\begin{array}{l}\text { libro } 732 \\
\text { libro } 735\end{array}$ & $\begin{array}{l}\text { reconciliado } \\
\text { absuelto }\end{array}$ \\
\hline Fraipueda, Frances (f) (s) & Barcelona & 1563 & libro 730 & + en persona \\
\hline & Puigcerdá & & & $\begin{array}{l}\text { recluida } \\
+ \text { en persona }\end{array}$ \\
\hline Fraviler, Samuel (a); ¿militar? & & 1690 & libro 735 & absuelto \\
\hline Frey, Gordi (in); marinero & & 1617 & libro 732 & desterrado \\
\hline Frayter, Jacques (f); labrador & Sisquella & 1583 & libro 730 & $\begin{array}{l}\text { azotado y } 5 \text { años } \\
\text { en galera }\end{array}$ \\
\hline $\begin{array}{l}\text { Fris, Guillaume de }(f) \text {; sastre } \\
\text { Frore, Jean }(f) \\
\text { Fusill, Durand }(f)\end{array}$ & Tona & $\begin{array}{l}1582 \\
1676 \\
1674\end{array}$ & $\begin{array}{l}\text { libro } 730 \\
\text { libro } 735 \\
\text { libro } 735\end{array}$ & $\begin{array}{l}\text { recluido } \\
\text { absuelto } \\
\text { absuelto }\end{array}$ \\
\hline Galan, Frances (f) & & 1564 & libro 730 & + en esta \\
\hline Galan, Nicholas (su) & & 1675 & libro 735 & \\
\hline Galet, Frances $(f)$ & & 1565 & libro 730 & azotado \\
\hline Gallardet, Jean (f) & & 1560 & libro 730 & - \\
\hline Gallart, Antoine (f); zapatero & & 1564 & libro 730 & absuelto \\
\hline Gallart, Antoine (f); zapatero & & 1564 & libro 730 & absuelto \\
\hline Gallera, Daniel de $(f)$ & & 1622 & libro 733 & reconciliado \\
\hline Gallina, Jacques $(f)$ & & 1617 & libro 732 & absuelto \\
\hline Garbau, Marie de Paul Antoine (f) & & 1578 & libro 730 & - \\
\hline Garra, Francesa (f) & & 1571 & libro 730 & reclusión \\
\hline Garriga, Jean (f); labrador & & 1563 & libro 730 & desterrado \\
\hline Gason, Peris (h) & & 1676 & libro 735 & absuelto \\
\hline Gasto, Jacques (f) & & 1571 & libro 730 & + en persona \\
\hline Gavarrocha, Guillaume (f) & & 1573 & libro 737 & + en persona \\
\hline Ge, Jacob $(\mathfrak{f}) ;$ galeote & & 1616 & libro 732 & reconciliado \\
\hline Geoland, Daniel (s); lapidario & & 1622 & libro 733 & reconciliado \\
\hline Germa, Pierre (f) & & 1575 & libro 730 & + en persona \\
\hline Germa, Raymond de (f); labrador & & 1575 & libro 730 & reclusión \\
\hline Gervasi, Gili (f) & Perpignan & 1575 & libro 730 & penitenciado \\
\hline Gete, Richard (in) & & 1606 & libro 732 & absuelto \\
\hline
\end{tabular}


Catálogo de los procesos inquisitoriales del Tribunal del...

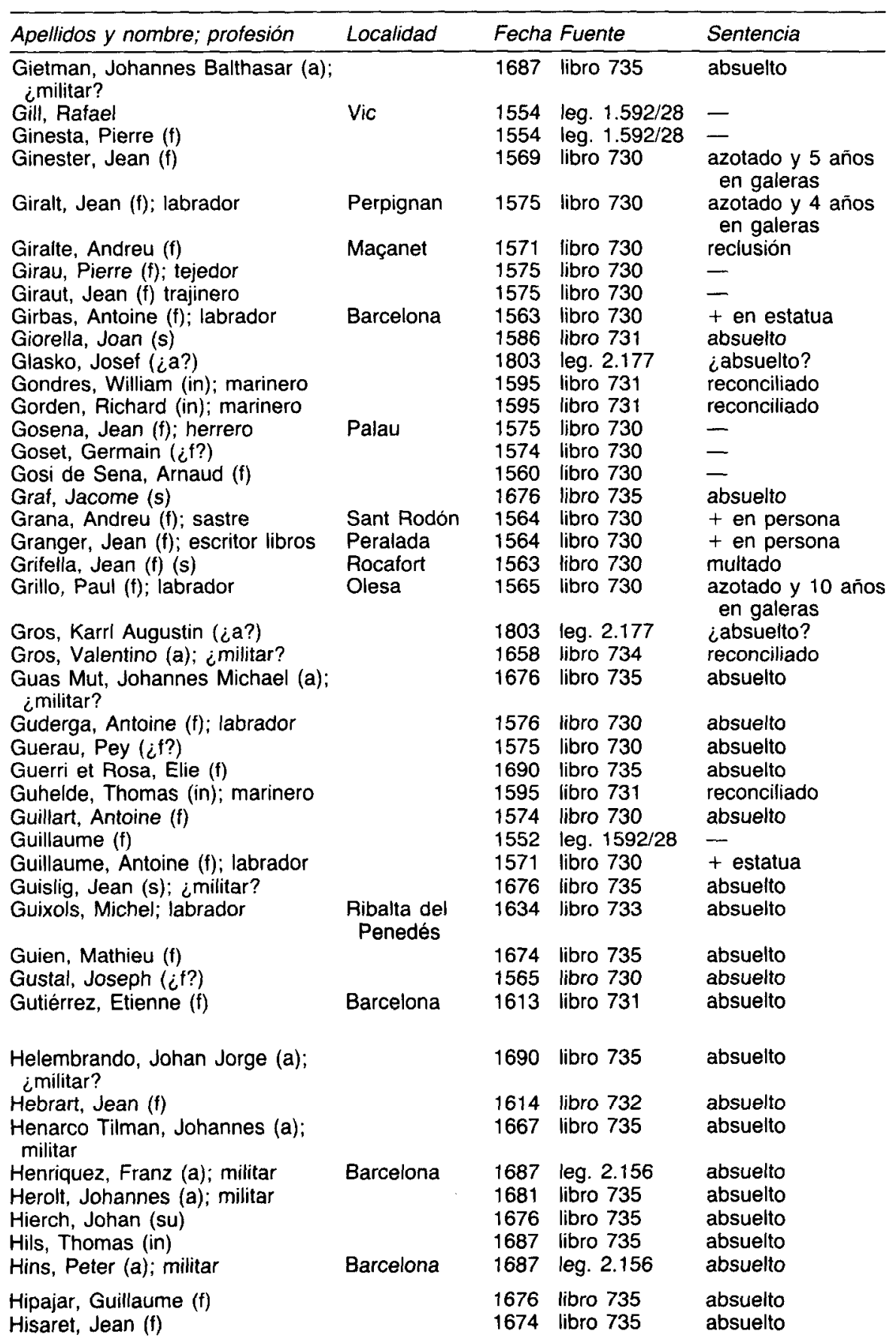




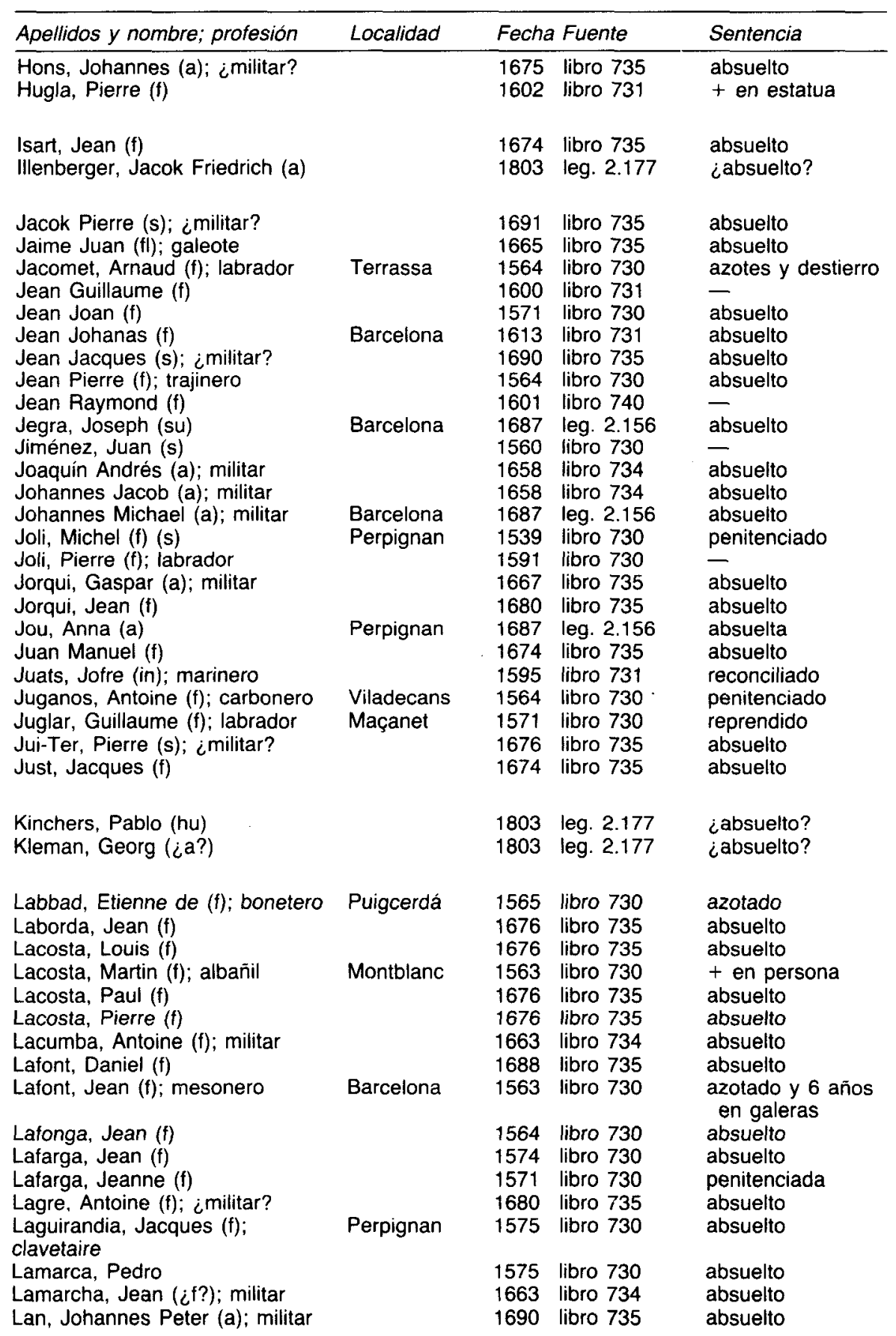




\begin{tabular}{|c|c|c|c|c|}
\hline Apellidos y nombre; profesión & Localidad & Fecha & Fuente & Sentencia \\
\hline $\begin{array}{l}\text { Lanver, Joseph (f); abogado } \\
\text { Lana, Pierre de (f) } \\
\text { Lao, Andre Raymond }(f) \text {; } \\
\text { sacerdote }\end{array}$ & & $\begin{array}{l}1627 \\
1571 \\
1575\end{array}$ & $\begin{array}{l}\text { libro } 733 \\
\text { libro } 730 \\
\text { libro } 730\end{array}$ & $\begin{array}{l}\text { reconciliado } \\
\text { multado } \\
\text { absuelto }\end{array}$ \\
\hline Lartor, Baltasar (a); ¿militar? & & 1690 & libro 735 & absuelto \\
\hline Larres, Jean de (f); vaquero & Montornés & 1565 & libro 730 & + en persona \\
\hline $\begin{array}{l}\text { Laporta, Barthelemy (f) } \\
\text { Latifa, Pierre (f) }\end{array}$ & & $\begin{array}{l}1575 \\
1674\end{array}$ & $\begin{array}{l}\text { libro } 730 \\
\text { libro } 735\end{array}$ & $\begin{array}{l}+ \text { en estatua } \\
\text { absuelto }\end{array}$ \\
\hline Lator, Supercio (f) & & 1674 & libro 735 & absuelto \\
\hline Laurier, Hugues (f) (s) & Peralada & 1563 & libro 730 & + en estatua \\
\hline Lauron, André (f) & & 1674 & libro 735 & absuelto \\
\hline Laxach, Jean (¿f?); pedreñalero & & 1565 & libro 730 & absuelto \\
\hline Lebamen, Jean (f); militar & Girona & 1682 & libro 757 & absuelto \\
\hline Lebe, Jean (f) & & 1675 & libro 735 & absuelto \\
\hline Lebell, Jacob (a); militar & & 1655 & libro 735 & absuelto \\
\hline $\begin{array}{l}\text { Leman, Johannes Georg (a); } \\
\text { militar }\end{array}$ & & 1680 & libro 735 & absuelto \\
\hline Lerna, Christof (a); ¿militar? & & 1676 & libro 735 & absuelto \\
\hline Lescolee, Barthelemy (f); labrador & Santpedor & 1564 & libro 730 & \\
\hline Leuza, Jean de (f) & & 1675 & libro 735 & absuelto \\
\hline Leyp, John (in); marinero & & 1595 & libro 731 & reconciliado \\
\hline Libra, Joan; notario & Ripoll & 1575 & libro 730 & absuelto \\
\hline Ligor, Pierre $(f)$; serrador & Terrassa & 1564 & libro 730 & $\begin{array}{l}\text { azotado y } 3 \text { años } \\
\text { en galeras }\end{array}$ \\
\hline Lion, Pierre (f) & & 1680 & libro 735 & reprendido \\
\hline $\begin{array}{l}\text { Lisendayren, Johan Ignacio (a); } \\
\text { ¿militar? }\end{array}$ & & 1690 & & absuelto \\
\hline Lobat, Antoine (f) & & 1552 & leg. $1.592 / 8$ & azotado y galeras \\
\hline Locovitz, Juan (hu); ¿militar? & & 1680 & libro 735 & absuelto \\
\hline Lodier, Jean $(t)$ & & 1617 & libro 732 & absuelto \\
\hline Lodier, Jean Baptiste (f) & & 1691 & libro 735 & absuelto \\
\hline Lon, James (in) & & 1639 & libro 734 & absuelto \\
\hline Lots, Cicolao (a); herrero & & 1676 & libro 735 & absuelto \\
\hline Luga, Andrea di (i); militar & & 1563 & libro 730 & reclusión \\
\hline Luna, Jean de la (f); labrador & & 1564 & libro 730 & + en persona \\
\hline Luna, Jean de la $(f)$; bandolero & & 1593 & libro 731 & falleció \\
\hline Llarc, Pierre (f); botonero & $\begin{array}{l}\text { Villafranca del } \\
\text { Penedés }\end{array}$ & 1571 & libro 730 & reclusión \\
\hline Llati, Mathieu (f) & & 1688 & libro 735 & absueito \\
\hline Llebera, Melchior (f); platero & Barcelona & 1621 & libro 733 & absuelto \\
\hline Lledat, Barthelemy $(f)$ & & $\begin{array}{l}1674 \\
1571\end{array}$ & $\begin{array}{l}\text { libro } 735 \\
\text { libro } 730\end{array}$ & absuelto \\
\hline $\begin{array}{l}\text { Llobet, Bartomeu } \\
\text { Llorens, Jean }(f) \text {; carbonero }\end{array}$ & Maçanet & 1575 & libro 730 & penitenciado \\
\hline Llort, Miquel; cirujano & & 1550 & leg. $1.592 / 8$ & - \\
\hline Magenu, Georg (a) & & 1676 & libro 735 & absuelto \\
\hline & & 1676 & & \\
\hline Male, Jean (f) & & 1674 & libro 735 & absuelto \\
\hline Malet, Pierre (f); herrero & & 1605 & libro 731 & reprendido \\
\hline Malrech, Guillaume (f); herrero & Berga & 1575 & libro 730 & recluido \\
\hline Malsach, Perri (f) & & 1647 & $\operatorname{leg} .2 .155(1)$ & reconciliado \\
\hline Mandel, Hans (a) & & 1662 & libro 734 & absuelto \\
\hline $\begin{array}{l}\text { Manero, Antic; terciopelero } \\
\text { Manolf, Johan (su); ¿militar? }\end{array}$ & Barcelona & $\begin{array}{l}1573 \\
1676\end{array}$ & libro 737 & azotes y destierro \\
\hline Manschalech, Gilbert (a) & & 1676 & libro 735 & absuelto \\
\hline
\end{tabular}


JUAN BLÁZQUEZ MIGUEL

\begin{tabular}{|c|c|c|c|c|}
\hline Apellidos y nombre; profesión & Localidad & Fecha & Fuente & Sentencia \\
\hline Maravilla, Michel de la (f) & & 1632 & libro 733 & absuelto \\
\hline Marechic, Karl (a); ¿militar? & & 1682 & libro 735 & absuelto \\
\hline Maribon, Jean (t) & & 1560 & libro 730 & - \\
\hline Marlo, Battista (i); calcetero & Barcelona & 1563 & libro 730 & + en persona \\
\hline $\begin{array}{l}\text { Marot, Perre (1); labraaor } \\
\text { Marsa, Leonard }(f) \text {; papelero }\end{array}$ & Girona & $\begin{array}{l}1620 \\
1563\end{array}$ & $\begin{array}{l}\text { 110ro } 732 \\
\text { libro } 730\end{array}$ & $\begin{array}{l}\text { absueito } \\
\text { azotado y } 5 \text { años } \\
\text { en galeras }\end{array}$ \\
\hline Marti, Guillaume (f); labrador & & 1654 & libro 734 & absuelto \\
\hline Marti, Barthelemy (f) & & 1564 & libro 730 & absuelto \\
\hline Martin, Bertrand $(f)$ & & 1564 & libro 730 & absuelto \\
\hline Martin, Johannes $(a) ;$ ¿militar? & & 1690 & libro 735 & absuelto \\
\hline $\begin{array}{l}\text { Martin Crasman, Francisco (a); } \\
\text { ¿militar? }\end{array}$ & & 1687 & libro 735 & absuelto \\
\hline Martin Haase, Johannes (¿a?) & & 1803 & leg. 2.177 & ¿absuelto? \\
\hline Marrenen, Jean (f) & & 1676 & libro 735 & absuelto \\
\hline Mas, Antoine del (f) & Barcelona & 1613 & libro 731 & absuelto \\
\hline Mas, Jean $(f)$ & Girona & 1575 & libro 730 & reclusión \\
\hline Mas, Jean (f); labrador & Girona & 1628 & libro 733 & reclusión \\
\hline Mas, Francisca del & $\begin{array}{l}\text { Puig de } \\
\text { Casas }\end{array}$ & 1581 & libro 730 & - \\
\hline Masi, Roger (in); militar & & 1633 & libro 733 & absuelto \\
\hline Masnobo, François $(f)$ & & 1680 & libro 735 & absuelto \\
\hline Masolo, Pierre $(\mathrm{f})$ & & 1680 & libro 735 & absuelto \\
\hline Matas, Anton (of) & & 1682 & libro 735 & reconciliado \\
\hline Mayerstot, Pierre $(f)$ & Barcelona & 1687 & leg. 2.156 & absuelto \\
\hline Mayfeus, Cornelius (in) & & 1621 & libro 733 & absuelto \\
\hline Memengen, Ludwig (a); ¿militar? & & 1690 & libro 735 & absuelto \\
\hline Menak, Jaime (d) & & 1803 & leg. 2.177 & ¿absuelto? \\
\hline Mentze, Jakel (s); ¿militar? & & 1690 & libro 735 & absuelto \\
\hline Mesunyol, Jaume; labrador & Sant Boi & 1563 & libro 730 & penitenciado \\
\hline Mico, Claude (s) & & 1621 & libro 733 & absuelto \\
\hline Miguel, Etienne (f) & & 1598 & libro 731 & reconciliado \\
\hline Miguel, Jean (f) & & 1552 & leg. $1.592 / 28$ & reconciliado \\
\hline Miguel, Jean (f) (s) & & 1562 & libro 730 & absuelto \\
\hline Miguel, Paul (f) & & 1644 & leg. $2.155(1)$ & reconciliado \\
\hline Miguel, Manavet ( $f$ ) & & 1571 & libro 730 & huyó \\
\hline Mijavita, Pierre (f) & & 1562 & libro 730 & desterrado \\
\hline Milán, Enrico (s); ¿militar? & & 1667 & libro 735 & absuelto \\
\hline Millar, Johannes (a); ¿militar? & & 1681 & libro 735 & absuelto \\
\hline Miller, Jaime $(\mathrm{s})$; ¿militar? & & 1676 & libro 735 & absuelto \\
\hline Milloret, Jacques (f) & & 1617 & libro 732 & absuelto \\
\hline Miros, Antoine (f) & & 1621 & libro 733 & absuelto \\
\hline Miseguer, Enric $(f)$ & & 1676 & libro 735 & absueito \\
\hline Miss, Stephanus (a); ¿militar? & & 1690 & libro 735 & absuelto \\
\hline Mixon, Carlo Antonio (i) & & 1690 & libro 735 & absuelto \\
\hline Mobz, George (a); ¿militar? & & 1676 & libro 735 & absuelto \\
\hline Moleria, Frances $(\mathrm{f})$; molinero & Montblanc & 1575 & libro 730 & + en estatua \\
\hline Moli, Jean (f); boyero & & 1570 & libro 730 & penitenciado \\
\hline Molino, François (f) & & 1680 & libro 735 & absuelto \\
\hline Mollet, Jacques (f) & & 1614 & libro 732 & absuelto \\
\hline Mondon, Jean de (f) & & 1621 & libro 733 & absuelto \\
\hline Monfalcona, Isabelle (f) & Barcelona & 1563 & libro 730 & desterrada \\
\hline Mongio Baster, Guillaume (f) & Valls & 1571 & libro 730 & recluido \\
\hline Monguillon, Guillaume $(f)$ & & 1573 & libro 730 & azotado y galeras \\
\hline Mons, Jean (s); ¿militar? & & 1691 & libro 735 & absuelto \\
\hline Monsech, Pierre (f); cardador & Andorra & 1565 & libro 730 & azotado \\
\hline
\end{tabular}


Catálogo de los procesos inquisitoriales del Tribunal del...

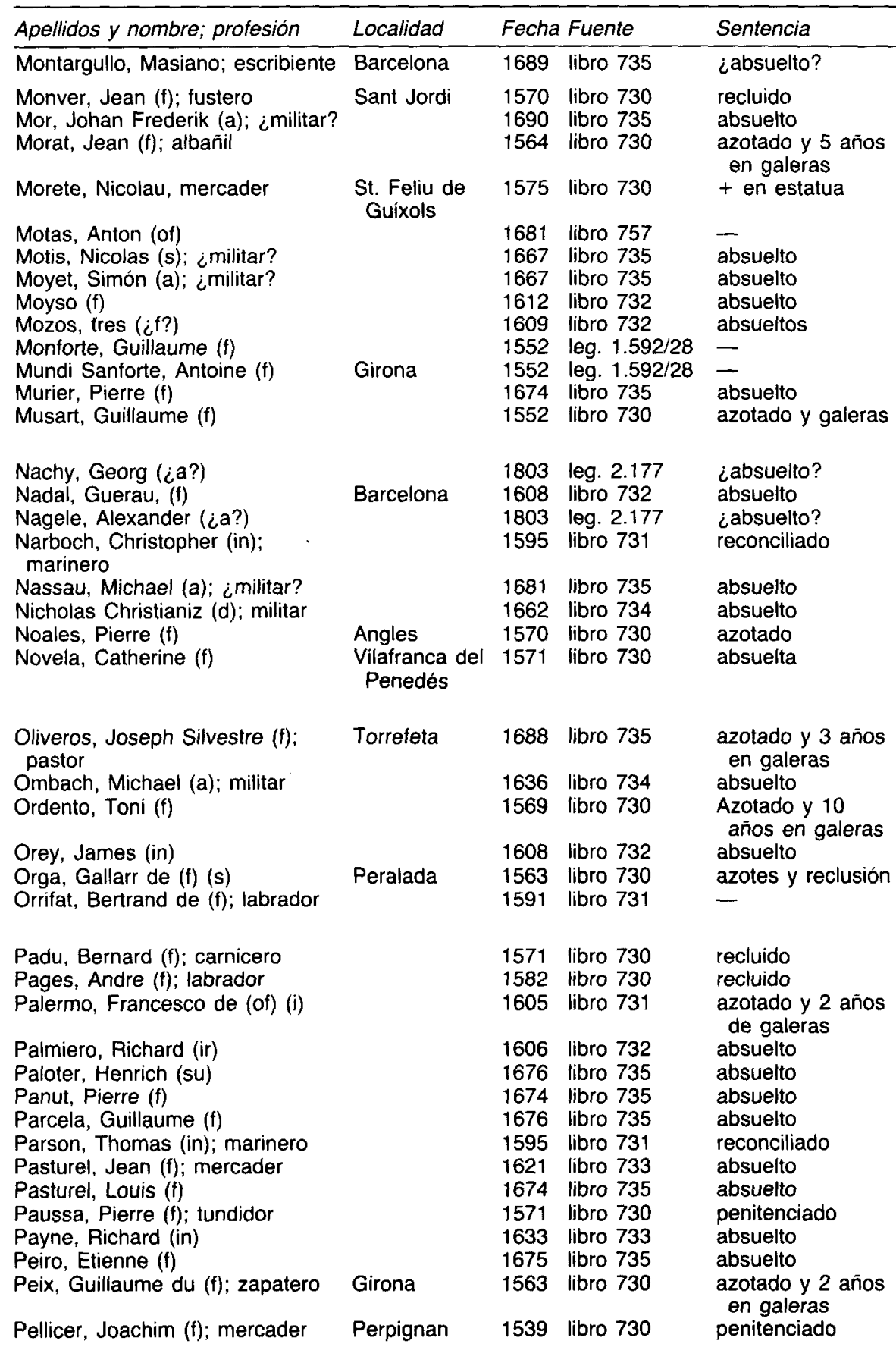




\begin{tabular}{|c|c|c|c|c|}
\hline \multirow{2}{*}{$\begin{array}{l}\text { Apellidos y nombre; profesión } \\
\text { Pellicer, Laurent }(\mathrm{f}) ; \text { mercader } \\
\text { Perburch, Guilhelm Johan (h); } \\
\text { cirujano }\end{array}$} & \multirow{2}{*}{$\frac{\text { Localidad }}{\text { Perpignan }}$} & \multicolumn{2}{|c|}{ Fecha Fuente } & \multirow{2}{*}{$\begin{array}{l}\text { Sentencia } \\
\begin{array}{l}\text { penitenciado } \\
\text { absuelto }\end{array}\end{array}$} \\
\hline & & $\begin{array}{l}1539 \\
1654\end{array}$ & $\begin{array}{l}\text { libro } 730 \\
\text { libro } 734\end{array}$ & \\
\hline Perchallos, Joseph (f) & & 1674 & libro 735 & absuelto \\
\hline & & $\begin{array}{l}1564 \\
1658\end{array}$ & & desterrado \\
\hline $\begin{array}{l}\text { Perifac, Issac (s); militar } \\
\text { Perons, Jerónima }\end{array}$ & & $\begin{array}{l}1658 \\
1564\end{array}$ & $\begin{array}{l}\text { libro } 734 \\
\text { libro } 730\end{array}$ & $\begin{array}{l}\text { absuelto } \\
\text { azotada }\end{array}$ \\
\hline & Ollana & 1675 & libro 735 & absuelto \\
\hline Perucho, Bertrand (f); militar & Salses & 1575 & libro 730 & - \\
\hline Perze, Jean $(f)$; criado & & 1654 & libro 734 & absuelto \\
\hline Petit, Jean (f) & & 1569 & libro 730 & absuelto \\
\hline Petir Gari, Jean (f); arriero & Perpignan & 1583 & libro 730 & $\begin{array}{l}\text { azotado y } 7 \text { años } \\
\text { en galeras }\end{array}$ \\
\hline $\begin{array}{l}\text { Peyret, Frances (f); zapatero } \\
\text { Peyret, Jean }(f)\end{array}$ & $\begin{array}{l}\text { Perpignan } \\
\text { Blanes }\end{array}$ & $\begin{array}{l}1569 \\
1594\end{array}$ & $\begin{array}{l}\text { libro } 730 \\
\text { libro } 731\end{array}$ & $\begin{array}{l}\text { penitenciado } \\
\text { absuelto }\end{array}$ \\
\hline Peyret, Pierre (t); labrador & Perpignan & 1575 & libro 730 & - \\
\hline $\mathrm{Pi}$, Pierre du $(\mathrm{f})$ & & 1570 & libro 730 & + en estatua \\
\hline Pias, Jean (f); peinero & & 1634 & libro 733 & absuelto \\
\hline $\begin{array}{l}\text { Picart, Nicolas (a); ¿militar? } \\
\text { Picarte, Marc }(f)\end{array}$ & & $\begin{array}{l}1680 \\
1674\end{array}$ & libro 735 & absuelto \\
\hline $\begin{array}{l}\text { Picarte, Marc ( } f) \\
\text { Piens, Andres, militar }\end{array}$ & Barcelona & $\begin{array}{l}1674 \\
1721\end{array}$ & $\begin{array}{l}\text { libro } 735 \\
\text { leg. } 2159\end{array}$ & absuelto \\
\hline Pierrot, Pierre ( $f$ ) & & 1680 & libro 735 & absuelto \\
\hline Piquer, Arnaud (f) & & 1564 & libro 730 & + en estatua \\
\hline Pixschivit, Joachim (a); militar & & 1658 & libro 734 & reconciliado \\
\hline Planas, Pere & & 1574 & libro 730 & absuelto \\
\hline Planca, Jacques ( $f$ ) & & 1562 & libro 730 & azotado \\
\hline Plante, Louis (f) & & 1687 & libro 735 & absuelto \\
\hline Plantier, Jean ( $\mathrm{f})$; labrador & & 1575 & libro 730 & recluido \\
\hline Platxeve, Claude $(f)$ & & 1676 & libro 735 & absuelto \\
\hline Pobleda, Andre (f) & & 1559 & leg. $1592 / 28$ & - \\
\hline Poer, James (in); marinero & & 1596 & libro 731 & absuelto \\
\hline Polonia Dorotea (a) & & 1654 & libro 734 & Ita \\
\hline Pons, Jean (f); labrador & Cardedeu & 1564 & libro 730 & azotado \\
\hline Pons Gay, François (f); zapatero & Perpignan & & & $\begin{array}{l}\text { azotado y galeras } \\
\text { a perpetuidad }\end{array}$ \\
\hline Pontach, Jean (f); serrador & $\begin{array}{l}\text { Cassá de la } \\
\text { Selva }\end{array}$ & 1575 & libro 730 & absuelto \\
\hline $\begin{array}{l}\text { Pontano, Louis (f) } \\
\text { Pontavets, Antoine (f); tejedor }\end{array}$ & & $\begin{array}{l}1610 \\
1586\end{array}$ & $\begin{array}{l}\text { libro } 732 \\
\text { libro } 731\end{array}$ & $\begin{array}{l}\text { reconciliado } \\
\text { reprendido }\end{array}$ \\
\hline $\begin{array}{l}\text { Poppo, John (in); militar } \\
\text { Port, Pierre (f); labrador }\end{array}$ & & $\begin{array}{l}1633 \\
1591\end{array}$ & $\begin{array}{l}\text { libro } 733 \\
\text { libro } 731\end{array}$ & absuelto \\
\hline Porquer, John (in); marinero & & 1595 & libro 731 & reconciliado \\
\hline & $\begin{array}{l}\text { Castello } \\
\text { d'Empuries }\end{array}$ & 1659 & libro 734 & desterrado \\
\hline $\begin{array}{l}\text { Prior, Pierre (s) } \\
\text { Pris, Mark (in): marinero }\end{array}$ & & 1676 & libro 735 & absuelto \\
\hline Pris, Mark (in); marinero & & 1595 & libro 731 & reconciliado \\
\hline Proa, Jean (f) & & 1616 & libro 732 & absuelto \\
\hline Probas, Jacob (a); ¿militar? & & 1676 & libro 735 & \\
\hline Probedit, Jean (f) & & 1575 & libro 730 & absuelto \\
\hline Probo, Jacques (f) & & 1667 & libro 735 & absuelto \\
\hline Proencal, Jean (f); labrador & Barcelona & 1565 & libro 730 & falleció \\
\hline Pront, Johannes (a); ¿militar? & & 1667 & libro 735 & absuelto \\
\hline Prot, William (in); galeote & & 1628 & libro 733 & reconciliado \\
\hline Provedid, Jean (f); mercero & Barcelona & 1575 & libro 730 & \\
\hline Puart, Jean (f) & & 1676 & libro 735 & absuelto \\
\hline Puda, Etienne (f) & & 1622 & libro 733 & absuelto \\
\hline
\end{tabular}


Catálogo de los procesos inquisitoriales del Tribunal del...

\begin{tabular}{|c|c|c|c|c|}
\hline Apellidos y nombre; profesión & Localidad & Fecha & Fuente & Sentencia \\
\hline $\begin{array}{l}\text { Puig, Jean (f) } \\
\text { Pujol, Raphael (f); labrador } \\
\text { Pujol, Tecla }\end{array}$ & & $\begin{array}{l}1619 \\
1591 \\
1560\end{array}$ & $\begin{array}{l}\text { libro } 732 \\
\text { libro } 731 \\
\text { libro } 730\end{array}$ & absuelto \\
\hline Quebrar, Karl (a); ¿militar? & & 1676 & libro 735 & absuelto \\
\hline Quexa, Pierre (f); labrador & $\begin{array}{l}\text { St. Vicenç de } \\
\text { Castellet }\end{array}$ & 1603 & libro 731 & reclusión \\
\hline $\begin{array}{l}\text { Quishug, Segismundo (a); } \\
\text { ¿militar? }\end{array}$ & & 1676 & libro 735 & absuelto \\
\hline Rabel, Bernard (f); labrador & & 1591 & libro 731 & \\
\hline Rabies, Pierre (f) & & 1613 & libro 731 & absuelto \\
\hline Radix, Nadal (f); platero & Barcelona & 1589 & libro 731 & absuelto \\
\hline $\begin{array}{l}\text { Rambel, Jaime (s); ¿militar? } \\
\text { Ramis, Antón; platero }\end{array}$ & & $\begin{array}{l}1690 \\
1757\end{array}$ & $\begin{array}{l}\text { libro } 735 \\
\text { leg. } 3.724 / 20\end{array}$ & \\
\hline Rance, Willian (in); marinero & & 1595 & libro 731 & reconciliado \\
\hline Raymes, Paulus (a); ¿militar? & & 1680 & libro 735 & absuelto \\
\hline Reguus, Johan (su) & & 1676 & libro 735 & absuelto \\
\hline Reichner, Franz Javier (¿a?) & & 1803 & leg. 2.177 & ¿absuelto? \\
\hline Reixal, Jean (f) & & 1614 & libro 732 & absuelto \\
\hline Rello, Paul (f) & & 1674 & libro 735 & absuelto \\
\hline Renart, Anna Marie (a) & & 1680 & libro 735 & absuelta \\
\hline Resseguier, François (f); tejedor & Barcelona & 1575 & libro 730 & $\begin{array}{l}\text { azotado y } 3 \text { años } \\
\text { en galeras }\end{array}$ \\
\hline Rey, José del (om) & Perpignan & 1617 & libro 732 & + en estatua \\
\hline Rey, Jean (f); albañil & Manresa & 1564 & libro 730 & + en persona \\
\hline Rey, Jean (f); bandolero & Perpignan & 1596 & libro 731 & $\begin{array}{l}\text { azotado y } 7 \text { años } \\
\text { en galeras }\end{array}$ \\
\hline $\begin{array}{l}\text { Reyman, Bernhardiner (a); } \\
\text { ¿militar? }\end{array}$ & & 1690 & libro 735 & absuelto \\
\hline Reynald, Jacques (i) & & 1674 & libro 735 & absuelto \\
\hline Reynaut, Joseph (f); labrador & Manresa & 1619 & libro 732 & suspenso \\
\hline Reyner, Jean; espadero & & 1570 & libro 730 & $\begin{array}{l}\text { azotado y } 3 \text { años } \\
\text { en galeras }\end{array}$ \\
\hline Reys, Jean (f); labrador & & 1632 & $\begin{array}{l}\text { libro } 733 \\
\text { leq. } 1.592 / 28\end{array}$ & reconciliado \\
\hline & & $\begin{array}{l}1552 \\
1688\end{array}$ & $\begin{array}{l}\text { leg. } 1.592 / 28 \\
\text { libro } 735\end{array}$ & absuelto \\
\hline Rigol, Jean (f); sastre & & 1569 & libro 730 & reclusión \\
\hline Ritxart, Bertrand (f); labrador & & 1564 & libro 730 & + en persona \\
\hline Rintz, Isabel (h) & & 1676 & libro 735 & absuelto \\
\hline Ris, Mathew (in); marinero & & 1595 & libro 731 & reconciliado \\
\hline Ristre, Elias (a); ¿militar? & & 1691 & libro 735 & absuelto \\
\hline Rit, Christolol (su) & & 1675 & libro 735 & absuelto \\
\hline Riu, Jacques (f) & & 1675 & libro 735 & absuelto \\
\hline Rius, Jean (f); labrador & & 1573 & libro 732 & reclusión \\
\hline $\begin{array}{l}\text { Rive, Giovanni Della (i); } \\
\text { estampero }\end{array}$ & & 1564 & libro 730 & reclusión \\
\hline Rober, Louis (of); (f) & & 1570 & libro 730 & + estatua \\
\hline Robin, Simón $(i)$ & & 1680 & libro 735 & absuelto \\
\hline Roca, Antón, labrador & & 1564 & libro 730 & reclusión \\
\hline Roca, Arnau (f); ¿labrador? & & 1570 & libro 730 & recluido \\
\hline Rocar, Bertrand (f); labrador & & 1570 & libro 730 & $\begin{array}{l}\text { azotado y } 3 \text { años } \\
\text { en galeras }\end{array}$ \\
\hline Roder, Jean (f); pastor & & 1574 & libro 730 & \\
\hline
\end{tabular}




\begin{tabular}{|c|c|c|c|c|}
\hline Apellidos y nombre; profesión & Localidad & Fecha & Fuente & Sentencia \\
\hline Rojo, Louis (f); labrador & $\begin{array}{l}\text { Vilafranca del } \\
\text { Penedés }\end{array}$ & 1578 & libro 730 & reclusión \\
\hline Rolf, Johan (hu); militar & & 1658 & libro 734 & absuelto \\
\hline Roqueta, Yaquillar (f) & & 1611 & libro 732 & reconciliado \\
\hline Ros, Abraham (f) & & 1617 & libro 732 & absuelto \\
\hline Ros, Jean (f) & & 1573 & libro 730 & $\begin{array}{l}\text { azotado y } 10 \text { años } \\
\text { en galeras }\end{array}$ \\
\hline Rosa, Juan de la & & 1565 & libro 730 & absuelto \\
\hline Rosell, March (s) & & 1610 & libro 732 & reconciliado \\
\hline Rosell, Jean (f); albañil & & 1565 & libro 730 & $\begin{array}{l}\text { azotado y } 6 \text { años } \\
\text { en galeras }\end{array}$ \\
\hline Roufle, André (f) & & 1676 & libro 735 & absuelto \\
\hline Roure, Barthelemy (¿f?) & Maçanet & 1571 & libro 730 & reprendido \\
\hline Rucho, Michel (f); calderero & & 1571 & libro 730 & reclusión \\
\hline Rueda, Gabriel (f) & & 1571 & libro 730 & reclusión \\
\hline Ruiperi, Jacques (f); maestro & Figueres & 1563 & libro 730 & penitenciado \\
\hline Rule, Gabriel (s); ¿militar? & & 1680 & libro 735 & absuelto \\
\hline Rule, Hals (su); militar & & 1654 & libro 734 & absuelto \\
\hline Rutler, Richard (in); militar & & 1633 & libro 733 & absuelto \\
\hline $\begin{array}{l}\text { Sabonadieva, Jacques (f); } \\
\text { mercader }\end{array}$ & Barcelona & & leg. 2.159 & \\
\hline $\begin{array}{l}\text { Sachs, Johannes Michael (a); } \\
\text { militar }\end{array}$ & & 1680 & libro 735 & absuelto \\
\hline Sais, Joanot $(\mathrm{f})$; marinero & & 1570 & libro 730 & recluido \\
\hline Sala, Mariano José; funcionario & Barcelona & 1769 & leg. 2,170 & ¿absuelto? \\
\hline $\begin{array}{l}\text { Sala, Ramón } \\
\text { Salprect, Andreas (a); militar }\end{array}$ & & 1540 & libro 736 & absuelto \\
\hline $\begin{array}{l}\text { Salprect, Andreas (a); militar } \\
\text { Salvi, André (f); herrero }\end{array}$ & & 1680 & libro 735 & absuelto \\
\hline $\begin{array}{l}\text { Salvi, André (f); herrero } \\
\text { San Andrés, Paul (f) }\end{array}$ & & 1575 & libro 730 & penitenciado \\
\hline $\begin{array}{l}\text { San Andrés, Paul (f) } \\
\text { Sánchez, Antoine (f); relojero }\end{array}$ & Barcelona & $\begin{array}{l}1639 \\
1562\end{array}$ & $\begin{array}{l}\text { libro } 734 \\
\text { libro } 730\end{array}$ & desterrado \\
\hline Sancho, Laurent $(f)$; carpintero & Perpignan & 1539 & libro 730 & penitenciado \\
\hline Sandes, John (in); marinero & & 1595 & libro 731 & reconciliado \\
\hline Santort, Antoine de $(f)$ & & 1552 & libro 730 & reconciliado \\
\hline Sanos, Jean (f); molinero & Piera & 1565 & libro 730 & + en estatua \\
\hline Santa Fe, Jacques (f); colchonero & & 1628 & libro 733 & absuelto \\
\hline Sanvel, Jacques ( $f)$ & Barcelona & 1613 & libro 731 & absuelto \\
\hline Sarrome, Charles (f) & & 1674 & libro 735 & absuelto \\
\hline Saur, Matthias (a); ¿militar? & & 1688 & libro 735 & absuelto \\
\hline Saurat, Jean $(f)$ & & 1562 & libro 730 & reconciliado \\
\hline Saveria, Guillaume (f); albañil & Alás & 1564 & libro 730 & + en persona \\
\hline Savonadeva, Paul $(f)$; mercader & & 1694 & libro 760 & ¿absuelto? \\
\hline Scheidecker, Nicholas (¿a?) & & 1803 & leg. 2.177 & ¿absuelto? \\
\hline $\begin{array}{l}\text { Schmidt, Johannes Philipp (a); } \\
\text { ¿militar? }\end{array}$ & & 1680 & libro 735 & absuelto \\
\hline Schneider, Albert (s); militar & & 1691 & libro 735 & absuelto \\
\hline Schober, Andreas (a) & & 1685 & leg. $2155 / 1$ & reclusión \\
\hline Schrib, Johannes (a) ¿militar? & & 1690 & libro 735 & absuelto \\
\hline Schulen, Matthias (a); ¿militar? & & 1667 & libro 735 & absuelto \\
\hline Schulzen, Juan (po) & & 1667 & libro 735 & absuelto \\
\hline $\begin{array}{l}\text { Sctuuan, Johannes Georg (a); } \\
\text { ¿militar? }\end{array}$ & & 1691 & libro 735 & absuelto \\
\hline $\begin{array}{l}\text { Schlesman, Johannes (a); } \\
\text { imilitar? }\end{array}$ & & 1680 & libro 735 & absuelto \\
\hline
\end{tabular}


Catálogo de los procesos inquisitoriales del Tribunal del...

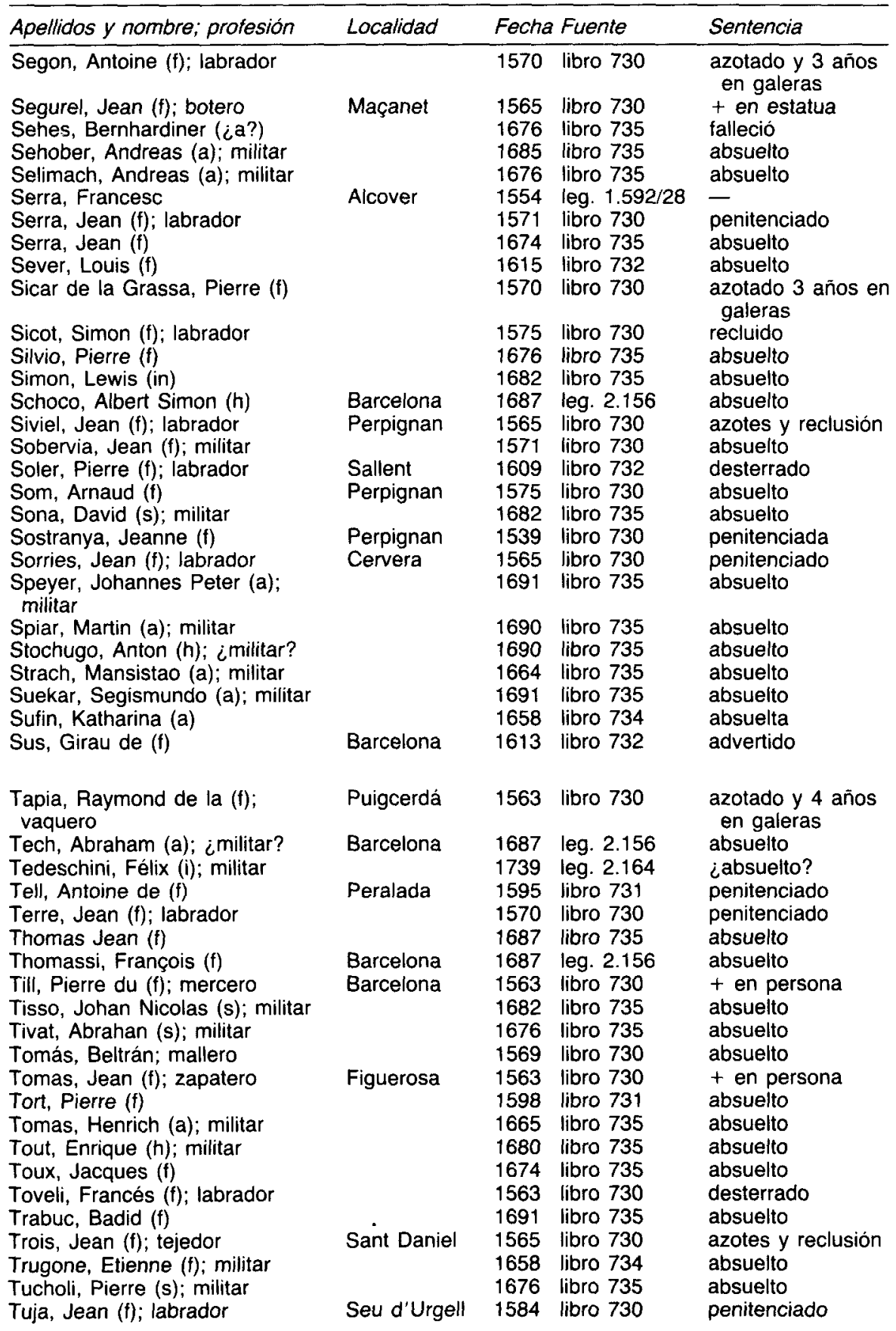




\begin{tabular}{|c|c|c|c|c|}
\hline \multirow{2}{*}{$\begin{array}{l}\text { Apellidos y nombre; profesión } \\
\text { Tuja, Raymond ( } \mathrm{f} \text { (s) }\end{array}$} & \multirow{2}{*}{$\frac{\text { Localidad }}{\text { Barcelona }}$} & \multicolumn{2}{|c|}{ Fecha Fuente } & \multirow{2}{*}{$\frac{\text { Sentencia }}{+ \text { en estatua }}$} \\
\hline & & 1563 & libro 730 & \\
\hline Ubos, Jean (f) & & 1571 & libro 730 & falleció \\
\hline Ucos, Dominique $(f)$; cocinero & Olesa & 1575 & libro 730 & absuelto \\
\hline Ugla, Pierre (f) & & 1601 & libro 740 & \\
\hline Uldrich Aman, Hans (s); militar & & 1688 & libro 735 & absuelto \\
\hline Umbert, Susana (a) & & 1632 & libro 733 & absuelta \\
\hline Unar, David (s); militar & & 1676 & libro 735 & absuelto \\
\hline Urt, Roger (in); marinero & & 1596 & libro 731 & $\begin{array}{l}\text { azotado y } 3 \text { años } \\
\text { en galeras }\end{array}$ \\
\hline Usero, Michel (s); militar & & 1676 & libro 735 & absuelto \\
\hline Valata, Alexandre (f); labrador & & 1619 & libro 732 & absuelto \\
\hline Valler, Filibert (fl); pintor & & 1562 & libro 730 & reconciliado \\
\hline Vaquer, Dorder $(f)$; cerrajero & Terrassa & 1564 & libro 730 & penintenciado \\
\hline Varillo, Infiel (fl); platero & & 1605 & libro 731 & reconciliado \\
\hline Vasia, Etienne $(f)$ & & 1593 & libro 731 & - \\
\hline Vasia, Raimon (f) & & 1593 & libro 731 & - \\
\hline Velen, Matías; militar & Barcelona & 1721 & leg. 2.159 & ¿absuelto? \\
\hline Veleta, Jean de la (f) & & 1691 & libro 735 & absuelto \\
\hline Veli, Dominique $(\mathrm{f})$; cocinero & & 1575 & libro 730 & huyó \\
\hline Velver, José; militar & & 1691 & libro 735 & absuelto \\
\hline Venera, Charles Pierre (f); militar & & 1658 & libro 734 & absuelto \\
\hline Verguer, Pierre (f) & & 1614 & libro 732 & absuelto \\
\hline Verlar, Ana (su) & & 1685 & libro 758 & absuelta \\
\hline Vert, Jean (s); militar & & 1656 & libro 750 & absuelto \\
\hline Viader $(f)(s)$ & Perpignan & 1539 & libro 730 & penitenciado \\
\hline Viera Colón, Joan; labrador & & 1575 & libro 730 & - \\
\hline $\begin{array}{l}\text { Viger, Michel (¿f?); asmolador de } \\
\text { tijeras }\end{array}$ & & 1571 & libro 730 & absuelto \\
\hline Vilar, Jean (f) & & 1681 & libro 735 & absuelto \\
\hline Vilelamo, Alexandre (h); militar & & 1664 & libro 735 & absuelto \\
\hline Villafort Moya $(f)$ & & 1575 & libro 735 & absuelto \\
\hline Villanueva, Abel de (f) & & 1676 & libro 735 & absuelto \\
\hline Villomier, Jaime (s) & & 1667 & libro 735 & absuelto \\
\hline Vin, Mathias (fl) & & 1676 & libro 735 & absuelto \\
\hline Viros, Etienne $(f)$ & Argentona & 1595 & libro 731 & absuelto \\
\hline Vivos, Gaspard (f); criado & Barcelona & 1667 & libro 735 & suspenso \\
\hline Volan, Mathieu de $(f)$ & & 1674 & libro 735 & absuelto \\
\hline Votafoc, Laurent ( $f$ ) & & 1674 & libro 735 & absuelto \\
\hline Vrandovert, Enrik (h) & & 1676 & libro 735 & absuelto \\
\hline Vrardermar, Jean (f) & & 1676 & libro 735 & absuelto \\
\hline Vullami, Joseph (s); ¿militar? & & 1676 & libro 735 & absuelto \\
\hline Wolfgang, Augustin (a); militar & & 1676 & libro 735 & absuelto \\
\hline Woods, Richard (in); ¿militar? & & 1681 & libro 735 & absuelto \\
\hline Wozhnlin, Magdalena (¿a?) & & 1803 & leg. 2.177 & - \\
\hline Xarli, Fraçcois $(\mathfrak{f})$; zapatero & & 1627 & libro 733 & reconciliado \\
\hline Xiralte, Jean (f); fustero & & 1570 & libro 730 & $\begin{array}{l}\text { azotado y } 6 \text { años } \\
\text { en galeras }\end{array}$ \\
\hline Xivert, Louis (f) (s) & & 1565 & libro 730 & penintenciado \\
\hline Ycarte, Jean (f) & Sabadell & 1588 & libro 731 & recluido \\
\hline
\end{tabular}


Catálogo de los procesos inquisitoriales del Tribunal del...

\begin{tabular}{|c|c|c|c|c|}
\hline Apellidos y nombre; profesión & Localidad & Fecha & Fuente & Sentencia \\
\hline YI, Henry (in); marinero & & 1596 & libro 731 & $\begin{array}{l}\text { azotado y } 3 \text { años } \\
\text { en galeras }\end{array}$ \\
\hline $\begin{array}{l}\text { Yousa, Claude (f) } \\
\text { Ysermi, Jean (f); pelaire }\end{array}$ & Perpignan & $\begin{array}{l}1674 \\
1565\end{array}$ & $\begin{array}{l}\text { libro } 735 \\
\text { libro } 730\end{array}$ & $\begin{array}{l}\text { absuelto } \\
\text { azotado y } 3 \text { años } \\
\text { en galeras }\end{array}$ \\
\hline $\begin{array}{l}\text { Zaballa, Lucas de } \\
\text { Zapatero, Catalina } \\
\text { Zeylinger, Matthias (a); militar } \\
\text { Zevaich, Johannes (a); militar }\end{array}$ & Barcelona & $\begin{array}{l}1628 \\
1575 \\
1665 \\
1681\end{array}$ & $\begin{array}{l}\text { libro } 733 \\
\text { libro } 730 \\
\text { libro } 735 \\
\text { libro } 735\end{array}$ & $\begin{array}{l}\text { reconciliado } \\
\text { absuelta } \\
\text { absuelto } \\
\text { absuelto }\end{array}$ \\
\hline
\end{tabular}

\section{BIGAMIA}

Ageta, Montserrat; labrador Agusti, Michele (i) Albar, Mariangela Alberni, Sebastiá; labrador

Almau, Marc de

Andreu, Joan; cirujano

Anglada, Isabelle (f)

Arbues, Jimeno de; boticario

Arlenga, Dominique (f); militar

Artola, María Josefa

Auno, Anne (f)

Auno, Joseph (f); médico

Auxel, Jean (f); carretero

Baena, Melchor de

Baissa, Jean de la (f); albañil

Baletas, Jean ( $f$ ); albañil

Bals, Jean (f); zapatero

Banacet, Miquel; pastor Barcelo, Pierre (f); pelaire

Barez, Salvador (i); tejedor

Barona, Joanota

Basanet, Miquel; pastor

Bastida, Jean (f); tejedor

Baurin, Anna Marie (a)

\begin{tabular}{|c|c|c|c|}
\hline Barcelona & 1554 & leg. $1.592 / 28$ & \\
\hline Girona & 1716 & leg. 2.158 & \\
\hline Barcelona & 1656 & libro 750 & suspensa \\
\hline Calaf & 1594 & libro 731 & $\begin{array}{l}\text { azotado y } 3 \text { años } \\
\text { en galeras }\end{array}$ \\
\hline $\begin{array}{l}\text { Castello } \\
\text { d'Empuries }\end{array}$ & 1551 & leg. $1.592 / 28$ & \\
\hline \multirow[t]{4}{*}{ Girona } & 1723 & $\operatorname{leg} .2 .159$ & \\
\hline & $\begin{array}{l}1575 \\
1586\end{array}$ & $\begin{array}{l}\text { libro } 730 \\
\text { libro } 731\end{array}$ & $\begin{array}{l}\text { azotada } \\
\text { azotado y } 6 \text { años } \\
\text { en galeras }\end{array}$ \\
\hline & 1606 & libro 732 & $\begin{array}{l}\text { azotado y } 10 \text { años } \\
\text { en galeras }\end{array}$ \\
\hline & 1753 & leg. 2.170 & \\
\hline \multirow{4}{*}{$\begin{array}{l}\text { Berga } \\
\text { Campmany }\end{array}$} & 1718 & leg. 2.156 & suspensa \\
\hline & $\begin{array}{l}1718 \\
1570\end{array}$ & $\begin{array}{l}\text { leg. } 2.156 \\
\text { libro } 730\end{array}$ & $\begin{array}{l}\text { desterrado } \\
\text { azotado y } 3 \text { años } \\
\text { en galeras }\end{array}$ \\
\hline & $\begin{array}{l}1552 \\
1639\end{array}$ & $\begin{array}{l}\text { libro } 730 \\
\text { libro } 734\end{array}$ & penitenciado \\
\hline & 1573 & leg. $1.592 / 27$ & $\begin{array}{l}\text { azotado y } 5 \text { años } \\
\text { en galeras }\end{array}$ \\
\hline Montblanquet & 1669 & libro 735 & $\begin{array}{l}\text { azotado y } 5 \text { años } \\
\text { en galeras }\end{array}$ \\
\hline $\begin{array}{l}\text { Pardines } \\
\text { San Celoni }\end{array}$ & $\begin{array}{l}1636 \\
1578\end{array}$ & $\begin{array}{l}\text { libro } 734 \\
\text { libro } 730\end{array}$ & falleció \\
\hline $\begin{array}{l}\text { St. Joan de } \\
\text { les Abades- } \\
\text { ses }\end{array}$ & 1613 & libro 732 & desterrado \\
\hline Barcelona & 1573 & leg. $1.592 / 27$ & abjuró de Levi \\
\hline $\begin{array}{l}\text { St. Esteve de } \\
\text { Pardines }\end{array}$ & 1636 & libro 734 & - \\
\hline $\begin{array}{l}\text { Vilafranca del } \\
\text { Penedés }\end{array}$ & 1578 & libro 730 & $\begin{array}{l}\text { azotado y } 5 \text { años } \\
\text { en galeras }\end{array}$ \\
\hline Girona & 1729 & leg. 2.162 & - \\
\hline
\end{tabular}




\begin{tabular}{|c|c|c|c|c|}
\hline Apellidos y nombre; profesión & Localidad & Fecha & Fuente & Sentencia \\
\hline $\begin{array}{l}\text { Belfor, Giovanni Antonio (i); zapa- } \\
\text { tero }\end{array}$ & Barcelona & 1658 & libro 734 & $\begin{array}{l}\text { azotes y } 9 \text { años } \\
\text { en galeras }\end{array}$ \\
\hline Belimunt, Joan; sastre & Barcelona & 1588 & libro 730 & $\begin{array}{l}\text { azotado y deste- } \\
\text { rrado }\end{array}$ \\
\hline Benavent, Caterina & Barcelona & 1717 & leg. 2.158 & $\begin{array}{l}\text { azotada y deste- } \\
\text { rrada }\end{array}$ \\
\hline Benet, Joan; labrador & Manlleu & 1659 & libro 734 & $\begin{array}{r}\text { destierro en un } \\
\text { presidio }\end{array}$ \\
\hline Benet, Joan; labrador & Vinya & 1664 & libro 735 & $\begin{array}{l}\text { azotado y } 4 \text { años } \\
\text { en galeras }\end{array}$ \\
\hline Bernat, Jean (f); labrador & Viladecans & 1561 & libro 730 & $\begin{array}{l}\text { azotado y a gale- } \\
\text { ras }\end{array}$ \\
\hline $\begin{array}{l}\text { Bernis, Pierre }(f) \text {; serrador } \\
\text { Bigorda Castellius, Jacint; labra- } \\
\text { dor }\end{array}$ & $\begin{array}{l}\text { Barcelona } \\
\text { Hospitalet }\end{array}$ & $\begin{array}{l}1685 \\
1744\end{array}$ & $\begin{array}{l}\text { libro } 758 \\
\text { leg. } 3.724 / 155\end{array}$ & \\
\hline Blanch, Pere, albañil & Parets & 1597 & libro 731 & $\begin{array}{l}\text { azotado y } 5 \text { años } \\
\text { en galeras }\end{array}$ \\
\hline Bley, Jean ( $f$ ); labrador & Puigcerdá & 1578 & libro 730 & $\begin{array}{l}\text { azotado y } 5 \text { años } \\
\text { en galeras }\end{array}$ \\
\hline $\begin{array}{l}\text { Bru, Jaume; músico } \\
\text { Bruno, Antonio (i) }\end{array}$ & Balaguer & $\begin{array}{l}1603 \\
1656\end{array}$ & $\begin{array}{l}\text { libro } 731 \\
\text { libro } 750\end{array}$ & penitenciado \\
\hline Bolea, Miquel; zapatero & Balaguer & 1623 & libro 733 & $\begin{array}{l}\text { azotado y } 3 \text { años } \\
\text { en galeras }\end{array}$ \\
\hline $\begin{array}{l}\text { Bonat, Pau } \\
\text { Bordas, Bernard (f); albañil }\end{array}$ & & $\begin{array}{l}1553 \\
1668\end{array}$ & leg. $1.592 / 28$ & suspenso \\
\hline $\begin{array}{l}\text { Bordas, Bernard (f); albanil } \\
\text { Batalla, Michel }(f) \text {; tejedor }\end{array}$ & Arenys & $\begin{array}{l}1668 \\
1570\end{array}$ & $\begin{array}{l}\text { libro } 735 \\
\text { libro } 730\end{array}$ & $\begin{array}{l}\text { suspenso } \\
\text { azotado y } 5 \text { años } \\
\text { en galeras }\end{array}$ \\
\hline Botella, Pere, zapatero & Surp & 1563 & libro 730 & $\begin{array}{l}\text { azotado y } 5 \text { años } \\
\text { en galeras }\end{array}$ \\
\hline $\begin{array}{l}\text { Boxi i Roig, María Rosa } \\
\text { Burges, Arnoud ( } f \text { ) }\end{array}$ & $\begin{array}{l}\text { Barcelona } \\
\text { Cervera }\end{array}$ & $\begin{array}{l}1719 \\
1597\end{array}$ & $\begin{array}{l}\text { leg. } 2.158 \\
\text { libro } 731\end{array}$ & $\begin{array}{l}\text { suspensa } \\
\text { absuelto }\end{array}$ \\
\hline Cambret, Caterina & Millas & 1571 & libro 730 & azotada \\
\hline $\begin{array}{l}\text { Campolongo, Gabriel; militar } \\
\text { Candeal, Antoni, cirujano }\end{array}$ & $\begin{array}{l}\text { Llacuna, La } \\
\text { Barcelona }\end{array}$ & $\begin{array}{l}1627 \\
1771\end{array}$ & $\begin{array}{l}\text { libro } 733 \\
\text { leg. } 2.170\end{array}$ & desterrado \\
\hline Cano, Francisco; militar & Barcelona & 1716 & leg. 2.158 & $\begin{array}{l}\text { azotado y } 5 \text { años } \\
\text { en galeras }\end{array}$ \\
\hline Camps, Margarida & Roca, La & 1597 & libro 731 & absuelta \\
\hline Canti Paulet, Jean ( $f$ ) & Barcelona & 1617 & libro 732 & $\begin{array}{l}\text { azotado y deste- } \\
\text { rrado }\end{array}$ \\
\hline Capella, Jaume; labrador & $\begin{array}{l}\text { St. Adria de } \\
\text { Besos }\end{array}$ & 1565 & libro 730 & $\begin{array}{l}\text { azotado y } 3 \text { años } \\
\text { en galeras }\end{array}$ \\
\hline Carbonell, Josep; sastre & Barcelona & 1744 & $\begin{array}{c}\text { leg. } 2.164 \\
3.724 / 165\end{array}$ & - \\
\hline Carsi, Miquel & Pontons & 1631 & libro 733 & $\begin{array}{l}\text { azotado ¿y deste- } \\
\text { rrado? }\end{array}$ \\
\hline Cartella, Galcera & Fogars & 1565 & libro 730 & $\begin{array}{l}\text { multado y a gale- } \\
\text { ras }\end{array}$ \\
\hline $\begin{array}{l}\text { Casanas, Antoni } \\
\text { Casanes, Antoni; labrador }\end{array}$ & Maçanet & 1594 & libro 731 & desterrado \\
\hline $\begin{array}{l}\text { Casanes, Antoni; labrador } \\
\text { Casangas, Antoine (f) }\end{array}$ & & $\begin{array}{l}1601 \\
1593\end{array}$ & $\begin{array}{l}\text { libro } 740 \\
\text { libro } 731\end{array}$ & rado \\
\hline Casas, Jean (f); tejedor & $\begin{array}{l}\text { St. Salvador } \\
\text { de Breda }\end{array}$ & 1578 & libro 730 & $\begin{array}{l}\text { azotado y } 7 \text { años } \\
\text { en galeras }\end{array}$ \\
\hline $\begin{array}{l}\text { Casasus, Pierre (f); colchonero } \\
\text { Casella, María }\end{array}$ & $\begin{array}{l}\text { Tremp } \\
\text { Crespiá }\end{array}$ & $\begin{array}{l}1638 \\
1664\end{array}$ & $\begin{array}{l}\text { libro } 748 \\
\text { libro } 735\end{array}$ & $\begin{array}{l}\text { azotada y deste- } \\
\text { rrada }\end{array}$ \\
\hline
\end{tabular}


Catálogo de los procesos inquisitoriales del Tribunal del...

\begin{tabular}{|c|c|c|c|c|}
\hline Apellidos y nombre; profesión & Localidad & Fecha & Fuente & Sentencia \\
\hline Castello, Jean (f); labrador & & 1570 & libro 730 & $\begin{array}{l}\text { azotado y } 3 \text { años } \\
\text { en galeras }\end{array}$ \\
\hline Castanyer, Jaume, labrador & Sarriá & 1588 & libro 731 & $\begin{array}{l}\text { azotado y } 3 \text { años } \\
\text { en galeras }\end{array}$ \\
\hline Castelló, Antoni & Taliada, La & 1677 & libro 735 & $\begin{array}{l}\text { azotado y } 5 \text { años } \\
\text { en galeras }\end{array}$ \\
\hline Castelló, Joan & Barcelona & 1716 & $\operatorname{leg} .2 .158$ & $\begin{array}{l}\text { azotado y } 5 \text { años } \\
\text { en galeras }\end{array}$ \\
\hline $\begin{array}{l}\text { Catalan, Barthelemy (f); relojero } \\
\text { Cercisa, Jeronima }\end{array}$ & & $\begin{array}{l}1672 \\
1555\end{array}$ & $\begin{array}{l}\text { libro } 755 \\
\text { leq } 1592 / 28\end{array}$ & - \\
\hline Cipriana (f) & Perpignan & 1611 & libro 732 & desterrada \\
\hline iurella, Quiteria & Begl & 1612 & libro 732 & desterrada \\
\hline Claramunt, Jaume; trajinero & Miquel d'Orpi & 1748 & $\begin{array}{l}\text { leg. } 2.165 \text { y } \\
3.724 / 98\end{array}$ & - \\
\hline $\begin{array}{l}\text { Corderch, Jean (f); picapedrero } \\
\text { Coll, Esperança }\end{array}$ & Girona & $\begin{array}{l}1573 \\
1554\end{array}$ & $\begin{array}{l}\text { leg. } 1592 / 27 \\
\text { leg. } 1.592 / 28\end{array}$ & abjuró de Leví \\
\hline $\begin{array}{l}\text { Coll, Margarida } \\
\text { Coll, Miquel; labrador }\end{array}$ & Valls & $\begin{array}{l}1560 \\
1661\end{array}$ & $\begin{array}{l}\text { libro } 730 \\
\text { libro } 734\end{array}$ & $\begin{array}{l}\text { azotada } \\
\text { azotado y } 5 \text { años } \\
\text { en galeras }\end{array}$ \\
\hline $\begin{array}{l}\text { Colla, Joana } \\
\text { Collado Fernández, Manuel; } \\
\text { militar }\end{array}$ & Sellent & $\begin{array}{l}1610 \\
1818\end{array}$ & $\begin{array}{l}\text { libro } 732 \\
\text { leg. } 2.177\end{array}$ & suspensa \\
\hline Collel, Joan & $\begin{array}{l}\text { St. Joan de } \\
\text { les } \\
\text { Abadesses }\end{array}$ & 1569 & libro 730 & ¿desterrado? \\
\hline Comadarán, Isabel & & 1590 & & azotada \\
\hline Guillaume $(f)$; trajinero & Barcelona & 1575 & libro 730 & $\begin{array}{l}\text { azotado y } 5 \text { años } \\
\text { en galeras }\end{array}$ \\
\hline Comes, Arnaud (f) & Cervera & 1605 & libro 731 & $\begin{array}{l}\text { azotado y } 5 \text { años } \\
\text { en galeras }\end{array}$ \\
\hline $\begin{array}{l}\text { Cos, Joan } \\
\text { Cosent, Antoni }\end{array}$ & Ridaura & $\begin{array}{l}1609 \\
1553\end{array}$ & $\begin{array}{l}\text { libro } 732 \\
\text { leg. } 1.592 / 28\end{array}$ & absuelto \\
\hline , Joaqu & & 1740 & leg. 2.164 & - \\
\hline Criols, Andreu; labrador & Busa & 1682 & libro 735 & suspenso \\
\hline $\begin{array}{l}\text { Dacorso, Giovanni Battista (i); } \\
\text { estanquero }\end{array}$ & $\begin{array}{l}\text { Vilanova de } \\
\text { Cubelles }\end{array}$ & 1726 & leg. 2.161 & $\begin{array}{l}\text { destierro en un } \\
\text { presidio }\end{array}$ \\
\hline Dalmau, Josep & Esparraguera & 1682 & libro 735 & $\begin{array}{l}\text { azotado y } 5 \text { años } \\
\text { en galeras }\end{array}$ \\
\hline $\begin{array}{l}\text { Desto, Caterina } \\
\text { Diaz de Arellano, Pedro; militar }\end{array}$ & Barcelona & $\begin{array}{l}1563 \\
1659\end{array}$ & $\begin{array}{l}\text { libro } 730 \\
\text { libro } 734\end{array}$ & $\begin{array}{l}\text { azotada } \\
\text { destierro en un } \\
\text { presidio }\end{array}$ \\
\hline Diaz del Monte, Juan; militar & & 1675 & & - \\
\hline Domenec, Jaume & Granollers & 1675 & libro 735 & $\begin{array}{l}\text { azotado y } 3 \text { años } \\
\text { en galeras }\end{array}$ \\
\hline Domingo, Juan Antonio & St. Cugat & 1610 & libro 732 & $\begin{array}{l}\text { azotado y } 3 \text { años } \\
\text { en galeras }\end{array}$ \\
\hline Duc, Pierre Jean (f?); labrador & Figueres & 1727 & leg. 2.161 & $\begin{array}{l}\text { destierro en un } \\
\text { presidio }\end{array}$ \\
\hline Duell, Guillaume (f); tejedor & Centelles & 1618 & libro 732 & desterrado \\
\hline Durán, Joan, panadero & & 1668 & & - \\
\hline Durán, Mariángela & Regenco & 1655 & libro 750 & - \\
\hline $\begin{array}{l}\text { Endavia, Pedro } \\
\text { Escader, Pere }\end{array}$ & Barcelona & $\begin{array}{l}1556 \\
1769\end{array}$ & $\begin{array}{l}\text { leg. } 1.592 / 23 \\
\text { leg. } 2.170\end{array}$ & huyó \\
\hline
\end{tabular}




\begin{tabular}{|c|c|c|c|c|}
\hline Apellidos y nombre; profesión & Localidad & Fecha & Fuente & Sentencia \\
\hline Escarrigar, Pere; labrador & Artés & 1662 & libro 752 & - \\
\hline Espaniach, Antoine (f); labrador & $\begin{array}{l}\text { Pallas Vall } \\
\text { d'Aneu }\end{array}$ & 1575 & libro 730 & $\begin{array}{l}\text { azotado y } 5 \text { años } \\
\text { en galeras }\end{array}$ \\
\hline Espassons, Miquel; labrador & Sta. Pau & 1665 & libro 735 & $\begin{array}{l}\text { azotado y } \\
\text { desterrado }\end{array}$ \\
\hline Esquiu, Andreu; labrador & & 1659 & libro 734 & - \\
\hline Estampa, Bernard (f); labrador & Martorell & 1578 & libro 730 & $\begin{array}{l}\text { azotado y } 7 \text { años } \\
\text { en galeras }\end{array}$ \\
\hline Estrada, Andrés, militar & & 1766 & leg. 2.170 & - \\
\hline Estrada, José; militar & & 1766 & $\begin{array}{c}\text { leg. } 2.170 \text { y } \\
3.724 / 71\end{array}$ & - \\
\hline Estrada, Mathieu (f) & Maçanet & 1597 & libro 731 & absuelto \\
\hline Fabregar, Francisca & & 1578 & libro 730 & - \\
\hline $\begin{array}{l}\text { Faidella, Ana María } \\
\text { Falla, Felipa }\end{array}$ & Barcelona & $\begin{array}{l}1665 \\
1764\end{array}$ & $\begin{array}{l}\text { libro } 735 \\
\text { leg. } 2.170\end{array}$ & desterrada \\
\hline Fardeu, Miquel; pastor & $\begin{array}{l}\text { St. Esteve de } \\
\text { Pardines }\end{array}$ & 1635 & libro 733 & - \\
\hline Fargas, Jean $(f)$; trajinero & Barcelona & 1615 & libro 732 & $\begin{array}{l}\text { azotado y } 5 \text { años } \\
\text { en galeras }\end{array}$ \\
\hline Ferrando, Francisc & $\begin{array}{l}\text { Espluga de } \\
\text { Francoli }\end{array}$ & 1670 & libro 755 & - \\
\hline Ferrer Catalán, Gabriel & Prat, El & 1571 & libro 730 & azotado \\
\hline Ferrer, Mariángela & Barcelona & 1666 & libro 735 & suspenso \\
\hline Ferrer, Montserrat; labrador & Barcelona & 1627 & libro 733 & $\begin{array}{l}\text { azotado y } 6 \text { años } \\
\text { en galeras }\end{array}$ \\
\hline Font, Antoni; pelaire & Sabadell & 1689 & libro 735 & - \\
\hline Font, Francesc & $\begin{array}{l}\text { Caldes de } \\
\text { Montbuí }\end{array}$ & 1589 & libro 731 & $\begin{array}{l}\text { azotado y } 3 \text { años } \\
\text { en galeras }\end{array}$ \\
\hline $\begin{array}{l}\text { Font, Jaume; } \\
\text { ayudante de verdugo }\end{array}$ & Barcelona & 1565 & libro 730 & $\begin{array}{l}\text { azotado y } 3 \text { años } \\
\text { en galeras }\end{array}$ \\
\hline Font, Pere, labrador & Artes & 1662 & libro 734 & $\begin{array}{l}\text { azotado y } 5 \text { años } \\
\text { en galeras }\end{array}$ \\
\hline Forner, Jean de $(f)$ & & 1569 & libro 730 & $\begin{array}{l}\text { azotado y } 5 \text { años } \\
\text { en galeras }\end{array}$ \\
\hline Forns, Jean (f); serrador & Tona & 1609 & libro 732 & $\begin{array}{l}\text { azotado y } 5 \text { años } \\
\text { en galeras }\end{array}$ \\
\hline Francés, María Teresa & Barcelona & 1770 & leg. 2.170 & suspensa \\
\hline François Elie $(f)$ & Barcelona & 1594 & libro 731 & $\begin{array}{l}\text { azotado y } 5 \text { años } \\
\text { en galeras }\end{array}$ \\
\hline Franch y Casales, Marianne ( $f$ ) & & 1631 & libro 733 & suspensa \\
\hline Frexes, Antoine (f); albañil & $\begin{array}{l}\text { St. Joan de } \\
\text { les } \\
\text { Abadesses }\end{array}$ & 1654 & libro 749 & \\
\hline Frexes, Etienne (f); tintorero & Olot & 1627 & libro 733 & $\begin{array}{l}\text { azotado y } 3 \text { años } \\
\text { en galeras }\end{array}$ \\
\hline $\begin{array}{l}\text { Galiazzo Pozzeti, Guiseppe (i); } \\
\text { zapatero }\end{array}$ & & 1756 & leg. $3.724 / 54$ & - \\
\hline Galici, Rafael; militar & Barcelona & 1631 & libro 733 & azotado \\
\hline & c. & 1750 & $\begin{array}{l}\text { leg. } 3.724 / \\
168\end{array}$ & \\
\hline Gairys, Marc; pelaire & & 1552 & libro 730 & azotado \\
\hline $\begin{array}{l}\text { Gembi i Berat, María } \\
\text { Gendra, Jean (f) }\end{array}$ & Omellons & $\begin{array}{l}1681 \\
1610\end{array}$ & $\begin{array}{l}\text { libro } 735 \\
\text { libro } 732\end{array}$ & desterrada \\
\hline
\end{tabular}


Catálogo de los procesos inquisitoriales del Tribunal del...

\begin{tabular}{|c|c|c|c|c|}
\hline \multirow{2}{*}{$\begin{array}{l}\text { Apellidos y nombre; profesión } \\
\text { Gener, Jaume }\end{array}$} & \multirow[t]{2}{*}{ Localidad } & \multicolumn{2}{|c|}{ Fecha Fuente } & \multirow{2}{*}{$\frac{\text { Sentencia }}{\text { falleció }}$} \\
\hline & & 1680 & libro 735 & \\
\hline Ger, Guillaume de (f); sastre & Barcelona & 1616 & libro 732 & suspenso \\
\hline Gestar, Dominique (f); labrador & Ullestret & 1675 & libro 756 & - \\
\hline Gigona, Antonia & & 1552 & libro 730 & penitenciada \\
\hline Ginovalt, Baltasar (a) & & 1718 & leg. 2.156 & $\begin{array}{l}\text { desterrado en un } \\
\text { presidio }\end{array}$ \\
\hline Giral, Esteve & Malgrat & 1552 & libro 730 & penitenciado \\
\hline Giralt, Jean (f) & & 1560 & libro 730 & - \\
\hline Girona, Raymon & Cubells & 1668 & libro 735 & - \\
\hline Gol, Benet; labrador & Barcelona & 1742 & leg. 2.164 & - \\
\hline Gómez, Juan; hornero & Barcelona & 1578 & libro 730 & $\begin{array}{l}\text { azotado y } 5 \text { años } \\
\text { en galeras }\end{array}$ \\
\hline Gónzalez, Joaquín & Mataró & 1739 & $\begin{array}{l}\text { leg. } 3.724 / \\
138\end{array}$ & - \\
\hline Gorgui, Pau; pastor & & 1793 & leg. $3724 / 49$ & - \\
\hline Goso, Jean François (f); minero & Seu d'Urgell & 1626 & libro 732 & desterrado \\
\hline Gracián, Rafael & & 1585 & libro 730 & $\begin{array}{l}\text { azotado y } 3 \text { años } \\
\text { en galeras }\end{array}$ \\
\hline Grifol, Antoni & & 1571 & libro 730 & falleció \\
\hline Grimau, Guillaume (f); trajinero & Olesa & 1575 & libro 730 & ¿suspenso? \\
\hline Grinoral, Balthasar (a); militar & Cardona & 1717 & leg. 2.158 & $\begin{array}{l}\text { azotado y } 5 \text { años } \\
\text { en galeras }\end{array}$ \\
\hline Guillaume Pascal (f); pelaire & Barcelona & 1631 & libro 733 & $\begin{array}{l}\text { azotado y } 5 \text { años } \\
\text { en galeras }\end{array}$ \\
\hline $\begin{array}{l}\text { Hernández, Domingo; cochero } \\
\text { Hesta. Dominique }(f)\end{array}$ & Barcelona & 1735 & leg. 2162 & - \\
\hline & & & & \\
\hline Ibáñez, Francisco; sastre & & 1672 & libro 755 & 一 \\
\hline Jerónima & & 1555 & leg. $1.592 / 28$ & - \\
\hline Jiménez, Bernard $(f)$; albañil & Monistrol & 1627 & libro 733 & $\begin{array}{l}\text { azotado y } \\
\text { desterrado }\end{array}$ \\
\hline Julia, Jaume & & 1553 & leg. $1.592 / 28$ & - \\
\hline Julia, Magdalena Jerónima & Barcelona & $\begin{array}{l}1631 \\
1731\end{array}$ & $\begin{array}{l}\text { libro } 733 \\
\text { lea } 2162\end{array}$ & desterrada \\
\hline Labaixa, Jean $(f)$ & & 1639 & libro 734 & $\begin{array}{l}\text { azotado y } 3 \text { años } \\
\text { en galeras }\end{array}$ \\
\hline Laines, Jean de $(f)$; trajinero & Vic & 1564 & libro 730 & $\begin{array}{l}\text { azotado y } \\
\text { desterrado }\end{array}$ \\
\hline $\begin{array}{l}\text { Lapedra, Antoni Bartomeu; } \\
\text { marinero }\end{array}$ & Barcelona & 1565 & libro 730 & $\begin{array}{l}\text { azotado y } 3 \text { años } \\
\text { en galeras }\end{array}$ \\
\hline Laris, François de (f) & & 1596 & libro 731 & desterrado \\
\hline Latrapa, François (f); sastre & Barcelona & 1564 & libro 730 & $\begin{array}{l}\text { azotado y } 3 \text { años } \\
\text { en galeras }\end{array}$ \\
\hline Laudes, Josep; tejedor & Barcelona & 1634 & libro 733 & $\begin{array}{l}\text { azotado y } 4 \text { años } \\
\text { en galeras }\end{array}$ \\
\hline León, Gabriel de; militar & Perpignan & 1565 & libro 735 & desterrado \\
\hline López de Cañete, Juan; galeote & & 1667 & libro 735 & $\begin{array}{l}\text { azotado y } \\
\text { devuelto a } \\
\text { galeras }\end{array}$ \\
\hline Lorens, Antoine (f); sastre & Barcelona & 1592 & libro 731 & $\begin{array}{l}\text { azotado y } 5 \text { años } \\
\text { en galeras }\end{array}$ \\
\hline
\end{tabular}


JUAN BLÁZQUEZ MIGUEL

\begin{tabular}{|c|c|c|c|c|}
\hline Apellidos y nombre; profesión & Localidad & Fecha & a Fuente & Sentencia \\
\hline Llanas, Pere; labrador & Tuixent & 1749 & $\begin{array}{l}\text { leg. } 2.165 \text { y } \\
3.724 / 92\end{array}$ & - \\
\hline $\begin{array}{l}\text { Llaurador, Francesc } \\
\text { Lliurella, Quiteria } \\
\text { Llops, Jaume; militar }\end{array}$ & $\begin{array}{l}\text { Bell Losell } \\
\text { Verges }\end{array}$ & $\begin{array}{l}1609 \\
1611 \\
1749\end{array}$ & $\begin{array}{l}\text { libro } 732 \\
\text { libro } 732 \\
\text { leg. } 3.725 / 2\end{array}$ & $\begin{array}{l}\text { azotado y recluido } \\
\text { suspensa } \\
\text { - }\end{array}$ \\
\hline Macip, Joan; molinero & $\begin{array}{l}\text { St. Vicenç } \\
\text { dels Horts }\end{array}$ & 1751 & $\begin{array}{c}\text { leg. } 2.167 y \\
3.724 / 109\end{array}$ & - \\
\hline $\begin{array}{l}\text { Madreny, Jaume } \\
\text { Malaforza, Guillaume ( } f)\end{array}$ & Tossa & $\begin{array}{l}1681 \\
1600\end{array}$ & $\begin{array}{l}\text { libro } 757 \\
\text { libro } 731\end{array}$ & huyó \\
\hline Mallol, Jean $(f)$ & & 1571 & libro 730 & $\begin{array}{l}\text { azotado y } \\
\text { desterrado }\end{array}$ \\
\hline Manaut, Guillaume (f); serrador & $\begin{array}{l}\text { Pobla de } \\
\text { Lillet }\end{array}$ & 1592 & libro 731 & desterrado \\
\hline $\begin{array}{l}\text { Marco, Francisco; boticario } \\
\text { Martí, Tomás; labrador }\end{array}$ & $\begin{array}{l}\text { Barcelona } \\
\text { St Adriá de } \\
\text { Besós }\end{array}$ & $\begin{array}{l}1718 \\
1697\end{array}$ & $\begin{array}{l}\text { leg. } 2.158 \\
\text { libro } 760\end{array}$ & desterrado \\
\hline Marti Taya, Onofre & Barcelona & 1615 & libro 732 & $\begin{array}{l}\text { azotado y } 5 \text { años } \\
\text { en galeras }\end{array}$ \\
\hline $\begin{array}{l}\text { Martin, Antonia } \\
\text { Martinez, Francisco; militar }\end{array}$ & Barcelona & $\begin{array}{l}1594 \\
1554\end{array}$ & $\begin{array}{l}\text { libro } 731 \\
\text { leg. } 1.592 / 28\end{array}$ & desterrada \\
\hline Martín, Juan; carnice & Girona & 1586 & libro 731 & $\begin{array}{l}\text { azotado y } 5 \text { años } \\
\text { en galeras }\end{array}$ \\
\hline Martín, Jean (f); guantero & Granollers & 1594 & libro 731 & $\begin{array}{l}\text { azotado y } 3 \text { años } \\
\text { en galeras }\end{array}$ \\
\hline $\begin{array}{l}\text { Martin Canadell, Pere } \\
\text { Martiria Falgas, Baldiri; labrador }\end{array}$ & $\begin{array}{l}\text { Manresa } \\
\text { Banyoles }\end{array}$ & $\begin{array}{l}1658 \\
1658\end{array}$ & $\begin{array}{l}\text { libro } 734 \\
\text { libro } 734\end{array}$ & $\begin{array}{l}\text { suspendido } \\
\text { suspenso }\end{array}$ \\
\hline Uasats, Sadurní; pastor & Talamanca & 1792 & leg. $3.731 / 9$ & - \\
\hline Mata, Bartome & Piera & 1668 & libro 735 & $\begin{array}{l}\text { azotado y } 5 \text { años } \\
\text { en galeras }\end{array}$ \\
\hline oń Alanoo dr & & 1675 & libro & susp \\
\hline Medrano, José Alonso de & Barcelona & 1716 & & $\begin{array}{l}\text { azotado y } 7 \text { años } \\
\text { en galeras }\end{array}$ \\
\hline Medreny, Jaume & Tossa & 1681 & libro 735 & $\begin{array}{l}\text { azotado y } 5 \text { años } \\
\text { en galeras }\end{array}$ \\
\hline Mendoza, Juan de; militar & & 1726 & leg. 2.160 & $\begin{array}{l}\text { desterrado en } \\
\text { presidio }\end{array}$ \\
\hline Mercader, Jean (f); tejedor & Pomar & 1570 & libro 730 & $\begin{array}{l}\text { azotado y } 3 \text { años } \\
\text { en galeras }\end{array}$ \\
\hline Mercet, Guillaume (f); pelaire & Peralada & 1603 & libro 731 & $\begin{array}{l}\text { azolado y } 5 \text { años } \\
\text { en galeras }\end{array}$ \\
\hline Merola, Pere; zapatero & Balaguer & 1564 & libro 730 & $\begin{array}{l}\text { azotado y } 2 \text { años } \\
\text { en galeras }\end{array}$ \\
\hline Mesa, Juan de; militar & & 1718 & $\operatorname{leg} .2 .158$ & $\begin{array}{l}\text { desterrado en un } \\
\text { presidio }\end{array}$ \\
\hline Mestra, Montserrat & Sitges & 1588 & libro 731 & deste \\
\hline & & 1617 & & \\
\hline Jean; labrador & Puigvert & 1603 & libro 731 & azotado y recluido \\
\hline Min, Jeroni; jubonero & & 1565 & libro 730 & $\begin{array}{l}\text { azotado y } 2 \text { años } \\
\text { en galeras }\end{array}$ \\
\hline larià; labrador & Riuc & 1737 & leg. & - \\
\hline & & 1718 & & $\begin{array}{l}\text { desterrado en un } \\
\text { presidio }\end{array}$ \\
\hline Molins, Miquel Manuel; zapatero & Sta. Pau & 1659 & libro 734 & $\begin{array}{l}\text { azotado y } 5 \text { años } \\
\text { en galeras }\end{array}$ \\
\hline Mongay, José; militar & & 1753 & leg. 2.167 & - \\
\hline
\end{tabular}


Catálogo de los procesos inquisitoriales del Tribunal del...

\begin{tabular}{|c|c|c|c|c|}
\hline Apellidos y nombre; profesión & Localidad & Fecha & Fuente & Sentencia \\
\hline $\begin{array}{l}\text { Montserrat, Margarida } \\
\text { Montarra, Joan }\end{array}$ & Barcelona & $\begin{array}{l}1590 \\
1749\end{array}$ & $\begin{array}{l}\text { libro } 731 \\
\text { leg. } 2.165\end{array}$ & desterrada \\
\hline Moragas, Josep; pastor & Vic & 1726 & $\operatorname{leg} .2 .161$ & - \\
\hline Morales, Juan Agustin; militar & & 1730 & leg. 2.162 & - \\
\hline Morell, Joan; cochero & Llagostera & 1605 & libro 731 & reconciliado \\
\hline Motas, Jean (f); hortelano & Barcelona & 1621 & libro 733 & $\begin{array}{l}\text { azotado y } 8 \text { años } \\
\text { en galeras }\end{array}$ \\
\hline Mur, Juan de; labrador & Barcelona & 1599 & libro 731 & $\begin{array}{l}\text { azotado y } 3 \text { años } \\
\text { en galeras }\end{array}$ \\
\hline Nadier, Bernard $(f)$; músico & Perpignan & 1571 & libro 730 & $\begin{array}{l}\text { azotado y a } \\
\text { galeras }\end{array}$ \\
\hline Naudet, Elie (f) & & 1666 & libro 735 & absuelto \\
\hline $\begin{array}{l}\text { Navarro, Dominique (f); carpintero } \\
\text { Navarro, Matias; militar }\end{array}$ & Llivia & $\begin{array}{l}1620 \\
1676\end{array}$ & $\begin{array}{l}\text { libro } 732 \\
\text { libro } 736\end{array}$ & $\begin{array}{l}\text { advertido } \\
\text { desterrado en un } \\
\text { presidio }\end{array}$ \\
\hline Negret i Rei, Margarida & Montardit & 1665 & libro 735 & suspensa \\
\hline Noguera, Josep & Brafim & 1697 & libro 760 & $\begin{array}{l}\text { azotado y } 5 \text { años } \\
\text { en galeras }\end{array}$ \\
\hline Noguer, Jean (f); pelaire & Cubells & 1611 & libro 732 & suspenso \\
\hline Noguer, Pierre $(f)$ & Irles, Les & 1563 & libro 730 & $\begin{array}{l}\text { azotado y a } \\
\text { galeras }\end{array}$ \\
\hline Oriols, Andreu; labrador & Esparraguera & 1681 & libro 757 & \\
\hline Ortal, Antoine $(f)$; albañil & Llavanera & 1592 & libro 731 & absuelto \\
\hline Pages, Jean (f); molinero & Vilves & 1631 & libro 733 & suspenso \\
\hline Palau, Jeroni; labrador & Pineda & 1570 & libro 730 & $\begin{array}{l}\text { azotado y } 5 \text { años } \\
\text { en galeras }\end{array}$ \\
\hline Palizzi, Pietro (i) & Barcelona & 1725 & leg. 2.161 & $\begin{array}{l}\text { azotado y } \\
\text { desterrao en un } \\
\text { presidio }\end{array}$ \\
\hline Palmerola, Ana & Valltorta & 1600 & libro 731 & suspensa \\
\hline $\begin{array}{l}\text { Pallaramch, Jean Baptiste (f); } \\
\text { tejedor }\end{array}$ & Perpignan & 1598 & libro 731 & \\
\hline Pastor, Bartomeu; pelaire & Pineda & 1582 & libro 730 & $\begin{array}{l}\text { azotado y } 3 \text { años } \\
\text { en galeras }\end{array}$ \\
\hline Pavici, Giovanni (i); zapatero & Barcelona & 1667 & libro 735 & $\begin{array}{l}\text { azotado y } 5 \text { años } \\
\text { en galeras }\end{array}$ \\
\hline Pascual, Pierre (f) & Barcelona & 1571 & libro 730 & azotado \\
\hline Pegibert, Jean (f); labrador & Canet & 1578 & libro 730 & $\begin{array}{l}\text { azotado y } 3 \text { años } \\
\text { en galeras }\end{array}$ \\
\hline Peiro, Antoine (f); sastre & & 1593 & libro 731 & $\begin{array}{l}\text { azotado y } 5 \text { años } \\
\text { en galeras }\end{array}$ \\
\hline Pellicer, Antoni; labrador & Bastida, La & 1605 & libro 731 & $\begin{array}{l}\text { azotado y } 3 \text { años } \\
\text { en galeras }\end{array}$ \\
\hline $\begin{array}{l}\text { Peralva, Isabel } \\
\text { Pérez, Sebastián; escultor }\end{array}$ & Perpignan & $\begin{array}{l}1557 \\
1570\end{array}$ & $\begin{array}{l}\text { leg. } 1.592 / 23 \\
\text { libro } 730\end{array}$ & $\begin{array}{l}\text { azotado y } \\
\text { desterrado }\end{array}$ \\
\hline Pérez Prieto, Manuel (p) & & 1718 & leg. 2.156 & $\begin{array}{l}\text { azotado y } 5 \text { años } \\
\text { en galeras }\end{array}$ \\
\hline Pierres, Paule (f) & & 1569 & libro 730 & azotada \\
\hline Piralt, Jean (f); tejedor & $\begin{array}{l}\text { Sta. Coloma } \\
\text { de Farners }\end{array}$ & 1561 & libro 730 & azotado \\
\hline
\end{tabular}




\begin{tabular}{|c|c|c|c|c|}
\hline Apellidos y nombre; profesión & Localidad & Fecha & Fuente & Sentencia \\
\hline $\begin{array}{l}\text { Pla, Jerónima } \\
\text { Port Peresech, Pierre }(f) \text {; labrador } \\
\text { Ponza, Olaria } \\
\text { Porta, Joan }\end{array}$ & $\begin{array}{l}\text { Barcelona } \\
\text { Sarros }\end{array}$ & $\begin{array}{l}1555 \\
1574 \\
1582 \\
1608\end{array}$ & $\begin{array}{l}\text { leg. } 1.592 / 28 \\
\text { libro } 730 \\
\text { libro } 730 \\
\text { libro } 732\end{array}$ & $\begin{array}{l}\text { azotada } \\
\text { azotado y } 5 \text { años } \\
\text { en galeras }\end{array}$ \\
\hline $\begin{array}{l}\text { Pou, Caterina } \\
\text { Prada, Pedro; militar } \\
\text { Prat, Jean (f); tejedor }\end{array}$ & $\begin{array}{l}\text { Lloret } \\
\text { Barcelona }\end{array}$ & $\begin{array}{l}1612 \\
1736 \\
1570\end{array}$ & $\begin{array}{l}\text { libro } 732 \\
\text { leg. } 2.164 \\
\text { libro } 730\end{array}$ & $\begin{array}{l}\text { desterrada } \\
\text { azotado y } 4 \text { años } \\
\text { en galeras }\end{array}$ \\
\hline $\begin{array}{l}\text { Prats, Joan; médico } \\
\text { Prejol, Joan; tejedor }\end{array}$ & $\begin{array}{l}\text { Barcelona } \\
\text { Pobleta }\end{array}$ & $\begin{array}{l}1661 \\
1596\end{array}$ & $\begin{array}{l}\text { libro } 752 \\
\text { libro } 731\end{array}$ & $\begin{array}{l}\text { azotado y } 3 \text { años } \\
\text { en galeras }\end{array}$ \\
\hline $\begin{array}{l}\text { Pugibert, Jean ( } f \text { ) } \\
\text { Puig, Joan } \\
\text { Pujades, Pierre (f); labrador } \\
\text { Pujol, Joan; pelaire } \\
\text { Pujol, Jean (f); tejedor }\end{array}$ & $\begin{array}{l}\text { Canyet, El } \\
\text { Barcelona } \\
\text { Reus } \\
\text { Tona }\end{array}$ & $\begin{array}{l}1574 \\
1588 \\
1606 \\
1578 \\
1593\end{array}$ & $\begin{array}{l}\text { libro } 730 \\
\text { libro } 731 \\
\text { libro } 732 \\
\text { libro } 730 \\
\text { libro } 731\end{array}$ & $\begin{array}{l}\text { azotado y } 5 \text { años } \\
\text { en galeras }\end{array}$ \\
\hline Pujades, Pierre ( $f$ ) & Reus & 1617 & libro 732 & $\begin{array}{l}\text { azotado y } 5 \text { años } \\
\text { en galeras }\end{array}$ \\
\hline Pujo, Sébastien (f); tejedor & Angles & 1631 & libro 733 & $\begin{array}{l}\text { azotado y } \\
\text { desterrado }\end{array}$ \\
\hline Quera, Juana & & 1578 & libro 730 & abjuró de Leví \\
\hline Reixart, Pierre (f); molinero & Seu d'Urgell & 1590 & libro 731 & $\begin{array}{l}\text { azotado y } 5 \text { años } \\
\text { en galeras }\end{array}$ \\
\hline Reixacch, Pere & Valls & 1594 & libro 731 & $\begin{array}{l}\text { azotado y } 3 \text { años } \\
\text { en galeras }\end{array}$ \\
\hline Revalli, Antic; maestro & & 1585 & libro 730 & $\begin{array}{l}\text { azotado y } 4 \text { años } \\
\text { en galeras }\end{array}$ \\
\hline $\begin{array}{l}\text { Rey, Raymond }(f) \\
\text { Ribas, Joseph }(f) \\
\text { Ribas, Vicenç de }\end{array}$ & & $\begin{array}{l}1560 \\
1569 \\
1731\end{array}$ & $\begin{array}{l}\text { libro } 730 \\
\text { libro } 730 \\
\text { leg. } 2.162\end{array}$ & azotado \\
\hline Ribera, Joan de & & 1553 & leg. $1.592 / 28$ & \\
\hline $\begin{array}{l}\text { Riber Ol, André (f); pelaire } \\
\text { Rico, Andrés Juan }\end{array}$ & Girona & $\begin{array}{l}1589 \\
1711\end{array}$ & $\begin{array}{l}\text { libro } 731 \\
\text { leg. } 3.724 / \\
121\end{array}$ & desterrado \\
\hline Riere, Antoine $(f)$; serrador & Riudecanyes & 1586 & libro 731 & $\begin{array}{l}\text { azotado y } 3 \text { años } \\
\text { en galeras }\end{array}$ \\
\hline Riera, Juan; sastre & $\begin{array}{l}\text { St. Salvador } \\
\text { de la } \\
\text { Vedella }\end{array}$ & 1614 & libro 732 & $\begin{array}{l}\text { azotado y } 5 \text { años } \\
\text { en galeras }\end{array}$ \\
\hline $\begin{array}{l}\text { Rius, Josep; pastor } \\
\text { Rius, Miquel, pastor }\end{array}$ & $\begin{array}{l}\text { Montblanc } \\
\text { Seu d'Urgell }\end{array}$ & $\begin{array}{l}1659 \\
1578\end{array}$ & $\begin{array}{l}\text { libro } 734 \\
\text { libro } 730\end{array}$ & falleció \\
\hline Robles y León, Álvaro de & Barcelona & 1592 & libro 731 & $\begin{array}{l}\text { desterrado en un } \\
\text { presidio }\end{array}$ \\
\hline Roca, Josep; militar & & 1719 & leg. 2.156 & $\begin{array}{l}\text { desterrado en un } \\
\text { presidio }\end{array}$ \\
\hline Rocha, Guillaume (f) & & 1569 & libro 730 & $\begin{array}{l}\text { azotado y } 5 \text { años } \\
\text { en galeras }\end{array}$ \\
\hline $\begin{array}{l}\text { Rodríguez de Trigo, Juan; } \\
\text { alguacil }\end{array}$ & Barcelona & 1726 & $\operatorname{leg} .2 .161$ & \\
\hline Roma, Francisco; militar & & 1734 & $\begin{array}{l}\operatorname{leg} .2 .164 \text { y } \\
3.724 / 2\end{array}$ & desterrado \\
\hline
\end{tabular}


Catálogo de los procesos inquisitoriales del Tribunal del...

\begin{tabular}{|c|c|c|c|c|}
\hline Apellidos y nombre; profesión & Localidad & Fecha & Fuente & Sentencia \\
\hline Romui, Joan; labrador & Rubies & 1575 & libro 730 & $\begin{array}{l}\text { azotado y } 5 \text { años } \\
\text { en galeras }\end{array}$ \\
\hline Rosell, Bartomeu & & 1554 & leg. $1.592 / 28$ & \\
\hline Rubies, Violant & Balaguer & 1564 & libro 730 & azotada \\
\hline Rufat, Etienne (f); cocinero & Barcelona & 1737 & $\begin{array}{l}\text { leg. } 3.724 / \\
149\end{array}$ & \\
\hline Sabateri, Raphael (f); pintor & Baga & 1564 & libro 730 & $\begin{array}{l}\text { azotado y } 10 \text { años } \\
\text { en galeras }\end{array}$ \\
\hline Sacarrius, Jaimeta (f) & Montroig & 1594 & libro 731 & absuelta \\
\hline Sala, Jean (f); labrador & & 1622 & libro 735 & $\begin{array}{l}\text { azotado y } 3 \text { años } \\
\text { en galeras }\end{array}$ \\
\hline Salas, Elena & $\begin{array}{l}\text { Conca de } \\
\text { Tremp }\end{array}$ & 1670 & libro 754 & desterrada \\
\hline Saliera, Jean (f); tejedor & $\begin{array}{l}\text { Castello } \\
\text { d'Empuries }\end{array}$ & 1575 & libro 730 & $\begin{array}{l}\text { azotado y } 5 \text { años } \\
\text { en galeras }\end{array}$ \\
\hline Sampso, Salvador (f); labrador & & 1687 & libro 735 & $\begin{array}{l}\text { azotado y } 5 \text { años } \\
\text { en galeras }\end{array}$ \\
\hline San Juan, Miguel de; labrador & Castellvi & 1719 & leg. 2.156 & $\begin{array}{l}\text { desterrado en un } \\
\text { presidio }\end{array}$ \\
\hline Sánchez, Garci; bordador & & 1554 & leg. 1.592/28 & penitenciado \\
\hline $\begin{array}{l}\text { Sancho, Vicente } \\
\text { Saneus, François (f) }\end{array}$ & Barcelona & $\begin{array}{l}1569 \\
1573\end{array}$ & $\begin{array}{l}\text { libro } 737 \\
\text { leg. } 1.592 / 27\end{array}$ & $\begin{array}{l}\text { absuelto } \\
\text { azotado y } 5 \text { años } \\
\text { en galeras }\end{array}$ \\
\hline Sanz, María Jesús & Ainet & 1627 & libro 733 & desterrada \\
\hline Sansat, Pierre (f); cochero & Girona & 1621 & libro 733 & $\begin{array}{l}\text { azotado y } 3 \text { años } \\
\text { en galeras }\end{array}$ \\
\hline Sanz, Pierre (f) & Barcelona & 1561 & & azotado \\
\hline Selles, Jean Joseph $(\boldsymbol{f})$ & Barcelona & 1594 & & $\begin{array}{l}\text { azotado y } 5 \text { años } \\
\text { en galeras }\end{array}$ \\
\hline Sem, Miquel & & 1553 & leg. $1,592 / 28$ & - \\
\hline $\begin{array}{l}\text { Santillana, Pedro de } \\
\text { Sempere, Isabel }\end{array}$ & Barcelona & $\begin{array}{l}1503 \\
1675\end{array}$ & $\begin{array}{l}\text { Carbonell } \\
\text { libro } 735\end{array}$ & $\begin{array}{l}\text { reconciliado } \\
\text { falleció }\end{array}$ \\
\hline Sercany, Etienne $(f)$; tejedor & & 1596 & libro 731 & azotado y recluido \\
\hline Serra, Joan; sombrerero & $\begin{array}{l}\text { Caldes de } \\
\text { Montbuí }\end{array}$ & 1663 & libro 734 & $\begin{array}{l}\text { azotado y } 3 \text { años } \\
\text { en galeras }\end{array}$ \\
\hline Serra Bodet, Francesca & & 1761 & leg. 2.170 & 一 \\
\hline $\begin{array}{l}\text { Serrato, Manuela } \\
\text { Sircan, Esteban }(f) \text {; tejedor }\end{array}$ & Barcelona & $\begin{array}{l}1689 \\
1597\end{array}$ & $\begin{array}{l}\text { libro } 735 \\
\text { libro } 731\end{array}$ & $\overline{\text { absuelto }}$ \\
\hline Sires, André (f); tejedor & Riber & 1609 & libro 732 & $\begin{array}{l}\text { azotado y } 4 \text { años } \\
\text { en galeras }\end{array}$ \\
\hline Soca, Joan; labrador & & 1627 & libro 745 & $\begin{array}{l}\text { azotado y } 5 \text { años } \\
\text { en galeras }\end{array}$ \\
\hline Soler, Caterina & Barcelona & 1610 & libro 732 & absuelta \\
\hline Soler, Pierre (f); militar & & 1614 & libro 732 & $\begin{array}{l}\text { azotado y } 5 \text { años } \\
\text { en galeras }\end{array}$ \\
\hline Spasa, Francina Jerónima & Agramunt & 1565 & libro 730 & penitenciada \\
\hline Subirats, Pierre Marc (f); labrador & Barcelona & 1608 & libro 732 & $\begin{array}{l}\text { azotado y } 5 \text { años } \\
\text { en galeras }\end{array}$ \\
\hline Taberner, Guillaume $(f)$; labrador & Cardona & 1628 & libro 733 & $\begin{array}{l}\text { azotado y } 3 \text { años } \\
\text { en galeras }\end{array}$ \\
\hline Tarragó, Agnes & $\begin{array}{l}\text { St. Feliu de } \\
\text { Codines }\end{array}$ & 1657 & libro 751 & suspensa \\
\hline
\end{tabular}


JUAN BLÁZQUEZ MIGUEL

\begin{tabular}{|c|c|c|c|c|}
\hline Apellidos y nombre; profesión & Localidad & Fecha & Fuente & Sentencia \\
\hline Tarragó, Pere; labrador & & 1721 & leg. 2.159 & $\begin{array}{l}\text { azotado y } 5 \text { años } \\
\text { en galeras }\end{array}$ \\
\hline $\begin{array}{l}\text { Taurant, Antoine (f) } \\
\text { Tejedor, Jean (f); tejedor }\end{array}$ & $\begin{array}{l}\text { Seu d'Urgell } \\
\text { Castello } \\
\text { d'Empuries }\end{array}$ & $\begin{array}{l}1640 \\
1639\end{array}$ & $\begin{array}{l}\text { libro } 732 \\
\text { libro } 734\end{array}$ & suspenso \\
\hline $\begin{array}{l}\text { Terrassa, Raimond } \\
\text { Terrel, Agustí }\end{array}$ & & $\begin{array}{l}1655 \\
1819\end{array}$ & $\begin{array}{l}\text { libro } 750 \\
\text { leg. } 2.177\end{array}$ & 二 \\
\hline Tolssa, Raphael (f); herrero & Palamós & 1592 & libro 731 & $\begin{array}{l}\text { azotado y } 5 \text { años } \\
\text { en galeras }\end{array}$ \\
\hline $\begin{array}{l}\text { Torre Coll, Jean (f); polvorero } \\
\text { Torrell, Agustí; marinero }\end{array}$ & $\begin{array}{l}\text { Girona } \\
\text { Cambrils }\end{array}$ & $\begin{array}{l}1589 \\
1815\end{array}$ & $\begin{array}{l}\text { libro } 731 \\
\text { leg. } 2.177\end{array}$ & absuelto \\
\hline Torres, Caterina & Castanyet & 1594 & libro 731 & $\begin{array}{l}\text { azotada y } \\
\text { desterrada }\end{array}$ \\
\hline Torres, Jean Isidre (fl); tornero & & 1662 & libro 752 & - \\
\hline 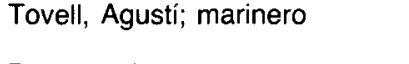 & Cambrils & 1800 & $\begin{array}{l}\operatorname{leg.~3.721/~} \\
204\end{array}$ & - \\
\hline Traserra, Macià; zapatero & Olot & 1766 & $\begin{array}{l}\text { leg. } 2.170 \mathrm{y} \\
3.724 / 68\end{array}$ & - \\
\hline Turner, Cebrià; labrador & Torrents & 1676 & libro 736 & $\begin{array}{l}\text { azotado y } 5 \text { años } \\
\text { en galeras }\end{array}$ \\
\hline Ubach, Pere; mercader & Barcelona & 1503 & Carbonell & reconciliado \\
\hline Valone, Mariángela & & 1784 & & - \\
\hline Valls, $J$ & Montblanquet & 1665 & & - \\
\hline Vaquer, Arnaud ( () ; hortelano & Reus & 1613 & libro 732 & $\begin{array}{l}\text { azotado y } 4 \text { años } \\
\text { en galeras }\end{array}$ \\
\hline Vargas, Juan de; militar & Barcelona & 1727 & leg. 2.161 & - \\
\hline Varór & Barc & 1658 & & - \\
\hline Verda & & 1578 & & - \\
\hline Vila, Jean $(\mathbf{f})$; labrador & Barcelona & 1565 & libro 730 & $\begin{array}{l}\text { azotado y } 2 \text { años } \\
\text { en galeras }\end{array}$ \\
\hline Vilamala, Antoine (f); corredor & Roses & 1662 & libro 731 & $\begin{array}{l}\text { azotado y } 3 \text { años } \\
\text { en galeras }\end{array}$ \\
\hline Vilaplana, Paula & Ager & 1627 & & desterra \\
\hline Villa, Margarida & Tarragona & & & azotada y recluida \\
\hline Villamala, Antoine (f) & & 1601 & & - \\
\hline Villanova, Bernat de & & 1557 & leg. $1.592 / 23$ & - \\
\hline $\begin{array}{l}\text { Villarredona, Clement (¿f?); } \\
\text { albañil }\end{array}$ & & 1595 & libro 731 & $\begin{array}{l}\text { azotado y } 5 \text { años } \\
\text { en galeras }\end{array}$ \\
\hline Villegas Ceballos, Francisco & & 1671 & & - \\
\hline Violata, Guillaume $(f)$; tejedor & Solsona & 1564 & & $\begin{array}{l}\text { azotado y } 2 \text { años } \\
\text { en galeras }\end{array}$ \\
\hline $\begin{array}{l}\text { Violata, María } \\
\text { Vital, Vito Antonio (i) }\end{array}$ & Figueres & $\begin{array}{l}1619 \\
1618\end{array}$ & $\begin{array}{l}\text { libro } 732 \\
\text { libro } 732\end{array}$ & $\begin{array}{l}\text { desterrada } \\
\text { azotado y } 4 \text { años } \\
\text { en galeras }\end{array}$ \\
\hline Voix, Jean (f) & & 1559 & leg. $1.592 / 28$ & - \\
\hline
\end{tabular}

\section{FORNICARIOS}

Abosser, Joan; herrero

Aguilar, Antoni

$\begin{array}{crrr}\begin{array}{c}\text { Torroella } \\ \text { Montgrí }\end{array} & 1637 & \text { libro } 734 \\ \text { La Guardia } & 1600 & \text { libro } 731\end{array}$

azotado y 3 años en galeras desterrado 
Catálogo de los procesos inquisitoriales del Tribunal del...

\begin{tabular}{|c|c|c|c|c|}
\hline Apellidos y nombre; profesión & Localidad & Fecha & Fuente & Sentencia \\
\hline Bales, Pierre $(f)$; tejedor & & 1573 & libro 737 & $\begin{array}{l}\text { azotado y } 5 \text { años } \\
\text { en galeras }\end{array}$ \\
\hline Benech, Ramón; trajinero & Barcelona & 1575 & libro 730 & azotado \\
\hline $\begin{array}{l}\text { Cais, Pere }(s) \\
\text { Cavaller, Pere }(s) \\
\text { Cornus, Joseph }(f)\end{array}$ & Peralada & $\begin{array}{l}1655 \\
1575 \\
1617\end{array}$ & $\begin{array}{l}\text { libro } 750 \\
\text { libro } 730 \\
\text { libro } 732\end{array}$ & $\begin{array}{l}\text { absuelto } \\
\text { desterrado }\end{array}$ \\
\hline $\begin{array}{l}\text { Diez, Francisca } \\
\text { Cortes, Dominique }(f) \text {; calcetero }\end{array}$ & $\begin{array}{l}\text { Barcelona } \\
\text { Barcelona }\end{array}$ & $\begin{array}{l}1655 \\
1600\end{array}$ & $\begin{array}{l}\text { libro } 734 \\
\text { libro } 731\end{array}$ & $\begin{array}{l}\text { desterrada } \\
\text { reprendido }\end{array}$ \\
\hline $\begin{array}{l}\text { Floret, Antoine (f); albañil } \\
\text { Font, Francesc; labrador }\end{array}$ & $\begin{array}{l}\text { Taradell } \\
\text { Olesa }\end{array}$ & $\begin{array}{l}1609 \\
1638\end{array}$ & $\begin{array}{l}\text { libro } 732 \\
\text { libro } 734\end{array}$ & $\begin{array}{l}\text { desterrado } \\
\text { reprendido }\end{array}$ \\
\hline $\begin{array}{l}\text { Galli, Joan; boticario } \\
\text { Garcia, Ángela } \\
\text { Grava, Brthelemy (f); cordelero } \\
\text { Gros, Joan; trajinero }\end{array}$ & $\begin{array}{l}\text { Baga } \\
\text { Barcelona } \\
\text { Barcelona } \\
\text { Montagudet }\end{array}$ & $\begin{array}{l}1617 \\
1582 \\
1635 \\
1573\end{array}$ & $\begin{array}{l}\text { libro } 732 \\
\text { libro } 730 \\
\text { libro } 733 \\
\text { libro } 737\end{array}$ & $\begin{array}{l}\text { reprendido } \\
\text { absuelta } \\
\text { reprendido } \\
\text { azotado }\end{array}$ \\
\hline Lamoros, Pierre (f) & Mataró & 1603 & libro 731 & reprendido \\
\hline Lluch, Joan; labrador & Falset & 1594 & libro 731 & multado \\
\hline $\begin{array}{l}\text { Masó, Ciprián; labrador } \\
\text { Mateu, Matali(f) } \\
\text { Mauri, Etienne (f) } \\
\text { Mayans, Nicolas (f); tejedor }\end{array}$ & $\begin{array}{l}\text { Besalú } \\
\text { Barcelona } \\
\text { Valls } \\
\text { Colomers }\end{array}$ & $\begin{array}{l}1629 \\
1603 \\
1697 \\
1600\end{array}$ & $\begin{array}{l}\text { libro } 733 \\
\text { libro } 731 \\
\text { libro } 760 \\
\text { libro } 731\end{array}$ & $\begin{array}{l}\text { desterrado } \\
\text { reprendido } \\
\text { desterrado } \\
\text { reprendido }\end{array}$ \\
\hline Nogués, Antoni; labrador & Reus & 1629 & libto 733 & multado \\
\hline $\begin{array}{l}\text { Passario, Antoine (f) } \\
\text { Piscin, Margarita (a) } \\
\text { Prim, Jaume } \\
\text { Rio, Antoine du (f); picapedrero } \\
\text { Rocamora, Antón; blanquero } \\
\text { Roger, Joan } \\
\text { Roget, Guillaume (f); labrador }\end{array}$ & $\begin{array}{l}\text { Barcelona } \\
\text { Seu d'Urgell } \\
\text { Borjas } \\
\text { Falset } \\
\text { Seu d'Urgell } \\
\text { Maçanet }\end{array}$ & $\begin{array}{l}1575 \\
1655 \\
1616 \\
1584 \\
1622 \\
1616 \\
1602\end{array}$ & $\begin{array}{l}\text { libro } 730 \\
\text { libro } 734 \\
\text { libro } 732 \\
\text { libro } 730 \\
\text { libro } 733 \\
\text { libro } 732 \\
\text { libro } 731\end{array}$ & $\begin{array}{l}\text { azotado } \\
\text { suspensa } \\
\text { reprendido } \\
\text { absuelto } \\
\text { reprendido } \\
\text { reprendido }\end{array}$ \\
\hline Salvador, Lluís; labrador & $\begin{array}{l}\text { Vilafranca del } \\
\text { Penedés }\end{array}$ & 1677 & libro 735 & desterrado \\
\hline $\begin{array}{l}\text { Seguens, Guillaume (f); tejedor } \\
\text { Sforçat, Montserrat (f); tejedor } \\
\text { Singles, Jaume; zapatero }\end{array}$ & $\begin{array}{l}\text { Barcelona } \\
\text { Centelles }\end{array}$ & $\begin{array}{l}1609 \\
1575 \\
1620\end{array}$ & $\begin{array}{l}\text { libro } 732 \\
\text { libro } 730 \\
\text { libro } 732\end{array}$ & $\begin{array}{l}\text { reprendido } \\
\text { absuelto } \\
\text { reprendido }\end{array}$ \\
\hline $\begin{array}{l}\text { Timo, Martín; labrador } \\
\text { Travi, Margarita }\end{array}$ & $\begin{array}{l}\text { Falset } \\
\text { Barcelona }\end{array}$ & $\begin{array}{l}1594 \\
1605\end{array}$ & $\begin{array}{l}\text { libro } 731 \\
\text { libro } 731\end{array}$ & $\begin{array}{l}\text { penitenciado } \\
\text { reprendida }\end{array}$ \\
\hline
\end{tabular}


JUAN BLÁZQUEZ MIGUEL

\begin{tabular}{llll}
\hline Apellidos y nombre; profesión & Localidad & Fecha Fuente & Sentencia \\
\hline $\begin{array}{l}\text { Apellidos y nombre; } \\
\text { orden religiosa }\end{array}$ & Localidad & Fecha Fuente & Sentencia \\
\hline
\end{tabular}

\section{SOLICITACIÓN}

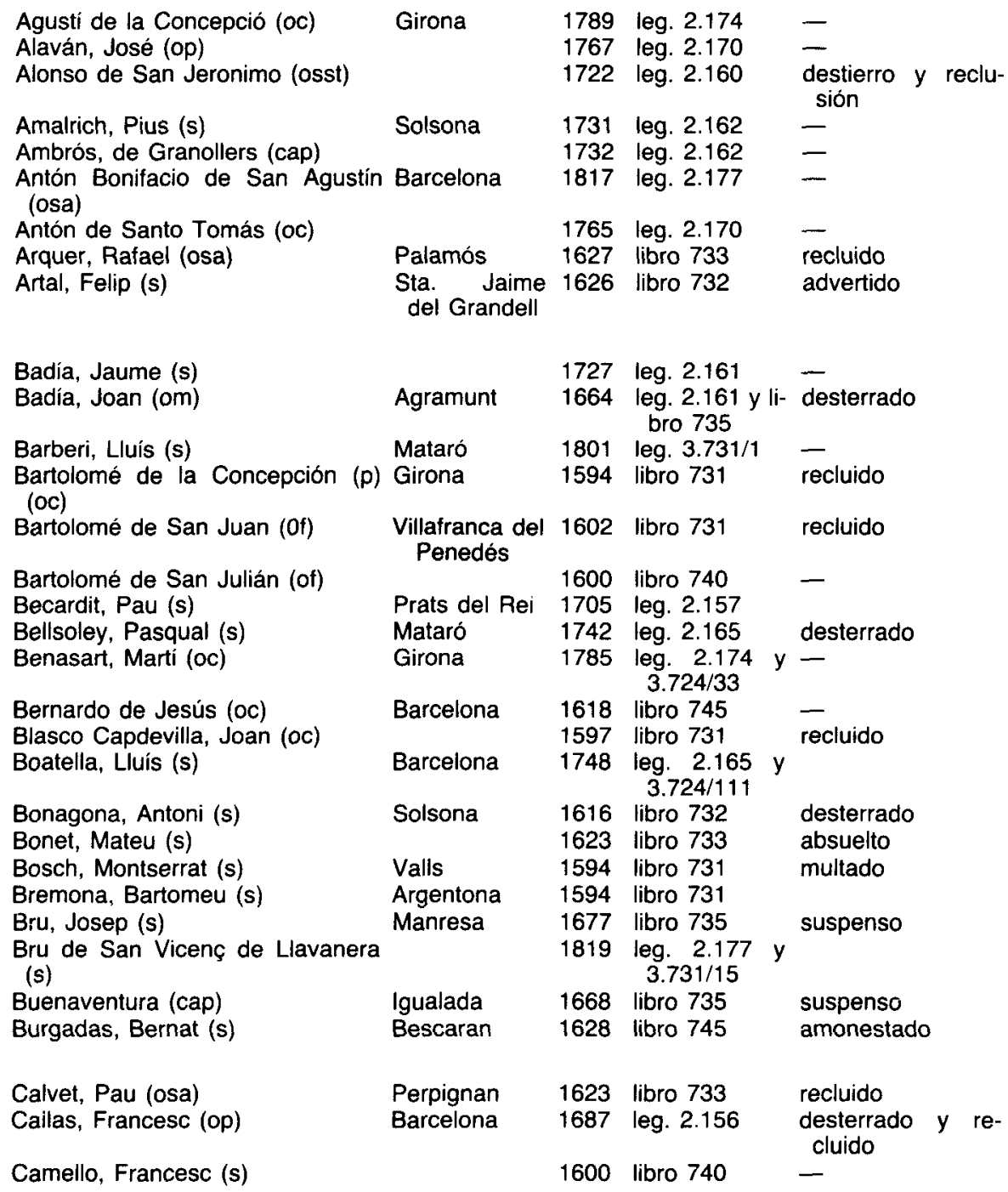


Catálogo de los procesos inquisitoriales del Tribunal del...

\begin{tabular}{|c|c|c|c|c|}
\hline $\begin{array}{l}\text { Apellidos y nombre; } \\
\text { orden religiosa }\end{array}$ & Localidad & Fecha & Fuente & Sentencia \\
\hline $\begin{array}{l}\text { Campany, Rafael (of) } \\
\text { Canti, Vicenç (osm) }\end{array}$ & Barcelona & $\begin{array}{l}1682 \\
1690\end{array}$ & $\begin{array}{l}\text { libro } 757 \\
\text { libro } 735\end{array}$ & $\begin{array}{l}\text { recluido } \\
\text { desterrado }\end{array}$ \\
\hline Cardedeu, Mateu de (cap) & Mataró & 1818 & $\begin{array}{l}\text { leg. } 2.177 \text { y } \\
3.721 / 207\end{array}$ & 一 \\
\hline Carrasco, Miquel (oc) & Mataró & 1779 & leg. $3.724 / 26$ & 一 \\
\hline $\begin{array}{l}\text { Casals, Miquel (of) } \\
\text { Ciurana, Josep (s) } \\
\text { Clarís, Francesc (s) } \\
\text { Crest, Domenec (osb) }\end{array}$ & $\begin{array}{l}\text { Girona } \\
\text { Gironella } \\
\text { St. Feliu de } \\
\text { Guixols }\end{array}$ & $\begin{array}{l}1722 \\
1791 \\
1617 \\
1817\end{array}$ & $\begin{array}{l}\text { leg. } 2.159 \\
\text { leg. } 3.131 / 10 \\
\text { libro } 732 \\
\text { leg. } 2.177 \text { y } \\
3.724 / 4\end{array}$ & absuelto \\
\hline Crexells, Montserrat (s) & $\begin{array}{l}\text { Sta. María de } \\
\text { Arenys }\end{array}$ & 1620 & libro 732 & reprendido \\
\hline Cristófol (op) & Tremp & 1626 & libro 744 & - \\
\hline Coll, Raimond (osst) & $\begin{array}{l}\text { Vilafranca de } \\
\text { Penedés }\end{array}$ & 1748 & leg. 2.165 & - \\
\hline Coll, Sebastiá (om) & Barcelona & 1759 & $\begin{array}{c}\text { leg. } 2.170 \text { y } \\
3.724 / 84\end{array}$ & - \\
\hline Comas, Francesc (s) & Montblanc & 1691 & libro 735 & 一 \\
\hline Comas, Joan (s) & Calonge & 1665 & libro 735 & suspenso \\
\hline Comellas, Jeroni (jer) & Manresa & 1633 & libro 746 & desterrado \\
\hline Corbera, Joan (op) & Barcelona & 1680 & libro 735 & suspenso \\
\hline Corominas, Josep (s) & Tartareu & 1768 & leg. 2.170 & - \\
\hline Corros, Miquel (oc) & Barcelona & 1597 & libro 740 & - \\
\hline Cosp, Francesc (s) & $\begin{array}{l}\text { St. Jaume de } \\
\text { Frontanya }\end{array}$ & 1746 & leg. 2.165 & - \\
\hline Custo, Gabriel (osa) & Puigcerdá & 1801 & $\begin{array}{l}\text { leg. } 2.177 \text { y } \\
3.731 / 5\end{array}$ & - \\
\hline Cuirama, Josep (of) & Girona & 1807 & leg. 2.177 & - \\
\hline Chavarria, Juan de (csb) & & 1638 & libro 734 & reprendido \\
\hline Dachs, Joan (op) & Barcelona & 1719 & leg. 2.158 & - \\
\hline Desvitar, Josep (s) & $\begin{array}{l}\text { St. Martí } \\
\text { Sacalm }\end{array}$ & 1763 & leg. 2.170 & - \\
\hline Domenech, Jaume (s) & Constantí & 1618 & libro 732 & desterrado \\
\hline Domenech, Vinvenç (s) & Blanes & 1593 & libro 731 & recluido \\
\hline Domingo de Jesús y María (oc) & $\begin{array}{l}\text { Vilanova de } \\
\text { Cubelles }\end{array}$ & 1782 & leg. 2.169 & - \\
\hline Doria, Narcis (s) & Arbucies & 1807 & $\begin{array}{c}\text { leg. } 2.177 y \\
3.726 / 1\end{array}$ & - \\
\hline Elías (op) & & 1595 & libro 740 & - \\
\hline Elías, Pere (s) & Barcelona & 1696 & libro 760 & desterrado \\
\hline Esbent, Gaspar (s) & Banyeres & 1718 & leg. 2.156 & $\begin{array}{l}\text { desterrado y } \\
\text { recluido }\end{array}$ \\
\hline Esteve, Jaume (s) & & 1594 & libro 731 & recluido \\
\hline Ester, Pere Joan (s) & Badalona & 1677 & libro 735 & suspenso \\
\hline Fages, Francesc (OC) & Vic & 1772 & $\begin{array}{c}\text { leg. } 2.169 \text { y } \\
3.724 / 10\end{array}$ & - \\
\hline Felipe de San José (osst) & Vic & 1735 & leg. 2.162 & - \\
\hline Félix de Santa Maria (oc) & Barcelona & 1764 & leg. 2.170 & - \\
\hline Fencanet, Francesc (s) & Bellver & 1674 & libro 735 & recluido \\
\hline Ferrán, Marius (s) & Barcelona & 1621 & libro 735 & - \\
\hline
\end{tabular}


JUAN BLÁZQUEZ MIGUEL

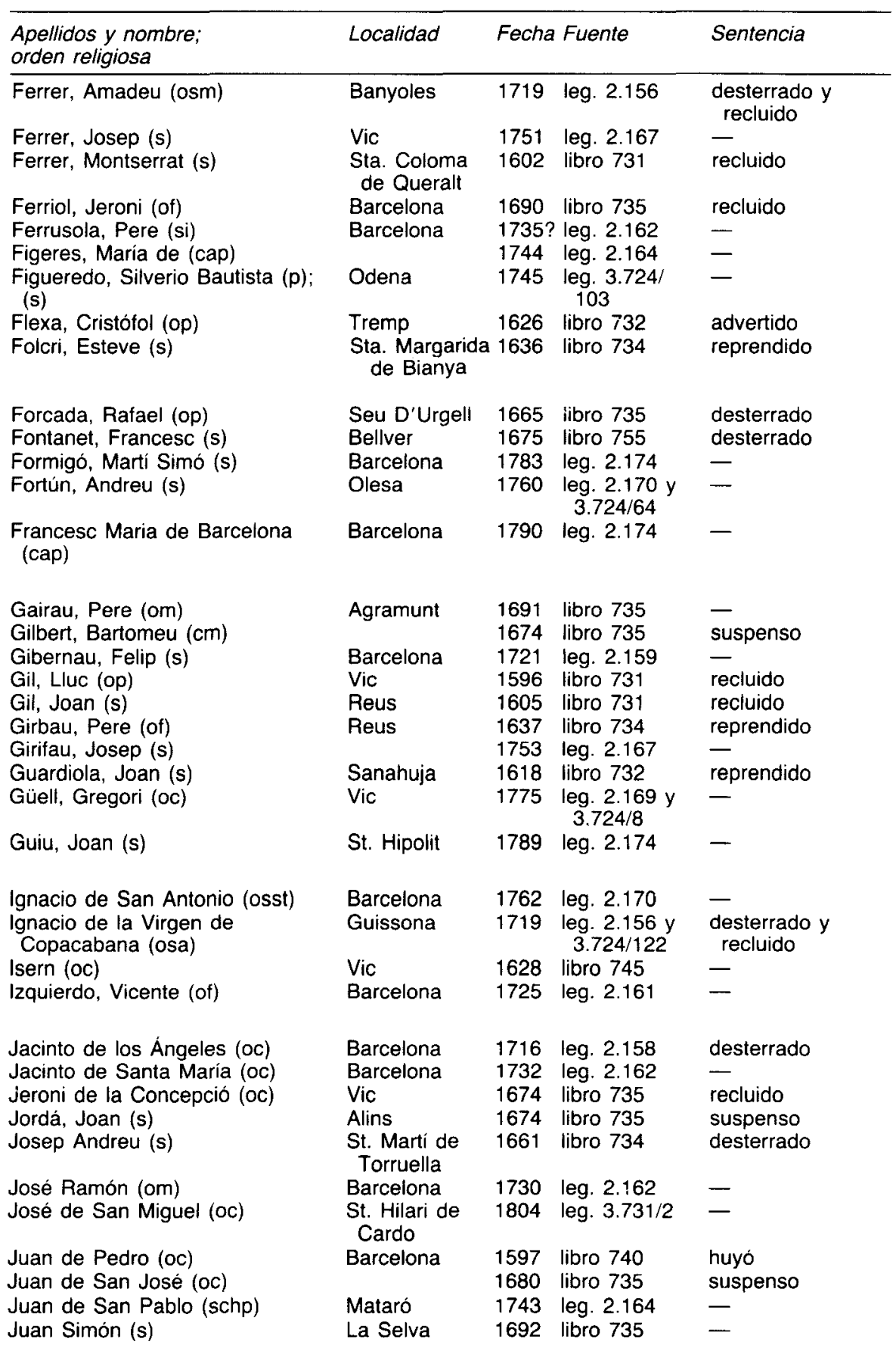


Catálogo de los procesos inquisitoriales del Tribunal del...

\begin{tabular}{|c|c|c|c|c|}
\hline $\begin{array}{l}\text { Apellidos y nombre; } \\
\text { orden religiosa }\end{array}$ & Localidad & Fecha & Fuente & Sentencia \\
\hline Juana, Vicente (jer) & $\begin{array}{l}\text { St. Jeroni de } \\
\text { Vall d'Ebron }\end{array}$ & 1818 & leg. 2.177 & - \\
\hline Lorenzo de Santa Bárbara (¿oc?) & & 1753 & leg. 2.167 & - \\
\hline Llanes, Jaume (s) & Perpignan & 1600 & libro 740 & - \\
\hline Lluch, Antoni (s) & $\begin{array}{l}\text { St. Miquel de } \\
\text { Vilar }\end{array}$ & 1675 & libro 735 & suspenso \\
\hline $\begin{array}{l}\text { Lluch, Miquel (s) } \\
\text { Llongard, Laurent (f); (s) }\end{array}$ & Riudoms & $\begin{array}{l}1618 \\
1621\end{array}$ & $\begin{array}{l}\text { libro } 732 \\
\text { libro } 733\end{array}$ & $\begin{array}{l}\text { desterrado } \\
\text { reprendido }\end{array}$ \\
\hline $\begin{array}{l}\text { Magrats, Antoni } \\
\text { March, Jaume (op) }\end{array}$ & Barcelona & $\begin{array}{l}1727 \\
1746\end{array}$ & $\begin{array}{l}\text { leg. } 2.161 \\
\text { leg. } 2.165 \text { y } \\
3.724 / 104\end{array}$ & - \\
\hline Mares i Serra, Domenec (s) & Vic & 1782 & $\begin{array}{c}\operatorname{leg} .2 .169 y \\
3.724 / 28\end{array}$ & - \\
\hline $\begin{array}{l}\text { Marqués, N. (of) } \\
\text { Martin, Francisco (of) }\end{array}$ & Barcelona & $\begin{array}{l}1666 \\
1664\end{array}$ & $\begin{array}{l}\text { libro } 735 \\
\text { leg. } 2.156\end{array}$ & suspenso \\
\hline Marral, Josep (of) & Reus & 1726 & leg. 2.161 & - \\
\hline Mas, Guillem (s) & Montreal & 1594 & libro 731 & recluido \\
\hline Mas, Josep (s) & $\begin{array}{l}\text { St. Agustí de } \\
\text { Lluçanes }\end{array}$ & 1690 & libro 735 & recluido \\
\hline Mas, Josep (of) & Cardona & 1764 & leg. 2.170 & \\
\hline Mascaró, Antoni (op) & Vic & 1794 & $\begin{array}{c}\operatorname{leg} .2 .174 \text { y } \\
3.724 / 41\end{array}$ & \\
\hline Masina, Vicent (f); (s) & & 1633 & libro 746 & multado \\
\hline Medina, Gabriel (of) & Cervera & 1597 & libro 731 & recluido \\
\hline Miguel de los Ángeles (s) & Moya & 1727 & leg. 2.161 & - \\
\hline Miro, Ignaçi (si) & Barcelona & 1734 & leg. 2.162 & - \\
\hline Modesto (cap) & Mataró & 1734 & leg. 2.162 & - \\
\hline Monfar, Josep (s) & Barcelona & 1721 & leg. 2.159 & $\begin{array}{l}\text { desterrado y } \\
\text { recluido }\end{array}$ \\
\hline Montero, Francisco (si) & Girona & 1765 & leg. 2.170 & - \\
\hline Montserrat, Oleguer (s) & Tarragona & 1676 & libro 735 & suspenso \\
\hline Mateo de San Lorenzo (oc) & Barcelona & 1686 & libro 758 & - \\
\hline Murtra, Francesc (s) & Montblanc & 1676 & libro 756 & 一 \\
\hline N., Amadeu (osm) & Banyoles & 1718 & $\begin{array}{c}\operatorname{leg} .2 .158 y \\
3.724 / 120\end{array}$ & - \\
\hline N., Mateu (cap) & $\begin{array}{l}\text { Sta. Eulalia } \\
\text { de Sarriá }\end{array}$ & 1817 & leg. 2.177 & - \\
\hline Narcís de Santa Teresa (oc) & Mataró & 1762 & leg. 2.170 & - \\
\hline Nogues, Josep (s) & Barcelona & 1742 & $\operatorname{leg} .2 .164$ & - \\
\hline Olivarte, Bernat (of) & Montblanc & 1598 & libro 731 & recluido \\
\hline Oliver, Carles (si) & Vic & 1680 & libro 735 & suspenso \\
\hline Pau, Feliu (of) & Tarragona & 1691 & libro 735 & - \\
\hline Pablo de San Matías (oc) & Reus & 1768 & leg. 2.170 & - \\
\hline Pablo de Santa Gertrudis (oc) & Mataró & 1790 & $\begin{array}{l}\text { leg. } 2.174 \text { y } \\
3.724 / 38\end{array}$ & - \\
\hline Palau, Joan (s) & Organya & 1675 & libro 735 & suspenso \\
\hline Paradell, Lluis (op) & Barcelona & 1666 & libro 735 & recluido \\
\hline
\end{tabular}


JUAN BLAZQUEZ MIGUEL

\begin{tabular}{|c|c|c|c|c|}
\hline $\begin{array}{l}\text { Apellidos y nombre; } \\
\text { orden religiosa }\end{array}$ & Localidad & Fecha & Fuente & Sentencia \\
\hline $\begin{array}{l}\text { Pierre Julien (f); (omi) } \\
\text { Pedrolo, Joan (oc) }\end{array}$ & Barcelona & $\begin{array}{l}1691 \\
1598\end{array}$ & $\begin{array}{l}\text { libro } 735 \\
\text { libro } 731\end{array}$ & $\begin{array}{l}\text { desterrado } \\
\text { recluido }\end{array}$ \\
\hline Peguera, Isidre (s) & Vilaplana & 1721 & leg. 2.159 & - \\
\hline Pelegrín de Santa Teresa $(\mathrm{oc})$ & Vic & 1818 & $\begin{array}{l}\text { leg. } 2.177 \text { y } \\
3.721 / 216\end{array}$ & - \\
\hline Pellicer, Jeroni Llorenç (osst) & Barcelona & 1687 & leg. 2.156 & $\begin{array}{l}\text { desterrado y } \\
\text { recluido }\end{array}$ \\
\hline Pineda, Francesc (of) & Barcelona & 1687 & leg. 2.156 & $\begin{array}{l}\text { desterrado y } \\
\text { recluido }\end{array}$ \\
\hline Planas, Dionis (s) & & 1790 & leg. 2.174 & - \\
\hline Planas, Francesc (s) & & 1770 & leg. 2.174 & - \\
\hline Pons, Carles (s) & Girona & 1815 & $\begin{array}{c}\text { leg. } 2.177 \text { y } \\
3.722 / 93\end{array}$ & - \\
\hline Pons, Josep (oc) & & 1799 & leg. 2.174 & - \\
\hline Prats, Antoni (s) & Peramea & 1797 & leg. $3.727 / 3$ & - \\
\hline Prats, Josep (omi) & Cervera & 1783 & leg. 2.174 & - \\
\hline Prats, Manuel (osb) & Besalú & 1744 & leg. 2.164 & - \\
\hline $\begin{array}{l}\text { Prim, Joan (s) } \\
\text { Pruenca, Ignaçi (osa) }\end{array}$ & $\begin{array}{l}\text { Verdú } \\
\text { Palamós }\end{array}$ & $\begin{array}{l}1688 \\
1817\end{array}$ & $\begin{array}{l}\text { libro } 735 \\
\text { leg. } 2.177 \text { y } \\
3.721 / 219\end{array}$ & desterrado \\
\hline Prunet, Josep (of) & $\begin{array}{l}\text { Castello } \\
\text { d'Empuries }\end{array}$ & 1687 & libro 758 & $\begin{array}{l}\text { desterrado y } \\
\text { recluido }\end{array}$ \\
\hline $\begin{array}{l}\text { Puig, Jaume (of) } \\
\text { Puigagut, Antoni (s) }\end{array}$ & $\begin{array}{l}\text { Riudoms } \\
\text { Darnius }\end{array}$ & $\begin{array}{l}1694 \\
1761\end{array}$ & $\begin{array}{l}\text { libro } 760 \\
\text { leg. } 2.170 \text { y } \\
3.724 / 59\end{array}$ & $\overline{-}$ \\
\hline Pujol, Jaume (s) & Montseny & 1677 & libro 735 & desterrado \\
\hline Raimond de Santa Suna (s) & & 1668 & libro 735 & suspenso \\
\hline Ramón de Santa Magdalena (oc) & Vic & 1780 & $\begin{array}{l}\text { leg. } 2.169 \text { y } \\
3.724 / 19\end{array}$ & - \\
\hline $\begin{array}{l}\text { Ramoneda, Esteve (com) } \\
\text { Ranes, Dionis (s) }\end{array}$ & Barcelona & $\begin{array}{l}1696 \\
1789\end{array}$ & $\begin{array}{l}\text { libro } 760 \\
\text { leg. } 2.174\end{array}$ & - \\
\hline Ribas, Joan (s) & Barcelona & 1591 & libro 731 & recluido \\
\hline Ribas, Pau (of) & & 1736 & leg. 2.164 & - \\
\hline Ribot, Mateu (of) & Escornalbou & 1767 & leg. 2.170 & - \\
\hline Roca, Antoni (osst) & Barcelona & 1797 & leg. 2.174 & - \\
\hline Roger, Miquel Joan (s) & Riudecanyes & 1605 & libro 731 & recluido \\
\hline Roger, Tomás (osst) & Riudecanyes & 1716 & leg. 2.158 & $\begin{array}{l}\text { desterrado y } \\
\text { recluido }\end{array}$ \\
\hline $\begin{array}{l}\text { Romeu, Alons Bartomeu (s) } \\
\text { Roma, Francesc (of) }\end{array}$ & Ager & $\begin{array}{l}1639 \\
1791\end{array}$ & $\begin{array}{l}\text { libro } 734 \\
\text { leg. } 2.174 \text { y } \\
3.724 / 42\end{array}$ & - \\
\hline $\begin{array}{l}\text { Rovira, Buenaventura (of) } \\
\text { Rovira, Joan (s) }\end{array}$ & $\begin{array}{l}\text { Sta Jaume de } \\
\text { Calaf }\end{array}$ & $\begin{array}{l}1736 \\
1667\end{array}$ & $\begin{array}{l}\text { leg. } 2.164 \\
\text { libro } 735\end{array}$ & suspenso \\
\hline Sayas (cm) & $\begin{array}{l}\text { St. Hilari de } \\
\text { Cardós }\end{array}$ & 1600 & libro 740 & - \\
\hline $\begin{array}{l}\text { Serra, Jeromi (s) } \\
\text { Silvestre, Antoni (s) }\end{array}$ & $\begin{array}{l}\text { Barcelona } \\
\text { Barcelona }\end{array}$ & $\begin{array}{l}1762 \\
1777\end{array}$ & $\begin{array}{l}\text { leg. } 2.170 \\
\text { leg. } 2.169 \mathrm{y} \\
3.724 / 14\end{array}$ & 二 \\
\hline Soldevilla, Joan (s) & Fores & 1637 & libro 734 & - \\
\hline Tallander, LLorenç & Miralles & 1705 & leg. 2.157 & - \\
\hline
\end{tabular}


Catálogo de los procesos inquisitoriales del Tribunal del...

\begin{tabular}{|c|c|c|c|c|}
\hline $\begin{array}{l}\text { Apellidos y nombre; } \\
\text { orden religiosa }\end{array}$ & Localidad & Feche & Fuente & Sentencia \\
\hline Tomás de San Antonio (oc) & & 1782 & leg. 2.169 & - \\
\hline Torrens, Gaspar & Valis & 1594 & libro 731 & recluido \\
\hline Torrens, Jean (f); (s) & Samalus & 1636 & libro 734 & multado \\
\hline Torres, Francesc de (osb) & $\begin{array}{l}\text { St. Pere de } \\
\text { la Portela }\end{array}$ & 1691 & libro 735 & - \\
\hline Torruguet, Buenaventura (s) & Barcelona & 1762 & $\operatorname{leg} .2 .170$ & - \\
\hline Vagen, Sebastià (s) & Montmagastre & 1627 & libro 733 & reprendido \\
\hline Valero, Gabriel (s) & & 1609 & libro 732 & recluido \\
\hline Valpalleras, Montserrat (of) & Perpignan & 1622 & libro 733 & falleció \\
\hline Vall, Esteve (of) & Girona & 1638 & libro 734 & suspenso \\
\hline Valls, Joan (s) & Santpedor & 1731 & leg. 2.162 & recluido \\
\hline Vidal (cap) & Barcelona & 1815 & leg. 2.177 & \\
\hline Vidal, Albert (oc) & Barcelona & 1633 & libro 733 & suspenso \\
\hline Vidal, Damià (s) & Vendrell & 1623 & libro 733 & suspenso \\
\hline Vidal, Francesc Vicenç & Tarragona & 1636 & libro 734 & absuelto \\
\hline Vila, Francesc (s) & $\begin{array}{l}\text { St. Joan de } \\
\text { les } \\
\text { Abadesses }\end{array}$ & 1758 & leg. 2.170 & desterrado \\
\hline Vilar, Joan (s) & Cantallops & 1762 & leg. $3.724 / 78$ & - \\
\hline Vilar, Ramón (of?) & Barcelona & 1759 & leg. $3.724 / 65$ & - \\
\hline Villanova, Gaspar de (osa) & Perpignan & 1617 & libro 732 & recluido \\
\hline Vives, Bastasar (s) & Tremp & 1595 & libro 740 & - \\
\hline Vives, Joan (s) & Valls & 1617 & libro 732 & suspenso \\
\hline
\end{tabular}

Apellidos y nombre; profesión Localidad Fecha Fuente Sentencia

\section{SODOMIA}

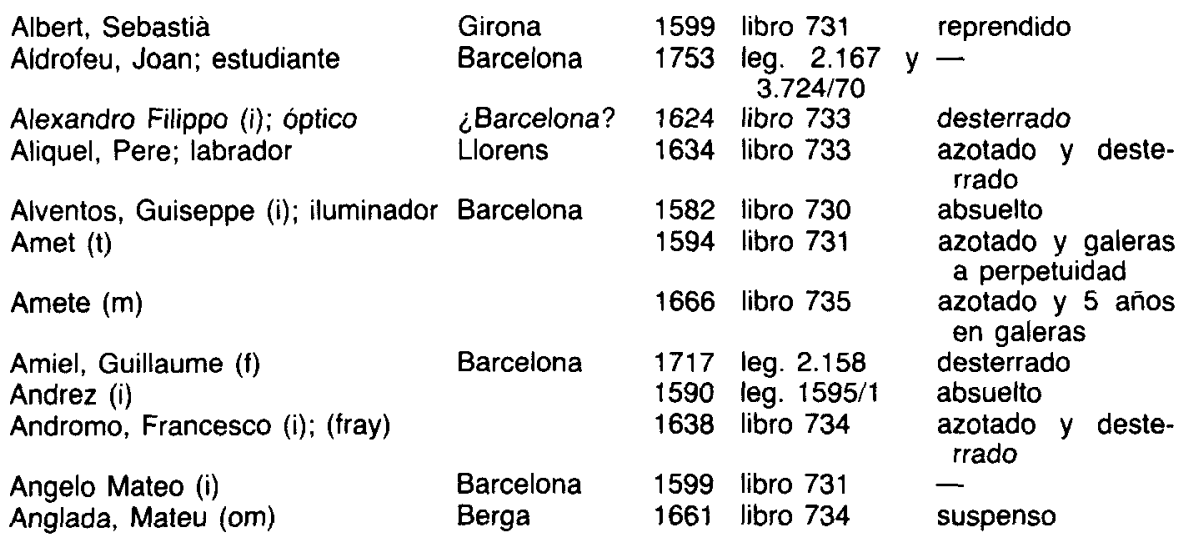


JUAN BLAZZQUEZ MIGUEL

\begin{tabular}{|c|c|c|c|c|}
\hline Apellidos y nombre; profesión & Localidad & Fecha & Fuente & Sentencia \\
\hline $\begin{array}{l}\text { Antigo, Joan (s) } \\
\text { Antonio Dionisio (i); galeote }\end{array}$ & Llinars & $\begin{array}{l}1635 \\
1610\end{array}$ & $\begin{array}{l}\text { libro } 733 \\
\text { libro } 732\end{array}$ & $\begin{array}{l}\text { recluido } \\
\text { azotado y } 8 \text { años } \\
\text { en galeras }\end{array}$ \\
\hline Antón Luis & $\begin{array}{l}\text { Sta. Coloma } \\
\text { de Queralt }\end{array}$ & 1575 & libro 730 & $\begin{array}{l}\text { azotado y deste- } \\
\text { rrado }\end{array}$ \\
\hline Ardobin, Guiovanni (i) & 1626 & & libro 732 & suspenso \\
\hline $\begin{array}{l}\text { Arlenga, Dominique (f) } \\
\text { Armandans, Pere }\end{array}$ & Tona & $\begin{array}{l}1605 \\
1614\end{array}$ & $\begin{array}{l}\text { libro } 731 \\
\text { libro } 732\end{array}$ & $\overline{\text { falleció }}$ \\
\hline Arrieta, Rafael; militar & & 1753 & leg. 2.167 & \\
\hline Astor, Antoni Joan (s) & Barcelona & 1614 & libro 732 & $\begin{array}{l}\text { azotado y } 5 \text { años } \\
\text { en galeras }\end{array}$ \\
\hline Augustinum & & 1546 & leg. 2.158 & - \\
\hline Baco, Raymond (f); jubonero & & 1562 & libro 730 & $\begin{array}{l}\text { azotado y deste- } \\
\text { rrado }\end{array}$ \\
\hline $\begin{array}{l}\text { Balles, Lluís; estudiante } \\
\text { Bartolomé Guiseppe (i) }\end{array}$ & Rupiá & $\begin{array}{l}1598 \\
1718\end{array}$ & $\begin{array}{l}\text { libro } 731 \\
\text { leg. } 2.156\end{array}$ & $\begin{array}{l}\text { desterrado } \\
\text { suspenso }\end{array}$ \\
\hline $\begin{array}{l}\text { Barrera, Pierre }(f) \\
\text { Baxa, Joan }\end{array}$ & Vallés & $\begin{array}{l}1581 \\
1570\end{array}$ & $\begin{array}{l}\text { libro } 730 \\
\text { libro } 730\end{array}$ & $\begin{array}{l}\text { falleció } \\
\text { absuelto }\end{array}$ \\
\hline Benvenuto, Nicola (i); militar & & 1662 & libro 734 & desterrado \\
\hline Berniola, Joan; mesonero & Agramunt & 1599 & libro 731 & $\begin{array}{l}\text { azotado y } 3 \text { años } \\
\text { en galeras }\end{array}$ \\
\hline Biso, Jacobo (i); sedero & & 1624 & libro 733 & $\begin{array}{l}\text { suspenso } \\
\text { recluido }\end{array}$ \\
\hline $\begin{array}{l}\text { Blasco Capdevila, Joan (oc) } \\
\text { Bonafe, Robert (f); serrador }\end{array}$ & & $\begin{array}{l}1597 \\
1578\end{array}$ & $\begin{array}{l}\text { libro } 731 \\
\text { libro } 730\end{array}$ & $\begin{array}{l}\text { recluido } \\
\text { azotado y galeras } \\
\text { a perpetuidad }\end{array}$ \\
\hline Bosch, Pierre (f); labrador & $\begin{array}{l}\text { Sta. Andreu } \\
\text { Palomars }\end{array}$ & 1578 & libro 730 & absuelto \\
\hline $\begin{array}{l}\text { Bossio, Joao }(p) \text {; herrero } \\
\text { Bover, Pau }\end{array}$ & Barcelona & 1639 & libro 734 & - \\
\hline Bregalo, Jeroni & & 1667 & libro 735 & $\begin{array}{l}\text { adsueto } \\
\text { suspenso }\end{array}$ \\
\hline Bros, Jacques (f); criado & Barcelona & 1575 & libro 730 & absuelto \\
\hline Burnete, Joan (s) & Moya & 1578 & libro 730 & - \\
\hline Buxonada, Antoni Pere Joan & Martorell & 1614 & libro 732 & reprendido \\
\hline Buracio, Antonio (i) & & 1670 & libro 754 & $\begin{array}{l}\text { azotado y } 3 \text { años } \\
\text { galeras }\end{array}$ \\
\hline Cabañer, Mateo (i) & Barcelona & 1603 & libro 731 & $\begin{array}{l}\text { azotado y } 3 \text { años } \\
\text { en galeras }\end{array}$ \\
\hline Caminadas, María & Barcelona & 1661 & libro 734 & suspensa \\
\hline Cambonias, Francesc; maestro & & 1590 & libro 731 & $\begin{array}{l}\text { azotado y } 7 \text { años } \\
\text { en galeras }\end{array}$ \\
\hline Campos, Antonio; militar & Barcelona & 1738 & $\begin{array}{l}\text { leg. } 2.164 \\
3.724 / 147\end{array}$ & $1-$ \\
\hline Canela, Jean (f) & & 1629 & libro 745 & - \\
\hline Carreres, Bartomeu; pintor & Barcelona & 1578 & & absuelto \\
\hline Casas, Bernat; polvorista & & 1575 & libro 730 & azotado y galeras \\
\hline Castellar, Gabriel, n & & 1623 & libro 733 & $\begin{array}{l}\text { azotado y } 7 \text { años } \\
\text { en galeras }\end{array}$ \\
\hline $\begin{array}{l}\text { Cesirach, Carmel (f); labrador } \\
\text { Cola, Francesco (i) }\end{array}$ & Premiá & $\begin{array}{l}1622 \\
1718\end{array}$ & $\begin{array}{l}\text { libro } 733 \\
\text { leg. } 2.156\end{array}$ & suspenso \\
\hline $\begin{array}{l}\text { Coll, Feliu } \\
\text { Collel, Guillem; galeote }\end{array}$ & Barcelona & 1750 & leg. 2.165 & - \\
\hline Collel, Guillem; galeote & & 1610 & libro 732 & $\begin{array}{l}\text { azotado y } 4 \text { años } \\
\text { en galeras }\end{array}$ \\
\hline Coma, Gabriel; comerciante & Manresa & 1626 & libro 733 & suspenso \\
\hline
\end{tabular}


Catálogo de los procesos inquisitoriales del Tribunal del...

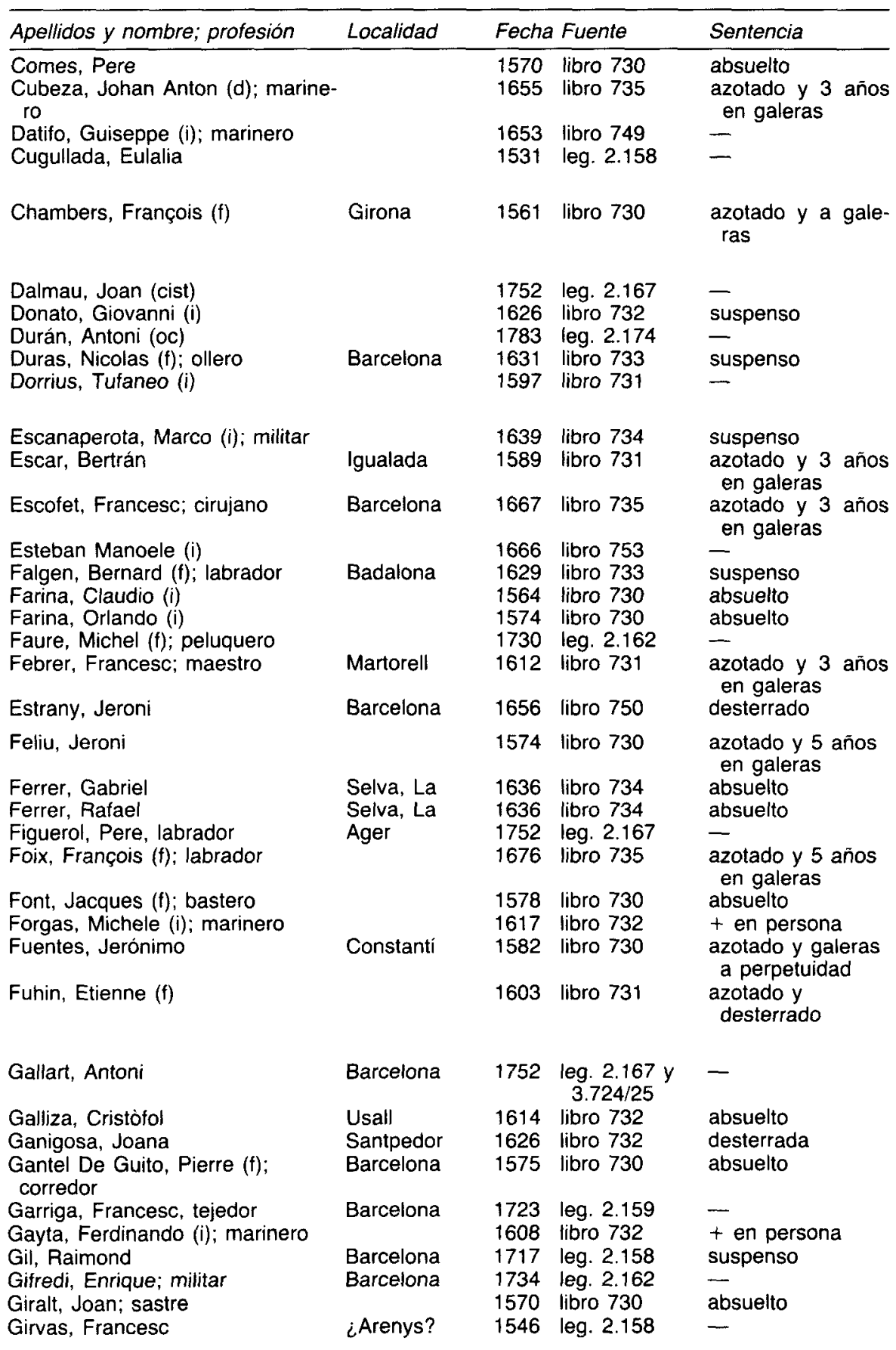


JUAN BLÁZQUEZ MIGUEL

\begin{tabular}{|c|c|c|c|c|}
\hline Apellidos y nombre; profesión & Localidad & Fecha & Fuente & Sentencia \\
\hline $\begin{array}{l}\text { Galeoto, Pietro (i); militar } \\
\text { Guiseppe (i); militar } \\
\text { Guiovanni Antonio (i); galeote } \\
\text { Guiseppe Albentos (i); iluminador } \\
\text { Gozana, Bertrand (f); labrador } \\
\text { Grau, Miquel (of) }\end{array}$ & $\begin{array}{l}\text { Arenys } \\
\text { Barcelona } \\
\text { Barcelona } \\
\text { Terrassa }\end{array}$ & $\begin{array}{l}1655 \\
1633 \\
1653 \\
1581 \\
1629 \\
1695\end{array}$ & $\begin{array}{l}\text { libro } 750 \\
\text { libro } 733 \\
\text { libro } 749 \\
\text { libro } 730 \\
\text { libro } 733 \\
\text { libro } 760\end{array}$ & $\begin{array}{l}\text { desterrado } \\
- \\
\overline{-} \\
\text { suspenso } \\
\text { azotado y } 3 \text { años } \\
\text { en galeras }\end{array}$ \\
\hline Huguet, Antoine (f) & Girona & 1560 & libro 730 & - \\
\hline $\begin{array}{l}\text { Jasse, Jacques (fl); cantante } \\
\text { Jaume de la Concepciò (osst) } \\
\text { Jean Robert (f); molinero }\end{array}$ & $\begin{array}{l}\text { Vullpellac } \\
\text { Barcelona }\end{array}$ & $\begin{array}{l}1575 \\
1752\end{array}$ & $\begin{array}{l}\text { libro } 730 \\
\text { leg. } 2.167 \\
\text { libro } 731\end{array}$ & $\begin{array}{l}\text { falleció } \\
\text { azotado y } 5 \text { años } \\
\text { en galeras }\end{array}$ \\
\hline $\begin{array}{l}\text { Jerez, Pedro de } \\
\text { Joan }(m) ;(\text { esclavo) }\end{array}$ & Barcelona & $\begin{array}{l}1562 \\
1575\end{array}$ & $\begin{array}{l}\text { libro } 730 \\
\text { libro } 730\end{array}$ & $\begin{array}{l}\text { absuelto } \\
\text { azotado y galeras } \\
\text { a perpetuidad }\end{array}$ \\
\hline $\begin{array}{l}\text { Juan Andrés; cordelero } \\
\text { Jorda, Onofre } \\
\text { Guiovanni Antonio Dionisio (i); } \\
\text { galeote }\end{array}$ & Barcelona & $\begin{array}{l}1639 \\
1550 \\
1610\end{array}$ & $\begin{array}{l}\text { libro } 734 \\
\text { libro } 736 \\
\text { libro } 732\end{array}$ & $\begin{array}{l}- \\
\text { azotado y } 8 \text { años } \\
\text { en galeras }\end{array}$ \\
\hline $\begin{array}{l}\text { Guiovanni Battista (i); marinero } \\
\text { Guiovanni Emmanuele (i); galeote }\end{array}$ & & $\begin{array}{l}1564 \\
1666\end{array}$ & $\begin{array}{l}\text { libro } 730 \\
\text { libro } 735\end{array}$ & $\begin{array}{l}\text { absuelto } \\
\text { azotado y } 5 \text { años } \\
\text { en galeras }\end{array}$ \\
\hline $\begin{array}{l}\text { Labrador, Isidre (s) } \\
\text { Londia, Antoine (f); criado }\end{array}$ & $\begin{array}{l}\text { Tarragona } \\
\text { Tarragona }\end{array}$ & $\begin{array}{l}1740 \\
1575\end{array}$ & $\begin{array}{l}\text { leg. } 2.164 \\
\text { libro } 730\end{array}$ & $\begin{array}{l}\text { - } \\
\text { azotes y galeras a }\end{array}$ \\
\hline $\begin{array}{l}\text { Lucas, Vicenç; estudiante } \\
\text { Llarurador, Ignasi (s) }\end{array}$ & $\begin{array}{l}\text { Barcelona } \\
\text { Tarragona }\end{array}$ & $\begin{array}{l}1606 \\
1739\end{array}$ & $\begin{array}{l}\text { libro } 732 \\
\text { leg. } 3.724 / \\
137 \text { y } 140\end{array}$ & huyó \\
\hline $\begin{array}{l}\text { Lledó, Felip (¿oc?) } \\
\text { Lledó, Miquel de (cist) } \\
\text { Lleón, Antoni (er) }\end{array}$ & $\begin{array}{l}\text { Stes. Creus } \\
\text { Valls de } \\
\text { Molins }\end{array}$ & $\begin{array}{l}1535 \\
1753 \\
1608\end{array}$ & $\begin{array}{l}\text { leg. } 2.158 \\
\text { leg. } 2167 \\
\text { libro } 732\end{array}$ & $\begin{array}{l}\text { - en persona } \\
+ \text { en persona }\end{array}$ \\
\hline Malavava, Alons; marinero & Palamós & 1582 & libro 730 & $\begin{array}{l}\text { azotado y galeras } \\
\text { a perpetuidad }\end{array}$ \\
\hline $\begin{array}{l}\text { Mairech, Guillaume (f) } \\
\text { Mañas, José; militar }\end{array}$ & & $\begin{array}{l}1575 \\
1723\end{array}$ & $\begin{array}{l}\text { libro } 731 \\
\text { leg. } 2.159\end{array}$ & - \\
\hline $\begin{array}{l}\text { Marco, Andrea (i); pescador } \\
\text { Marco, Juan Bautista (osm) } \\
\text { Marello, Pietro Antonio (i) } \\
\text { Marquez, Ascanio (i); militar } \\
\text { Martí, Pau }\end{array}$ & Tarragona & $\begin{array}{l}1617 \\
1675 \\
1598 \\
1615 \\
1575\end{array}$ & $\begin{array}{l}\text { libro } 732 \\
\text { libro } 735 \\
\text { libro } 731 \\
\text { libro } 732 \\
\text { libro } 730\end{array}$ & $\begin{array}{l}\text { desterrado } \\
\text { suspenso } \\
\text { recluido } \\
\text { reprendido } \\
\text { azotado y } \\
\text { desterrado }\end{array}$ \\
\hline Martín, Juan & Tarragona & 1584 & libro 730 & $\begin{array}{l}\text { azotado y galeras } \\
\text { a perpetuidad }\end{array}$ \\
\hline $\begin{array}{l}\text { Martín, Valentino (ma); (s) } \\
\text { Mas, Etienne (f) }\end{array}$ & Barcelona & $\begin{array}{l}1561 \\
1562\end{array}$ & $\begin{array}{l}\text { libro } 730 \\
\text { libro } 730\end{array}$ & $\begin{array}{l}\text { azotado y recluido } \\
\text { azotado y } \\
\text { desterrado }\end{array}$ \\
\hline $\begin{array}{l}\text { Maymón, Pere } \\
\text { Medigar, Bernard (f); albañil }\end{array}$ & Granollers & $\begin{array}{l}1614 \\
1662\end{array}$ & $\begin{array}{l}\text { libro } 732 \\
\text { libro } 734\end{array}$ & $\begin{array}{l}\text { absuelto } \\
\text { desterrado }\end{array}$ \\
\hline
\end{tabular}


Catálogo de los procesos inquisitoriales del Tribunal del...

\begin{tabular}{|c|c|c|c|c|}
\hline \multirow{2}{*}{$\frac{\text { Apellidos y nombre; profesión }}{\text { Miguel de Santa María }(p) ;(o s a)}$} & \multirow[t]{2}{*}{ Localidad } & \multicolumn{2}{|c|}{ Fecha Fuente } & \multirow{2}{*}{ 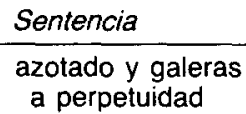 } \\
\hline & & 1571 & libro 730 & \\
\hline Millas, Joan & Barcelona & 1660 & libro 731 & penitenciado \\
\hline Molero, Mateu (s) & Girona & 1571 & libro 730 & penitenciado \\
\hline Monsar de Liñola, Joan & & 1552 & libro 730 & $\begin{array}{l}\text { azotado y a } \\
\text { galeras }\end{array}$ \\
\hline Mont, Jean du (f) & & 1629 & libro 745 & - \\
\hline Montorio, Battista (i); marinero & & 1614 & libro 732 & $\begin{array}{l}\text { azotado y } 5 \text { años } \\
\text { en galeras }\end{array}$ \\
\hline $\begin{array}{l}\text { Morell, Battista Vicente (i); } \\
\text { galeote }\end{array}$ & & 1601 & libro 740 & $\begin{array}{l}\text { azotado y } 6 \text { años } \\
\text { en galeras }\end{array}$ \\
\hline Mustafá, Yusuf (m); esclavo & & 1656 & libro 750 & - \\
\hline Navarro, Juan & & 1569 & libro 730 & absuelto \\
\hline Navarro, Pedro & Barcelona & 1588 & libro 731 & $\begin{array}{l}\text { azotado y } 7 \text { años } \\
\text { en galeras }\end{array}$ \\
\hline Orio, Tufonio di (i); cirujano & & 1595 & libro 731 & huyó \\
\hline Pages, Lluis; pastor & Catllar & 1682 & libro 735 & falleció \\
\hline Parisi, Giovanni (i); zapatero & Barcelona & 1667 & libro 735 & suspenso \\
\hline $\begin{array}{l}\text { Parmesano, Guiseppe (i); } \\
\text { marinero }\end{array}$ & & 1617 & libro 732 & + en persona \\
\hline Pedrola, Joan de (oc) & & 1597 & libro 731 & - \\
\hline Pelens, Jean (f); (s) & & 1569 & libro 730 & absuelto \\
\hline Pérez de Ucra, Agustín (s) & Barcelona & 1661 & libro 734 & absuelto \\
\hline Pérez Antón, José & & 1560 & libro 730 & $-\infty$ \\
\hline Pérez, Sebastián, maestro & & 1604 & libro 731 & - \\
\hline Pericás, Benet & Barcelona & 1575 & libro 730 & absuelto \\
\hline Perola, Raphael (f) & & 1583 & libro 730 & $\begin{array}{l}\text { azotado y } 3 \text { años } \\
\text { en galeras }\end{array}$ \\
\hline Pers, Antoni & & 1560 & libro 730 & - \\
\hline $\begin{array}{l}\text { Pertigal, Giulio (i); hornero } \\
\text { Piedra, Jean Antoine }(f) \text {; } \\
\text { panadero }\end{array}$ & $\begin{array}{l}\text { Barcelona } \\
\text { Perpignan }\end{array}$ & $\begin{array}{l}1583 \\
1575\end{array}$ & $\begin{array}{l}\text { libro } 730 \\
\text { libro } 730\end{array}$ & $\begin{array}{l}\text { desterrado } \\
\text { absuelto }\end{array}$ \\
\hline Pineda, Domenec & Taradell & 1790 & leg. 2.174 & - \\
\hline Perruca, Giovanni Pietro (i) & & 1696 & & - \\
\hline Plana, Joan; comerciante & Barcelona & 1749 & $\begin{array}{l}\text { leg. } 2.165 y \\
3.724 / 96\end{array}$ & - \\
\hline $\begin{array}{l}\text { Planes, Gaspar } \\
\text { Planya, Pierre (f); albañil }\end{array}$ & Girona & $\begin{array}{l}1619 \\
1564\end{array}$ & $\begin{array}{l}\text { libro } 732 \\
\text { libro } 730\end{array}$ & $\begin{array}{l}\text { reprendido } \\
\text { absuelto }\end{array}$ \\
\hline Portas, Antic; labrador & & 1781 & libro 730 & $\begin{array}{l}\text { azotado y } 8 \text { años } \\
\text { en galeras }\end{array}$ \\
\hline Pujol, Baltasar (s) & & 1533 & leg. 2.158 & - \\
\hline Raguseo, Bertrán & & 1570 & libro 730 & $\begin{array}{l}\text { azotado y } 10 \text { años } \\
\text { en galeras }\end{array}$ \\
\hline Ramirez, Alejo; tejedor & & 1599 & libro 731 & $\begin{array}{l}\text { azotado y } 7 \text { años } \\
\text { en galeras }\end{array}$ \\
\hline Ramirez, Cristóbal & & 1624 & libro 733 & suspenso \\
\hline Ratto, Antonio (i); terciopelero & Barcelona & 1591 & libro 731 & $\begin{array}{l}\text { azotado y } \\
\text { desterrado }\end{array}$ \\
\hline Reyes, Juan de los (osst) & Barcelona & 1752 & leg. 2167 & - \\
\hline
\end{tabular}


JUAN BLÁZQUEZ MIGUEL

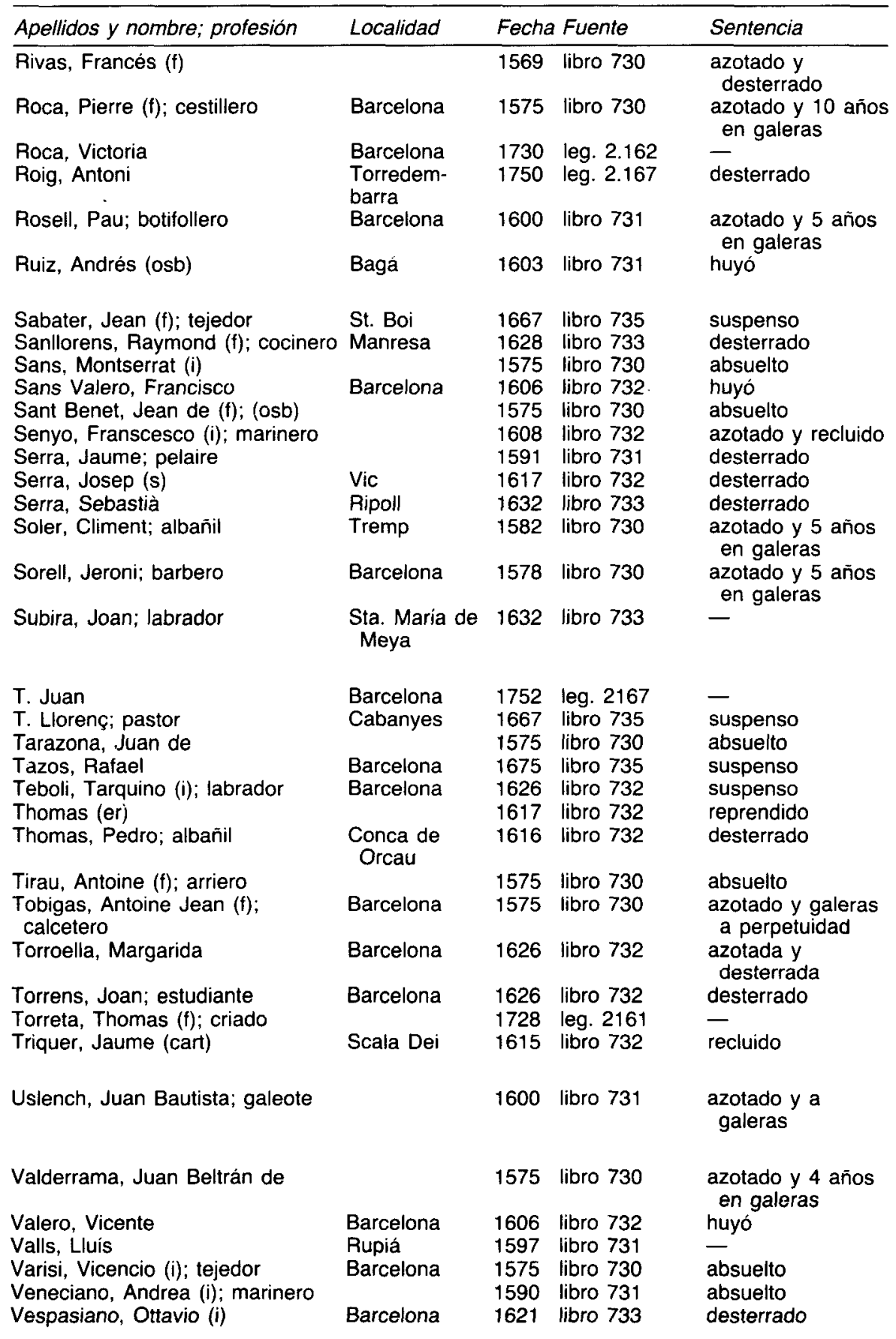


Catálogo de los procesos inquisitoriales del Tribunal del...

\begin{tabular}{|c|c|c|c|c|}
\hline Apellidos y nombre; profesión & Localidad & Fecha & Fuente & Sentencia \\
\hline Vicens, Pierre (f); labrador & & 1639 & libro 734 & - \\
\hline Víctor; militar & & 1632 & libro 746 & - \\
\hline Vidal, Francesc (s) & Tarragona & 1635 & libro 733 & suspenso \\
\hline Vilalta, Pere & & 1610 & libro 732 & - \\
\hline Vilardell, Bartomeu; labrador & Sta. Pau & 1621 & libro 733 & suspenso \\
\hline Vilaret, Pere & $\begin{array}{l}\text { Castell de Val } \\
\text { d'Aran }\end{array}$ & 1667 & libro 735 & suspenso \\
\hline Vinyas, Joan & $\begin{array}{l}\text { Vilafranca del } \\
\text { Penedés }\end{array}$ & 1634 & libro 733 & $\begin{array}{l}\text { azotado y } \\
\text { desterrado }\end{array}$ \\
\hline Vives, Josep Pere & Ametlla & 1638 & libro 734 & $\begin{array}{l}\text { azotado y } \\
\text { desterrado }\end{array}$ \\
\hline Xapello, Michele (i); carpintero & & 1624 & libro 733 & suspenso \\
\hline
\end{tabular}

\section{BESTIALIDAD}

Aranés, Joan

Artal, Joan, pastor

Bagaudas, Antoni

Beltrán, Antic; labrador

Bernat Vilaseca, Jacques (f); pas-

tor

Bresau, Jean (f)

Bruñiola, Francesc; pastor

Calvet, Bernard (f); portero

Casanovas, Jean ( $f$ )

Casanovas, Pierre ( $f)$; pastor

Carnicer, Joan Montserrat; labrador

Canella, Jean (f); pastor

Castellot, Miquel (osst)

Codern, Mateu; labrador

Coll, Joan; labrador

Copeto, Camilo (i); militar

Cotura, Bertrand (f); labrador

Cubom, Antonio (i); militar

Diegues, Gregori, labrador

Durán, Pere; zapatero

Estrada, Salvador, labrador

$\begin{array}{lrl} & 1633 & \text { libro } 746 \\ \text { Ager } & 1624 & \text { libro } 733 \\ & & \\ \text { Grabuac } & 1594 & \text { libro } 731 \\ & 1598 & \text { libro } 731 \\ & 1583 & \text { libro } 730 \\ & & \\ \text { Llavanera } & 1612 & \text { libro } 732 \\ \text { Fages } & 1665 & \text { libro } 735\end{array}$

1612 libro 732

1591 libro 731

Valls de No- 1606 libro 731 guera

Espluga

Francolí

Sogas, Las
Piera

de 1608 libro 732

1629 libro 733

1662 libro 734

1667 libro 735

St. Juliá Sa- 1617 libro 732 zorba?

1633 libro 733

1584 libro 730

1723 leg. 2159

1623 libro 733

Vilafranca del 1583 alibro 730 Penedés absuelto

azotado y galeras

a perpetuidad

azotado y 8 años

en galeras

desterrado

azotado y 6 años

en galeras

azotado y 3 años en galeras

desterrado

azotado y 10 años

en galeras

azotado y galeras

a perpetuidad

suspenso

suspenso

suspenso

suspenso

azotado y 8 años en galeras

absuelto

absuelto

azotado y galera a perpetuidad 


\begin{tabular}{|c|c|c|c|c|}
\hline Apellidos y nombre; profesión & Localidad & Fecha & Fuente & Sentencia \\
\hline Español, Bernard (f); labrador & Vallmoll & 1594 & libro 731 & desterrado \\
\hline Ferrer, Jaume & $\begin{array}{l}\text { Vilafranca del } \\
\text { Penedés }\end{array}$ & 1615 & libro 732 & falleció \\
\hline Font, Jean (f); labrador & & 1609 & libro 732 & $\begin{array}{l}\text { azotado y } 3 \text { años } \\
\text { en galeras }\end{array}$ \\
\hline $\begin{array}{l}\text { Fontanet, Joan; boticario } \\
\text { Forner, Johannes Georg (a); mili- } \\
\text { tar }\end{array}$ & Tirvia & $\begin{array}{l}1668 \\
1691\end{array}$ & $\begin{array}{l}\text { libro } 735 \\
\text { libro } 735\end{array}$ & suspenso \\
\hline $\begin{array}{l}\text { Garriga, Josep } \\
\text { Gascol, Pere Joan; labrador } \\
\text { Giró, Jaume; labrador } \\
\text { Gutiérrez, Agustín; militar }\end{array}$ & $\begin{array}{l}\text { Cardona } \\
\text { Termes } \\
\text { Artés }\end{array}$ & $\begin{array}{l}1682 \\
1620 \\
1639 \\
1722\end{array}$ & $\begin{array}{l}\text { libro } 735 \\
\text { libro } 732 \\
\text { libro } 734 \\
\text { leg. } 2.159\end{array}$ & $\begin{array}{l}\text { suspenso } \\
\text { absuelto }\end{array}$ \\
\hline Homs, Juan & Osera & 1613 & libero 731 & suspenso \\
\hline Jean Baptiste (f); labrador & & 1605 & libro 731 & $\begin{array}{l}\text { azotado y galeras } \\
\text { a perpetuidad }\end{array}$ \\
\hline Juan Ramón; labrador & Tárrega & 1667 & libro 735 & $\begin{array}{l}\text { azotado y } 3 \text { años } \\
\text { en galeras }\end{array}$ \\
\hline $\begin{array}{l}\text { Labardagas, Anton; criado } \\
\text { Lafita, Jean ( } f \text { ) }\end{array}$ & & $\begin{array}{l}1594 \\
1594\end{array}$ & $\begin{array}{l}\text { libro } 731 \\
\text { leg. } 1595 / 1\end{array}$ & $\begin{array}{l}\text { absuelto } \\
\text { azotado y galeras } \\
\text { a perpetuidad }\end{array}$ \\
\hline $\begin{array}{l}\text { Lauray, Jean (f); pastor } \\
\text { Lisorgas, Pierre (f); albañil } \\
\text { Lopez, Jean (f); labrador }\end{array}$ & $\begin{array}{l}\text { Valldaro } \\
\text { Brucs }\end{array}$ & $\begin{array}{l}1594 \\
1627 \\
1659\end{array}$ & $\begin{array}{l}\text { libro } 731 \\
\text { libro } 733 \\
\text { libro } 734\end{array}$ & $\begin{array}{l}\text { azotado y recluido } \\
\text { desterrado } \\
\text { azotado y } 5 \text { años } \\
\text { en galeras }\end{array}$ \\
\hline Llean, Joan, labrador & $\begin{array}{l}\text { St. Esteve de } \\
\text { Guialbes }\end{array}$ & 1674 & libro 735 & suspenso \\
\hline Lleo, Isidre & Puig & 1658 & libro 734 & suspenso \\
\hline $\begin{array}{l}\text { Mauran, Michel (f); zapatero } \\
\text { Marcos, Carles, labrador }\end{array}$ & $\begin{array}{l}\text { Torroella de } \\
\text { Montgrí }\end{array}$ & $\begin{array}{l}11598 \\
1598\end{array}$ & $\begin{array}{l}\text { leg. } 1.595 / 1 \\
\text { libro } 731\end{array}$ & $\begin{array}{l}\text { absuelto } \\
\text { desterrado }\end{array}$ \\
\hline Marti, Antoni; labrador & $\begin{array}{l}\text { Sta. María de } \\
\text { Bellver }\end{array}$ & 1659 & libro 734 & $\begin{array}{l}\text { azotado y } 3 \text { años } \\
\text { en galeras }\end{array}$ \\
\hline Megret, Pierre (f); labrador & $\begin{array}{l}\text { St. Martí de } \\
\text { Malda }\end{array}$ & 1591 & libro 731 & absuelto \\
\hline Moncortes, Mateu; labrador & Tahus & 1634 & lịbro 733 & $\begin{array}{l}\text { azotado y } 10 \text { años } \\
\text { en galeras }\end{array}$ \\
\hline Munt, Jean Du (f); labrador & $\begin{array}{l}\text { St. Feliu de } \\
\text { Llobregat }\end{array}$ & 1629 & libro 733 & $\begin{array}{l}\text { azotado y } 5 \text { años } \\
\text { en galeras }\end{array}$ \\
\hline $\begin{array}{l}\text { Montaner, Vocenç; molinero } \\
\text { Mas. Thomas (f); labrador } \\
\text { Mir, Francesc Pere; labrador }\end{array}$ & $\begin{array}{l}\text { Salo } \\
\text { Masoteras }\end{array}$ & $\begin{array}{l}1611 \\
1605 \\
1668\end{array}$ & $\begin{array}{l}\text { libro } 732 \\
\text { libro } 731 \\
\text { libro } 735\end{array}$ & $\begin{array}{l}\text { absuelto } \\
\text { absuelto } \\
\text { azotes y } 5 \text { años } \\
\text { en galeras }\end{array}$ \\
\hline $\begin{array}{l}\text { Pagueroles, Guillen } \\
\text { Pellicer, Pierre (f); labrador }\end{array}$ & Botarell & 1618 & libro 731 & $\begin{array}{l}\text { azotes y } 7 \text { años } \\
\text { en galeras } \\
\text { desterrado }\end{array}$ \\
\hline
\end{tabular}


Catálogo de los procesos inquisitoriales del Tribunal del...

\begin{tabular}{|c|c|c|c|c|}
\hline Apellidos y nombre; profesión & Localidad & Fecha & Fuente & Sentencia \\
\hline $\begin{array}{l}\text { Peiro, Peret de (f); labrador } \\
\text { Poch, Joan; labrador }\end{array}$ & $\begin{array}{l}\text { Ager } \\
\text { Torroella de } \\
\text { Montgrí }\end{array}$ & $\begin{array}{l}1615 \\
1665\end{array}$ & $\begin{array}{l}\text { libro } 732 \\
\text { libro } 735\end{array}$ & $\begin{array}{l}\text { desterrado } \\
\text { falleció }\end{array}$ \\
\hline Ponset, Pierre (f); pastor & $\begin{array}{l}\text { ¿St. Miquel } \\
\text { de la Gorga }\end{array}$ & 1599 & libro 731 & $\begin{array}{l}\text { azotado y deste- } \\
\text { rrado }\end{array}$ \\
\hline Pradell, Jean (f); sastre & & 1585 & libro 730 & $\begin{array}{l}\text { azotado y galeras } \\
\text { a perpetuidad }\end{array}$ \\
\hline $\begin{array}{l}\text { Prebinat, Pere; pastor } \\
\text { Puig, Marc; labrador }\end{array}$ & $\begin{array}{l}\text { Gaver } \\
\text { Barcelona }\end{array}$ & $\begin{array}{l}1666 \\
1608 \\
1659\end{array}$ & $\begin{array}{l}\text { libro } 735 \\
\text { libro } 732\end{array}$ & $\begin{array}{l}\text { suspenso } \\
+ \text { persona }\end{array}$ \\
\hline Pujo, Joan; labrador & St. Esteve & 1659 & libro 734 & \\
\hline Quer, Cosme & Susqueda & 1594 & leg. $1.595 / 1$ & $\begin{array}{l}\text { azotado y deste- } \\
\text { rrado }\end{array}$ \\
\hline Rabajas, Pierre (f); labrador & & 1603 & libro 731 & $\begin{array}{l}\text { azotado y } 10 \text { años } \\
\text { en galeras }\end{array}$ \\
\hline Ribas, Miquel; labrador & Olesa & 1676 & libro 756 & desterrado \\
\hline Riu, Joan; pastor & $\begin{array}{l}\text { Castellondou } \\
\text { del Vall de } \\
\text { St. Serni }\end{array}$ & 1617 & libro 732 & desterrado \\
\hline Robaudi, Bernard ( $f$ ) & Agramunt & 1609 & libro 732 & recluido \\
\hline Sala, Jacques (f) & Barcelona & 1593 & libro 731 & $\begin{array}{l}\text { azotado y } 10 \text { años } \\
\text { en galeras }\end{array}$ \\
\hline Sala, Jaume; labrador & Palau & 1620 & libro 732 & desterrado \\
\hline Salvat, Agustí & Riudoms & 1615 & libro 732 & desterrado \\
\hline Sayau, Pierre (f); boyero & St. Sebastiá & 1616 & libro 732 & desterrado \\
\hline Sazirach, Bernard (f) & & 1623 & libro 733 & desterrado \\
\hline Serrador, Jean (f); labrador & $\begin{array}{l}\text { St. Feliu Sa- } \\
\text { serra }\end{array}$ & 1634 & libro 733 & desterrado \\
\hline Sobres, Josep & Calella & 1722 & leg. 2.159 & - \\
\hline Solsona, Jaume & Boixols & 1600 & libro 731 & suspenso \\
\hline Soria, Miquel; labrador & $\begin{array}{l}\text { St. Marsal de } \\
\text { Terrasola }\end{array}$ & 1601 & libro 740 & desterrado \\
\hline Subira, Joan; labrador & $\begin{array}{l}\text { Sta. Maria de } \\
\text { Meya }\end{array}$ & 1633 & libro 733 & $\begin{array}{l}\text { azotado y deste- } \\
\text { rrado }\end{array}$ \\
\hline $\begin{array}{l}\text { Tarral, Francesc; labrador } \\
\text { Teixeire, François (f); labrador } \\
\text { Túnez de Herrera, Johan (d) }\end{array}$ & Agramunt & $\begin{array}{l}1680 \\
1605 \\
1669\end{array}$ & $\begin{array}{l}\text { libro } 735 \\
\text { libro } 731 \\
\text { libro } 735\end{array}$ & $\begin{array}{l}\text { suspenso } \\
\text { absuelto } \\
\text { azotado y } 3 \text { años } \\
\text { en galeras }\end{array}$ \\
\hline $\begin{array}{l}\text { Vantallo, Antoni Joan; herrero } \\
\text { Vilavent, Aranaud (f); labrador }\end{array}$ & $\begin{array}{l}\text { Vilafranca del } \\
\text { Penedés }\end{array}$ & $\begin{array}{l}1612 \\
1617\end{array}$ & $\begin{array}{l}\text { libro } 732 \\
\text { libro } 732\end{array}$ & $\begin{array}{l}\text { desterrado } \\
\text { azotado y } 4 \text { años } \\
\text { en galeras }\end{array}$ \\
\hline
\end{tabular}




Apellidos y nombre; profesión Localidad Fecha Fuente Sentencia

\section{PROPOSICIONES}

Adan, Hyacinthe $(f) ;(O c)$

Agell, Tomás; capintero

Agustí de la Concepció (osa)

Alaçot, Pere $(\mathrm{cm})$

Alavés, Álvaro; militar

Albaneda, Joan; labrador

Albon, Pierre (f)

Alces, Agustí

Alevet, Piñana ( $f$ ); cerrajero

Angelats, Jaume; sastre

Angelich, Macià (osb)

Amorós, Josep

Antoni de Girona (cap)

Antoine Jean Raymond (f); traji- Puigcerdá nero

Arnabat, Nicolau (om)

Artigues, Michel (f); (s)

Artus, Jean $(f) ;(s)$

Atienza, Cristóbal de (osa)

Ardet i River, Francesc (s)

Auger, Francesc; escribano

Austri, Samson (f)

Aymerich, Antoine (f); labrador

Ayral, Joan; pelaire

Azara, Luis; militar

Bajas, Antón; militar

Baltasar de Lérida (op)

Barcelo, Ciril (oc)

Barillas, Jean (f)

Barus, Joan (s)

Barriga, Francesc

Bastida, Antoine (f)

Basso Amigo, Francesc

Bau i Guitart, Francesc

Bedel, Pierre (f); retorcedor

Benjamin

Berges, Rosa (cla)

Beulo, María Antonia

Bernarch, Francés (f); albañil

Bernis, Jean ( $f)$; herrero

Bertrand, Jeroni; baile

Bianch, David (i); militar

Bigo, Joan; labrador

Ullastret

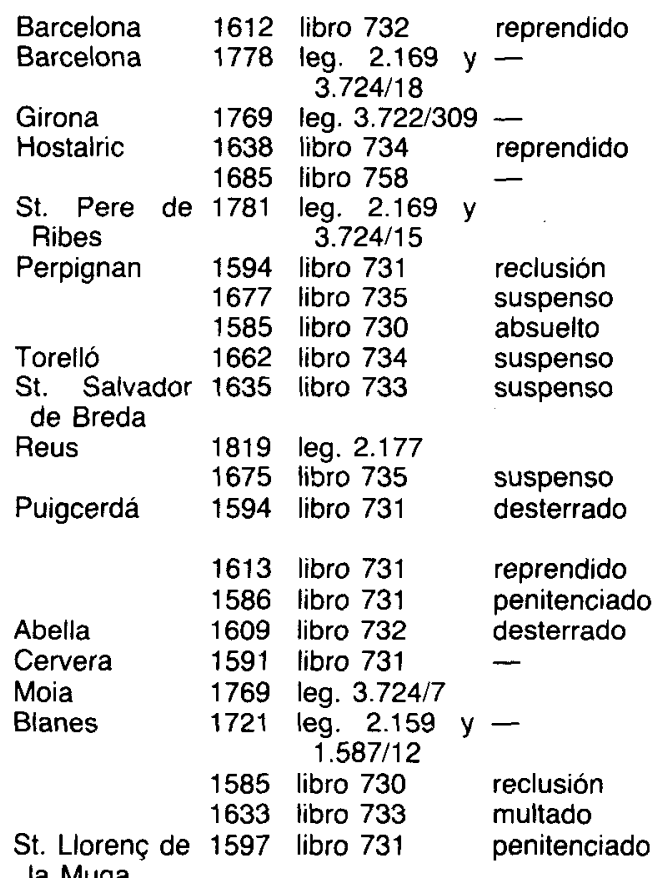

1816 leg. 2.177

1816 lleg. 2.177

Tremp $\quad 1628$ libro 733 advertido

Olot 1634 libro 733 advertido

1593 libro 731 reclusión

Sellent $\quad 1638$ libro 734 reprendido

Badalona $\quad 1816$ leg. $2.177 \quad-$

Perpignan 1583 libro $730 \quad 7$ años en galeras

Guissona $\quad 1571$ libro $730 \quad$ multado

1762 leg. $3.724 / 21$ y 58

1571 libro 730 azotado

1685 libro 758 -

Puigcerdá 1722 leg. 2159 -

$\begin{array}{llll}\text { Vic } & \text { c. } 1740 & \text { leg. } 3.724 / 199-\end{array}$

Guissona 1575 libro 730 absuelto

Servi $\quad 1611$ libro 730 reprendido

Santpedor 1612 libro 732 desterrado

1752 leg. 2.167 y $3.724 / 93$

La Bisbal 1594 libro 731 multado 
Catálogo de los procesos inquisitoriales del Tribunal del...

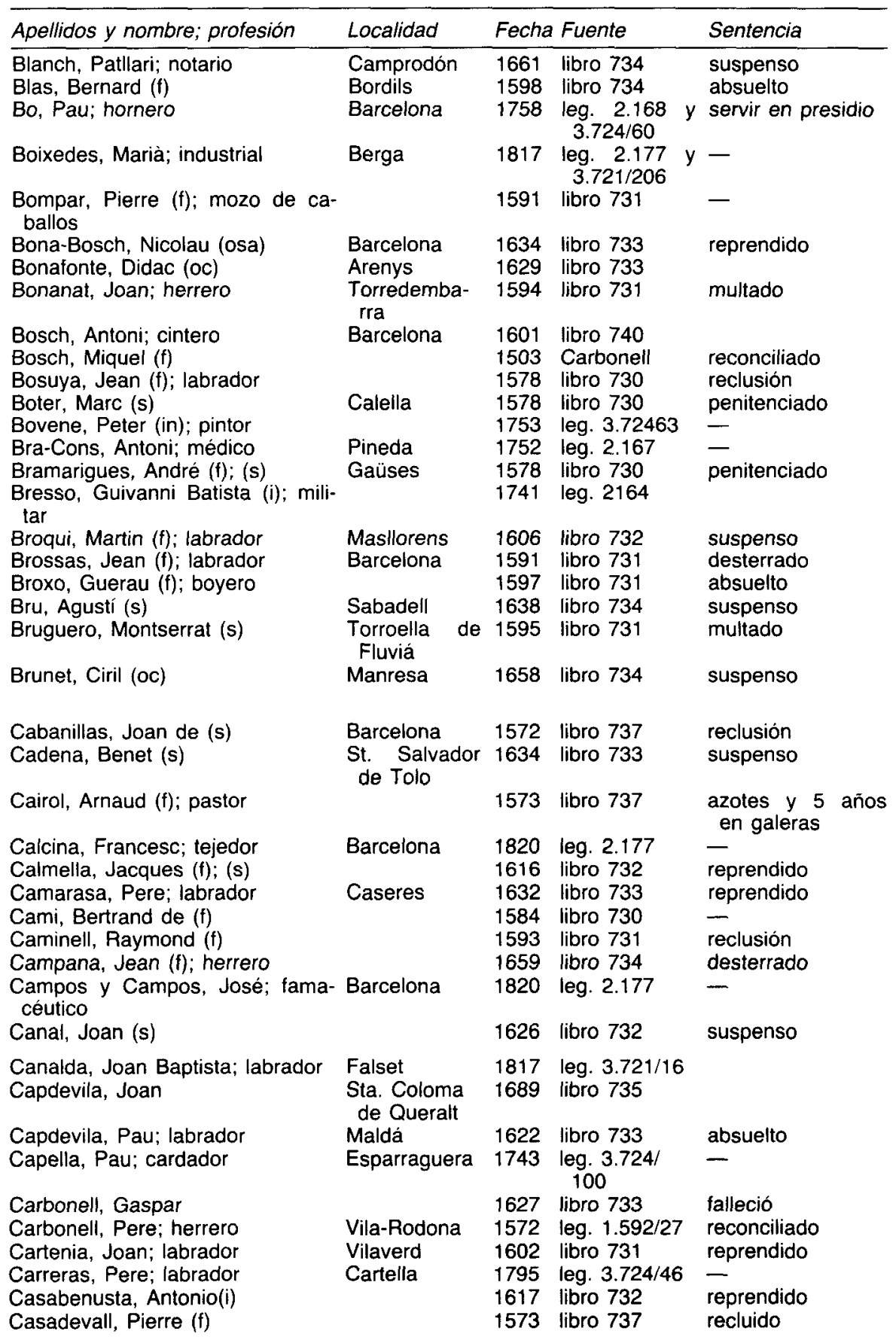


JUAN BLÁZQUEZ MIGUEL

\begin{tabular}{|c|c|c|c|c|}
\hline Apellidos y nombre; profesión & Localidad & Fecha & Fuente & Sentencia \\
\hline Casanova, François (f); militar & Barcelona & 1738 & $\begin{array}{l}\operatorname{leg} .3 .724 / \\
167\end{array}$ & \\
\hline Casas, Isidre; tejedor & Vendrell, El & 1753 & leg. 2.167 & - \\
\hline Casas, Jaume (cart) & Barcelona & 1676 & libro 735 & suspenso \\
\hline Cases, Jean Pierre $(f)$ & & 1610 & libro 732 & desterrado \\
\hline $\begin{array}{l}\text { Castaños, Andrés; guardarropa } \\
\text { de teatro }\end{array}$ & Barcelona & 1778 & $\begin{array}{l}\text { leg. } 2.169 \text { y } \\
3.724 / 12\end{array}$ & - \\
\hline Castelló, Francesc (s) & Tárrega & 1623 & libro 733 & multado \\
\hline Catala, Jacques (f); zapatero & Argelaguer & 1593 & libro 731 & recluido \\
\hline Cerdá, Narcis (s) & Sabadell & 1632 & libro 733 & reprendido \\
\hline Citarini, Andrea (i) & & 1680 & libro 735 & desterrado \\
\hline Clará, Martiniano; notario & Amer & 1776 & leg. $3.724 / 29$ & - \\
\hline Clará, Salvador & Catllar & 1614 & libro 732 & reprendido \\
\hline Clarach, Jean (f); pelaire & & 1573 & libro 737 & $\begin{array}{l}\text { azotado y a } \\
\text { galeras }\end{array}$ \\
\hline Claramunt, Ángela & Barcelona & 1575 & libro 730 & - \\
\hline Claresich, Jean (f) & Sarral & 1597 & libro 731 & penitenciado \\
\hline Claris; abogado & Barcelona & 1562 & libro 730 & reclusión \\
\hline $\begin{array}{l}\text { Claris } \\
\text { Claude }(\mathfrak{f}) ;(\mathrm{s})\end{array}$ & & $\begin{array}{l}1669 \\
1597\end{array}$ & $\begin{array}{l}\text { leg. } 2.155(1) \\
\text { libro } 731\end{array}$ & $\begin{array}{l}\text { penitenciado } \\
\text { absuelto }\end{array}$ \\
\hline Cosell, Lluis & Barcelona & 1610 & libro 732 & reprendido \\
\hline Colomer, Joan; blanquero & & 1624 & libro 733 & \\
\hline Colubret, Anna & Girona & 1658 & libro 734 & suspensa \\
\hline Coll, Raimond (¿of?) & $\begin{array}{l}\text { Vilafranca } \\
\text { del Penedés }\end{array}$ & 1748 & $\begin{array}{l}\log .3 .724 / \\
119\end{array}$ & \\
\hline Coll Ferrer, Narcís (om) & Girona & 1661 & libro 734 & desterrado \\
\hline Comas, Segimon (s) & Barcelona & 1722 & leg. 2.159 & \\
\hline Comes, Bernard (f); (s) & Perpignan & 1622 & libro 732 & reprendido \\
\hline Canónigo, un (s) & & 1608 & libro 732 & - \\
\hline Corde, François (f) & & 1570 & libro 730 & $\begin{array}{l}\text { azotado y } 3 \text { años } \\
\text { en galeras }\end{array}$ \\
\hline Corellano, Pedro; militar & & 1765 & leg. 2.170 & - \\
\hline Cornella, André (f); albañil & Hospitalet & 1594 & libro 731 & absuelto \\
\hline Corominas, (s) & Tallteüll & 1768 & $\operatorname{leg} .3 .724 / 76$ & - \\
\hline Corral, Juan del (of) & & 1605 & libro 731 & reprendido \\
\hline Cosp, Francesc (s) & $\begin{array}{l}\text { St. Jaume de } \\
\text { Frontanya }\end{array}$ & 1740 & leg. $3.724 / 95$ & - \\
\hline Costa (op) & Barcelona & 1668 & libro 735 & suspenso \\
\hline $\begin{array}{l}\text { Crussat, Blaise }(\mathfrak{f}) \text {; cocinero } \\
\text { Cunill Bajalus, Bernard (¿f?) }\end{array}$ & Perpignan & $\begin{array}{l}1568 \\
1502\end{array}$ & $\begin{array}{l}\text { libro } 731 \\
\text { Carbonell }\end{array}$ & $\begin{array}{l}\text { desterrado } \\
\text { reconciliado }\end{array}$ \\
\hline Cuviller, Gabriel (f); sastre & Perpignan & 1611 & libro 732 & absuelto \\
\hline $\begin{array}{l}\text { Chebani, Claude }(f) ;(\text { osb) } \\
\text { Cheyla, Jean de la }(f) \text {; pastor }\end{array}$ & Montserrat & 1662 & libro 732 & reprendido \\
\hline Cheyla, Jean de la (f); pastor & San Celoní & 1585 & libro 730 & reclusión \\
\hline Dachs, Joan (op) & Barcelona & 1717 & leg. 2.156 & absuelto \\
\hline Dardech, Francesc; sacristán & Montblanc & 1591 & libro 731 & desterrado \\
\hline Dens, Louis (f); tejedor & & 1605 & libro 731 & reprendido \\
\hline Descatllau, Maria Engracia (cla) & Puigcerdá & 1722 & leg. 2.159 & - \\
\hline Deu, Bernart (op) & Barcelona & 1634 & libro 733 & reprendido \\
\hline Domenjo, Miquel; labrador & Olot & 1578 & libro 730 & reprendido \\
\hline Domingo, Francisco; abogado & Cervera & 1819 & $\begin{array}{l}\text { leg. } 2.177 \text { y } \\
3.722 / 91\end{array}$ & - \\
\hline Domingo de Jesús María; fraile & Barcelona & 1781 & leg. $3.724 / 34$ & - \\
\hline
\end{tabular}


Catálogo de los procesos inquisitoriales del Tribunal del...

\begin{tabular}{|c|c|c|c|c|}
\hline Apellidos y nombre; profesión & Localidad & Fecha & a Fuente & Sentencia \\
\hline $\begin{array}{l}\text { Dondana y Mileti, Miguel Antonio; } \\
\text { militar }\end{array}$ & & 1736 & $\begin{array}{l}\text { leg. } 3.724 / \\
164\end{array}$ & - \\
\hline Duhl, Jean (fl) & & 1612 & libro 732 & recluido \\
\hline $\begin{array}{l}\text { Dundana, Michel Antonio (i); } \\
\text { militar }\end{array}$ & & 1737 & leg. 2.164 & desterrado \\
\hline $\begin{array}{l}\text { Duran, Bernard }(\mathfrak{f}) \text {; labrador } \\
\text { Durán, Jaume }(\mathrm{s}) \\
\text { Duran, Jean }(\mathrm{f}) ; \text { buhonero } \\
\text { Duro, Bernard }(\mathrm{f}) \text {; molinero }\end{array}$ & Pradell & $\begin{array}{l}1586 \\
1612 \\
1586 \\
1573\end{array}$ & $\begin{array}{l}\text { libro } 731 \\
\text { libro } 732 \\
\text { libro } 731 \\
\text { libro } 737\end{array}$ & $\begin{array}{l}\text { - } \\
\text { reprendido } \\
\text { recluido } \\
\text { recluido }\end{array}$ \\
\hline $\begin{array}{l}\text { Elias, Josep; notario } \\
\text { Escardo, Pere; marinero }\end{array}$ & $\begin{array}{l}\text { Tordera } \\
\text { Arenys de } \\
\text { Mar }\end{array}$ & $\begin{array}{l}1755 \\
1791\end{array}$ & $\begin{array}{l}\text { leg. } 3.724 / 85 \\
\text { leg. } 2.193 / 12 \\
\text { y } 3.731 / 3\end{array}$ & $\overline{-}$ \\
\hline Escardo i Rufart, Gertrudis & Barcelona & 1771 & $\begin{array}{l}\text { leg. } 2.169 \text { y } \\
3.724 / 27\end{array}$ & - \\
\hline $\begin{array}{l}\text { Escoia, Josep Joan } \\
\text { Español, Damià (s) }\end{array}$ & $\begin{array}{l}\text { Mataró } \\
\text { Vilabertran }\end{array}$ & $\begin{array}{l}1791 \\
1665\end{array}$ & $\begin{array}{l}\text { leg. } 3.731 / 11 \\
\text { libro } 735\end{array}$ & reprendido \\
\hline $\begin{array}{l}\text { Estelech, Antoni (s) } \\
\text { Estella, Bartomeu }\end{array}$ & Barcelona & $\begin{array}{l}1765 \\
1570\end{array}$ & $\begin{array}{l}\text { leg. } 2.170 \\
\text { libro } 730\end{array}$ & multado \\
\hline Esteve, Josef & Vila-Rodona & 1817 & leg. 2.177 & \\
\hline $\begin{array}{l}\text { Etienne Jordi (f); sombrerero } \\
\text { Estrada, Arnaud (f) } \\
\text { Extranjero, un (¿f?) }\end{array}$ & & $\begin{array}{l}1573 \\
1594 \\
1691\end{array}$ & $\begin{array}{l}\text { libro } 737 \\
\text { libro } 731 \\
\text { libro } 735\end{array}$ & $\begin{array}{l}\text { reprendido } \\
\text { penitenciado } \\
\text { - }\end{array}$ \\
\hline Falconet, Nicolas (s) & & 1744 & leg. 2.164 & - \\
\hline $\begin{array}{l}\text { Fals, Francesc; comisario de } \\
\text { Marina }\end{array}$ & Sitges & 1762 & leg. 2.170 & - \\
\hline Farrés, Joan; labrador & $\begin{array}{l}\text { Castellfollit de } \\
\text { Riubregos }\end{array}$ & 1622 & libro 733 & desterrado \\
\hline $\begin{array}{l}\text { Faxe, Pierre (f); sastre } \\
\text { Felipe de San José (oc) }\end{array}$ & $\begin{array}{l}\text { Barcelona } \\
\text { Vic }\end{array}$ & $\begin{array}{l}1603 \\
1735\end{array}$ & $\begin{array}{l}\text { libro } 731 \\
\text { leg. } 3724 / 131\end{array}$ & absuelto \\
\hline Feliu, Martí & Calella & 1750 & $\begin{array}{l}\text { leg. } 3.724 / \\
102\end{array}$ & - \\
\hline Fernández, José & Sta. Linya & 1736 & leg. 2.164 & - \\
\hline Fernández, Manuel; escribiente & Tarragona & 1815 & leg. $3.722 / 92$ & - \\
\hline Ferrán, Llorenç & Masllorens & 1606 & libro 732 & multado \\
\hline $\begin{array}{l}\text { Ferrer de la Farga, Amador (f); } \\
\text { labrador }\end{array}$ & Selma & 1605 & libro 731 & multado \\
\hline Ferrer, Bertrand (f); carretero & & 1632 & libro 733 & reprendido \\
\hline Ferrer, Bernat & & 1598 & libro 731 & - \\
\hline Ferrer, Francesc (si) & Vic & 1631 & libro 733 & reprendido \\
\hline Ferrer, Llorenç, labrador & Senyus & 1594 & libro 731 & recluido \\
\hline Ferrer, Saldoni (s) & $\begin{array}{l}\text { Vilafranca } \\
\text { del Penedes }\end{array}$ & 1674 & libro 735 & suspenso \\
\hline $\begin{array}{l}\text { Feu, Dionisia } \\
\text { Figueras, Maria (¿of?) }\end{array}$ & $\begin{array}{l}\text { Santpedor } \\
\text { Mataró }\end{array}$ & $\begin{array}{l}1675 \\
1742\end{array}$ & $\begin{array}{l}\text { libro } 735 \\
\text { leg. } 3.724 / \\
156\end{array}$ & suspenso \\
\hline $\begin{array}{l}\text { Figuerola, Pere (s) } \\
\text { Figuerols Josep }\end{array}$ & $\begin{array}{l}\text { Talarn } \\
\text { Ager }\end{array}$ & $\begin{array}{l}1620 \\
1766\end{array}$ & $\begin{array}{l}\text { libro } 732 \\
\text { lea. } 2170\end{array}$ & ¿reprendido? \\
\hline Flaquer, Jacint (s) & & 1636 & libro 734 & multado \\
\hline Florensa, Pierre (f) & Figueres & 1612 & libro 732 & suspenso \\
\hline Foix, Jean (f); buhonero & & 1598 & libro 731 & recluido \\
\hline Fons, Pierre (f); labrador & Solsona & 1575 & libro 730 & absuelto \\
\hline Font, Blai; médico & & 1764 & leg. 2.170 & - \\
\hline Font, Raimond; estudiante & Barcelona & 1668 & libro 735 & suspenso \\
\hline
\end{tabular}




\begin{tabular}{|c|c|c|c|c|}
\hline Apellidos y nombre; profesión & Localidad & Fecha & Fuente & Sentencia \\
\hline $\begin{array}{l}\text { Fontena, Jacques de la (f); } \\
\text { médico }\end{array}$ & & 1605 & libro 731 & suspenso \\
\hline Forcada, François $(f)$ & & 1618 & libro 732 & reprendido \\
\hline Forest, Pierre (f); boyero & & 1610 & libro 732 & \\
\hline Forgas, Jean (f); labrador & Cornellá & 1603 & libro 731 & multado \\
\hline Fornes, Andreu & Cabra & 1671 & libro 755 & \\
\hline Franquet, Pere (s) & Falset & 1690 & libro 735 & reprendido \\
\hline Fransech $(f)$ & Alcover & 1593 & libro 731 & - \\
\hline Frassi, Marich (f); albañil & Pineda & 1597 & libro 731 & reprendido \\
\hline Fulgenci de Girona (cap) & Barcelona & 1637 & libro 734 & absuelto \\
\hline Fulgenci de san Renat (ep) & Barcelona & 1717 & leg. 2.158 & - \\
\hline Gabriel (s) & Pradell & 1574 & libro 730 & - \\
\hline Gaçol, Jacint & Pallars & 1629 & libro 745 & - \\
\hline Galceran Carles & & 1570 & 730 & multado \\
\hline Gania, Gili (f); librero & Barcelona & 1575 & libro 730 & - \\
\hline García Bolias, José; albañil & & 1786 & leg. 2.174 & - \\
\hline Garriga, Bernat ( & $\begin{array}{l}\text { St. Joan de } \\
\text { Vilatorrada }\end{array}$ & 1619 & libro 732 & reprendido \\
\hline Gavernet, Francesc; labrador & Pons & 1680 & libro 749 & - \\
\hline $\begin{array}{l}\text { Gener, Vidal (f); sastre } \\
\text { Gerri, Galderil (f); labrador }\end{array}$ & Alcover & $\begin{array}{l}1586 \\
1609\end{array}$ & $\begin{array}{l}\text { libro } 731 \\
\text { libro } 732\end{array}$ & $\begin{array}{l}\text { penitenciado } \\
\text { absuelto }\end{array}$ \\
\hline Gibert, Pierre (f); albañil & Perpignan & 1586 & libro 731 & desterrado \\
\hline Gifreu, Histle; labrador & Sentís & 1617 & libro 732 & reprendido \\
\hline $\begin{array}{l}\text { Gil, Jaume; labrador } \\
\text { Gil, Pierre (f) }\end{array}$ & Vimbodí & $\begin{array}{l}1597 \\
1603\end{array}$ & $\begin{array}{l}\text { libro } 731 \\
\text { libro } 731\end{array}$ & multado \\
\hline Ginesta, Joan; labrador & St. Martí Vell & 1681 & libro 735 & suspenso \\
\hline Giove & & 1675 & libro 735 & suspenso \\
\hline losep; cirujano & Peralada & 1742 & leg. 2.164 & - \\
\hline Gispert, Antoni (s) & Girona & 1737 & $\begin{array}{l}\text { leg. } 3.724 / \\
141\end{array}$ & - \\
\hline Golada, Domingo (g) & $\begin{array}{l}\text { Vilanova de } \\
\text { Cubells }\end{array}$ & 1599 & libro 731 & - \\
\hline Gomá, Jaime; militar & & 1765 & leg. 2.170 & - \\
\hline Gomes, Antoine (f); sastre & Figueres & 1573 & libro 737 & azotes y reclusión \\
\hline Gorgoll, Joan (s) & Palamós & 1575 & libro 6.730 & - \\
\hline Gothier, Juan Andrés & Barcelona & 1782 & leg. $3.724 / 31$ & 一 \\
\hline Grandi, Angelo (i); relojero & Girona & 1784 & leg. $3.724 / 43$ & - \\
\hline Grassons, Antoni; labrador & Selva, La & 1584 & libro 730 & multado \\
\hline Gregori, Juan Pablo; músico & Barcelona & 1765 & leg. 3.724/67 & - \\
\hline Grillón, Macià; cirujano & Barcelona & $\begin{array}{l}1593 \\
1735\end{array}$ & $\begin{array}{l}\text { libro } 731 \\
\text { leg. } 2.162 \text { y } \\
3.724 / 88\end{array}$ & reprendido \\
\hline $\begin{array}{l}\text { Griñó, Llorenç Joan (s) } \\
\text { Grisofulo, Jerónimo (i); militar }\end{array}$ & Montblanc & 1592 & libro 731 & reprendido \\
\hline $\begin{array}{l}\text { Grisofulo, Jerónimo (i); militar } \\
\text { Guadany, Jacques (f); botonero }\end{array}$ & & $\begin{array}{l}1605 \\
1578\end{array}$ & $\begin{array}{l}\text { libro } 731 \\
\text { libro } 730\end{array}$ & reprendido \\
\hline Gualbe, Francesc; ermitaño & Scala Dei & 1594 & libro 731 & recluido \\
\hline Guiamet, Francisco; militar & & 1818 & leg. 2.177 & - \\
\hline Guimernau, Isidre (ber) & & 1659 & libro 734 & - \\
\hline Guiola, Jean (f); ermitaño & & 1575 & libro 730 & absuelto \\
\hline Guiral (f); herrero & & 1591 & libro 731 & - \\
\hline Guisseldo, Johannes (a) & & 1617 & libro 732 & desterrado \\
\hline Guixaut, Antoni; militar & Seu d'Urgell & 1784 & leg. $3.724 / 37$ & - \\
\hline Gurri, Pere (of) & & 1664 & libro 735 & \\
\hline Guxench, Arnaud (f); molinero & Esparraguera & 1636 & libro 734 & reprendido \\
\hline
\end{tabular}


Catálogo de los procesos inquisitoriales del Tribunal del...

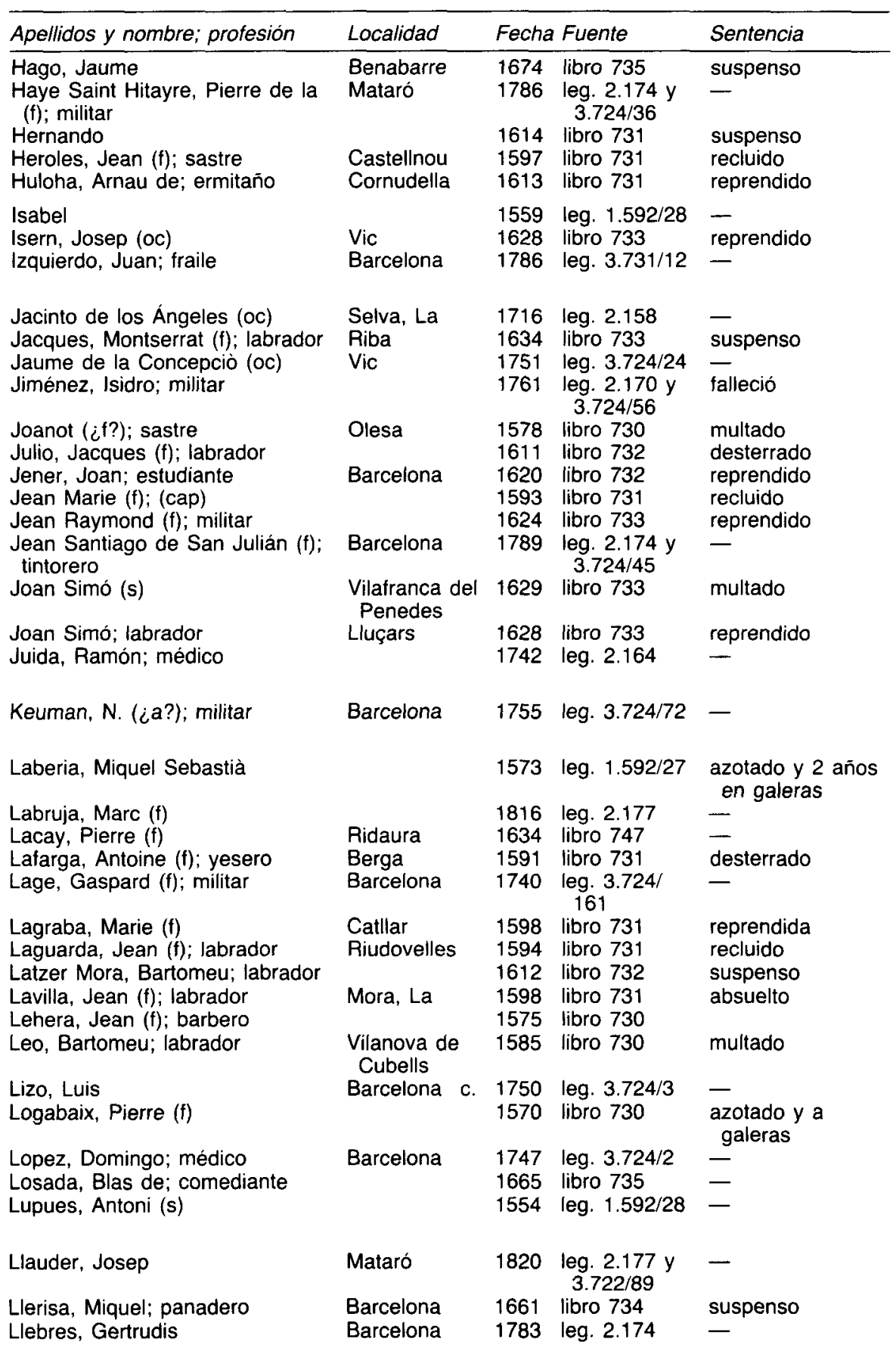


JUAN BLAZQUEZ MIGUEL

\begin{tabular}{|c|c|c|c|c|}
\hline Apellidos y nombre; profesión & Localidad & Fecha & Fuente & Sentencia \\
\hline $\begin{array}{l}\text { Llobot, Pere; fraile } \\
\text { Llonch, Pere (s) } \\
\text { Llor, Joan }\end{array}$ & $\begin{array}{l}\text { Argentona } \\
\text { Romanya de } \\
\text { la Selva }\end{array}$ & $\begin{array}{l}1602 \\
1594 \\
1741\end{array}$ & $\begin{array}{l}\text { libro } 731 \\
\text { libro } 731 \\
\text { leg. } 3.724 / \\
136\end{array}$ & $\begin{array}{l}\text { reprendido } \\
\text { falleció } \\
-\end{array}$ \\
\hline $\begin{array}{l}\text { Llorentics, Jean (f); criado } \\
\text { Llucia, Jaume; labrador }\end{array}$ & $\begin{array}{l}\text { Cubells } \\
\text { Claramunt }\end{array}$ & $\begin{array}{l}1594 \\
1764\end{array}$ & $\begin{array}{l}\text { libro } 731 \\
\text { leg. } 2.170\end{array}$ & absuelto por loco \\
\hline Maciá, Marià; sastre & $\begin{array}{l}\text { Arenys de } \\
\text { Mar }\end{array}$ & 1776 & $\begin{array}{l}\text { leg. } 2.169 \text { y } \\
3.724 / 23\end{array}$ & - \\
\hline Maestre, Gabriel (s) & Pradell & 1591 & libro 731 & \\
\hline $\begin{array}{l}\text { Maguinya, Joan; labrador } \\
\text { Marcal, Francesc }\end{array}$ & Masllorens & $\begin{array}{l}1764 \\
1675\end{array}$ & $\begin{array}{l}\text { leg. } 2.170 \\
\text { libro } 735\end{array}$ & suspenso \\
\hline Marcos Simón (osa) & Palamós & 1661 & libro 734 & reprendido \\
\hline María de la Trinidad (omin) & Barcelona & 1627 & libro 745 & - \\
\hline Marillach, Jean $(f)$; cirujano & Girona & 1725 & leg. 2.161 & - \\
\hline $\begin{array}{l}\text { Martín Comas, Pere; cubero } \\
\text { Martín Oller, Pedro (op) }\end{array}$ & Mataró & $\begin{array}{l}1769 \\
1658\end{array}$ & $\begin{array}{l}\text { leg. } 2.170 \\
\text { libro } 734\end{array}$ & suspenso \\
\hline $\begin{array}{l}\text { Martínez, Bartolomé (s) } \\
\text { Martínez Cano, Francisco de } \\
\text { Paula; militar }\end{array}$ & Perpignan & $\begin{array}{l}1612 \\
1816\end{array}$ & $\begin{array}{l}\text { libro } 732 \\
\text { leg. } 3.721 / \\
213\end{array}$ & reprendido \\
\hline Martorell, Joan; militar & & 1734 & leg. 2.162 & - \\
\hline Marturia, Joan (s) & Calonge & 1611 & libro 732 & reprendido \\
\hline Marxant, Pere; labrador & Llambilles & 1744 & $\begin{array}{l}\text { leg. } 3.724 / \\
166\end{array}$ & - \\
\hline $\begin{array}{l}\text { Marroig, Gabriel } \\
\text { Mas, Guerau (s) }\end{array}$ & Barcelona & $\begin{array}{l}1721 \\
1575\end{array}$ & $\begin{array}{l}\text { leg. } 2.159 \\
\text { libro } 730\end{array}$ & $\overline{\text { absuelto }}$ \\
\hline Mas, Martí; labrador & Vilanant & 1629 & libro 733 & reprendido \\
\hline Mas, Rafael & $\begin{array}{l}\text { Vilafranca del } \\
\text { Penedés }\end{array}$ & 1623 & libro 733 & multado \\
\hline $\begin{array}{l}\text { Massalies, Pere; labrador } \\
\text { Masso, Antoni; labrador }\end{array}$ & $\begin{array}{l}\text { Blancafort } \\
\text { Riudoms }\end{array}$ & $\begin{array}{l}1584 \\
1815\end{array}$ & $\begin{array}{l}\text { libro } 730 \\
\text { leg. } 2.177\end{array}$ & recluido \\
\hline Masso, François ( $f$ ) & Vila-Rodona & 1584 & libro 730 & reprendido \\
\hline Mata, Cayetano de; militar & & 1816 & $\begin{array}{l}\text { leg. } 3.721 / \\
218\end{array}$ & - \\
\hline Maura, Pere (s) & & 1559 & leg. $1.592 / 28$ & - \\
\hline Mauri, Tomás, (op) & Barcelona & 1658 & libro 734 & reprendido \\
\hline Maymó, Joan; cubero & Vallmoll & 1594 & libro 731 & desterrado \\
\hline Menescal, Paul (l); albeitar & & 1620 & libro 732 & advertido \\
\hline Mestre, Gabriel (s) & Pradell & 1578 & libro 730 & absuelto \\
\hline $\begin{array}{l}\text { Minguela, Joan Antoni; } \\
\text { practicante de notario }\end{array}$ & & 1762 & leg. 2.170 & - \\
\hline Miguel Alfonso; boticario & Barcelona & 1575 & libro 730 & - \\
\hline Miranda, Marià; fraile & & 1798 & $\begin{array}{l}\operatorname{leg} .3 .724 / \\
197\end{array}$ & - \\
\hline $\begin{array}{l}\text { Miras, Dominique (f) } \\
\text { Miret, Josep (s) }\end{array}$ & Tarragona & $\begin{array}{l}1598 \\
1629\end{array}$ & $\begin{array}{l}\text { libro } 731 \\
\text { libro } 733\end{array}$ & - multado \\
\hline Miró, Joan Antoni; pelaire & Reus & 1632 & libro 733 & falleció \\
\hline Miró, Ignasi & Barcelona & 1733 & $\begin{array}{l}\operatorname{leg} .3 .724 / \\
126\end{array}$ & 一 \\
\hline Mitján, Josep; tejedor & Barcelona & 1748 & leg. 2.165 & - \\
\hline Modolall, Bernat (s) & Pradell & 1665 & leg. 2.156 & suspenso \\
\hline Moix, Josep; notario & Sellent & 1661 & libro 734 & reprendido \\
\hline Molas, Josep; maestro & Olot & 1792 & leg. $3.731 / 7$ & - \\
\hline Molas, Josep (oc) & & 1798 & leg. 2.174 & - \\
\hline Moliner, Jean (f); sastre & Bonastre & 1605 & libro 731 & reprendido \\
\hline
\end{tabular}


Catálogo de los procesos inquisitoriales del Tribunal del...

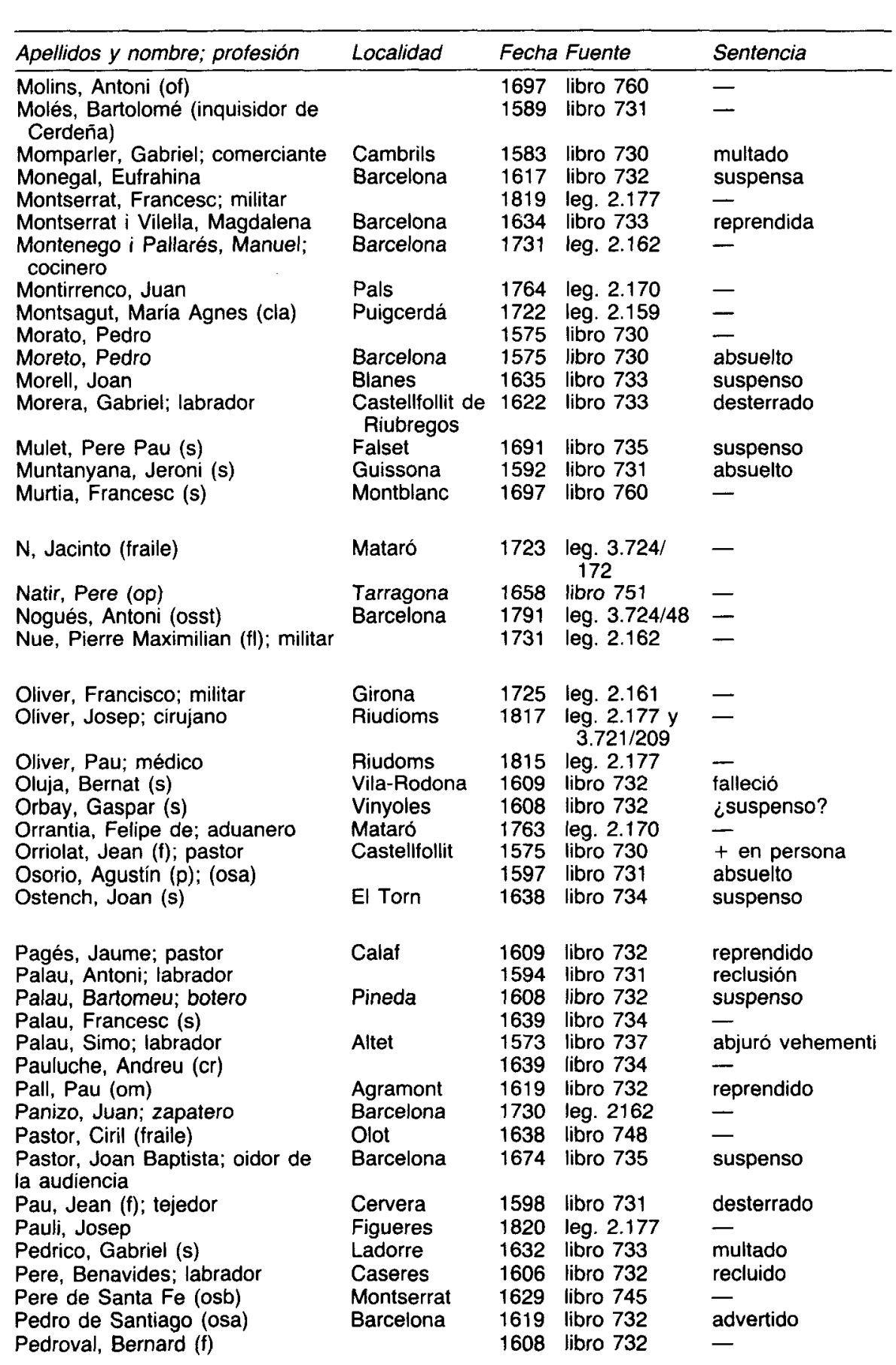




\begin{tabular}{|c|c|c|c|c|}
\hline Apellidos y nombre; profesión & Localidad & Fecha & Fuente & Sentencia \\
\hline $\begin{array}{l}\text { Perareda, Montserrat, (s) } \\
\text { Pere, Cebrián; labrador }\end{array}$ & $\begin{array}{l}\text { Barcelona } \\
\text { Vilanova de } \\
\text { l'Aquda }\end{array}$ & $\begin{array}{l}1610 \\
1614\end{array}$ & $\begin{array}{l}\text { libro } 732 \\
\text { libro } 731\end{array}$ & $\overline{\text { desterrado }}$ \\
\hline $\begin{array}{l}\text { Perez, Simon Pierre (f); labrador } \\
\text { Petit, Jean ( } f)\end{array}$ & & $\begin{array}{l}1656 \\
1600\end{array}$ & $\begin{array}{l}\text { libro } 750 \\
\text { libro } 731\end{array}$ & reprendido \\
\hline Pex, Antoine du (f) & Vilassar & 1581 & libro 730 & $\begin{array}{l}\text { azotado y } 6 \text { años } \\
\text { en galeras }\end{array}$ \\
\hline $\begin{array}{l}\text { Peyrona (f) } \\
\text { Pi, Vicenç; receptor limosnas de } \\
\text { Cruzada }\end{array}$ & $\begin{array}{l}\text { Terrassa } \\
\text { Esparraguera }\end{array}$ & $\begin{array}{l}1610 \\
1662\end{array}$ & $\begin{array}{l}\text { libro } 732 \\
\text { libro } 731\end{array}$ & $\begin{array}{l}\text { desterrada } \\
\text { multado }\end{array}$ \\
\hline $\begin{array}{l}\text { Piaza, Francesco (i); militar } \\
\text { Pina, Sebastià; militar }\end{array}$ & & $\begin{array}{l}1634 \\
1816\end{array}$ & $\begin{array}{l}\text { libro } 733 \\
\text { leg. } 3.721 / \\
225\end{array}$ & reprendido \\
\hline $\begin{array}{l}\text { Pineda, Domeneç; comerciante } \\
\text { Pineda, Francesç (cap) } \\
\text { Pons, Antoine ( } f \text { ); tejedor } \\
\text { Porta, Josep; militar }\end{array}$ & $\begin{array}{l}\text { Taradell } \\
\text { Blanes } \\
\text { Palafrugell }\end{array}$ & $\begin{array}{l}1784 \\
1685 \\
1578 \\
1816\end{array}$ & $\begin{array}{l}\text { leg. } 3.724 / 39 \\
\text { leg. } 2.158 \\
\text { libro } 730 \\
\text { leg. } 3.721 / \\
225\end{array}$ & $\begin{array}{l}- \\
\text { recluido } \\
-\end{array}$ \\
\hline Prats, Manuel (fraile) & Besalú & 1737 & $\begin{array}{l}\operatorname{leg} .3 .724 / \\
132\end{array}$ & - \\
\hline Prinyana, Antoni; baile & $\begin{array}{l}\text { Esterri de } \\
\text { Cardós }\end{array}$ & 1638 & libro 734 & suspenso \\
\hline $\begin{array}{l}\text { Prodonella, Pedro; militar } \\
\text { Pros, Rafael; ¿militar? } \\
\text { Puig, Lluis; militar }\end{array}$ & Barcelona & $\begin{array}{l}1818 \\
1818 \\
1819\end{array}$ & $\begin{array}{l}\text { leg. } 2.177 \\
\text { leg. } 2.177 \\
\text { leg. } 2.177\end{array}$ & $\bar{z}$ \\
\hline Puig, Miquel; cirujano & Bascara & 1655 & libro 734 & $\begin{array}{l}\text { azotado y } 3 \text { años } \\
\text { en galeras }\end{array}$ \\
\hline $\begin{array}{l}\text { Puig, Pau; músico } \\
\text { Puigmanten, Louis (f); labrador }\end{array}$ & Barcelona & $\begin{array}{l}1778 \\
1750\end{array}$ & $\begin{array}{l}\text { leg. } 3.724 / 57 \\
\text { leg. } 2.174\end{array}$ & - \\
\hline $\begin{array}{l}\text { Puigmaner, Masic; sastre } \\
\text { Puli, Josep }\end{array}$ & $\begin{array}{l}\text { Tous } \\
\text { Figueres }\end{array}$ & $\begin{array}{l}1594 \\
1816\end{array}$ & $\begin{array}{l}\text { libro } 731 \\
\text { leg. } 3.721 / \\
217\end{array}$ & reprendido \\
\hline Puniet, Bernat; boticario & $\begin{array}{l}\text { Vilanova i la } \\
\text { Geltru }\end{array}$ & 1796 & $\operatorname{leg} .3 .731 / 6$ & - \\
\hline $\begin{array}{l}\text { Quedo, Jean ( } f \text { ) } \\
\text { Quen, Antoni; alcalde } \\
\text { Quer, Benet; labrador } \\
\text { Quer, Climent (osb) }\end{array}$ & $\begin{array}{l}\text { Montseny } \\
\text { Agramunt } \\
\text { Suria } \\
\text { Viladamat }\end{array}$ & $\begin{array}{l}1611 \\
1778 \\
1637 \\
1591\end{array}$ & $\begin{array}{l}\text { libro } 732 \\
\text { leg. } 2.169 \\
\text { libro } 734 \\
\text { libro } 731\end{array}$ & $\begin{array}{l}\text { reprendido } \\
\text { reprendido } \\
\text { penitenciado }\end{array}$ \\
\hline Rafael Pedro & Vic & 1573 & libro 737 & $\begin{array}{l}\text { azotado y } 3 \text { años } \\
\text { en galeras }\end{array}$ \\
\hline $\begin{array}{l}\text { Ramada, Paula } \\
\text { Rami, Joan (op) }\end{array}$ & Mont-Roig & $\begin{array}{l}1612 \\
1726\end{array}$ & $\begin{array}{l}\text { libro } 732 \\
\text { leg. } 2.161\end{array}$ & reprendida \\
\hline Ramírez, Blas; militar & & 1732 & $\begin{array}{l}\text { records. } p . \\
169-175\end{array}$ & - \\
\hline Ramis, Antón; militar & & 1761 & leg. 2.170 & 一 \\
\hline & Sort & 1634 & libro 733 & \\
\hline Rauger, Etienne (f); labrador & $\begin{array}{l}\text { Torroella de } \\
\text { Montgri }\end{array}$ & 1593 & libro 731 & reprendido \\
\hline Redonella, Per; fajero & $\begin{array}{l}\text { Pobla de } \\
\text { Lillet }\end{array}$ & 1816 & $\begin{array}{l}\operatorname{leg} .3 .721 / \\
215\end{array}$ & - \\
\hline $\begin{array}{l}\text { Regordeta, Miguel (s) } \\
\text { Reig, Raphael (f) } \\
\text { Reull, Tomás }(f)\end{array}$ & $\begin{array}{l}\text { Barcelona } \\
\text { Perpignan } \\
\text { Igualada }\end{array}$ & $\begin{array}{l}1615 \\
1586 \\
1620\end{array}$ & $\begin{array}{l}\text { libro } 732 \\
\text { libro } 731 \\
\text { libro } 732\end{array}$ & $\begin{array}{l}\text { suspenso } \\
\text { multado } \\
\text { reprendido }\end{array}$ \\
\hline
\end{tabular}


Catálogo de los procesos inquisitoriales del Tribunal del...

\begin{tabular}{|c|c|c|c|c|}
\hline Apellidos y nombre; profesión & Localidad & Fecha & Fuente & Sentencia \\
\hline $\begin{array}{l}\text { Reverter, Antoni (s) } \\
\text { Rexach, Silvestre (s) } \\
\text { Rey, Jaume del } \\
\text { Reynau, Jean (f); calcetero } \\
\text { Reyner, Jean (f); pintor }\end{array}$ & $\begin{array}{l}\text { Oris } \\
\text { Sert } \\
\text { Barcelona } \\
\text { Vilanova de } \\
\text { Sitges }\end{array}$ & $\begin{array}{l}1585 \\
1616 \\
1620 \\
1578 \\
1594\end{array}$ & $\begin{array}{l}\text { libro } 730 \\
\text { libro } 732 \\
\text { libro } 732 \\
\text { libro } 732 \\
\text { libro } 731\end{array}$ & $\begin{array}{l}\text { multado } \\
\text { multado } \\
\text { reprendido } \\
\text { recluido } \\
\text { recluido }\end{array}$ \\
\hline $\begin{array}{l}\text { Ribas, Felix; militar } \\
\text { Ribas, Francesc; estudiante } \\
\text { Ribas, Margarida } \\
\text { Ribera, Miquel de (cap } \\
\text { Rigau, Pere; zapatero }\end{array}$ & $\begin{array}{l}\text { Arenys } \\
\text { Perpignan } \\
\text { St. Feliu de } \\
\text { Guixols }\end{array}$ & $\begin{array}{l}1816 \\
1734 \\
1594 \\
1592 \\
1593\end{array}$ & $\begin{array}{l}\text { leg. } 2.177 \\
\text { leg. } 2.162 \\
\text { libro } 731 \\
\text { libro } 731 \\
\text { libro } 731\end{array}$ & $\begin{array}{l}\overline{-} \\
\text { penitenciada } \\
\text { reprendido } \\
\text { penitenciado }\end{array}$ \\
\hline $\begin{array}{l}\text { Riquert, Francesc } \\
\text { Riu, Guillaume de (f); peinador } \\
\text { Riu, Martial (f); pedreñalero } \\
\text { Riudalbas, Gaspar; calcetero } \\
\text { Rivert, Josep (s) }\end{array}$ & $\begin{array}{l}\text { Barcelona } \\
\text { Alcover } \\
\text { Guissona } \\
\text { Vilafranca del } \\
\text { Penedés }\end{array}$ & $\begin{array}{l}1790 \\
1594 \\
1570 \\
1591 \\
1659\end{array}$ & $\begin{array}{l}\text { leg. } 3.724 / 47 \\
\text { libro } 731 \\
\text { libro } 730 \\
\text { libro } 731 \\
\text { libro } 734\end{array}$ & $\begin{array}{l}\text { recluido } \\
\text { penitenciado } \\
\text { penitenciado }\end{array}$ \\
\hline $\begin{array}{l}\text { Roda, Gaspar (osa) } \\
\text { Roger, Michel (f); (s) } \\
\text { Roig, Pere; labrador } \\
\text { Romero, Álvaro; militar } \\
\text { Roma, Francesc; abogado } \\
\text { Romero, Benito (osb) } \\
\text { Romeu, Baptiste (f); (op) } \\
\text { Roquer, Josep (s) } \\
\text { Ros, Alexandre (si) } \\
\text { Ros, Guillaume (f); tejedor } \\
\text { Ros, Llorenç } \\
\text { Ros, Rafael; platero }\end{array}$ & $\begin{array}{l}\text { Barcelona } \\
\text { Barcelona } \\
\text { Reus } \\
\text { Barcelona } \\
\text { Ripoll } \\
\text { Vic } \\
\text { Vila-Rodona } \\
\text { Barcelona } \\
\text { Mataró }\end{array}$ & $\begin{array}{l}1654 \\
1620 \\
1617 \\
1677 \\
1757 \\
1766 \\
1613 \\
1758 \\
1638 \\
1581 \\
1593 \\
1816\end{array}$ & $\begin{array}{l}\text { libro } 734 \\
\text { libro } 732 \\
\text { libro } 732 \\
\text { libro } 735 \\
\text { leg. } 3.724 / 74 \\
\text { leg. } 2170 \\
\text { libro } 732 \\
\text { leg. } 3.724 / 73 \\
\text { libro } 734 \\
\text { libro } 730 \\
\text { libro } 731 \\
\text { leg. } 3.721 / \\
210\end{array}$ & $\begin{array}{l}\text { desterrado } \\
\text { desterrado } \\
\text { suspenso } \\
\text { reprendido } \\
\frac{\text { absuelto }}{\text { recluido }} \\
\text { absuelto } \\
-\end{array}$ \\
\hline $\begin{array}{l}\text { Roseflo, Agnes } \\
\text { Rosell, Bernat; cardero } \\
\text { Roselló, Sebastià; tejedor } \\
\text { Rosich, Antoni; tintero } \\
\text { Rospillet, Giovanni (i); militar } \\
\text { Rovira, Buenaventura (of) }\end{array}$ & $\begin{array}{l}\text { Vimbodí } \\
\text { Calella } \\
\text { Vimbodi } \\
\text { Tarragona } \\
\text { Vilafranca del }\end{array}$ & $\begin{array}{l}1795 \\
1600 \\
1795 \\
1602 \\
1732 \\
1726\end{array}$ & $\begin{array}{l}\text { leg. } 3.724 / 51 \\
\text { libro } 731 \\
\text { leg. } 3.724 / 52 \\
\text { libro } 731 \\
\text { leg. } 2.162 \\
\text { leg. } 3.724 /\end{array}$ & $\begin{array}{l}\text { reprendido } \\
\text { reprendido } \\
\text { - }\end{array}$ \\
\hline $\begin{array}{l}\text { Rovira, Joan; estudiante } \\
\text { Rubio, Juan; militar } \\
\text { Ruiz de Porras, Joaquín; mariscal } \\
\text { de campo }\end{array}$ & Barcelona & $\begin{array}{l}1662 \\
1638 \\
1817\end{array}$ & $\begin{array}{l}\text { libro } 734 \\
\text { libro } 734 \\
\text { leg. } 2.177\end{array}$ & $\begin{array}{l}\text { suspenso } \\
\text { desterrado } \\
-\end{array}$ \\
\hline Sabonadiere, Jacques ( $f$ ) & Barcelona & 1720 & $\begin{array}{l}\operatorname{leg}_{128} 3.724 / \\
\end{array}$ & - \\
\hline $\begin{array}{l}\text { Sagas, Domenech; cirujano } \\
\text { Sague, Francesco; militar } \\
\text { Sala, Josep María; secretario } \\
\text { San Martin, Dominique (f) } \\
\text { Sanón, Nicolás (jer) } \\
\text { Santos, Francisco (s) }\end{array}$ & $\begin{array}{l}\text { Barcelona } \\
\text { Garriga, La } \\
\text { Barcelona } \\
\text { Barcelona } \\
\text { Barcelona }\end{array}$ & $\begin{array}{l}1726 \\
1764 \\
1757 \\
1573 \\
1611 \\
1753\end{array}$ & $\begin{array}{l}\text { leg. } 2.161 \\
\text { leg. } 3.724 / 61 \\
\text { leg. } 3.724 / 77 \\
\text { leg. } 1.592 / 27 \\
\text { libro } 732 \\
\text { leg. } 1.865 / 3 \text { y } \\
\text { 3.724/91 }\end{array}$ & $\begin{array}{l}- \\
\overline{-} \\
\text { recluido } \\
\text { reprendido }\end{array}$ \\
\hline $\begin{array}{l}\text { Sague, Jaime; militar } \\
\text { Sapera, Andreu; blanquero } \\
\text { Senerench, Guillaume }(\mathfrak{f}) \text {; sastre } \\
\text { Sentmanat, Antoni }\end{array}$ & $\begin{array}{l}\text { Cervera } \\
\text { Cubells }\end{array}$ & $\begin{array}{l}1819 \\
1608 \\
1591 \\
1816\end{array}$ & $\begin{array}{l}\text { leg. } 2.177 \\
\text { libro } 732 \\
\text { libro } 731 \\
\text { leg. } 2.177\end{array}$ & $\begin{array}{l}\text { reprendido } \\
\text { penitenciado } \\
-\end{array}$ \\
\hline
\end{tabular}




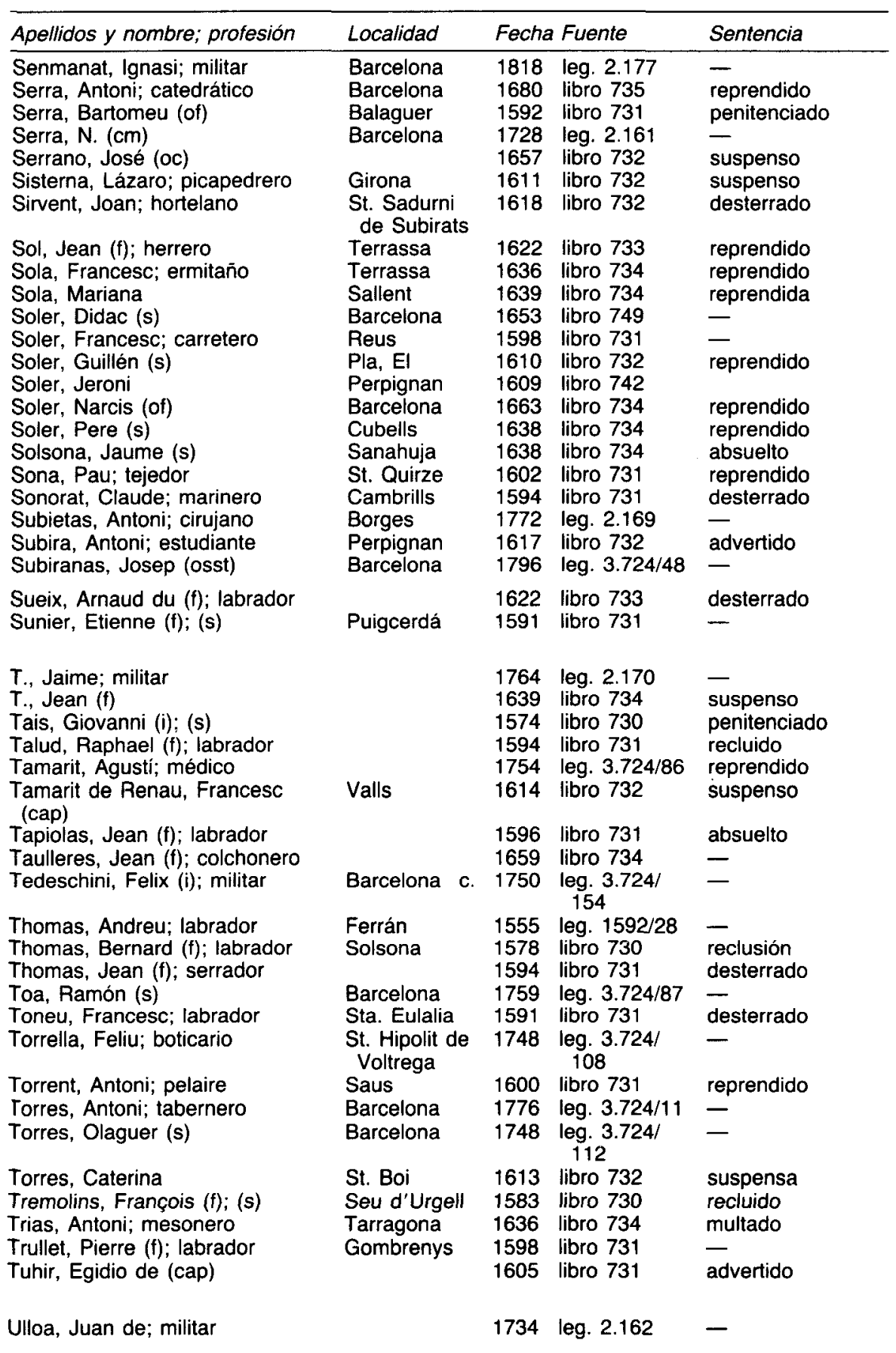


Catálogo de los procesos inquisitoriales del Tribunal del...

\begin{tabular}{|c|c|c|c|c|}
\hline Apellidos y nombre; profesión & Localidad & Fecha & Fuente & Sentencia \\
\hline $\begin{array}{l}\text { Valet, Josep; abogado } \\
\text { Valldosera, Garau; velero } \\
\text { Vallejo, José; visitador general de } \\
\text { rentas }\end{array}$ & $\begin{array}{l}\text { Barcelona } \\
\text { Barcelona } \\
\text { Olot }\end{array}$ & $\begin{array}{l}1639 \\
1632 \\
1739\end{array}$ & $\begin{array}{l}\text { libro } 734 \\
\text { libro } 733 \\
\text { leg. } 3.724 / \\
148\end{array}$ & multado \\
\hline Vallejo, Juan (osb) & Artesa & 1619 & libro 732 & reprendido \\
\hline $\begin{array}{l}\text { Valls, Bertrand }(\mathrm{f}) ; \text { pescador } \\
\text { Valldosera Joan }(\mathrm{cm})\end{array}$ & Tamarit & $\begin{array}{l}1578 \\
1658\end{array}$ & $\begin{array}{l}\text { libro } 730 \\
\text { libro } 734\end{array}$ & $\begin{array}{l}\text { azotado } \\
\text { suspenso }\end{array}$ \\
\hline Veguer, Josep Antoni; procurador & Barcelona & 1757 & leg. $3.724 / 69$ & - \\
\hline $\begin{array}{l}\text { Vegueria, Rafael de la }(f) \text {; } \\
\text { trajinero }\end{array}$ & & 1591 & libro 731 & - \\
\hline Velella, Joana & Bresca & 1596 & libro 731 & absuelta \\
\hline Vera, Anne de la $(f)$ & Perpignan & 1586 & libro 731 & penitenciada \\
\hline $\begin{array}{l}\text { Verges y Sevilla, José; } \\
\text { comerciante }\end{array}$ & Calella & 1820 & leg. 2.177 & - \\
\hline Verni, Pierre de (f); labrador & St. Pol & 1594 & libro 731 & recluido \\
\hline Verte, Magdalena & $\begin{array}{l}\text { St. Pere de } \\
\text { Pineda }\end{array}$ & 1595 & libro 731 & penitenciado \\
\hline Vidal, Bertrand (f); zapatero & Esparraguera & 1591 & libro 731 & desterrado \\
\hline Vidal, Elies; procurador & Puigcerdá & 1791 & leg. $3.731 / 8$ & - \\
\hline Vidal, Enric (op) & Barcelona & 1661 & libro 734 & suspenso \\
\hline Vidal, Pere (fraile) & & 1675 & libro 735 & suspenso \\
\hline Vidal, Sebastià; taponero & $\begin{array}{l}\text { St. Feliu de } \\
\text { Guíxols }\end{array}$ & 1780 & $\operatorname{leg} .3 .137 / 31$ & - \\
\hline Vila, Julia & Roca, La & 1595 & libro 731 & penitenciada \\
\hline Villallonga, Pere & Llambilles & 1745 & leg. 2.165 & - \\
\hline Vilancosa, Vicenç; pelaire & Cardona & 1596 & libro 731 & reprendido \\
\hline Vilapúa, Ana María & $\begin{array}{l}\text { St. Cugat c. } \\
\text { del Vallés }\end{array}$ & 1750 & $\begin{array}{l}\text { leg. } 3.724 / \\
163\end{array}$ & - \\
\hline Vilar, Segimon & Prats, Els & 1610 & libro 732 & - \\
\hline Vilaseca, Jacint (fraile) & Girona & 1778 & leg. $3.724 / 13$ & - \\
\hline Vilella, Joana & Broca & 1594 & libro 731 & - \\
\hline Vilella, Magdalena & Medionaaia & 1634 & libro 747 & multada \\
\hline Villa, Antoni; labrador & Domenys & 1633 & libro 733 & suspenso \\
\hline Villadoms, Ramón (s) & Samalus & 1653 & libro 749 & - \\
\hline Villajuana, Tomás; abogado & Barcelona & 1757 & leg. $3.724 / 17$ & - \\
\hline Villarroel y Portugal, Teresa & & 1734 & leg. 2.162 & - \\
\hline Vinacha, Josep (s) & & 1816 & leg. 2177 & - \\
\hline Vinyoles, Magi; herrero & Cervera & 1594 & libro 731 & recluido \\
\hline Viñes, Jaume; estudiante & Ivorra & 1621 & libro 733 & reprendido \\
\hline Vonnues, Antón; tabernero & Barcelona & 1778 & leg. 2.169 & \\
\hline Yanguas, Martín de (osb) & Montserrat & 1662 & libro 734 & reprendido \\
\hline
\end{tabular}

\section{PALABRAS}

Abadia, Jean (f)

Adin, Jean (f); pedralero

Alaret, Piñana (f)

Alcira, Pau; labrador

Aldevo, Joan

Alemán Jeroni 
JUAN BLÁZQUEZ MIGUEL

\begin{tabular}{|c|c|c|c|c|}
\hline Apellidos y nombre; profesión & Localidad & Fecha & Fuente & Sentencia \\
\hline $\begin{array}{l}\text { Alonso; boticario } \\
\text { Amat, Francina } \\
\text { Andriu, Michel (f); labrador } \\
\text { Anglada, Antoine (f) } \\
\text { Antoine Raphael (f) } \\
\text { Ardanes (s) } \\
\text { Aroch, Juan } \\
\text { Ataujana, Magdalena } \\
\text { Audela, Nicolas (f) } \\
\text { Aulessa, Caterina } \\
\text { Auseralt, Giralt (s) } \\
\text { Ayala, Hernado de } \\
\text { Aymerich, Antoni; labrador } \\
\text { Baleti, Miquel Josep; médico } \\
\text { Ball, Garau de } \\
\text { Ballas, Joan; labrador }\end{array}$ & $\begin{array}{l}\text { Torroellas } \\
\text { Barcelona } \\
\text { Besalú } \\
\text { Cornellá }\end{array}$ & $\begin{array}{l}1575 \\
1553 \\
1575 \\
1617 \\
1571 \\
1571 \\
1558 \\
1574 \\
1561 \\
1571 \\
1569 \\
1565 \\
1633 \\
1639 \\
1571 \\
1595\end{array}$ & $\begin{array}{l}\text { libro } 730 \\
\text { leg. } 1.592 / 28 \\
\text { libro } 730 \\
\text { libro } 732 \\
\text { libro } 730 \\
\text { libro } 730 \\
\text { leg. } 1.592 / 28 \\
\text { libro } 730 \\
\text { libro } 730 \\
\text { libro } 730 \\
\text { libro } 730 \\
\text { libro } 730 \\
\text { libro } 746 \\
\text { libro } 734 \\
\text { libro } 730 \\
\text { libro } 731\end{array}$ & $\begin{array}{l}\text { absuelto } \\
\text { recluido } \\
\text { reprendido } \\
\text { reprendido } \\
\text { multado } \\
\text { ¿reprendido? } \\
\text { absuelta } \\
\text { reconciliado } \\
\text { penitenciada } \\
\text { recluido } \\
\text { penitenciado } \\
\text { multado } \\
\text { recluido } \\
\text { desterrado }\end{array}$ \\
\hline Barri (f) & $\begin{array}{l}\text { Castello } \\
\text { d'Empuries }\end{array}$ & 1617 & libro 732 & suspensa \\
\hline $\begin{array}{l}\text { Barri, Joan }(s) \\
\text { Bauta, Jean de la (f); tejedor } \\
\text { Baylert, François }(f) \\
\text { Bayo, Antoine }(f) \text {; zapatero } \\
\text { Bejo, Jean (f) } \\
\text { Beltran, Jacques (f); zapatero } \\
\text { Benavent, Jerónima de } \\
\text { Benedit, Pere (s) } \\
\text { Berembela, Guillaume (f) } \\
\text { Beril, Guimot (f); zapatero } \\
\text { Bermuy, Joan; campanero } \\
\text { Bernat, Mateu; labrador } \\
\text { Besac, Pierre (f); blanquero } \\
\text { Blanc, Joanot (f) } \\
\text { Blanco, Pierre (f); labrador } \\
\text { Blanel, Clement (f) } \\
\text { Bolsia, Jean (f); pelaire } \\
\text { Boltas, Guillén; pelaire } \\
\text { Bollo, Arnaud (f); palafranero }\end{array}$ & $\begin{array}{l}\text { Guissona } \\
\text { Barcelona } \\
\text { Castellgalí } \\
\text { Balaguer } \\
\text { Sanahuja } \\
\text { Prades } \\
\text { Tordera } \\
\text { Alcover } \\
\text { Botarell } \\
\text { Torroella de } \\
\text { Montgri }\end{array}$ & $\begin{array}{l}1560 \\
1561 \\
1561 \\
1561 \\
1569 \\
1575 \\
1565 \\
1554 \\
1570 \\
1570 \\
1571 \\
1571 \\
1570 \\
1573 \\
1595 \\
1599 \\
1581 \\
1571 \\
1600\end{array}$ & $\begin{array}{l}\text { libro } 730 \\
\text { libro } 730 \\
\text { libro } 730 \\
\text { libro } 730 \\
\text { libro } 730 \\
\text { libro } 730 \\
\text { libro } 730 \\
\text { leg. } 1.592 / 28 \\
\text { libro } 730 \\
\text { libro } 730 \\
\text { libro } 730 \\
\text { libro } 730 \\
\text { libro 730 } \\
\text { leg. } 1.592 / 27 \\
\text { libro } 731 \\
\text { libro } 731 \\
\text { libro } 730 \\
\text { libro } 730 \\
\text { libro } 731\end{array}$ & $\begin{array}{l}\text { penitenciado } \\
\text { reconciliado } \\
\text { reconciliado } \\
\text { reprendido } \\
\text { penitenciado } \\
\text { recluido } \\
\text { absuelta } \\
\text { recluido } \\
\text { recluido } \\
\text { penitenciado } \\
\text { multado } \\
\text { reprendido } \\
\text { reprendido } \\
\text { desterrado } \\
\text { reprendido } \\
\text { recluido } \\
\text { penitenciado } \\
\text { reprendido }\end{array}$ \\
\hline $\begin{array}{l}\text { Bomba, Dominique }(\mathfrak{f}) \text {; labrador } \\
\text { Bompar, Pierre }(\mathfrak{f}) \text {; mozo de ca- } \\
\text { ballos }\end{array}$ & Vila-Rodona & $\begin{array}{l}1582 \\
1578\end{array}$ & $\begin{array}{l}\text { libro } 730 \\
\text { libro } 730\end{array}$ & $\begin{array}{l}\text { huyó } \\
\text { absuelto }\end{array}$ \\
\hline $\begin{array}{l}\text { Bona, Jean de (f); ligador } \\
\text { Borrás, Joan; labrador } \\
\text { Borrell, Francesc; labrador }\end{array}$ & $\begin{array}{l}\text { Pau } \\
\text { Fullola, La } \\
\text { Arenys de } \\
\text { Munt }\end{array}$ & $\begin{array}{l}1590 \\
1575 \\
1665\end{array}$ & $\begin{array}{l}\text { libro } 731 \\
\text { libro } 730 \\
\text { libro } 735\end{array}$ & $\begin{array}{l}\text { penitenciado } \\
\text { reprendido }\end{array}$ \\
\hline $\begin{array}{l}\text { Bosch, Leonard (f); tallador } \\
\text { Botinya, Francesc; blanquero } \\
\text { Bou, Onofre (f) } \\
\text { Brianca, Jacques (f) } \\
\text { Bugia de la Roca, Jean (f); pelaire } \\
\text { Burguera, Francesc (s) }\end{array}$ & $\begin{array}{l}\text { Alcover } \\
\text { Riudoms }\end{array}$ & $\begin{array}{l}1561 \\
1561 \\
1570 \\
1561 \\
1581 \\
1571\end{array}$ & $\begin{array}{l}\text { libro } 730 \\
\text { libro } 730 \\
\text { libro } 730 \\
\text { libro } 730 \\
\text { libro } 730 \\
\text { libro } 730\end{array}$ & $\begin{array}{l}\text { reconciliado } \\
\text { multado } \\
\text { recluido } \\
\text { reconciliado } \\
\text { recluído } \\
\text { multado }\end{array}$ \\
\hline $\begin{array}{l}\text { Cabrell, Jean Pierre (f) } \\
\text { Cairo, Michel du ( } f)\end{array}$ & & $\begin{array}{l}1578 \\
1570\end{array}$ & $\begin{array}{l}\text { libro } 730 \\
\text { libro } 730\end{array}$ & $\begin{array}{l}\text { absuelto } \\
\text { absuelto }\end{array}$ \\
\hline
\end{tabular}


Catálogo de los procesos inquisitoriales del Tribunal del...

\begin{tabular}{|c|c|c|c|c|}
\hline Apellidos y nombre; profesión & Localidad & Fecha & Fuente & Sentencia \\
\hline $\begin{array}{l}\text { Cajero, Alonso } \\
\text { Camprubina, Valentina } \\
\text { Camps, Pere (s) }\end{array}$ & $\begin{array}{l}\text { St. Jaume de } \\
\text { Calaf }\end{array}$ & $\begin{array}{l}1559 \\
1622 \\
1629\end{array}$ & $\begin{array}{l}\text { leg. } 1.592 / 28 \\
\text { libro } 733 \\
\text { libro } 733\end{array}$ & $\begin{array}{l}\text { - } \\
\text { reprendida } \\
\text { suspenso }\end{array}$ \\
\hline $\begin{array}{l}\text { Carbonell, Rosa } \\
\text { Carciner, Cristófol; botero } \\
\text { Campanedo, Francesco (i); lapi- } \\
\text { dario }\end{array}$ & Cervera & $\begin{array}{l}1562 \\
1571 \\
1633\end{array}$ & $\begin{array}{l}\text { libro } 730 \\
\text { libro } 730 \\
\text { libro } 733\end{array}$ & $\begin{array}{l}\text { penitenciada } \\
\text { penitenciado } \\
\text { desterrado }\end{array}$ \\
\hline $\begin{array}{l}\text { Cartheña, Juan } \\
\text { Carreras, Salvador } \\
\text { Casademar, Jeroni; labrador } \\
\text { Castanyer, Bartomeu } \\
\text { Cavestano, Julián } \\
\text { Cayre, Pierre (f); labrador } \\
\text { Cazane, Garau; baile } \\
\text { Cerda, Pierre, (f) } \\
\text { Claramonte, Angela de } \\
\text { Clariana, Pere; pelaire } \\
\text { Clocha, Benoit de la (f); pintor }\end{array}$ & $\begin{array}{l}\text { Olesa } \\
\text { Lladó } \\
\text { St. Esteve } \\
\text { Barcelona } \\
\text { Ager } \\
\text { Blanes } \\
\text { Barcelona } \\
\text { Oliana } \\
\text { Stes. Creus }\end{array}$ & $\begin{array}{l}1601 \\
1572 \\
1619 \\
1600 \\
1571 \\
1594 \\
1638 \\
1601 \\
1575 \\
1666 \\
1570\end{array}$ & $\begin{array}{l}\text { libro } 740 \\
\text { leg. } 1.592 / 27 \\
\text { libro } 732 \\
\text { libro } 731 \\
\text { libro } 730 \\
\text { libro } 731 \\
\text { libro } 734 \\
\text { libro } 740 \\
\text { libro } 730 \\
\text { libro } 735 \\
\text { libro } 730\end{array}$ & $\begin{array}{l}\text { reprendido } \\
\text { reprendido } \\
\text { reprendido } \\
\text { multado } \\
\text { recluido } \\
\text { reprendido } \\
\text { absuelto } \\
\text { suspenso } \\
\text { recluido }\end{array}$ \\
\hline $\begin{array}{l}\text { Cochart, François (f); cerrajero } \\
\text { Combas, Joan; labrador } \\
\text { Corp, Jean }(f) ; \text { labrador } \\
\text { Cortada, Dominique }(f) \text {; labrador } \\
\text { Cosi, François }(f) \text {; pintor } \\
\text { Costa, François }(f) \text {; sastre } \\
\text { Costa, Pierre }(f) \\
\text { Cros, Pierre }(f) \text {; labrador } \\
\text { Culgat, Jaume }\end{array}$ & $\begin{array}{l}\text { Barcelona } \\
\text { Cervera } \\
\text { St. Pons }\end{array}$ & $\begin{array}{l}1602 \\
1617 \\
1594 \\
1590 \\
1561 \\
1634 \\
1569 \\
1571 \\
1571\end{array}$ & $\begin{array}{l}\text { libro } 731 \\
\text { libro } 732 \\
\text { libro } 731 \\
\text { libro } 731 \\
\text { libro } 730 \\
\text { libro } 733 \\
\text { libro } 730 \\
\text { libro } 730 \\
\text { libro } 730\end{array}$ & $\begin{array}{l}\text { recluido } \\
\text { reprendido } \\
\text { absuelto } \\
\text { penitenciado } \\
\text { reconciliado } \\
\text { suspenso } \\
\text { penitenciado } \\
\text { azotado } \\
\text { azotado }\end{array}$ \\
\hline $\begin{array}{l}\text { Deupot, Gailard (f); barbero } \\
\text { Diego, Nicolás; militar } \\
\text { Díez, Martín (p); (er) } \\
\text { Domenjo, Miquel; labrador } \\
\text { Domenjo, Pierre (f); labrador }\end{array}$ & $\begin{array}{l}\text { Martorell } \\
\text { Guissona } \\
\text { Olot } \\
\text { Villafranca } \\
\text { del Penedés }\end{array}$ & $\begin{array}{l}1575 \\
1593 \\
1600 \\
1574 \\
1575\end{array}$ & $\begin{array}{l}\text { libro } 730 \\
\text { libro } 731 \\
\text { libro } 731 \\
\text { libro } 730 \\
\text { libro } 730\end{array}$ & $\begin{array}{l}\text { absuelto } \\
\text { reprendido } \\
\text { azotado y recluido } \\
\text { recluido }\end{array}$ \\
\hline $\begin{array}{l}\text { Domer, Garau (f); (s) } \\
\text { Dosán, Francesc } \\
\text { Dull, Johan, (fl) } \\
\text { Duran, Jean (f); labrador } \\
\text { Durban, Pierre (f) }\end{array}$ & $\begin{array}{l}\text { Prades } \\
\text { Perpignan }\end{array}$ & $\begin{array}{l}1571 \\
1571 \\
1610 \\
1600 \\
1600\end{array}$ & $\begin{array}{l}\text { libro } 730 \\
\text { libro } 730 \\
\text { libro } 732 \\
\text { libro } 731 \\
\text { libro } 731\end{array}$ & $\begin{array}{l}\text { penitenciado } \\
\text { multado } \\
\text { reprendido } \\
\text { reprendido }\end{array}$ \\
\hline Elies, Antoni; labrador & $\begin{array}{l}\text { Torredem- } \\
\text { barra }\end{array}$ & 1601 & libro 740 & desterrado \\
\hline $\begin{array}{l}\text { Esquiu, Jean }(f) \text {; carpintero } \\
\text { Estrada, Arnaud }(f)\end{array}$ & & $\begin{array}{l}1594 \\
1593\end{array}$ & $\begin{array}{l}\text { libro } 731 \\
\text { libro } 731\end{array}$ & desterrado \\
\hline $\begin{array}{l}\text { Fage Galties, Pierre }(f) \text {; sastre } \\
\text { Falquet, Pere; regador }\end{array}$ & $\begin{array}{l}\text { St. Fruitos } \\
\text { de Bages }\end{array}$ & $\begin{array}{l}1601 \\
1595\end{array}$ & $\begin{array}{l}\text { libro } 740 \\
\text { libro } 731\end{array}$ & recluido \\
\hline $\begin{array}{l}\text { Farga, Guillaume de la (f) } \\
\text { Fauria, Min de la (f); labrador } \\
\text { Faus, Guillén (s) } \\
\text { Ferrer, Bernard (f); tejedor } \\
\text { Ferrer, Francesc; correo }\end{array}$ & $\begin{array}{l}\text { Duesaigues } \\
\text { Manresa }\end{array}$ & $\begin{array}{l}1571 \\
1565 \\
1574 \\
1599 \\
1590\end{array}$ & $\begin{array}{l}\text { libro } 730 \\
\text { libro } 730 \\
\text { libro } 730 \\
\text { libro } 731 \\
\text { libro } 731\end{array}$ & $\begin{array}{l}\text { recluido } \\
\text { azotado } \\
\text { multado } \\
\text { reprendido } \\
\text { penitenciado }\end{array}$ \\
\hline
\end{tabular}


JUAN BLÁZQUEZ MIGUEL

\begin{tabular}{|c|c|c|c|c|}
\hline Apellidos y nombre; profesión & Localidad & Fecha & Fuente & Sentencia \\
\hline $\begin{array}{l}\text { Ferrer, Joan; candelero } \\
\text { Ferrer, Nadal } \\
\text { Ferrer, Narcis (s) } \\
\text { Ferre, Onofre (s) } \\
\text { Ferrer, Pere; maestro } \\
\text { Figarola Fragment, Etienne (f) } \\
\text { Florac, Jean (f) } \\
\text { Folora, Miquel; pelaire } \\
\text { Font, Joanot; tejedor } \\
\text { Forn, Joan } \\
\text { Fornat, Antoine (f) } \\
\text { Forner, Etienne (f); cantero } \\
\text { Forno, Gabriel } \\
\text { Fortanet, Bernard (f); pastor } \\
\text { Francina, Francesca (f) } \\
\text { Frexa, Pierre (f); trajinero } \\
\text { Fuente, Francisco; droguero } \\
\text { Furel, Antoni; labrador } \\
\text { Fusqueta, François (f) }\end{array}$ & $\begin{array}{l}\text { Gironella } \\
\text { Blanes } \\
\text { Barcelona } \\
\text { Bisbal, La } \\
\text { Camprodón }\end{array}$ & $\begin{array}{l}1659 \\
1571 \\
1608 \\
1635 \\
1565 \\
1637 \\
1569 \\
1602 \\
1571 \\
1565 \\
1584 \\
1582 \\
1572 \\
1618 \\
1571 \\
1602 \\
1619 \\
1556 \\
1603\end{array}$ & $\begin{array}{l}\text { libro } 734 \\
\text { libro } 730 \\
\text { libro } 732 \\
\text { libro } 733 \\
\text { libro } 730 \\
\text { libro } 734 \\
\text { libro } 730 \\
\text { libro } 731 \\
\text { libro } 730 \\
\text { libro } 730 \\
\text { libro } 730 \\
\text { libro } 730 \\
\text { leg. } 1.592 / 27 \\
\text { libro } 732 \\
\text { libro } 730 \\
\text { libro } 731 \\
\text { libro } 732 \\
\text { leg. } 1.592 / 23 \\
\text { libro } 731\end{array}$ & $\begin{array}{l}\text { - } \\
\text { reprendido } \\
\text { suspenso } \\
\text { reprendido } \\
\text { desterrado } \\
\text { suspenso } \\
\text { absuelto } \\
\text { reprendido } \\
\text { reprendido } \\
\text { absuelto } \\
\text { penitenciado } \\
\text { reprendido } \\
\text { desterrado } \\
\text { penitenciada } \\
\text { reprendido } \\
\text { reprendido } \\
\text { reprendido }\end{array}$ \\
\hline $\begin{array}{l}\text { Gabanach, Pierre (f) } \\
\text { Gallart, Antoni } \\
\text { Gallo, Fernando; militar } \\
\text { Gamboa, Antoine (f) } \\
\text { Garriga, Aleran; Antoni } \\
\text { Garrigas, Jacques (f); guantero }\end{array}$ & $\begin{array}{l}\text { Torá } \\
\text { Barcelona } \\
\text { Tarragona } \\
\text { Vilafranca } \\
\text { del Penedés }\end{array}$ & $\begin{array}{l}1571 \\
1574 \\
1638 \\
1571 \\
1571 \\
1599\end{array}$ & $\begin{array}{l}\text { libro } 730 \\
\text { libro } 730 \\
\text { libro } 734 \\
\text { libro } 730 \\
\text { libro } 730 \\
\text { libro } 731\end{array}$ & $\begin{array}{l}\text { penitenciado } \\
\text { absuelto } \\
\text { reprendido } \\
\text { penitenciado } \\
\text { penitenciado } \\
\text { reprendido }\end{array}$ \\
\hline $\begin{array}{l}\text { Gausach, Jean (f); pelaire } \\
\text { Geller Ferrer, Barthelemy (f) } \\
\text { Gener, Pere; labrador } \\
\text { Genes, Joanot de (f) } \\
\text { Geraldo } \\
\text { Gervasio, Antón (s) } \\
\text { Gibert, Gaspar; pelaire } \\
\text { Gileta, Tomás (of) } \\
\text { Gili, Jerome (f); labrador } \\
\text { Giligania (f); encuadernador }\end{array}$ & $\begin{array}{l}\text { Barcelona } \\
\text { Igualada } \\
\text { Reus } \\
\text { Barcelona }\end{array}$ & $\begin{array}{l}1599 \\
1569 \\
1665 \\
1571 \\
1559 \\
1570 \\
1622 \\
1571 \\
1619 \\
1575\end{array}$ & $\begin{array}{l}\text { libro } 731 \\
\text { libro } 730 \\
\text { libro } 735 \\
\text { libro } 730 \\
\text { leg. } 1.592 / 28 \\
\text { libro } 730 \\
\text { libro } 733 \\
\text { libro } 730 \\
\text { libro } 732 \\
\text { libro } 730\end{array}$ & $\begin{array}{l}\text { reprendido } \\
\text { penitenciado } \\
\text { suspenso } \\
\text { absuelto } \\
\text { absuelto } \\
\text { reprendido } \\
\text { penitenciado } \\
\text { reprendido } \\
\text { azotado y } 3 \text { años } \\
\text { en qaleras }\end{array}$ \\
\hline $\begin{array}{l}\text { Gio, Juan (s) } \\
\text { Giovanni, Domenico (i); (s) } \\
\text { Giraut, Jean (f) } \\
\text { Gitte, Montserrat } \\
\text { Golada, Domingo (g) }\end{array}$ & $\begin{array}{l}\text { Vilanova de } \\
\text { Cubells }\end{array}$ & $\begin{array}{l}1571 \\
1557 \\
1570 \\
1575 \\
1600\end{array}$ & $\begin{array}{l}\text { libro } 730 \\
\text { leg. } 1.592 / 23 \\
\text { libro } 730 \\
\text { libro } 732 \\
\text { libro } 731\end{array}$ & $\begin{array}{l}\text { penitenciado } \\
\text { absuelto } \\
\overline{\text { falleció }}\end{array}$ \\
\hline $\begin{array}{l}\text { Gordo, Bartolomé; labrador } \\
\text { Gorgoll, Joan (s) } \\
\text { Goreoch, Jeroni; notario }\end{array}$ & $\begin{array}{l}\text { Palamós } \\
\text { Barcelona }\end{array}$ & $\begin{array}{l}1599 \\
1575 \\
1561\end{array}$ & $\begin{array}{l}\text { libro } 731 \\
\text { libro } 730 \\
\text { libro } 730\end{array}$ & $\begin{array}{l}\text { reprendido } \\
\text { falleció } \\
\text { multado }\end{array}$ \\
\hline $\begin{array}{l}\text { Gran, Marsal del (f); labrador } \\
\text { Grau, Gabriel (s) } \\
\text { Grau, Pere Joan; militar } \\
\text { Grau Molés, Jaume; ganadero } \\
\text { Gresella, Antoni } \\
\text { Grisot, Guillaume (f) } \\
\text { Guardia, Pere, ¿relojero? } \\
\text { Gubias, Bernard (f); sastre }\end{array}$ & $\begin{array}{l}\text { Mataró } \\
\text { Esparraguera } \\
\text { Andorra } \\
\text { Barcelona } \\
\text { Barcelona } \\
\text { St. Boi } \\
\text { Barcelona }\end{array}$ & $\begin{array}{l}1603 \\
1654 \\
1659 \\
1619 \\
1574 \\
1574 \\
1562 \\
1571\end{array}$ & $\begin{array}{l}\text { libro } 731 \\
\text { libro } 734 \\
\text { libro } 734 \\
\text { libro } 732 \\
\text { libro } 730 \\
\text { libro } 730 \\
\text { libro } 730 \\
\text { libro } 730\end{array}$ & $\begin{array}{l}\text { reprendido } \\
\text { desterrado } \\
\text { reprendido } \\
\text { azotado } \\
\text { reclusión } \\
\text { reprendido } \\
\text { penitenciado }\end{array}$ \\
\hline
\end{tabular}


Catálogo de los procesos inquisitoriales del Tribunal del...

\begin{tabular}{|c|c|c|c|c|}
\hline Apellidos y nombre; profesion & Localidad & Fecha & Fuente & Sentencia \\
\hline $\begin{array}{l}\text { Guelles, Simó; militar } \\
\text { Gui, Miquel } \\
\text { Guioneta, Jeanne (f) } \\
\text { Gullona } \\
\text { Guiran (f); mozo de espuelas }\end{array}$ & $\begin{array}{l}\text { Pujalt } \\
\text { Castellbell }\end{array}$ & $\begin{array}{l}1617 \\
1665 \\
1602 \\
1565 \\
1562\end{array}$ & $\begin{array}{l}\text { libro } 732 \\
\text { libro } 735 \\
\text { libro } 731 \\
\text { libro } 730 \\
\text { libro } 730\end{array}$ & $\begin{array}{l}\text { reprendido } \\
\text { suspenso } \\
\text { desterrada } \\
\text { absuelta } \\
\text { azotado }\end{array}$ \\
\hline $\begin{array}{l}\text { Jacques, Montserrat } \\
\text { Jean Bernardi }(\mathfrak{f}) \\
\text { Jean Raymond }(\mathfrak{f}) \text {; trajinero }\end{array}$ & & $\begin{array}{l}1634 \\
1569 \\
1602\end{array}$ & $\begin{array}{l}\text { libro } 747 \\
\text { libro } 730 \\
\text { libro } 731\end{array}$ & $\begin{array}{l}\text { reconciliado } \\
\text { azotado y } 3 \text { años } \\
\text { en galeras }\end{array}$ \\
\hline $\begin{array}{l}\text { Joanot; sastre } \\
\text { Joli, Pierre (f); labrador } \\
\text { Jonsana, Tecla } \\
\text { Jean Barthelemy (f); labrador } \\
\text { Juan Bautista (t); lapidario } \\
\text { Joan Pasqual; baile } \\
\text { Juárez, Catalina } \\
\text { Juro, Miquel (s) }\end{array}$ & $\begin{array}{l}\text { Olesa } \\
\text { Alcover } \\
\text { Barcelona } \\
\text { Blancafort } \\
\text { Banyoles }\end{array}$ & $\begin{array}{l}1574 \\
1578 \\
1571 \\
1599 \\
1623 \\
1622 \\
1562 \\
1631\end{array}$ & $\begin{array}{l}\text { libro } 730 \\
\text { libro } 730 \\
\text { libro } 730 \\
\text { libro } 731 \\
\text { libro } 733 \\
\text { libro } 733 \\
\text { libro } 730 \\
\text { libro } 733\end{array}$ & $\begin{array}{l}\text { absuelto } \\
\text { penitenciada } \\
\text { reprendido } \\
\text { reprendido } \\
\text { reprendido } \\
\text { penitenciada } \\
\text { reprendido }\end{array}$ \\
\hline Hebrea, Miquel (s) & $\begin{array}{l}\text { Vilafranca } \\
\text { del Penedés }\end{array}$ & 1571 & libro 730 & reprendido \\
\hline $\begin{array}{l}\text { Haverret, Francesc; labrador } \\
\text { Haves, Jaume; hortelano } \\
\text { Heves, Jacob (s) } \\
\text { Heveter, Raphael (f) (s) }\end{array}$ & $\begin{array}{l}\text { St. Ponç } \\
\text { Perpignan }\end{array}$ & $\begin{array}{l}1654 \\
1639 \\
1570 \\
1570\end{array}$ & $\begin{array}{l}\text { libro } 734 \\
\text { libro } 734 \\
\text { libro } 730 \\
\text { libro } 730\end{array}$ & $\begin{array}{l}\text { suspenso } \\
\text { reprendido } \\
\text { absuelto } \\
\text { multado }\end{array}$ \\
\hline $\begin{array}{l}\text { Lafont, Etienne (f) } \\
\text { Leger, Juan } \\
\text { Leonart, Pierre (f); carretero } \\
\text { Lorens, Jean (f); carbonero } \\
\text { Llobet, Pere (osb) } \\
\text { Llordat, Ricard du (f) }\end{array}$ & $\begin{array}{l}\text { Perpignan } \\
\text { Gurri, El }\end{array}$ & $\begin{array}{l}1623 \\
1556 \\
1620 \\
1575 \\
1601 \\
1569\end{array}$ & $\begin{array}{l}\text { libro } 733 \\
\text { leg. } 1.592 / 23 \\
\text { libro } 732 \\
\text { libro } 730 \\
\text { libro } 740 \\
\text { libro } 730\end{array}$ & $\begin{array}{l}\text { desterrado } \\
\text { reprendido } \\
\text { falleció } \\
\text { azotado y } \\
\text { desterrado }\end{array}$ \\
\hline $\begin{array}{l}\text { Maestro, Jeronimo; pintor } \\
\text { Malafosa, Guillaume (f) } \\
\text { Malaret, Pierre (f); (s) } \\
\text { Manaut (f); (s) } \\
\text { Manero, Artic; terciopelero }\end{array}$ & $\begin{array}{l}\text { Barcelona } \\
\text { Espolla } \\
\text { Perpignan } \\
\text { Barcelona }\end{array}$ & $\begin{array}{l}1608 \\
1598 \\
1571 \\
1570 \\
1573\end{array}$ & $\begin{array}{l}\text { libro } 732 \\
\text { libro } 731 \\
\text { libro } 731 \\
\text { libro } 730 \\
\text { libro } 730\end{array}$ & $\begin{array}{l}\text { multado } \\
\text { reciuido } \\
\text { recluido } \\
\text { recluido } \\
\text { azotado y } \\
\text { desterrado }\end{array}$ \\
\hline $\begin{array}{l}\text { Marin, Gregorio; tejedor } \\
\text { March, Jaume; labrador } \\
\text { Martí } \\
\text { Martí, José } \\
\text { Mariner, Jaume; labrador } \\
\text { Martín, Damià; pelaire } \\
\text { Martorell, Onofre (s) } \\
\text { Mas, Bernard } \\
\text { Mas, Climent; pasamanero } \\
\text { Mas, Marti; labrador } \\
\text { Masó, Sebastià (s) } \\
\text { Matons?, Bartomeu; sastre } \\
\text { Mauri, Ambroise (f); albañil } \\
\text { May, Climent (osb) }\end{array}$ & $\begin{array}{l}\text { Barcelona } \\
\text { Castelldefels } \\
\text { Perpignan } \\
\text { Solsona } \\
\text { Borges } \\
\text { Armentera } \\
\text { Martorell }\end{array}$ & $\begin{array}{l}1575 \\
1599 \\
1561 \\
1622 \\
1632 \\
1617 \\
1571 \\
1598 \\
1565 \\
1628 \\
1629 \\
1619 \\
1595 \\
1574\end{array}$ & $\begin{array}{l}\text { libro } 730 \\
\text { libro } 731 \\
\text { libro } 730 \\
\text { libro } 733 \\
\text { libro } 733 \\
\text { libro } 732 \\
\text { libro } 730 \\
\text { libro } 731 \\
\text { libro } 730 \\
\text { libro } 733 \\
\text { libro } 733 \\
\text { libro } 732 \\
\text { libro } 731 \\
\text { libro } 730\end{array}$ & $\begin{array}{l}\text { azotado } \\
\text { reprendido } \\
\text { desterrado } \\
\text { reprendido } \\
\text { multado } \\
\text { multado } \\
\text { multado } \\
\text { desterrado } \\
\text { desterrado }\end{array}$ \\
\hline
\end{tabular}




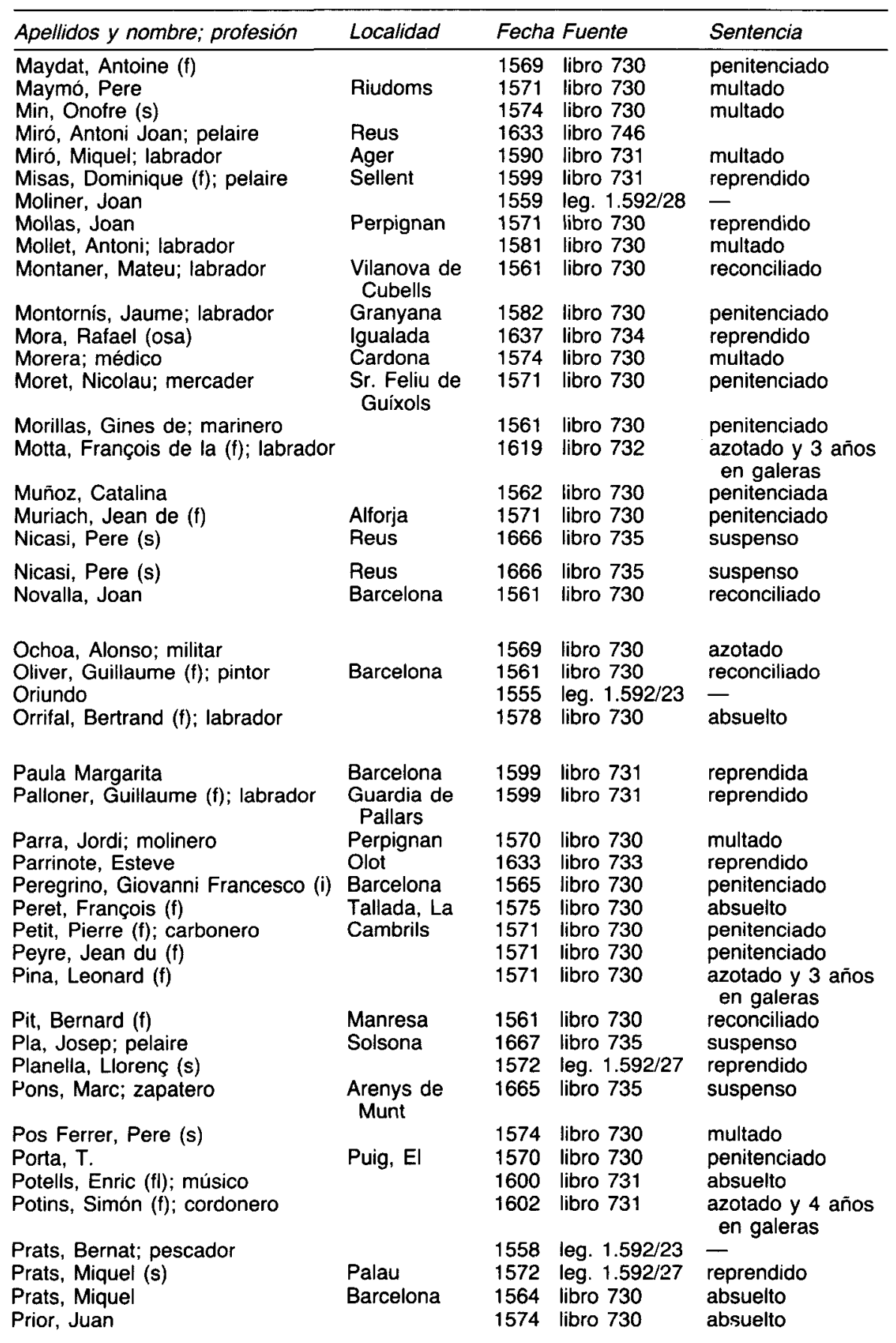


Catálogo de los procesos inquisitoriales del Tribunal del...

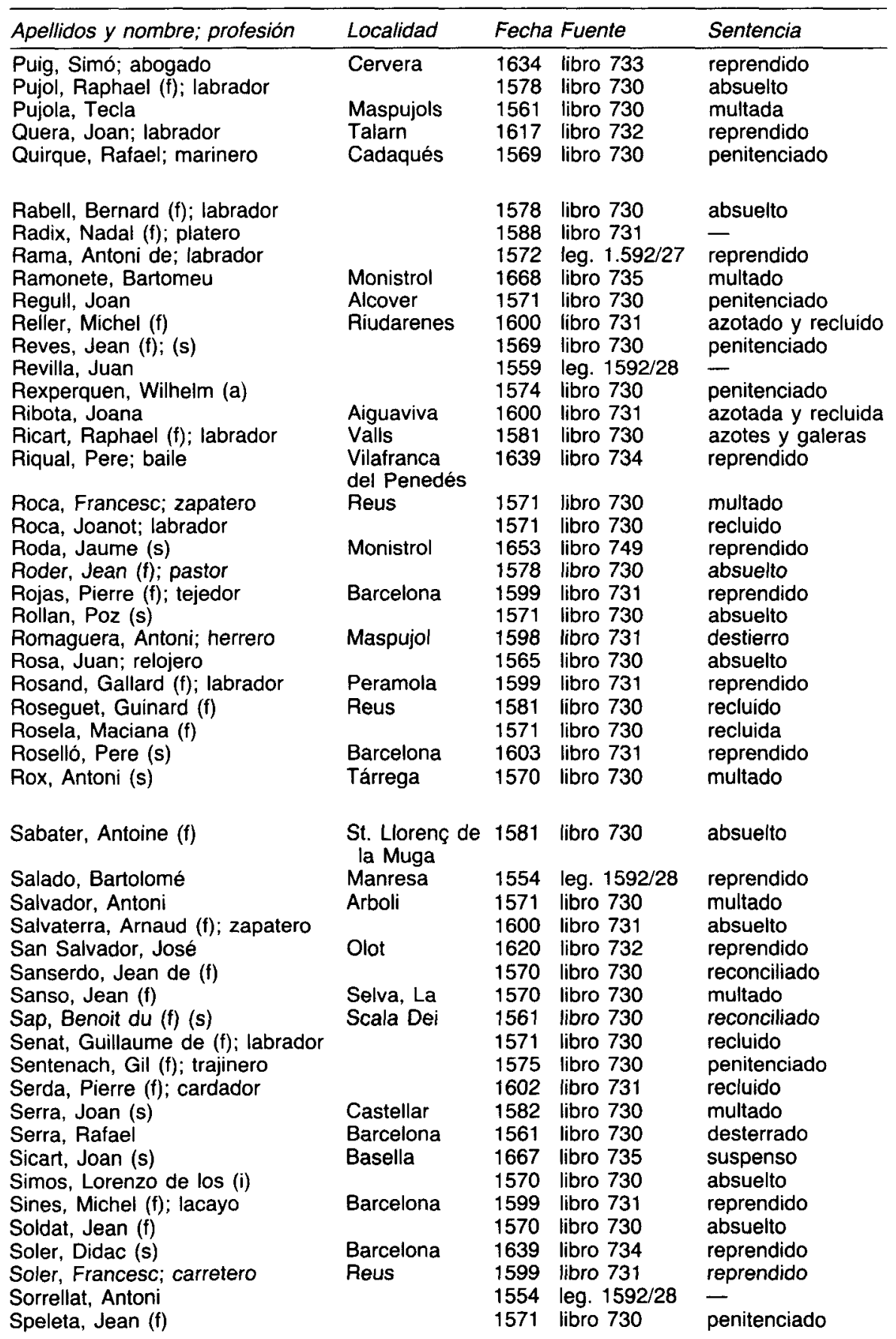




\begin{tabular}{|c|c|c|c|c|}
\hline Apellidos y nombre; profesión & Localidad & Fecha & Fuente & Sentencia \\
\hline $\begin{array}{l}\text { Tapias, Jean }(\mathfrak{f}) \\
\text { Taracan, Francés }(f)\end{array}$ & & $\begin{array}{l}1594 \\
1562\end{array}$ & $\begin{array}{l}\text { libro } 731 \\
\text { libro } 730\end{array}$ & $\begin{array}{l}\text { azotado y } \\
\text { desterrado }\end{array}$ \\
\hline $\begin{array}{l}\text { Tarlich, Miquel } \\
\text { Terço, Bernardo (i); militar } \\
\text { Texedor, Jean (f); albañil } \\
\text { Torrent, Joan } \\
\text { Torrens, Pau; labrador } \\
\text { Tremolet, Etienne (f); pastor } \\
\text { Trullet, Pierre (f) }\end{array}$ & $\begin{array}{l}\text { Taradell } \\
\text { Gombren }\end{array}$ & $\begin{array}{l}1574 \\
1654 \\
1617 \\
1565 \\
1658 \\
1575 \\
1599\end{array}$ & $\begin{array}{l}\text { libro } 730 \\
\text { libro } 734 \\
\text { libro } 732 \\
\text { libro } 730 \\
\text { libro } 751 \\
\text { libro } 730 \\
\text { libro } 731\end{array}$ & $\begin{array}{l}\text { multado } \\
\text { suspenso } \\
\text { reprendido } \\
\text { absuelto } \\
\text { recluido } \\
\text { reprendido }\end{array}$ \\
\hline $\begin{array}{l}\text { Ullo Estrella, Jeanne (f) } \\
\text { Valtes, Alexo; pescador } \\
\text { Valldoçera, Garau; toquero } \\
\text { Vidal, Pere; criado } \\
\text { Viejas, Antoine (f); cocinero }\end{array}$ & $\begin{array}{l}\text { Barcelona } \\
\text { Tarragona } \\
\text { Barcelona } \\
\text { Barcelona } \\
\text { Perpignan }\end{array}$ & $\begin{array}{l}1571 \\
1632 \\
1631 \\
1666 \\
1602\end{array}$ & $\begin{array}{l}\text { libro } 730 \\
\text { libro } 733 \\
\text { libro } 733 \\
\text { libro } 735 \\
\text { libro } 731\end{array}$ & $\begin{array}{l}\text { penitenciada } \\
\text { desterrado } \\
\text { suspenso } \\
\text { azotado y } \\
\text { desterrado }\end{array}$ \\
\hline $\begin{array}{l}\text { Vila, Antoni; labrador } \\
\text { Viladoms, Ramón (s) } \\
\text { Vilacossa, Vicenç } \\
\text { Vilar, Miquel (s) } \\
\text { Villa, Caterina } \\
\text { Viñals, Vicenç (s) } \\
\text { Vinyas, Jean des (f); cerrajero } \\
\text { Zapater, Pere (s) } \\
\text { Zapatero, Marc; pelaire }\end{array}$ & $\begin{array}{l}\text { Cornellá } \\
\text { Samalus } \\
\text { Cardona } \\
\text { St. Martí Vell } \\
\text { Cervera } \\
\text { Vilasar } \\
\text { Scala Dei } \\
\text { Passanant } \\
\text { Cardedeu }\end{array}$ & $\begin{array}{l}1633 \\
1639 \\
1595 \\
1639 \\
1557 \\
1639 \\
1629 \\
1584 \\
1569\end{array}$ & $\begin{array}{l}\text { libro } 746 \\
\text { libro } 734 \\
\text { libro } 731 \\
\text { libro } 734 \\
\text { leg. } 1592 / 23 \\
\text { libro } 734 \\
\text { libro } 733 \\
\text { libro } 730 \\
\text { libro } 730\end{array}$ & $\begin{array}{l}\text { suspenso } \\
\text { reprendido } \\
\text { reprendido } \\
\text { reprendido } \\
\text { multado } \\
\text { azotado }\end{array}$ \\
\hline
\end{tabular}

\section{BLASFEMIAS}

Arnís, Pere Pau; albañil Argiles, Pere; mesonero Agulló, Bernat; calcetero Agustí Nicolau; zapatero Alacayo, Juan; salmista Albengau, Michel (f) Albert, Bernard (f); carpintero Alomir, Josep; arriero Alonter, Pau

Altariba, Ignacio de; militar Amico, Jacomo $D^{\prime}$ (i); albañil Amorós, Bernat

Ana

Aneya, Josep; pescador

Aramus, Josep

Arani, Mariana

Aviñó, Francesc; caballero

Axer, Esteve

Aymerich, Jeroni

Ayralt, Jean (f); herrero

$\begin{array}{llll}\text { Barcelona } & 1668 & \text { libro } 735 & \text { multado } \\ \text { Tarragona } & 1618 & \text { libro } 732 & \begin{array}{l}\text { reprendido } \\ \text { reprendido }\end{array} \\ \text { Reus } & 1602 & \text { libro } 731 & \text { reprendido } \\ \text { Reus } & 1624 & \text { libro } 733 & \text { azotes y galeras } \\ \text { Balaguer } & 1564 & \text { libro } 730 & \text { las } \\ & 1554 & \text { leg. } 1.592 / 28 & \text { - } \\ \text { Perpignan } & 1575 & \text { libro } 730 & \text { penitenciado } \\ \text { Palafrugell } & 1674 & \text { libro } 735 & \text { suspenso } \\ \text { Selva, La } & 1638 & \text { libro } 734 & \text { suspenso } \\ & 1654 & \text { libro } 734 & \text { suspenso } \\ & 1639 & \text { libro } 734 & \text { desterrado } \\ \text { Barcelona } & 1676 & \text { libro } 735 & \text { suspenso } \\ \text { St. Feliu Sas- } & 1553 & \text { leg. } 1.592 / 28 & - \\ \text { serra } & 1687 & \text { leg. } 2.156 & \text { azotes y destierro } \\ \text { Reus } & 1696 & \text { libro } 760 & - \\ \text { Peralada } & 1617 & \text { libro } 732 & \text { reprendida } \\ \text { Barcelona } & 1569 & \text { libro } 730 & \text { multado } \\ \text { Besalú } & 1591 & \text { libro } 731 & - \\ \text { Barcelona } & 1610 & \text { libro } 732 & \text { reprendido } \\ \text { Vil-Avella } & 1608 & \text { libro } 732 & \text { reprendido }\end{array}$


Catálogo de los procesos inquisitoriales del Tribunal del...

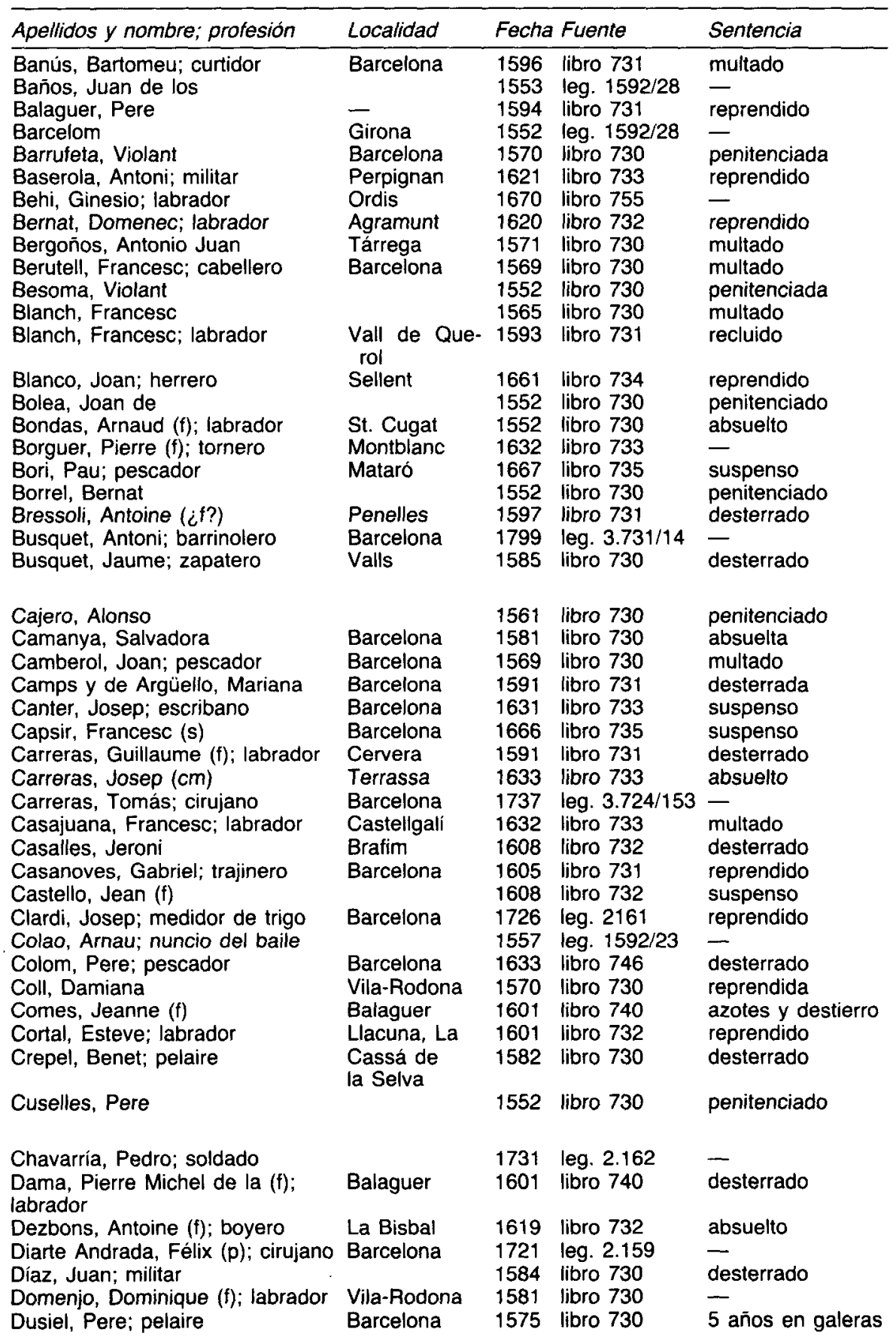




\begin{tabular}{|c|c|c|c|c|}
\hline Apellidos y nombre; profesión & Localidad & Fecha & Fuente & Sentencia \\
\hline Dovalls, Bernat; tejedor & Barcelona & 1584 & libro 730 & desterrado \\
\hline $\begin{array}{l}\text { Estadella, Francesc; mercader } \\
\text { Esteve, Leonor } \\
\text { Estrany, Pau; mercader }\end{array}$ & $\begin{array}{l}\text { Barcelona } \\
\text { Barcelona }\end{array}$ & $\begin{array}{l}1569 \\
1574 \\
1602\end{array}$ & $\begin{array}{l}\text { libro } 730 \\
\text { libro } 730 \\
\text { libro } 731\end{array}$ & $\begin{array}{l}\text { penitenciado } \\
\text { multada } \\
\text { azotado }\end{array}$ \\
\hline Fábregas, Miquel; pelaire & Balaguer & 1635 & libro 733 & suspenso \\
\hline $\begin{array}{l}\text { Falla, Jean (f) } \\
\text { Faner, Montserrat; hidalgo } \\
\text { Fato, Bartolomé; soldado } \\
\text { Ferida, Geraldo } \\
\text { Fernández, José; soldado }\end{array}$ & $\begin{array}{l}\text { Barcelona } \\
\text { Barcelona } \\
\text { Barcelona }\end{array}$ & $\begin{array}{l}1603 \\
1583 \\
1666 \\
1556 \\
1736\end{array}$ & $\begin{array}{l}\text { libro } 731 \\
\text { libro } 730 \\
\text { libro } 735 \\
\text { leg. } 1.592 / 23 \\
\text { leg. } 2.164 \text { y } \\
3.724 / 135\end{array}$ & $\begin{array}{l}\text { reprendido } \\
\text { suspenso } \\
-\end{array}$ \\
\hline $\begin{array}{l}\text { Ferrán, Damiá } \\
\text { Ferrera, Candia } \\
\text { Fexa, Pierre ( } f \text { ) } \\
\text { Finit, Pau } \\
\text { Font, Antoni; pescador } \\
\text { Font, Pere; portero } \\
\text { Forment, Jean (f); tejedor } \\
\text { Form, Jaume; labrador } \\
\text { Forner, Francesc; cintero } \\
\text { Fortuny, Antoni; labrador }\end{array}$ & $\begin{array}{l}\text { Barcelona } \\
\text { Montblanc } \\
\text { Sitges } \\
\text { Barcelona } \\
\text { Valls } \\
\text { Torá } \\
\text { Barcelona } \\
\text { Constantí }\end{array}$ & $\begin{array}{l}1581 \\
1600 \\
1601 \\
1658 \\
1564 \\
1565 \\
1575 \\
1622 \\
1616 \\
1654\end{array}$ & $\begin{array}{l}\text { libro } 730 \\
\text { libro } 731 \\
\text { libro } 740 \\
\text { libro } 734 \\
\text { libro } 730 \\
\text { libro } 730 \\
\text { libro } 730 \\
\text { libro } 733 \\
\text { libro } 732 \\
\text { libro } 734\end{array}$ & $\begin{array}{l}\text { absuelto } \\
\text { reprendida } \\
\text { reprendido } \\
\text { multado } \\
\text { penitenciado } \\
\text { penitenciado } \\
\text { reprendido } \\
\text { desterrado }\end{array}$ \\
\hline $\begin{array}{l}\text { Gabriel Simó; herrero } \\
\text { Galabor, Pere; hortelano } \\
\text { Garcés, Marti; criado } \\
\text { Gebolli, Pere } \\
\text { Gener, Simó; soldado } \\
\text { Gibert de Livia, Jean (f); } \\
\text { picapedrero }\end{array}$ & $\begin{array}{l}\text { Pons } \\
\text { Barcelona } \\
\text { Montblanc } \\
\text { Andorra }\end{array}$ & $\begin{array}{l}1609 \\
1574 \\
1564 \\
1558 \\
1658 \\
1631\end{array}$ & $\begin{array}{l}\text { libro } 732 \\
\text { libro } 730 \\
\text { libro } 730 \\
\text { leg. } 1.592 / 28 \\
\text { libro } 734 \\
\text { libro } 733\end{array}$ & $\begin{array}{l}\text { desterrado } \\
\text { penitenciado } \\
\text { azotes y destierro } \\
- \\
\text { reprendido } \\
\text { reprendido }\end{array}$ \\
\hline $\begin{array}{l}\text { Gil, Francesco (i) } \\
\text { Gilabert, Miquel; labrador } \\
\text { Gomez y Santagati, Andrea (i) } \\
\text { Gómez, Jorge } \\
\text { Gorgot, Andreu } \\
\text { Gorgot, Margarida }\end{array}$ & $\begin{array}{l}\text { Terrades } \\
\text { Terrades }\end{array}$ & $\begin{array}{l}1598 \\
1598 \\
1722 \\
1553 \\
1571 \\
1565\end{array}$ & $\begin{array}{l}\text { libro } 731 \\
\text { libro } 731 \\
\text { leg. } 2.159 \\
\text { leg. } 1.592 / 28 \\
\text { libro } 730 \\
\text { libro } 730\end{array}$ & $\begin{array}{l}\text { reprendido } \\
\text { desterrado } \\
\overline{-} \\
\overline{\text { multado }} \\
\text { multada }\end{array}$ \\
\hline $\begin{array}{l}\text { Jean Marie (f) } \\
\text { Jimenez, Ana Ángela } \\
\text { Joanot; sastre } \\
\text { Juan Jacobo (i); pintor } \\
\text { Guarner, Climent; sastre } \\
\text { Grau, Pere Joan; soldado } \\
\text { Gressa, Josep; albañil } \\
\text { Guardia, Jaume; criado }\end{array}$ & $\begin{array}{l}\text { Barcelona } \\
\text { Olesa } \\
\text { Manresa } \\
\text { Girona } \\
\text { Llers } \\
\text { Tarragona }\end{array}$ & $\begin{array}{l}1571 \\
1574 \\
1591 \\
1610 \\
1570 \\
1659 \\
1685 \\
1636\end{array}$ & $\begin{array}{l}\text { libro } 730 \\
\text { libro } 730 \\
\text { libro } 731 \\
\text { libro } 732 \\
\text { libro } 730 \\
\text { libro } 734 \\
\text { libro } 758 \\
\text { libro } 734\end{array}$ & $\begin{array}{l}\text { penitenciado } \\
\text { azotes y destierro } \\
\text { reprendido } \\
\text { absuelto } \\
\text { - } \\
\text { suspenso }\end{array}$ \\
\hline $\begin{array}{l}\text { Gumila, Joana } \\
\text { Guzil, Leonor }\end{array}$ & $\begin{array}{l}\text { Barcelona } \\
\text { Pons }\end{array}$ & $\begin{array}{l}1737 \\
1667\end{array}$ & $\begin{array}{l}\text { leg. } 2.164 \\
\text { libro } 735\end{array}$ & suspensa \\
\hline $\begin{array}{l}\text { Ibarra, Esteban de } \\
\text { Lacay, Pierre }(\mathfrak{f}) \text {; pastor } \\
\text { Leo, Juan Antonio } \\
\text { León, Cristóbal de }\end{array}$ & & $\begin{array}{l}1574 \\
1634 \\
1565 \\
1553\end{array}$ & $\begin{array}{l}\text { libro } 730 \\
\text { libro } 733 \\
\text { libro } 730 \\
\text { leg. } 1592 / 28\end{array}$ & $\begin{array}{l}- \\
\text { falleció } \\
\text { penitenciado }\end{array}$ \\
\hline
\end{tabular}


Catálogo de los procesos inquisitoriales del Tribunal del...

\begin{tabular}{|c|c|c|c|c|}
\hline \multirow{2}{*}{$\frac{\text { Apellidos y nombre; profesión }}{\text { Leonard Philippe (f) }}$} & \multirow{2}{*}{$\frac{\text { Localidad }}{\text { Tarragona }}$} & \multicolumn{2}{|c|}{ Fecha Fuente } & \multirow{2}{*}{$\frac{\text { Sentencia }}{\text { suspenso }}$} \\
\hline & & 1637 & $\begin{array}{l}\text { Rrcords., pp. } \\
78-113\end{array}$ & \\
\hline Lesoma, Violant & & 1552 & leg. $1.592 / 28$ & - \\
\hline Lizo, Luis & Barcelona & 1748 & leg. 2.165 & - \\
\hline Logaya de los Olivos, Pubil & & 1552 & libro 730 & penitenciado \\
\hline López, Ana & Barcelona & 1562 & libro 730 & azotada \\
\hline Llana, Jean (f); criado & & 1602 & libro 731 & reprendido \\
\hline Llevaneras, Joan de & & 1574 & libro 730 & falleció \\
\hline Llevat, Ramón; labrador & Barcelona & 1729 & leg. 2.162 & - \\
\hline $\begin{array}{l}\text { Llevat, Salvador; hortelano } \\
\text { Llovet, Margarida }\end{array}$ & Barcelona & $\begin{array}{l}1728 \\
1668\end{array}$ & $\begin{array}{l}\text { leg. } 2.161 \\
\text { libro } 735\end{array}$ & $\begin{array}{l}5 \text { años en presidio } \\
\text { suspensa }\end{array}$ \\
\hline $\begin{array}{l}\text { Llovet, Margarida } \\
\text { Llordera, Pere Joan; herrero }\end{array}$ & Prats de Rei & $\begin{array}{l}1008 \\
1685\end{array}$ & libro 758 & suspensa \\
\hline Llorens, Panevo & Barcelona & 1668 & libro 735 & suspenso \\
\hline al, Pierre (f); (s) & & 1571 & libro 730 & multado \\
\hline e, Francesc (s) & Ager & 1603 & libro 731 & - \\
\hline Majona, Ana & & 1565 & libro 730 & azotes y destierro \\
\hline Malafeta, María & & 1610 & libro 732 & suspensa \\
\hline Malla, Miguel (g) & Barcelona & 1667 & libro 735 & suspenso \\
\hline Marques, Antic; labrador & Palafrugell & 1565 & libro 730 & multado \\
\hline Martín & Barcelona & 1743 & leg. 2.164 & - \\
\hline Martín Nicolau, Antoni & Castelvell & 1594 & libro 731 & multado \\
\hline Martínez, Francisco & & 1552 & libro 730 & penitenciado \\
\hline Mas Joan, Vidal & Viladrau & 1584 & libro 730 & multado \\
\hline Masona, Ana & & 1553 & leg. $1.592 / 28$ & - \\
\hline Mateo Pascual; papelero & Olot & 1634 & libro 733 & desterrado \\
\hline Mauri, Gregori; abogado & Tremp & 1606 & libro 732 & desterrado \\
\hline Maymó, Denis (f) & Perpignan & 1571 & libro 730 & absuelto \\
\hline Mayoral, Sebastián; labradcr & Cornellana & 1606 & libro 732 & reprendido \\
\hline Mendoza, Marcos de; soldado & & 1560 & libro 730 & - \\
\hline Mensa, Pere; coralero & Barcelona & 1575 & libro 730 & penitenciado \\
\hline Merce, Guillaume (f); cerrajero & Tremp & 1600 & libro 731 & desterrado \\
\hline Mercet, Josep & & 1574 & libro 730 & multado \\
\hline Miró, Pere; mesonero & & 1585 & libro 730 & reprendido \\
\hline Montells, Jean ( () ; labrador & Terrassa & 1565 & libro 730 & penitenciado \\
\hline Montenego, Manuel & Barcelona & 1725 & leg. 2.161 & - \\
\hline Motornés, Jaume & Granyana & 1581 & libro 730 & - \\
\hline Mota, Pons; labrador & Orfes & 1589 & libro 731 & multado \\
\hline Moreras, Antoni & & 1629 & libro 733 & \\
\hline Mosach, Joan; labrador & Camprodón & 1569 & libro 730 & multado \\
\hline Naves, Jaume; hortelano & Barcelona & 1639 & libro 734 & - \\
\hline Nin, Francesc & Albinyana & 1674 & libro 735 & suspenso \\
\hline Nollat, Paul (f); (s) & Garriga, La & 1570 & libro 730 & reclusión \\
\hline Ogalde, Miguel Ángel; guarda & Cardona & 1741 & $\begin{array}{l}\text { leg. } 2.164 y \\
3.724 / 125\end{array}$ & - \\
\hline Ordóñez, Sebastián & - & 1580 & $\operatorname{leg} .2158$ & - \\
\hline Orellas, Grau; carpintero & Barcelona & 1575 & libro 730 & multado \\
\hline Pagés, Antoine (f) & Puigcerdá & 1570 & libro 730 & penitenciado \\
\hline & & 1622 & libro 733 & \\
\hline Palomer, Guillaume (f) & Guardia & 1598 & libro 731 & desterrado \\
\hline Panicer, Nadal; comerciante & Terri, EI & 1578 & libro 730 & - \\
\hline
\end{tabular}


JUAN BLAZZQUEZ MIGUEL

\begin{tabular}{|c|c|c|c|c|}
\hline Apellidos y nombre; profesión & Localidad & Fecha & Fuente & Sentencia \\
\hline $\begin{array}{l}\text { Panies, Francesc; labrador } \\
\text { Pansola, Joan; trajinero } \\
\text { Perarnau, Pere de; labrador } \\
\text { Pere Simó } \\
\text { Pinos, Bernat; labrador } \\
\text { Pionato, Teodoro (i); soldado } \\
\text { Plana, Toni } \\
\text { Planes, Pere } \\
\text { Plaza, Francesco (i); soldado } \\
\text { Pons, Miquel } \\
\text { Pontons, Francesc } \\
\text { Posigles, Andreu; labrador } \\
\text { Prats, Jaume } \\
\text { Pros, Antoni; carnicero } \\
\text { Prunero, Perot } \\
\text { Puig, Miquel; portero } \\
\text { Puig, Pere } \\
\text { Pujol, Sebastià; tejedor } \\
\text { Ramonete, Bartomeu; criado } \\
\text { Regás, Antón; escopetero } \\
\text { Regás, Toni; pedreñalero } \\
\text { Rey, Joan; zapatero }\end{array}$ & $\begin{array}{l}\text { Valcerbre } \\
\text { Perpignan } \\
\text { St. Salvador } \\
- \\
\text { Manresa } \\
\text { Granollers } \\
\text { Alcover } \\
\text { Tarragona } \\
\text { Hospitalet } \\
\text { Barcelona } \\
\text { Valls } \\
\text { Barcelona } \\
\text { Barcelona } \\
\text { Vic } \\
\text { Monistrol } \\
\text { Arenys }\end{array}$ & $\begin{array}{l}1584 \\
1609 \\
1575 \\
1571 \\
1621 \\
1633 \\
1565 \\
1610 \\
1634 \\
1557 \\
1674 \\
1554 \\
1608 \\
1562 \\
1571 \\
1612 \\
1610 \\
1637 \\
1665 \\
1588 \\
1565 \\
1570\end{array}$ & $\begin{array}{l}\text { libro } 730 \\
\text { libro } 732 \\
\text { libro } 730 \\
\text { libro } 730 \\
\text { libro } 733 \\
\text { libro } 733 \\
\text { libro } 735 \\
\text { libro } 732 \\
\text { libro } 747 \\
\text { leg. } 1.592 / 23 \\
\text { libro } 755 \\
\text { leg. } 1.592 / 28 \\
\text { libro } 732 \\
\text { libro } 730 \\
\text { libro } 730 \\
\text { libro } 732 \\
\text { libro } 732 \\
\text { libro } 734 \\
\text { libro } 735 \\
\text { libro } 731 \\
\text { libro } 730 \\
\text { libro } 730\end{array}$ & $\begin{array}{l}\text { penitenciado } \\
\text { desterrado } \\
\text { penitenciado } \\
\text { azotado } \\
\text { reprendido } \\
\text { desterrado } \\
\text { penitenciado } \\
\text { reprendido } \\
- \\
- \\
\text { suspenso } \\
\text { multado } \\
\text { multado } \\
\text { reclusión } \\
\text { desterrado } \\
\text { reprendido } \\
\text { reprendido } \\
\text { multado } \\
\text { reprendido }\end{array}$ \\
\hline $\begin{array}{l}\text { Ribó, Jaume; carpintero } \\
\text { Riera, Joan; currador } \\
\text { Roca, Rafael (s) } \\
\text { Roch, Andreu; labrador } \\
\text { Roda, Francisco de; verdugo } \\
\text { Roig, Mateu; chapinero } \\
\text { Roma, Juan } \\
\text { Roquer, Francesc } \\
\text { Roquer, Llorenç }\end{array}$ & $\begin{array}{l}\text { Isona } \\
\text { Arenys } \\
\text { Biure } \\
\text { Barcelona } \\
\text { Mongai } \\
\text { Tárrega } \\
\text { St. Andreu de } \\
\text { Socarrats }\end{array}$ & $\begin{array}{l}1620 \\
1575 \\
1665 \\
1571 \\
1596 \\
1574 \\
1609 \\
1594 \\
1569\end{array}$ & $\begin{array}{l}\text { libro } 732 \\
\text { libro } 730 \\
\text { libro } 735 \\
\text { libro } 730 \\
\text { libro } 731 \\
\text { libro } 730 \\
\text { libro } 732 \\
\text { libro } 731 \\
\text { libro } 730\end{array}$ & $\begin{array}{l}\text { reprendido } \\
\text { multado } \\
\text { desterrado } \\
\text { azotado } \\
\text { azotado } \\
\text { multado } \\
\text { desterrado } \\
\text { desterrado } \\
\text { azotado y } 6 \text { años } \\
\text { en galeras }\end{array}$ \\
\hline $\begin{array}{l}\text { Roquer, Miquel; labrador } \\
\text { Rosa, Ángela } \\
\text { Rossell, Coloma } \\
\text { Rosell, Joan; labrador } \\
\text { Rosell, Joan; cirujano } \\
\text { Rosell, Miquel } \\
\text { Ruiz Albarracin, Juan } \\
\text { Ruiz, Martin; soldado }\end{array}$ & $\begin{array}{l}\text { Barcelona } \\
\text { Ardevol } \\
\text { Balaguer } \\
\text { St. Gregori }\end{array}$ & $\begin{array}{l}1610 \\
1594 \\
1661 \\
1581 \\
1626 \\
1570 \\
1565 \\
1610\end{array}$ & $\begin{array}{l}\text { libro } 732 \\
\text { libro } 731 \\
\text { libro } 734 \\
\text { libro } 730 \\
\text { libro } 732 \\
\text { libro } 730 \\
\text { libro } 730 \\
\text { libro } 732\end{array}$ & $\begin{array}{l}\text { reprendido } \\
\text { multada } \\
\text { suspenso } \\
\text { multado } \\
\text { reprendido } \\
\text { penitenciado } \\
\text { penitenciado } \\
\text { multado }\end{array}$ \\
\hline $\begin{array}{l}\text { Saldoni, Gil; barbero } \\
\text { Salvi Puig, Gaspar; labrador } \\
\text { Santa Clara, Jean de (f) } \\
\text { Sauret, Guillaume (f); sastre } \\
\text { Sebastia,, Ramón } \\
\text { Segalas, Pierre (f) } \\
\text { Selma, Lluis } \\
\text { Serra, Antoni } \\
\text { Soguer, Antoni } \\
\text { Sola, Miquel; arriero }\end{array}$ & $\begin{array}{l}\text { Calaf } \\
\text { Perpignan } \\
\text { Guardiola } \\
\text { Selva, La } \\
\text { Tarragona } \\
\text { Tárrega }\end{array}$ & $\begin{array}{l}1602 \\
1626 \\
1570 \\
1589 \\
1614 \\
1569 \\
1597 \\
1571 \\
1555 \\
1685\end{array}$ & $\begin{array}{l}\text { libro } 731 \\
\text { libro } 732 \\
\text { libro } 730 \\
\text { libro } 731 \\
\text { libro } 732 \\
\text { libro } 730 \\
\text { libro } 731 \\
\text { libro } 730 \\
\text { leg. } 1.592 / 28 \\
\text { libro } 758\end{array}$ & $\begin{array}{l}\text { - } \\
\text { reprendido } \\
\text { azotado } \\
\text { penitenciado } \\
\text { reprendido } \\
\text { penitenciado } \\
\text { penitenciado } \\
\text { multado } \\
\text { reprendido }\end{array}$ \\
\hline $\begin{array}{l}\text { Soldado, un; soldado } \\
\text { Solera, Ángela }\end{array}$ & $\begin{array}{l}\text { Palamós } \\
\text { Barcelona }\end{array}$ & $\begin{array}{l}1668 \\
1569\end{array}$ & $\begin{array}{l}\text { libro } 735 \\
\text { libro } 730\end{array}$ & $\begin{array}{l}\text { suspenso } \\
\text { penitenciada }\end{array}$ \\
\hline
\end{tabular}


Catálogo de los procesos inquisitoriales del Tribunal del...

\begin{tabular}{|c|c|c|c|c|}
\hline Apellidos y nombre; profesión & Localidad & Fecha & Fuente & Sentencia \\
\hline Sunyer, Etienne (f); (s) & Puigcerdá & 1574 & libro 730 & - \\
\hline $\begin{array}{l}\text { T, José; pescador } \\
\text { Taragal, Carlos; militar } \\
\text { Tarrida, Gaspar; marinero } \\
\text { Texidor, José; soldado } \\
\text { Terolet, Bernard (f) } \\
\text { Travesset, Jeroni } \\
\text { Tolsa, Buenaventura; criado } \\
\text { Tollet, Jean (f); labrador } \\
\text { Torrens, Pere; labrador } \\
\text { Torrentey, Joan }\end{array}$ & $\begin{array}{l}\text { Barcelona } \\
\text { Barcelona } \\
\text { Balaguer } \\
\text { Solsona } \\
\text { Barcelona } \\
\text { Monistrol } \\
\text { Miralles }\end{array}$ & $\begin{array}{l}1764 \\
1655 \\
1725 \\
1655 \\
1602 \\
1622 \\
1731 \\
1626 \\
1581 \\
1553\end{array}$ & $\begin{array}{l}\text { leg. } 2.170 \\
\text { libro } 750 \\
\text { leg. } 2.161 \\
\text { libro } 750 \\
\text { libro } 731 \\
\text { libro } 733 \\
\text { leg. } 2.162 \\
\text { libro } 732 \\
\text { libro } 730 \\
\text { leg. } 1.593 / 28\end{array}$ & $\begin{array}{l}- \\
- \\
\text { - } \\
\text { reprendido } \\
\text { reprendido } \\
\text { desterrado } \\
\text { multado } \\
-\end{array}$ \\
\hline $\begin{array}{l}\text { Valdeperas, Jaume; labrador } \\
\text { Valenciano, Manuel; soldado } \\
\text { Valls, Lluis (om) } \\
\text { Vaquer, Gaspar; labrador } \\
\text { Vellú, Juan Baptista; labrador } \\
\text { Vergara, Joan } \\
\text { Vergés, Esteve; mesonero } \\
\text { Veynat, Francesc; notario } \\
\text { Vicents, Bernat; labrador } \\
\text { Vicens, Antoni; labrador } \\
\text { Villanova, Francesc; herrero } \\
\text { Visquet, Pere (s) } \\
\text { Vives, Andreu; labrador } \\
\text { Vives, Joan; soldado }\end{array}$ & $\begin{array}{l}\text { Olesa } \\
\text { Seu d'Urgell } \\
\text { Barcelona } \\
\text { Castellfollit } \\
\text { Figueres } \\
\text { Barcelona } \\
\text { Castellbo } \\
\text { Gurb } \\
\text { Solsona } \\
\text { Peralada } \\
\text { Barcelona }\end{array}$ & $\begin{array}{l}1662 \\
1726 \\
1583 \\
1685 \\
1674 \\
1558 \\
1581 \\
1575 \\
1571 \\
1602 \\
1616 \\
1623 \\
1612 \\
1692\end{array}$ & $\begin{array}{l}\text { libro } 734 \\
\text { leg. } 2.161 \\
\text { libro } 730 \\
\text { libro } 758 \\
\text { libro } 735 \\
\text { leg. } 1.592 / 28 \\
\text { libro } 730 \\
\text { libro } 730 \\
\text { libro } 730 \\
\text { libro } 731 \\
\text { libro } 732 \\
\text { libro } 733 \\
\text { libro } 732 \\
\text { libro } 735\end{array}$ & $\begin{array}{l}\text { reprendido } \\
\text { reprendido } \\
\text { reclusión } \\
\text { suspenso } \\
\text { multado } \\
\text { absuelto } \\
\text { azotado } \\
\text { multado } \\
\text { reprendido } \\
\text { reprendido } \\
\text { reprendido }\end{array}$ \\
\hline Zapater, Joan & Perpignan & 1552 & leg. $1.592 / 28$ & - \\
\hline
\end{tabular}

\section{MISTICISMO HETERODOXO}

\section{Alumbrados}

$\begin{array}{llrl}\text { Maria de Sant Josep (omi) } & \text { Barcelona } & 1627 & \text { libro 733 } \\ \text { María de la Trinidad (OMI) } & \text { Barcelona } & 1633 & \text { libro } 746 \\ & & & \\ \text { Montserrat, Oleguer (s) } & \text { Tarragona } & 1674 & \text { libro } 755 \\ \text { Moratón, Antoni (OM) } & \text { Barcelona } & 1628 & \text { libro 733 } \\ \text { Sánchez, Alonso (s) } & \text { Barcelona } & 1628 & \text { libro 733 }\end{array}$

penitencias espirituales penitencias espirituales

reprendido azotado y 6 años en galeras

\section{Molinosistas}

Alberto de la Virgen (oc) Audet i Ribert, Francesc
Reus

Moia
1691 libro 735

1771 leg. 2.170 recluido 
JUAN BLAZQUEZ MIGUEL

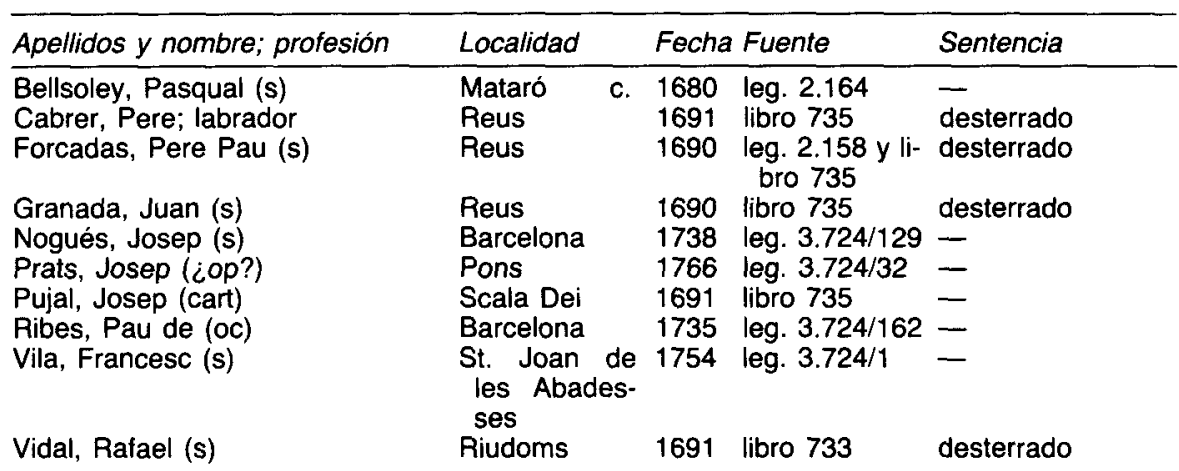

Ilusos

Arbiol, Gertrudis

Capdevila, Joan de; cerrajero

Casternellas, María

Dernils, Antoni (op)

Domenge, Ana (dom)

Espiral, Joaquim

Fábregas, Pau

Francisca de Aviñón

Francisco de Menorca (cap)

Fulgencio de San Renato (ep)

Guash i Vidal, María

López de Aguilar, Jerónimo (osst)

Marfá, Jordi; revendedor

Maria de la Cruz (conc)

Riudoms

1691 libro 733

desterrado

Marti, Francesc (jer)

Poch, Mariana

Portiels, Enrique (f); músico

Ruzola, Domingo (oc)

Urbano (i)

Xipell, María

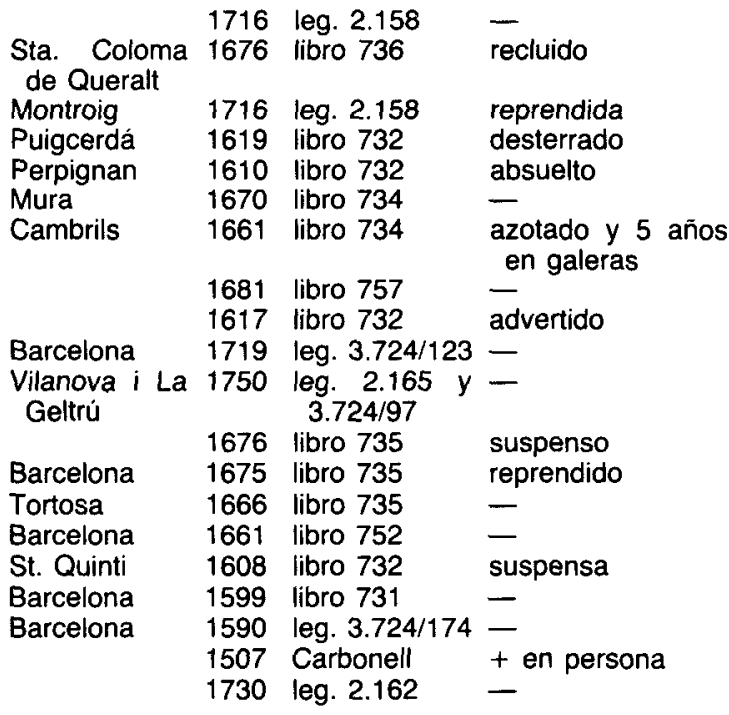

\section{SUPERSTICIÓN}

Adorno, Antonio (i); militar

Aguilona, Nicolasa (i)

Aimeric, Francesc

Alceda, Gabriel; labrador

$\begin{array}{llll}\text { Barcelona } & 1750 & \text { leg. } 3.724 / 90 & - \\ \text { Barcelona } & 1633 & \text { libro } 746 & \text { desterrada } \\ \text { ¿Barcelona? } & 1675 & \text { libro } 735 & \text { suspensa } \\ \text { Llovera } & 1654 & \text { libro } 749 & -\end{array}$


Catálogo de los procesos inquisitoriales del Tribunal del...

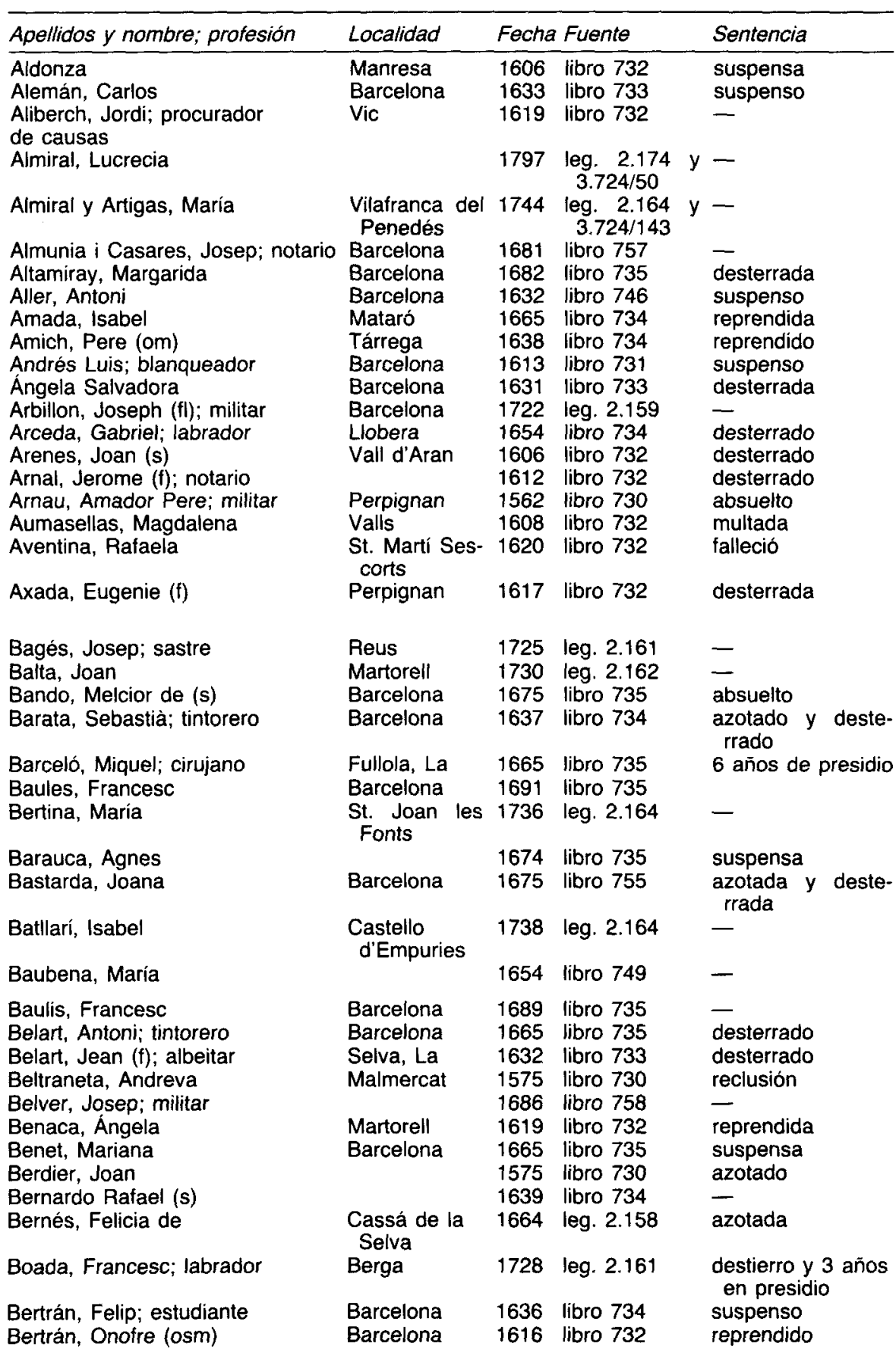


JUAN BLAZZQUEZ MIGUEL

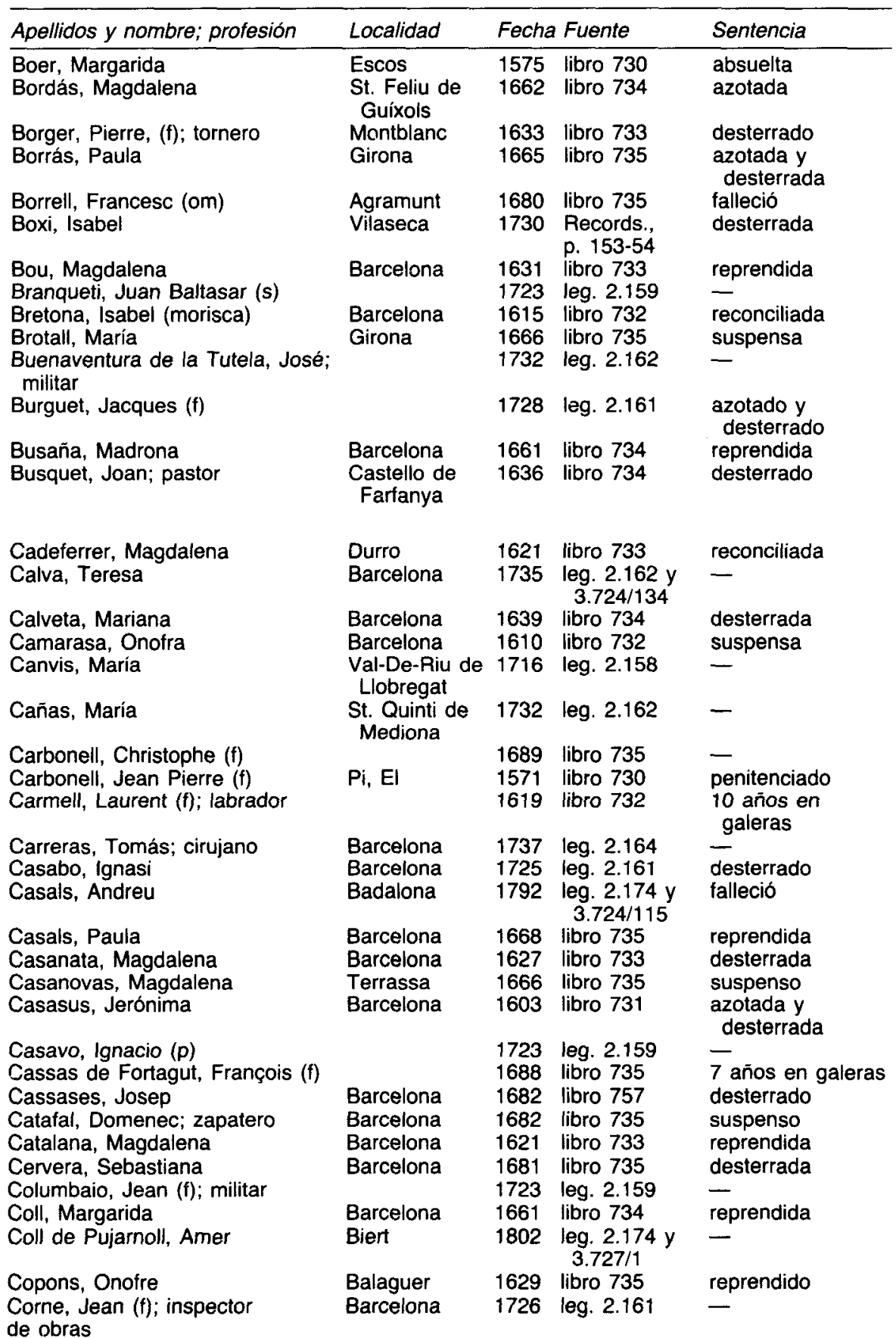


Catálogo de los procesos inquisitoriales del Tribunal del...

\begin{tabular}{|c|c|c|c|c|}
\hline \multirow{2}{*}{$\frac{\text { Apellidos y nombre; profesión }}{\text { Costa, Mariana }}$} & \multirow{2}{*}{$\frac{\text { Localidad }}{\text { Barcelona }}$} & \multicolumn{2}{|c|}{ Fecha Fuente } & \multirow{2}{*}{$\frac{\text { Sentencia }}{\text { desterrada }}$} \\
\hline & & 1716 & $\begin{array}{l}\text { leg. } 2.158 y \\
3.724 / 118\end{array}$ & \\
\hline Costaseca, Bernard (f); labrador & & 1605 & libro 732 & $\begin{array}{l}\text { azotado y } \\
\text { desterrado }\end{array}$ \\
\hline Cuba, Pierre La (f); peinero & & 1687 & libro 735 & desterrado \\
\hline Cutufal, Domenec; zapatero & Barcelona & 1682 & libro 757 & - \\
\hline Cunillera, Baltasar; pastor & & 1662 & libro 734 & desterrado \\
\hline Cristóbal, Agustín (om) & $\begin{array}{l}\text { Castello } \\
\text { d'Empuries }\end{array}$ & 1637 & libro 734 & \\
\hline $\begin{array}{l}\text { Dalfau, François }(f) \\
\text { Deviu, Joan; labrador }\end{array}$ & $\begin{array}{l}\text { Barcelona } \\
\text { St. Adriá de } \\
\text { Besós }\end{array}$ & $\begin{array}{l}1610 \\
1636\end{array}$ & $\begin{array}{l}\text { libro } 732 \\
\text { libro } 734\end{array}$ & $\begin{array}{l}\text { suspenso } \\
\text { multado }\end{array}$ \\
\hline Dezvalls, Bertrán & Barcelona & 1632 & libro 746 & suspenso \\
\hline Domenech, Miquel; estudiante & Barcelona & 1608 & libro 732 & reprendido \\
\hline Domenjona, Marie (f) & $\begin{array}{l}\text { Vilafranca del } \\
\text { Penedés }\end{array}$ & 1565 & libro 730 & recluida \\
\hline Domerch, Arnaud (f) & $\mathrm{Pi}, \mathrm{EI}$ & 1571 & libro 730 & penitenciado \\
\hline Domingo, Joana & Regola & 1627 & libro 733 & desterrada \\
\hline Domingo, Lluisa & Barcelona & 1602 & libro 731 & desterrada \\
\hline Domingo, Serafina & Barcelona & 1602 & libro 731 & desterrada \\
\hline Dot, Joan; labrador & $\begin{array}{l}\text { St. Joan } \\
\text { Despi }\end{array}$ & 1726 & leg. 2161 & desterrado \\
\hline Duel, Magdalena & Oliveda & 1611 & libro 732 & absuelta \\
\hline Dufay, Bertrand (f); labrador & Llavanera & 1609 & libro 732 & desterrado \\
\hline Durán, Joan; herrero & Vila-Rodona & 1632 & $\begin{array}{l}\text { Records., p. } \\
40-77\end{array}$ & desterrado \\
\hline Enríquez Alpont, Francisco & & 1575 & libro 730 & - \\
\hline Entrada, Maciana & Barcelona & 1603 & libro 731 & recluida \\
\hline Escaler, Ana & $\begin{array}{l}\text { Sta. Coloma } \\
\text { de Farners }\end{array}$ & 1735 & $\begin{array}{l}\text { leg. } 2.162 y \\
3.724 / 130\end{array}$ & - \\
\hline $\begin{array}{l}\text { Escot, Catalina (i) } \\
\text { Escanell, Eulalia }\end{array}$ & $\begin{array}{l}\text { Barcelona } \\
\text { Barcelona }\end{array}$ & $\begin{array}{l}1655 \\
1735\end{array}$ & $\begin{array}{l}\text { libro } 750 \\
\text { leg. } 2.164 \text { y } \\
3.724 / 142\end{array}$ & - \\
\hline $\begin{array}{l}\text { Escola, Bartomeu } \\
\text { Estrada, Pere Joan (s) }\end{array}$ & $\begin{array}{l}\text { Portella, La } \\
\text { Vic }\end{array}$ & $\begin{array}{l}1608 \\
1639\end{array}$ & $\begin{array}{l}\text { libro } 732 \\
\text { libro } 734\end{array}$ & reprendido \\
\hline Esturri, Josep & Arbucies & 1744 & $\operatorname{leg.~}_{114} 3.724 /$ & - \\
\hline Eulalia Úrsula & $\begin{array}{l}\text { Caldes de } \\
\text { Montbuí }\end{array}$ & 1621 & libro 733 & reprendida \\
\hline Farrés, Jeanne (f) & Terrassa & 1615 & libro 732 & desterrada \\
\hline $\begin{array}{l}\text { Faura, Josep (s) } \\
\text { Faydella, Ana Maria }\end{array}$ & Barcelona & $\begin{array}{l}1674 \\
1664\end{array}$ & libro 735 & reprendido \\
\hline $\begin{array}{l}\text { Faydella, Ana Maria } \\
\text { Fernández, José; famacéutico }\end{array}$ & Linya & $\begin{array}{l}1004 \\
1736\end{array}$ & $\begin{array}{l}\text { leg. } 2.156 \\
\text { leg. } 2.162\end{array}$ & - \\
\hline $\begin{array}{l}\text { Fernández y Salazar, Maria } \\
\text { Candelaria (gitana) }\end{array}$ & Barcelona & 1682 & libro 757 & recluída \\
\hline Ferrer, Felip & Maçanet & 1571 & libro 730 & penitenciado \\
\hline Ferrer, Isidre; jornalero & Barcelona & 1667 & libro 735 & suspenso \\
\hline Ferrer, Joan; labrador & Montmeló & 1611 & libro 732 & reprendido \\
\hline Ferrer, Joan & & 1656 & libro 750 & - \\
\hline Ferrer, Pau; labrador & Vinyoles & 1680 & libro 735 & suspendido \\
\hline Ferrer, Pere (s) & Montcal & 1668 & libro 735 & suspendido \\
\hline Ferrer, Rafael; zapatero & Barcelona & 1666 & libro 735 & suspenso \\
\hline Ferrera, Joana & Barcelona & 1606 & libro 732 & reprendida \\
\hline
\end{tabular}


JUAN BLÁZQUEZ MIGUEL

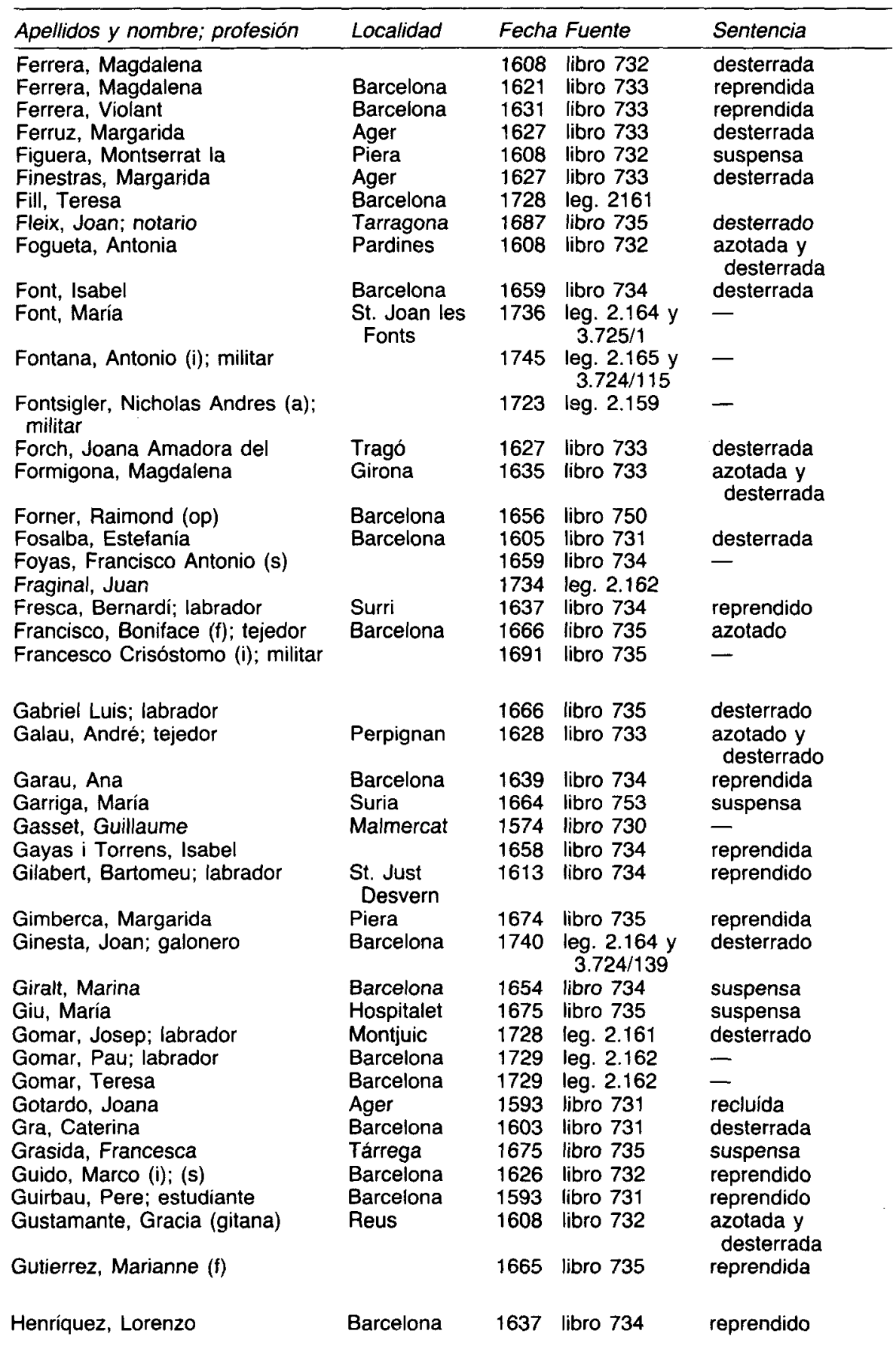


Catálogo de los procesos inquisitoriales del Tribunal del...

\begin{tabular}{|c|c|c|c|c|}
\hline Apellidos y nombre; profesión & Localidad & Fecha & Fuente & Sentencia \\
\hline $\begin{array}{l}\text { Hirles, Paula } \\
\text { Homs, Magdalena } \\
\text { Hispana, María } \\
\text { Hugueta, Joana }\end{array}$ & $\begin{array}{l}\text { Barcelona } \\
\text { Vic } \\
\text { Barcelona } \\
\text { Montmaneu }\end{array}$ & $\begin{array}{l}1659 \\
1614 \\
1664 \\
1608\end{array}$ & $\begin{array}{l}\text { libro } 734 \\
\text { libro } 731 \\
\text { libro } 735 \\
\text { libro } 732\end{array}$ & $\begin{array}{l}\text { desterrada } \\
\text { desterrada } \\
\text { desterrada } \\
\text { desterrada }\end{array}$ \\
\hline $\begin{array}{l}\text { Isaac Barthelemy (f); labrador } \\
\text { Isabel Carlos } \\
\text { Isabel, Juana } \\
\text { Islamar, Juan; militar }\end{array}$ & $\begin{array}{l}\text { Tiana } \\
\text { Oliola } \\
\text { Barcelona }\end{array}$ & $\begin{array}{l}1628 \\
1691 \\
1676 \\
1733\end{array}$ & $\begin{array}{l}\text { libro } 733 \\
\text { libro } 735 \\
\text { libro } 736 \\
\text { leg. } 2.164 \text { y } \\
3.724 / 145\end{array}$ & $\begin{array}{l}\text { desterrado } \\
\text { reprendida }\end{array}$ \\
\hline $\begin{array}{l}\text { Jansana, Mateu; labrador } \\
\text { Jocha, Eulalia } \\
\text { Jofre, François (f); escribano } \\
\text { Jofre, Joana } \\
\text { José Carlos } \\
\text { Josefa }\end{array}$ & $\begin{array}{l}\text { Terrassa } \\
\text { Girona } \\
\text { Barcelona } \\
\text { Illerda }\end{array}$ & $\begin{array}{l}1732 \\
1615 \\
1687 \\
1597 \\
1691 \\
1674\end{array}$ & $\begin{array}{l}\text { leg. } 2.162 \\
\text { libro } 732 \\
\text { libro } 758 \\
\text { libro } 731 \\
\text { libro } 735 \\
\text { libro } 735\end{array}$ & $\begin{array}{l}\text { suspensa } \\
\text { suspenso } \\
\text { desterrada } \\
- \\
\text { suspensa }\end{array}$ \\
\hline $\begin{array}{l}\text { Leán Gallardo, Pedro; militar } \\
\text { León, Magdalena de }\end{array}$ & $\begin{array}{l}\text { Barcelona } \\
\text { Balaguer }\end{array}$ & $\begin{array}{l}1717 \\
1667\end{array}$ & $\begin{array}{l}\text { leg. } 2.158 \\
\text { libro } 735\end{array}$ & $\begin{array}{l}\text { suspenso } \\
\text { suspensa }\end{array}$ \\
\hline $\begin{array}{l}\text { Letrilla, François (f); herbolario } \\
\text { Liébana, Jerónimo de } \\
\text { Lucia, Valentina (gitana) }\end{array}$ & $\begin{array}{l}\text { Manresa } \\
\text { Barcelona } \\
\text { Tárrega }\end{array}$ & $\begin{array}{l}1636 \\
1632 \\
1725\end{array}$ & $\begin{array}{l}\text { libro } 734 \\
\text { libro } 746 \\
\text { leg. } 2.161\end{array}$ & $\begin{array}{l}\text { falleció } \\
-\end{array}$ \\
\hline $\begin{array}{l}\text { Lladós, Pere } \\
\text { Llaneras, Nicolau } \\
\text { Llauradona, Eulalia } \\
\text { Llavadías, Felip; labrador } \\
\text { Llobet, Josep; escudero } \\
\text { Llorenç Pasqual } \\
\text { Lloreta, Isabel } \\
\text { Lloreta, María Ana } \\
\text { Llucat, Pierre (f); labrador } \\
\text { Lluch, Teresa }\end{array}$ & $\begin{array}{l}\text { Reus } \\
\text { Aleixar } \\
\text { Castellet } \\
\text { Reus }\end{array}$ & $\begin{array}{l}1662 \\
1608 \\
1659 \\
1659 \\
1608 \\
1574 \\
1696 \\
1696 \\
1571 \\
1751\end{array}$ & $\begin{array}{l}\text { libro } 734 \\
\text { libro } 732 \\
\text { libro } 734 \\
\text { libro } 734 \\
\text { libro } 732 \\
\text { libro } 730 \\
\text { libro } 760 \\
\text { libro } 760 \\
\text { libro } 730 \\
\text { leg. } 3.724 / 94 \\
\text { y } 144\end{array}$ & $\begin{array}{l}\text { suspenso } \\
\text { reprendido } \\
\text { desterrada } \\
\text { reprendido } \\
\text { absuelto } \\
\text { - } \\
\text { penitenciado }\end{array}$ \\
\hline $\begin{array}{l}\text { Madroño Bori, Isabel } \\
\text { Malet, Joan, (morisco) } \\
\text { Malla, Magdalena (gitana) } \\
\text { Malla, Miguel (gitano); labrador } \\
\text { March, Joan; pastor } \\
\text { Margarida Pasquala } \\
\text { María Bernarda } \\
\text { María Francisca } \\
\text { Mariot, Pau } \\
\text { Marqués, Antonio (i) } \\
\text { Marsilla, Angela } \\
\text { Martín, Didac; estudiante } \\
\text { Marti, Francesc (jer) } \\
\text { Martina, Caterina } \\
\text { Martina, Teresa } \\
\text { Martínez, Cristóbal (osm) } \\
\text { Masaguer, Miquel } \\
\text { Matas, Francisco } \\
\text { Mauri, Gregori }\end{array}$ & $\begin{array}{l}\text { Tarragona } \\
\text { Flix } \\
\text { Balaguer } \\
\text { Balaguer } \\
\text { St. Quirze } \\
\text { La Selva } \\
\text { Andorra } \\
\text { Barcelona } \\
\text { Pontons }\end{array}$ & $\begin{array}{l}1730 \\
1549 \\
1667 \\
1667 \\
1667 \\
1667 \\
1689 \\
1725 \\
1658 \\
1639 \\
1603 \\
1665 \\
1659 \\
1608 \\
1661 \\
1606 \\
1608 \\
1725 \\
1605\end{array}$ & $\begin{array}{l}\text { leg. } 2.162 \\
\text { libro } 736 \\
\text { libro } 735 \\
\text { libro } 735 \\
\text { libro } 735 \\
\text { libro } 735 \\
\text { libro } 759 \\
\text { leg. } 2.161 \\
\text { libro } 734 \\
\text { libro } 734 \\
\text { libro } 731 \\
\text { libro } 735 \\
\text { libro } 734 \\
\text { libro } 732 \\
\text { libro } 734 \\
\text { libro } 732 \\
\text { libro } 732 \\
\text { leg. } 2.161 \\
\text { libro } 731\end{array}$ & $\begin{array}{l}\text { - } \\
\text { reprendida } \\
\text { reprendido } \\
\text { suspenso } \\
\text { suspensa } \\
- \\
\text { desterrado } \\
\text { absuelto } \\
\text { desterrada } \\
\text { desterrado } \\
\text { multada } \\
\text { suspensa } \\
\text { reprendido } \\
\text { desterrado } \\
\text { desterrado }\end{array}$ \\
\hline
\end{tabular}




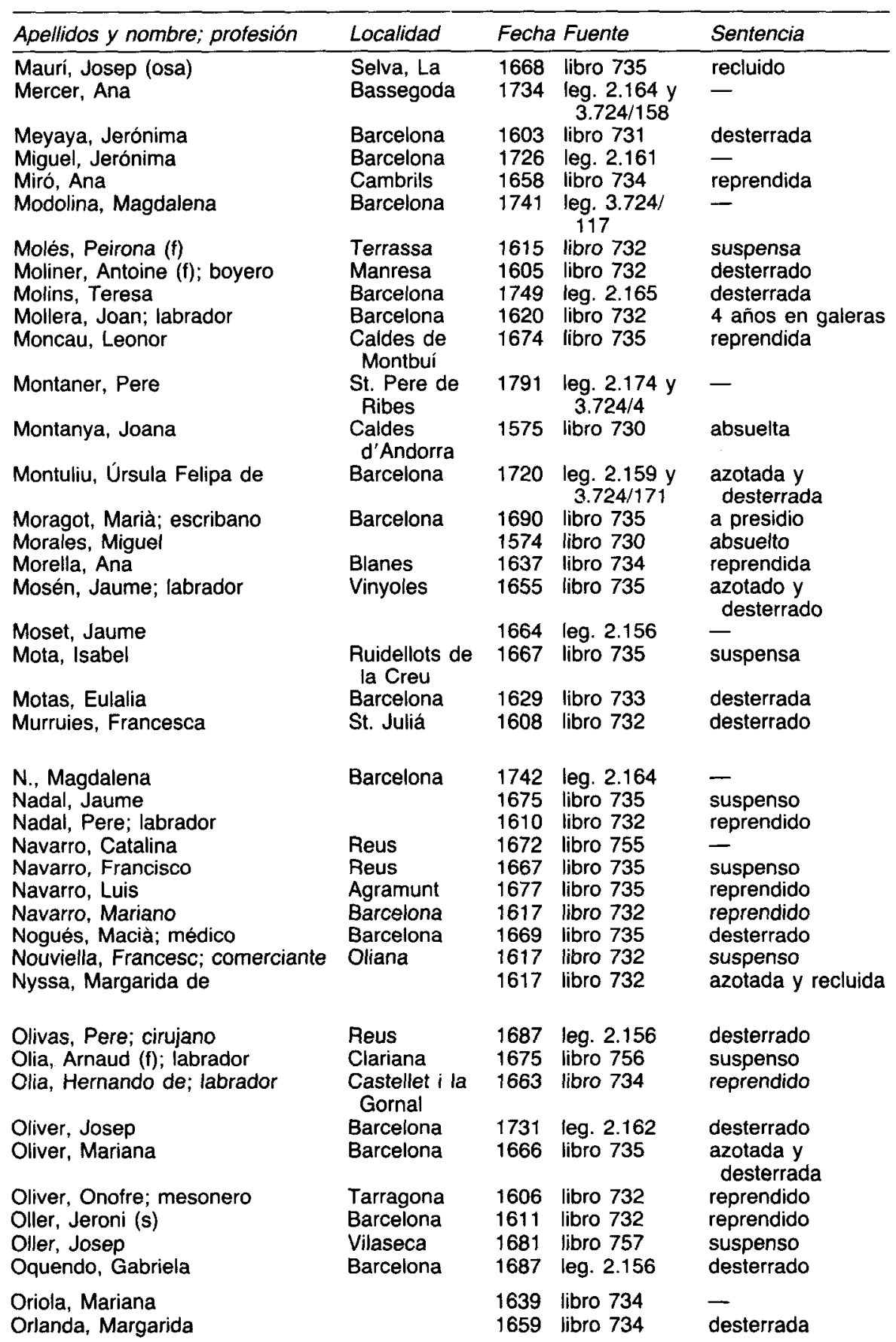


Catálogo de los procesos inquisitoriales del Tribunal del...

\begin{tabular}{|c|c|c|c|c|}
\hline Apellidos y nombre; profesión & Localidad & Fecha & Fuente & Sentencia \\
\hline Orpia, Josep; jornalero & Barcelona & 1726 & leg. 2.161 & $\begin{array}{l}\text { azotado y } \\
\text { desterrado }\end{array}$ \\
\hline $\begin{array}{l}\text { Ortich, Teresa } \\
\text { Ovando, Melcior de (s) }\end{array}$ & $\begin{array}{l}\text { Barcelona } \\
\text { Barcelona }\end{array}$ & $\begin{array}{l}1728 \\
1674\end{array}$ & $\begin{array}{l}\text { leg. } 2.161 \\
\text { libro } 755\end{array}$ & 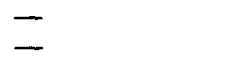 \\
\hline $\begin{array}{l}\text { Pagés, Lluis } \\
\text { Pagés, Paula } \\
\text { Pallás, María } \\
\text { Parasol, Maria }\end{array}$ & $\begin{array}{l}\text { Catllar } \\
\text { Barcelona } \\
\text { Barcelona } \\
\text { Vall-De-Riu } \\
\text { de Llobregat }\end{array}$ & $\begin{array}{l}1682 \\
1725 \\
1728 \\
1716\end{array}$ & $\begin{array}{l}\text { libro } 757 \\
\text { leg. } 2.161 \\
\text { leg. } 2.161 \\
\text { leg. } 2.158\end{array}$ & $\begin{array}{l}\overline{\text { desterrada }} \\
\text { suspensa }\end{array}$ \\
\hline Parisot, Janeta (f) & Barcelona & 1818 & $\begin{array}{l}\operatorname{leg}_{3} 2.177 \mathrm{y} \\
3.721 / 208\end{array}$ & - \\
\hline $\begin{array}{l}\text { Parma, Leonardo de (i); (er) } \\
\text { Patllari, Isabel }\end{array}$ & $\begin{array}{l}\text { Barcelona } \\
\text { Castello } \\
\text { d'Empuries }\end{array}$ & $\begin{array}{l}1613 \\
1735\end{array}$ & $\begin{array}{l}\text { libro } 732 \\
\text { leg. } 3.725 / 3\end{array}$ & suspenso \\
\hline Paubena, Maria & $\begin{array}{l}\text { St. Joan de } \\
\text { Mondarn }\end{array}$ & 1684 & libro 734 & desterrada \\
\hline $\begin{array}{l}\text { Pax, Bernard (¿f?) } \\
\text { Payás, Paula }\end{array}$ & $\begin{array}{l}\text { Perpignan } \\
\text { Barcelona }\end{array}$ & $\begin{array}{l}1636 \\
1725\end{array}$ & $\begin{array}{l}\text { libro } 734 \\
\text { Relación... } \\
1725\end{array}$ & $\begin{array}{l}\text { multado } \\
\text { desterrado }\end{array}$ \\
\hline $\begin{array}{l}\text { Pelleja, Joan, notario } \\
\text { Pequera, Francisca }\end{array}$ & Tarragona & $\begin{array}{l}1685 \\
1675\end{array}$ & $\begin{array}{l}\text { libro } 758 \\
\text { libro } 735\end{array}$ & suspensa \\
\hline Perdiguera, Maria & Barcelona & 1682 & libro 757 & $\begin{array}{l}\text { azotada y } \\
\text { desterrada }\end{array}$ \\
\hline $\begin{array}{l}\text { Pereira, Baltasar de (¿p?); militar } \\
\text { Pérez, Domingo; médico } \\
\text { Petit, Josep } \\
\text { Pi, Ambrosia del } \\
\text { Pico, Isabel } \\
\text { Plajana, Sabina } \\
\text { Planes, Leonor } \\
\text { Pobla i Torrens, Magdalena } \\
\text { Pomareda José. militar }\end{array}$ & $\begin{array}{l}\text { Cubells } \\
\text { Barcelona } \\
\text { Pi, El } \\
\text { Barcelona } \\
\text { Tragó } \\
\text { Barcelona } \\
\text { Manresa }\end{array}$ & $\begin{array}{l}1658 \\
1610 \\
1682 \\
1571 \\
1726 \\
1627 \\
1662 \\
1636 \\
1686\end{array}$ & $\begin{array}{l}\text { libro } 734 \\
\text { libro } 732 \\
\text { libro } 717 \\
\text { libro } 730 \\
\text { leg. } 2.161 \\
\text { libro } 733 \\
\text { libro } 734 \\
\text { libro } 734 \\
\text { libro } 758\end{array}$ & $\begin{array}{l}\text { suspensa } \\
\text { reprendido } \\
\text { desterrado } \\
\text { penitenciada } \\
\text { desterrada } \\
\text { desterrada } \\
\text { reprendida } \\
\text { advertida }\end{array}$ \\
\hline & Barcelona & $\begin{array}{l}1742 \\
1728\end{array}$ & $\begin{array}{l}\text { leg. } 2.164 \\
\text { leg. } 2.161\end{array}$ & $\overline{-}$ \\
\hline Porta, Madrona & Barcelona & 1621 & líbro 733 & reprendida \\
\hline Portal, Marie del (f) & $\begin{array}{l}\text { Caldes de } \\
\text { Montbuí }\end{array}$ & 1615 & libro 732 & suspensa \\
\hline $\begin{array}{l}\text { Portals, Tecla } \\
\text { Prats, Antoni; jornalero }\end{array}$ & $\begin{array}{l}\text { Barcelona } \\
\text { Vic }\end{array}$ & $\begin{array}{l}1665 \\
1725\end{array}$ & $\begin{array}{l}\text { libro } 735 \\
\text { leg. } 2.161\end{array}$ & $\begin{array}{l}\text { suspensa } \\
\text { azotado y } \\
\text { desterrado }\end{array}$ \\
\hline $\begin{array}{l}\text { Prats, Salvador; ropero } \\
\text { Prats, Tecla } \\
\text { Presas i Cortils, Isabel }\end{array}$ & $\begin{array}{l}\text { Montblanc } \\
\text { St. Climent }\end{array}$ & $\begin{array}{l}1626 \\
1549 \\
1675\end{array}$ & $\begin{array}{l}\text { libro } 732 \\
\text { libro } 736 \\
\text { libro } 735\end{array}$ & $\begin{array}{l}\text { suspenso } \\
\text { absuelta } \\
\text { azotada y } \\
\text { desterrada }\end{array}$ \\
\hline Puig, Antoni, labrador & $\begin{array}{l}\text { St. Sadurni } \\
\text { de } \\
\text { Montornés }\end{array}$ & 1606 & libro 732 & azotado y reciuido \\
\hline Puig, Jaume; molinero & Pons & 1694 & libro 760 & - \\
\hline Puig, Joan & Agramunt & 1667 & libro 735 & suspenso \\
\hline Puig, Maria & Copons & 1629 & libro 733 & absuelta \\
\hline Puig, Pere (s) & Garriga, La & 1637 & libro 734 & reprendido \\
\hline $\begin{array}{l}\text { Puig, Teresa } \\
\text { Pujol, Antoine (f); ahechador de } \\
\text { trigo }\end{array}$ & $\begin{array}{l}\text { Barcelona } \\
\text { Maçanet }\end{array}$ & $\begin{array}{l}1751 \\
1631\end{array}$ & $\begin{array}{l}\text { leg. } 2.167 \\
\text { libro } 733\end{array}$ & azotado y a \\
\hline Pujol, Dominique (f); sastre & Barcelona & 1687 & libro 735 & azotado y recluido \\
\hline
\end{tabular}




\begin{tabular}{|c|c|c|c|c|}
\hline Apellidos y nombre; profesión & Localidad & Fecha & Fuente & Sentencia \\
\hline Pujol, Madrona & $\begin{array}{l}\text { St. Quinti de } \\
\text { Mediona }\end{array}$ & 1658 & libro 734 & reprendido \\
\hline $\begin{array}{l}\text { Pujol, Magdalena } \\
\text { Pujol, María Ángela }\end{array}$ & $\begin{array}{l}\text { Barcelona } \\
\text { Barcelona }\end{array}$ & $\begin{array}{l}1675 \\
1668\end{array}$ & $\begin{array}{l}\text { libro } 735 \\
\text { libro } 735\end{array}$ & $\begin{array}{l}\text { suspensa } \\
\text { suspenso }\end{array}$ \\
\hline $\begin{array}{l}\text { Rabescall, Josep (op) } \\
\text { Ralphes, Michel (¿f?); tejedor } \\
\text { Ramírez, Blas } \\
\text { Ramón, Jerónima } \\
\text { Resplanda, Isabel } \\
\text { Reznera, Magdalena } \\
\text { Rialp, Pere (s) } \\
\text { Ribas, Francesc; abogada } \\
\text { Ribert, N. } \\
\text { Ribona, Catalina } \\
\text { Ricardo Rafael (s) } \\
\text { Riera i Serdaña, N. } \\
\text { Rius, Isabel } \\
\text { Robustera, Isabel } \\
\text { Roca, Caterina } \\
\text { Roca, Isabel } \\
\text { Roca, Isabel }\end{array}$ & $\begin{array}{l}\text { Barcelona } \\
\text { Barcelona } \\
\text { Barcelona } \\
\text { Banyoles } \\
\text { Montblanc } \\
\text { Barcelona } \\
\text { Creixell } \\
\text { Organya } \\
\text { Barcelona } \\
\text { Forgars } \\
\text { Barcelona } \\
\text { Barcelona } \\
\text { Tornafort } \\
\text { Barcelona } \\
\text { Caldes de } \\
\text { Montbuí }\end{array}$ & $\begin{array}{l}1680 \\
1612 \\
1734 \\
1663 \\
1617 \\
1549 \\
1552 \\
1617 \\
1668 \\
1619 \\
1639 \\
1668 \\
1743 \\
1631 \\
1574 \\
1658 \\
1674\end{array}$ & $\begin{array}{l}\text { libro } 735 \\
\text { libro } 732 \\
\text { leg. } 21.62 \\
\text { libro } 734 \\
\text { libro } 732 \\
\text { libro } 736 \\
\text { libro } 730 \\
\text { libro } 732 \\
\text { libro } 735 \\
\text { libro } 732 \\
\text { libro } 734 \\
\text { libro } 735 \\
\text { leg. } 2.164 \\
\text { libro } 733 \\
\text { libro } 730 \\
\text { libro } 734 \\
\text { libro } 735\end{array}$ & $\begin{array}{l}\text { desterrado } \\
\text { desterrado } \\
\text { suspensa } \\
\text { reprendido } \\
\text { absuelta } \\
+ \text { en estatua } \\
\text { reprendido } \\
\text { suspenso } \\
\text { desterrado } \\
\text { suspenso } \\
\text { suspenso } \\
\text { reprendida } \\
\frac{}{\text { reprendida }} \\
\text { desterrada }\end{array}$ \\
\hline $\begin{array}{l}\text { Rodríguez, Ángela } \\
\text { Roig, Jaume } \\
\text { Roig, Miquel; sastre } \\
\text { Romaneda, Josep } \\
\text { Romero, Bartolomé (i); cortador } \\
\text { de papel }\end{array}$ & $\begin{array}{l}\text { Barcelona } \\
\text { Mollerussa } \\
\text { Barcelona } \\
\text { Barcelona }\end{array}$ & $\begin{array}{l}1668 \\
1674 \\
1674 \\
1689 \\
1619\end{array}$ & $\begin{array}{l}\text { libro } 735 \\
\text { libro } 735 \\
\text { libro } 735 \\
\text { libro } 735 \\
\text { libro } 732\end{array}$ & $\begin{array}{l}\text { suspensa } \\
\text { reprendida } \\
\text { suspenso } \\
\overline{\text { desterrado }}\end{array}$ \\
\hline $\begin{array}{l}\text { Romero, Sebastiana (gitana) } \\
\text { Roselló, Antoni (oc) }\end{array}$ & $\begin{array}{l}\text { Barcelona } \\
\text { Peralada }\end{array}$ & $\begin{array}{l}1725 \\
1744\end{array}$ & $\begin{array}{c}\text { leg. } 2.161 \\
\text { leg. } 2.164 \text { y } \\
3.724 / 79\end{array}$ & - \\
\hline Rossa, Aldonza & Bellver & 1620 & libro 732 & absuelta \\
\hline $\begin{array}{l}\text { Roura, Joan; labrador } \\
\text { Rovira, Llorenç; cirujano } \\
\text { Rovira, Joana } \\
\text { Rubio, Jaime; mesonero }\end{array}$ & $\begin{array}{l}\text { Figueres } \\
\text { Reus } \\
\text { St. Coloma } \\
\text { de Queralt }\end{array}$ & $\begin{array}{l}1761 \\
1682 \\
1610 \\
1603\end{array}$ & $\begin{array}{l}\text { leg. } 3.724 / 79 \\
\text { libro } 757 \\
\text { libro } 732 \\
\text { libro } 731\end{array}$ & $\begin{array}{l}\text { desterrado } \\
\text { suspensa } \\
\text { suspenso }\end{array}$ \\
\hline $\begin{array}{l}\text { Rubirós, Eulalia } \\
\text { Ruguane, Joan } \\
\text { Sala, Ana Maria } \\
\text { Sala, Jaume; labrador } \\
\text { Sala, Josep; notario } \\
\text { Sala i Rosell, Margarida } \\
\text { Saladriga, Joan; labrador } \\
\text { Salaverda, Joana } \\
\text { Salsada, Caterina }\end{array}$ & $\begin{array}{l}\text { Barcelona } \\
\text { Sarriá } \\
\text { Santpedor } \\
\text { Viladrau } \\
\text { Barcelona } \\
\text { Barcelona } \\
\text { Sabadell } \\
\text { Espolla } \\
\text { Barcelona }\end{array}$ & $\begin{array}{l}1728 \\
1675 \\
1661 \\
1593 \\
1615 \\
1639 \\
1692 \\
1575 \\
1741\end{array}$ & $\begin{array}{l}\text { leg. } 2.161 \\
\text { libro } 735 \\
\text { libro } 734 \\
\text { libro } 731 \\
\text { libro } 732 \\
\text { libro } 748 \\
\text { libro } 759 \\
\text { libro } 730 \\
\text { leg. } 2.164 \text { y } \\
3.724 / 117\end{array}$ & $\begin{array}{l}\text { reprendida } \\
\text { suspenso } \\
\text { desterrada } \\
\text { absuelto } \\
\text { multado } \\
\text { desterrada } \\
\text { absuelta }\end{array}$ \\
\hline $\begin{array}{l}\text { Saludes, Tecla } \\
\text { San Martin, Caterina } \\
\text { Sanovira, Joan Miquel } \\
\text { Santos, Jaime de los (oc) } \\
\text { Sanz, Francisca }\end{array}$ & $\begin{array}{l}\text { Tarragona } \\
\text { Barcelona } \\
\text { Barcelona } \\
\text { Vic } \\
\text { Barcelona }\end{array}$ & $\begin{array}{l}1608 \\
1730 \\
1617 \\
1667 \\
1734\end{array}$ & $\begin{array}{l}\text { libro } 732 \\
\text { leg. } 2.162 \\
\text { libro } 732 \\
\text { libro } 735 \\
\text { leg. } 3.724 \text { / } \\
105\end{array}$ & $\begin{array}{l}\text { falleció } \\
\text { suspenso } \\
\text { - }\end{array}$ \\
\hline Sardanias, Pere (s) & Pons & 1669 & libro 735 & recluido \\
\hline
\end{tabular}


Catálogo de los procesos inquisitoriales del Tribunal del...

\begin{tabular}{|c|c|c|c|c|}
\hline Apellidos y nombre; profesión & Localidad & Fecha & Fuente & Sentencia \\
\hline $\begin{array}{l}\text { Sedeño, Antón; militar } \\
\text { Segalas, Antoine }(\mathfrak{f}) ; \text { picador de } \\
\text { limas }\end{array}$ & Manresa & $\begin{array}{l}1606 \\
1613\end{array}$ & $\begin{array}{l}\text { libro } 732 \\
\text { libro } 732\end{array}$ & $\begin{array}{l}\text { reprendido } \\
\text { desterrado }\end{array}$ \\
\hline $\begin{array}{l}\text { Segondi, Jean Baptiste (f); } \\
\text { relojero }\end{array}$ & & 1748 & $\begin{array}{l}\operatorname{leg} .2 .164 \mathrm{y} \\
3.724 / 124\end{array}$ & \\
\hline Segura, Joan; labrador & Vic & 1654 & libro 734 & reprendido \\
\hline Sendio, Jaume; pregonero & $\begin{array}{l}\text { Mont-Roig } \\
\text { Campos }\end{array}$ & 1740 & leg. 2.164 & - \\
\hline $\begin{array}{l}\text { Sentelles, Novello (in) } \\
\text { Serra, Joan Pere; estudiante }\end{array}$ & $\begin{array}{l}\text { Barcelona } \\
\text { Lloret de Mar }\end{array}$ & $\begin{array}{l}1608 \\
1736\end{array}$ & $\begin{array}{l}\text { libro } 732 \\
\text { leg. } 2.164 \text { y } \\
3.724 / 146\end{array}$ & desterrado \\
\hline Serra, Maria & Girona & 1638 & libro 733 & desterrada \\
\hline Serola, Joan; pelaire & Sallent & 1633 & libro 733 & absuelto \\
\hline Sicarda, Caterina & Barcelona & 1639 & libro 734 & suspensa \\
\hline $\begin{array}{l}\text { Sierra, Antoni; labrador } \\
\text { Sijar, Jeroni (fray) }\end{array}$ & $\begin{array}{l}\text { Seros } \\
\text { St. Miquel de } \\
\text { Cruilles }\end{array}$ & $\begin{array}{l}1655 \\
1608\end{array}$ & $\begin{array}{l}\text { libro } 750 \\
\text { libro } 732\end{array}$ & multado \\
\hline $\begin{array}{l}\text { Sijar, Rafael; lavandero } \\
\text { Silva, Francisco } \\
\text { Silvestre Olveros, Joseph (f); } \\
\text { pastor }\end{array}$ & $\begin{array}{l}\text { Begues } \\
\text { Puigcerdá }\end{array}$ & $\begin{array}{l}1605 \\
1726 \\
1686\end{array}$ & $\begin{array}{l}\text { libro } 741 \\
\text { leg. } 2161 \\
\text { libro } 758\end{array}$ & $\begin{array}{l}\text { reprendido } \\
\text { ¿suspenso? }\end{array}$ \\
\hline $\begin{array}{l}\text { Solanes, Francisco } \\
\text { Soler, Cosme; labrador }\end{array}$ & Cabra & $\begin{array}{l}1675 \\
1617\end{array}$ & $\begin{array}{l}\text { libro } 735 \\
\text { libro } 732\end{array}$ & $\begin{array}{l}\text { suspenso } \\
\text { absuelto }\end{array}$ \\
\hline Soler, Joan; tejedor & Girona & 1776 & leg. $3.724 / 6$ & - \\
\hline Soler, Nicolau; labrador & Parlava & 1661 & libro 734 & suspenso \\
\hline $\begin{array}{l}\text { Soler, Vicenç (om) } \\
\text { Sotemar, Sebastián (a); militar }\end{array}$ & $\begin{array}{l}\text { Tarragona } \\
\text { Barcelona }\end{array}$ & $\begin{array}{l}1638 \\
1728\end{array}$ & $\begin{array}{l}\text { libro } 734 \\
\text { leg. } 2.161\end{array}$ & reprendido \\
\hline Suhaces, Pere (s) & $\begin{array}{l}\text { St. Mateu de } \\
\text { Joanete }\end{array}$ & 1674 & libro 735 & suspenso \\
\hline Sureda, Ana & Barcelona & 1606 & libro 732 & reprendida \\
\hline Tacha, Thomas $(f)$ & Lladros & 1691 & libro 735 & - \\
\hline Tajes, Mateu; pelaire & Riudecanyes & 1658 & libro 734 & suspenso \\
\hline Tarragona, Caterina de & Barceloná & 1667 & libro 735 & suspensa \\
\hline Tarragona, Cosme; labrador & Rialp & 1617 & libro 732 & suspenso \\
\hline Terral, Joan (s) & Agramunt & 1681 & libro 735 & desterrado \\
\hline Terraza, Ramón & Barcelona & 1661 & libro 734 & reprendido \\
\hline Terrera, Ana & Barcelona & 1661 & libro 734 & desterrada \\
\hline Texidor, Agnes & Manresa & 1665 & libro 735 & suspensa \\
\hline Texidor, Josep (s) & Barcelona & 1662 & libro 752 & \\
\hline Texidor, María & Barcelona & 1661 & libro 734 & suspensa \\
\hline Tixayre, Isabelle ( $)$ & Perpignan & 1593 & libro 731 & absuelto \\
\hline Toca, Caterina & Tornafort & 1591 & libro 731 & - \\
\hline Tolo, Madrona & Barcelona & 1664 & libro 735 & suspensa \\
\hline Tolo, Sebastià; sastre & Barcelona & 1664 & libro 735 & suspenso \\
\hline Toneta, Joana & $\begin{array}{l}\text { Caldes } \\
\text { d'Andorra }\end{array}$ & 1575 & libro 730 & - \\
\hline Torca, Francesc & Tárrega & 1675 & libro 735 & suspenso \\
\hline Torrents, Pere & $\begin{array}{l}\text { St. Feliu de } \\
\text { Guíxols }\end{array}$ & 1785 & leg. $3.724 / 53$ & - \\
\hline Torras, María & Mataró & 1680 & libro 735 & reprendida \\
\hline Torres, Caterina & Barcelona & 1593 & libro 731 & falleció \\
\hline Torres, Esperanza & Barcelona & 1603 & libro 731 & desterrada \\
\hline Torres, François (f) (op) & & 1603 & libro 731 & penitenciado \\
\hline Torres, y Garay, Juana (i) & Barcelona & 1726 & leg. 2161 & falleció \\
\hline
\end{tabular}




\begin{tabular}{|c|c|c|c|c|}
\hline Apellidos y nombre; profesión & Localidad & Fecha & Fuente & Sentencia \\
\hline Valentina, Lucía (gitana) & & 1726 & leg. 2.161 & desterrada \\
\hline Vega, Clemente de & $\begin{array}{l}\text { Sra. Maria de } \\
\text { Marles }\end{array}$ & 1620 & libro 732 & reprendido \\
\hline $\begin{array}{l}\text { Verniola i Formigana, Magdalena } \\
\text { Vicente, Joan }\end{array}$ & Barcelona & $\begin{array}{l}1631 \\
1556\end{array}$ & $\begin{array}{l}\text { libro } 733 \\
\text { leg. } 1.592 / 23\end{array}$ & desterrado \\
\hline Vidal, Antoine (f) (of) & & 1603 & libro 731 & advertido \\
\hline Vidal, Joan; zapatero & $\begin{array}{l}\text { Vilafranca del } \\
\text { Penedés }\end{array}$ & 1614 & libro 731 & desterrado \\
\hline Vidal Camacho, Juan; zapatero & Barcelona & 1685 & libro 758 & - \\
\hline Vidal, Maria & Cambrils & 1658 & libro 734 & reprendida \\
\hline Vidreras, María Ana & Blanes & 1637 & libro 734 & reprendida \\
\hline Vijavilla, Rafaela & Barcelona & 1617 & libro 732 & desterrada \\
\hline Vila y Campos, Ana & Barcelona & 1726 & leg. 2.161 & $\begin{array}{l}\text { azotada y } \\
\text { desterrada }\end{array}$ \\
\hline Vilalobos, Isabel de (morisca) & Barcelona & 1603 & libro 731 & desterrada \\
\hline Vilar, Lluís; estudiante & Barcelona & 1603 & libro 731 & desterrado \\
\hline Vilar, Teresa & Girona & 1725 & leg. 2.161 & - \\
\hline Villagret, Sebastiá; profesor & Barcelona & 1629 & libro 733 & desterrado \\
\hline Viu, Joan & $\begin{array}{l}\text { St. Adriá de } \\
\text { Besós }\end{array}$ & 1637 & libro 747 & - \\
\hline Viulas, Joan Francesc; estudiante & Barcelona & 1667 & libro 735 & - \\
\hline Vivas, Caterina & Barcelona & 1631 & libro 733 & desterrada \\
\hline Xirac, Josep; cirujano & Peralada & 1741 & $\begin{array}{l}\text { leg. } 3.724 / \\
133\end{array}$ & - \\
\hline Zabater, Antoni; tejedor & Barcelona & 1617 & libro 732 & reprendido \\
\hline
\end{tabular}

\section{MASONERIA}

Bonach, Luis, militar Bonilla, José Antonio (of)

Boquet, Emmanuel (f)

Boyer Rollar, Jean Lazare (f); médico

Bretón, Francisco; militar

Carandole, Barón de; militar

Casañas, Peregrín (osm)

Ceruti, Florencio; militar

Danguines, N.; militar

Echevarría, Antón

\begin{tabular}{|c|c|c|c|}
\hline $\begin{array}{l}\text { Barcelona } \\
\text { Barcelona }\end{array}$ & $\begin{array}{l}1755 \\
1817\end{array}$ & $\begin{array}{l}\text { leg. } 3.724 / 82 \\
\text { leg. } 2.177\end{array}$ & - \\
\hline Barcelona & 1792 & $\begin{array}{l}\text { Ferrer Beni- } \\
\text { meli * }\end{array}$ & - \\
\hline & 1790 & leg. 2.174 & - \\
\hline Barcelona & 1817 & leg. 2.177 & - \\
\hline Barcelona & 1817 & leg. 2.177 & - \\
\hline Barcelona & 1818 & $\begin{array}{l}\text { leg. } 2.177 \text { y } \\
3.721 / 205\end{array}$ & - \\
\hline Barcelona & 1817 & leg. 2.177 & - \\
\hline Barcelona & 1817 & leg. 2.177 & - \\
\hline & 1815 & leg. 2.177 & \\
\hline
\end{tabular}

- J. A. Ferrer Benimeli: Inquisición y Masoneria, pp. 737. 
Catálogo de los procesos inquisitoriales del Tribunal del...

\begin{tabular}{|c|c|c|c|c|}
\hline Apellidos y nombre; profesión & Localidad & Fecha & Fuente & Sentencia \\
\hline $\begin{array}{l}\text { Fargas, Hipolite Daniel }(\mathrm{f}) \\
\text { Flugen, Gabriel; militar }\end{array}$ & Barcelona & $\begin{array}{l}1752 \\
1817\end{array}$ & $\begin{array}{l}\text { leg. } 2.167 \\
\text { leg. } 2.177\end{array}$ & - \\
\hline Grau, Jean (f); militar & Barcelona & 1751 & leg. 2167 & - \\
\hline Legarde, Juan Crisostomo & Barcelona & 1751 & $\begin{array}{c}\text { leg. } 2.167 \mathrm{y} \\
3.724 / 89\end{array}$ & $y-$ \\
\hline Llinas, Francisco; militar & Barcelona & 1817 & leg. 2.177 & - \\
\hline $\begin{array}{l}\text { Martínez, Juan Antonio; militar } \\
\text { Martín, N. } \\
\text { Masuti, N.; militar } \\
\text { Morales, Francisco; militar }\end{array}$ & $\begin{array}{l}\text { Barcelona } \\
\text { Barcelona } \\
\text { Barcelona }\end{array}$ & $\begin{array}{l}1817 \\
1815 \\
1817 \\
1817\end{array}$ & $\begin{array}{l}\text { leg. } 2.177 \\
\text { leg. } 2.177 \\
\text { leg. } 2.177 \\
\text { leg. } 2.177\end{array}$ & $\begin{array}{l}- \\
z\end{array}$ \\
\hline Oxbuch, Didac; militar & Manresa & 1768 & leg. 2.171 & - \\
\hline $\begin{array}{l}\text { Rivas, Francisco; militar } \\
\text { Rosell y Sala, Francesc; músico }\end{array}$ & $\begin{array}{l}\text { Barcelona } \\
\text { Barcelona }\end{array}$ & $\begin{array}{l}1817 \\
1772\end{array}$ & $\begin{array}{l}\text { leg. } 2.177 \\
\text { leg. } 2.172 \text { y } \\
3.724 / 83\end{array}$ & $\overline{4}$ años en presidio \\
\hline $\begin{array}{l}\text { Serviá, Antoni (s) } \\
\text { Serrat, Antoni } \\
\text { Serrat, Francesc }\end{array}$ & $\begin{array}{l}\text { Barcelona } \\
\text { Barcelona } \\
\text { Barcelona }\end{array}$ & $\begin{array}{l}1755 \\
1751 \\
1751\end{array}$ & $\begin{array}{l}\text { leg. } 3.724 / 83 \\
\text { leg. } 3.724 / 89 \\
\text { leg. } 3.724 / 80\end{array}$ & $\begin{array}{l}\text { ¿absuelto? } \\
-\end{array}$ \\
\hline $\begin{array}{l}\text { Tavernier, Jean }(f) \text {; comerciante } \\
\text { Titermans, Claude (f?); comer- } \\
\text { ciante }\end{array}$ & Barcelona & $\begin{array}{l}1757 \\
1759\end{array}$ & $\begin{array}{l}\text { leg. } 3.724 / 62 \\
\text { leg. } 3.724 / 81\end{array}$ & - \\
\hline $\begin{array}{l}\text { Torre, Domingo de la; funcionario } \\
\text { Trillo, José; militar }\end{array}$ & $\begin{array}{l}\text { Barcelona } \\
\text { Barcelona }\end{array}$ & $\begin{array}{l}1764 \\
1817\end{array}$ & $\begin{array}{l}\text { leg. } 2.170 \\
\text { leg. } 2.177\end{array}$ & - \\
\hline Vallosera, Joaquím (s) & Barcelona & 1751 & leg. $3.724 / 89$ & - \\
\hline
\end{tabular}

\section{FAUTORIA. OPOSICIÓN AL SANTO OFICIO}

Arnau, Francesc

Alberti, Jean (f); jabonero

Alcira, Pau; estudiante

Alemany, Llorenç; cirujano

Álvarez, Andrés; chapinero

Arenes, Joan (s)

Argensola, Jeroni

Batalla, Constrance (f)

Balaguer, Montserrat

Bardaxí, Ferrán

$\begin{array}{llll}\text { Mataró } & 1592 & \text { libro 731 } & - \\ \text { Girona } & 1629 & \text { libro 733 } & \text { desterrado } \\ & 1770 & \text { leg. 2.170 } & - \\ \text { Tarragona } & 1562 & \text { libro 730 } & \text { multado } \\ \text { Ripoliet } & 1631 & \text { libro 733 } & \text { desterrado } \\ \text { Usall } & 1615 & \text { libro 732 } & \begin{array}{l}\text { desterrado } \\ \text { suspenso }\end{array} \\ \text { Torá } & 1586 & \text { libro 731 } & \\ & & & \text { multada } \\ & 1619 & \text { libro 732 } & \text { desterrado } \\ \text { Copons } & 1593 & \text { libro 731 } & \text { desterrado } \\ \text { Seu d'Urgell } & 1586 & \text { libro 731 } & \end{array}$


JUAN BLÁZQUEZ MIGUEL

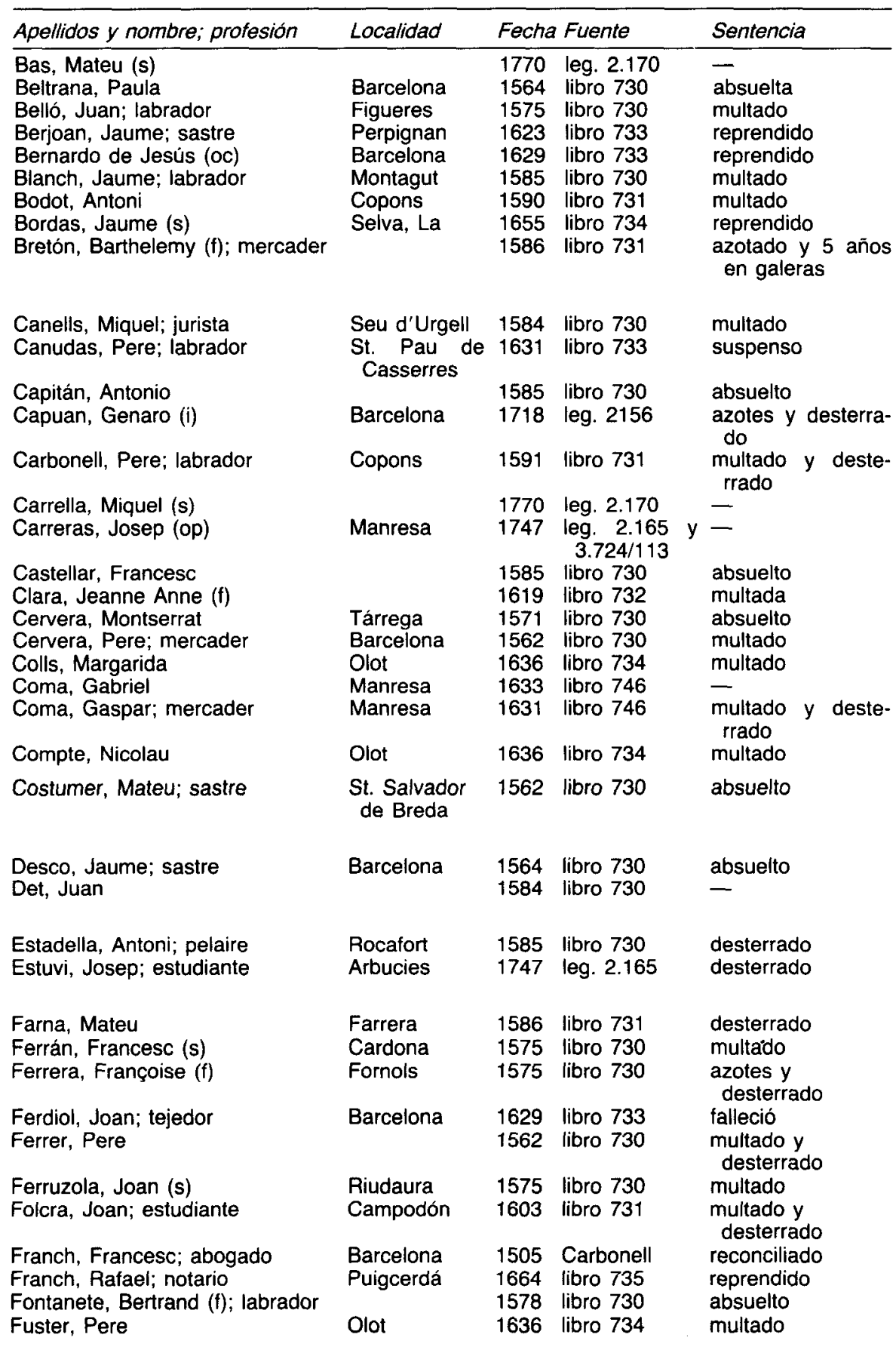


Catálogo de los procesos inquisitoriales del Tribunal del...

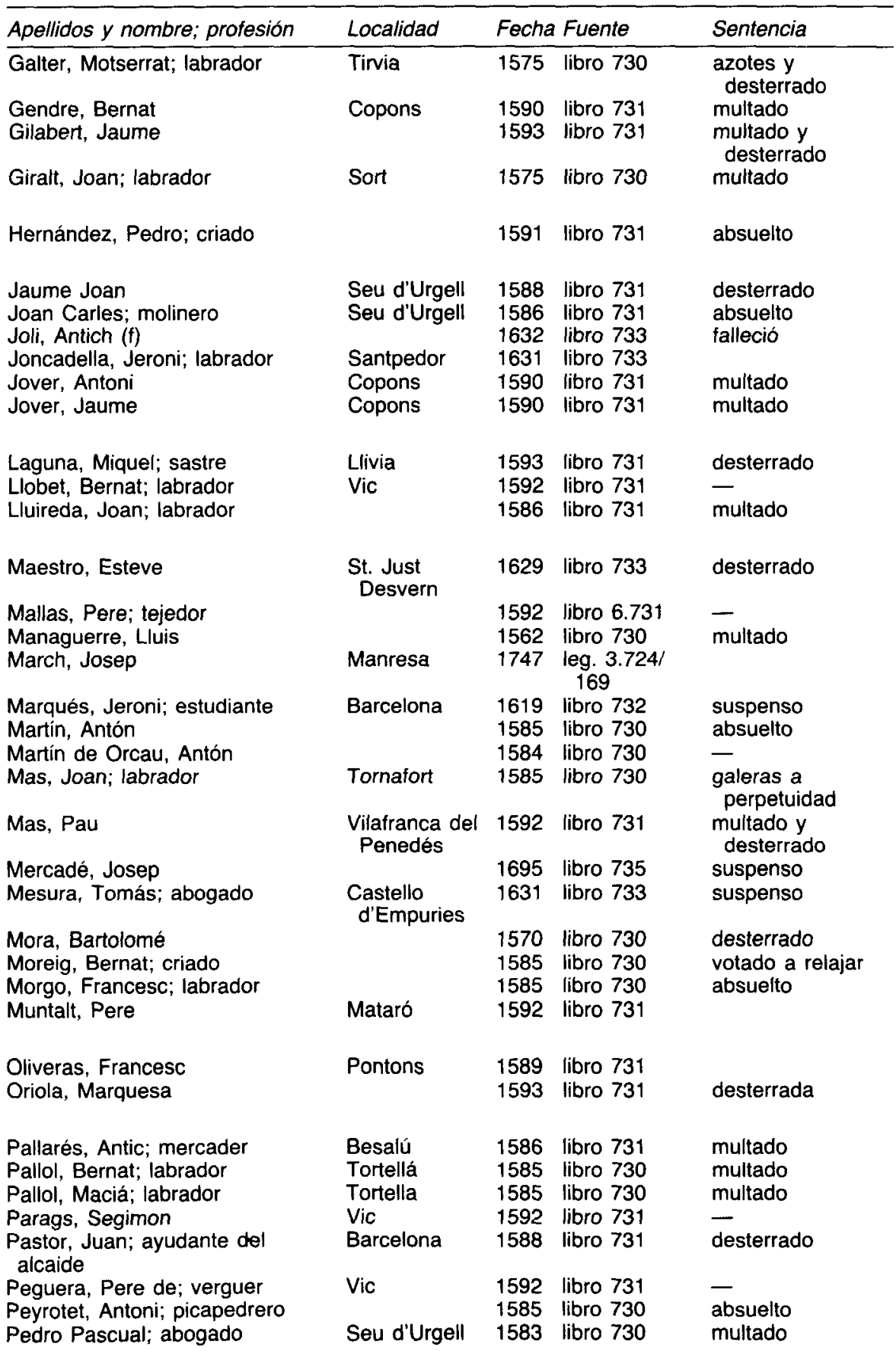


JUAN BLÁZQUEZ MIGUEL

\begin{tabular}{|c|c|c|c|c|}
\hline \multirow{2}{*}{$\frac{\text { Apellidos y nombre; profesión }}{\text { Plan de San, Gaspar }}$} & \multirow{2}{*}{$\frac{\text { Localidad }}{\text { Mantesa }}$} & \multicolumn{2}{|c|}{ Fecha Fuente } & \multirow{2}{*}{ 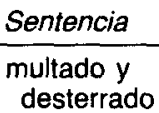 } \\
\hline & & 1565 & libro 730 & \\
\hline Plenisoles, Agustí (s) & Malmercat & 1585 & libro 730 & falleció \\
\hline Pons, Miquel & Figuerola & 1664 & libro 735 & suspenso \\
\hline Pou, Bernat; jurado & Mataró & 1592 & libro 731 & \\
\hline Pranollastre, Antoni; criado & & 1562 & libro 730 & multado \\
\hline Prats, Antoni & Copons & 1592 & libro 731 & desterrado \\
\hline Puig, Roger del; sastre & Besalú & 1585 & libro 730 & desterrado \\
\hline Pujol, Francesc & Vilamur & 1585 & libro 730 & absuelto \\
\hline Puxat, Pau & Tárrega & 1571 & libro 730 & absuelto \\
\hline $\begin{array}{l}\text { Ricarda, Joana } \\
\text { Romera, Antonia }\end{array}$ & & $\begin{array}{l}1619 \\
1619\end{array}$ & $\begin{array}{l}\text { libro } 732 \\
\text { libro } 732\end{array}$ & $\begin{array}{l}\text { reprendida } \\
\text { rependida }\end{array}$ \\
\hline $\begin{array}{l}\text { Roquetes, Bartolomé (i); } \\
\text { tabernero }\end{array}$ & Barcelona & 1667 & libro 735 & desterrado \\
\hline Sala, Amer & Bascara & 1589 & libro 731 & \\
\hline Santallo, Joan; labrador & Tortella & 1585 & libro 730 & multado \\
\hline Saparriga (s) & $\begin{array}{l}\text { St. Salvador } \\
\text { de Breda }\end{array}$ & 1562 & libro 730 & absuelto \\
\hline $\begin{array}{l}\text { Segura, Benet } \\
\text { Selle, Miquel }\end{array}$ & Copons & $\begin{array}{l}1590 \\
1551\end{array}$ & $\begin{array}{l}\text { libro } 731 \\
\text { leg. } 1.592 / 28\end{array}$ & multado \\
\hline Serra, Pere; labrador & $\begin{array}{l}\text { Claret dels } \\
\text { Cavallers }\end{array}$ & 1623 & libro 733 & $\begin{array}{l}\text { multado y } \\
\text { desterrado }\end{array}$ \\
\hline Simó Bartomeu; notario & $\begin{array}{l}\text { Vilafranca del } \\
\text { Penedés }\end{array}$ & 1592 & libro 731 & $\begin{array}{l}\text { multado y } \\
\text { desterrado }\end{array}$ \\
\hline Soldevila, Joan (s) & Fores & 1636 & libro 734 & multado \\
\hline Soler Ferrán, Jaume; notario & Barcelona & 1631 & libro 733 & multado \\
\hline Tapies, Valenti (op) & Manresa & 1746 & $\begin{array}{l}\operatorname{leg} .3 .724 / \\
113\end{array}$ & - \\
\hline $\begin{array}{l}\text { Texidor, Joan } \\
\text { Terreros, Jacques (f); militar }\end{array}$ & Montcortes & $\begin{array}{l}1584 \\
1583\end{array}$ & $\begin{array}{l}\text { libro } 730 \\
\text { libro } 730\end{array}$ & multado \\
\hline Trago, Alemany; gobernador & Castellbo & 1586 & libro 731 & $\begin{array}{l}\text { multado y } \\
\text { desterrado }\end{array}$ \\
\hline Uñiola, Jaume; mercader & Puigcerdá & 1575 & libro 730 & multado \\
\hline Ussach, Mariana & Aiguaviva & 1688 & libro 735 & reprendida \\
\hline Ussach, Paula & Girona & 1688 & libro 735 & rependida \\
\hline $\begin{array}{l}\text { Valle, Bartomeu; labrador } \\
\text { Vallobera, Montserrat; labrador }\end{array}$ & Tortellá & $\begin{array}{l}1586 \\
1629\end{array}$ & $\begin{array}{l}\text { libro } 731 \\
\text { libro } 733\end{array}$ & $\begin{array}{l}\text { multado } \\
\text { multado y } \\
\text { desterrado }\end{array}$ \\
\hline Valls, Perotus; tendero & & 1504 & Carbonell & condenado \\
\hline Vell, Antoine (f); labrador & & 1619 & libro 732 & desterrado \\
\hline Vernal, Bartomeu; labrador & Montagut & 1585 & libro 730 & multado \\
\hline Violante & & 1505 & Carbonell & reconciliada \\
\hline Yllafreda, Bartomeu; labrador & Argelaguer & 1586 & libro 731 & multado \\
\hline
\end{tabular}


Catálogo de los procesos inquisitoriales del Tribunal del...

Apellidos y nombre; profesión Localidad Fecha Fuente Sentencia

16. FALSAS TESTIFICACIONES

Andreu, Joan (osa)

Auger, Francesc; labrador

Baura, Domenec; calcetero

Bou, Narcis; militar

Busquet, Joan; fustero

Boquet, Pere (s)

Cabanyes, Antoni; notario

Caldes, Montserrat

Carvajal, José; militar

Castelló, Pere; cirujano

Cortés, Alonso; militar

Cotoner, Jean ( $\uparrow$ ?)

Domenech, Domenec; militar

Domenech, Francesc; militar

Esteban; abogado

Feliz, Juan; hornero

Ferrer, Antoni; labrador

Ferrer, Joan

Ferrer, Magdalena

Francés, Pere

Grandes, Juan

Guardiola, Jeroni

Guardiola, Jeroni (hijo)

Iglera, Mar Garida

Jauli, Marc; labrador

Lobet, Jaume

Lluch, Jerónima

\begin{tabular}{|c|c|c|c|}
\hline Castellví & $\begin{array}{l}1621 \\
1565\end{array}$ & $\begin{array}{l}\text { libro } 733 \\
\text { libro } 730\end{array}$ & $\begin{array}{l}\text { recluido } \\
\text { multado y recluido }\end{array}$ \\
\hline & 1575 & libro 730 & absuelto \\
\hline arce & 1736 & leg. $3.724 / 152$ & - \\
\hline alls & 1584 & libro 730 & - \\
\hline eu d'Urgell & 1575 & libro 730 & $\begin{array}{l}\text { azotado y deste- } \\
\text { rrado }\end{array}$ \\
\hline
\end{tabular}

Vilanova

de Cubelles

1623 libro 733

1562 libro 730

multado y desterrado

multado y deste-

rrado

Alforja $\quad 1718$ leg. $2.158 \quad$ suspenso

St. Sadurni 1740 leg. 3.724/101 -

d'Anoia

Barcelona

1559 leg. $1.592 / 28$

1748 leg. 2.165 -

Barcelona $\quad 1747$ leg. 3.724/107 -

Perpignan

1717 leg. 2.156

desterrado

Vichfret

1737 leg. 2.164

1659 libro 734

1562 libro 730

-

multado y desterrado

1562 libro 730 multada y destarrada

1562 libro 730 multado y desterrado

1562 libro 730 multado y desterrado

Sanahuja 1610 libro 732 multado

Sanahuja 1610 libro 732 multado y desterrado

Castellnou 1634 libro $747 \quad$ reprendida

Barcelona $\quad 1720$ leg. 2.159 azotes y 5 años en galeras

Barcelona 1573 libro 737

azotado y 5 años en galeras

Tarragona $\quad 1675$ libro 756 


\begin{tabular}{|c|c|c|c|c|}
\hline Apellidos y nombre; profesión & Localidad & Fecha & Fuente & Sentencia \\
\hline Madrid, Juan & & 1562 & libro 730 & $\begin{array}{l}\text { multado y deste- } \\
\text { rrado }\end{array}$ \\
\hline Mas Gros, Joan & & 1562 & libro 730 & $\begin{array}{l}\text { multado y deste- } \\
\text { rrado }\end{array}$ \\
\hline $\begin{array}{l}\text { Nin, Pere; tendero } \\
\text { Novella, Joana }\end{array}$ & $\begin{array}{l}\text { Tarragona } \\
\text { Barcelona }\end{array}$ & $\begin{array}{l}1623 \\
1573\end{array}$ & $\begin{array}{l}\text { libro } 733 \\
\text { libro } 737\end{array}$ & $\begin{array}{l}\text { desterrado } \\
\text { azotada }\end{array}$ \\
\hline Oliver, Joan & Masnou, El & 1571 & libro 730 & $\begin{array}{l}\text { ¿multado y deste- } \\
\text { rrado? }\end{array}$ \\
\hline $\begin{array}{l}\text { Pagés, Joan; labrador } \\
\text { Pericás, Benet } \\
\text { Picón, José; militar }\end{array}$ & $\begin{array}{l}\text { Barcelona } \\
\text { Barcelona }\end{array}$ & $\begin{array}{l}1720 \\
1575 \\
1728\end{array}$ & $\begin{array}{l}\text { leg. } 2.159 \\
\text { libro } 730 \\
\text { leg. } 3.724 / 116\end{array}$ & $\bar{z}$ \\
\hline $\begin{array}{l}\text { Rafart, Francisco; militar } \\
\text { Ramona (f) } \\
\text { Reixach, Miquel; labrador } \\
\text { Roger, Pere; arcabucero }\end{array}$ & $\begin{array}{l}\text { Pineda } \\
\text { Girona }\end{array}$ & $\begin{array}{l}1748 \\
1578 \\
1608 \\
1575\end{array}$ & $\begin{array}{l}\text { leg. } 2.165 \\
\text { libro } 730 \\
\text { libro } 732 \\
\text { libro } 730\end{array}$ & $\begin{array}{l}\text { azotada y recluida } \\
\text { multado } \\
\text { absuelto }\end{array}$ \\
\hline $\begin{array}{l}\text { Salvador, Juan (of) } \\
\text { Soler, Jeroni }\end{array}$ & & $\begin{array}{l}1664 \\
1662\end{array}$ & $\begin{array}{l}\text { libro } 735 \\
\text { libro } 730\end{array}$ & $\begin{array}{l}\text { desterrado } \\
\text { multado y deste- } \\
\text { rrado }\end{array}$ \\
\hline Tomas, Antoine (f); escribano & Perpignan & 1575 & libro 730 & $\begin{array}{l}\text { azotado y deste- } \\
\text { rrado }\end{array}$ \\
\hline $\begin{array}{l}\text { Tomás, Isidre; labrador } \\
\text { Torner, Arnaud (f); labrador }\end{array}$ & $\begin{array}{l}\text { Guissona } \\
\text { Cervera }\end{array}$ & $\begin{array}{l}1659 \\
1605\end{array}$ & $\begin{array}{l}\text { libro } 734 \\
\text { libro } 731\end{array}$ & azotado \\
\hline Vergés, Joan; labrador & Guissona & 1659 & libro 734 & - \\
\hline
\end{tabular}

\section{IRREVERENCIAS Y SACRILEGIOS}

\begin{tabular}{|c|c|c|c|c|}
\hline $\begin{array}{l}\text { Abril Miguelete, Francisco; labra- } \\
\text { dor }\end{array}$ & Palau Tordera & 1654 & libro 734 & suspenso \\
\hline Abdalla $(\mathrm{m})$; galeote & & 1653 & libro 749 & - \\
\hline Alvareda, Pierre (f) & & 1570 & libro 730 & reprendido \\
\hline Alvarez, Martin (a) & & 1569 & libro 730 & penitenciado \\
\hline Amador, Andreu & Montblanc & 1558 & leg. $1.592 / 28$ & \\
\hline Antrer, Paulet ( () & & 1570 & libro 730 & absuelto \\
\hline Arranz, Francisco (s) & Barcelona & 1632 & libro 733 & reprendido \\
\hline Balaguer, Jordi; maestro & Cervera & 1621 & libro 731 & $\begin{array}{l}\text { azotado y } 3 \text { años } \\
\text { en galeras }\end{array}$ \\
\hline $\begin{array}{l}\text { Bassia, Esteve } \\
\text { Bassia, Rafael } \\
\text { Berenquer, Ginés (si) }\end{array}$ & Barcelona & $\begin{array}{l}1602 \\
1602 \\
1638\end{array}$ & $\begin{array}{l}\text { libro } 731 \\
\text { libro } 731 \\
\text { libro } 734\end{array}$ & $\begin{array}{l}\text { + en estatua } \\
+ \text { en estatua } \\
\text { reprendido }\end{array}$ \\
\hline
\end{tabular}


Catálogo de los procesos inquisitoriales del Tribunal del...

\begin{tabular}{|c|c|c|c|c|}
\hline Apellidos y nombre; profesión & Localidad & Fecha & Fuente & Sentencia \\
\hline $\begin{array}{l}\text { Bernard de Jean (f); labrador } \\
\text { Bets, Joan } \\
\text { Blanchi, Antoine (f); serrador } \\
\text { Blanch, Etienne (f); serrador } \\
\text { Bosquetes, Francesc; labrador } \\
\text { Bru, Llorenç (s) } \\
\text { Busquets, Antoni }\end{array}$ & $\begin{array}{l}\text { Cervera } \\
\text { Porrera } \\
\text { Barcelona }\end{array}$ & $\begin{array}{l}1571 \\
1574 \\
1570 \\
1570 \\
1557 \\
1654 \\
1806\end{array}$ & $\begin{array}{l}\text { libro } 730 \\
\text { libro } 730 \\
\text { libro } 730 \\
\text { libro } 730 \\
\text { leg. } 1592 / 23 \\
\text { libro } 749 \\
\text { leg. } 2.177\end{array}$ & $\begin{array}{l}\text { penitenciado } \\
\text { absuelto } \\
\text { suspenso } \\
\text { suspenso }\end{array}$ \\
\hline $\begin{array}{l}\text { Camps, Pere } \\
\text { Capdevila, Joan } \\
\text { Casamitjana, Jaume; tejedor } \\
\text { Caso, Joan del } \\
\text { Clauset Catalan, Guillaume (f) (s) } \\
\text { Coburna, Carles de }\end{array}$ & $\begin{array}{l}\text { Reus } \\
\text { Montblanc } \\
\text { Moya }\end{array}$ & $\begin{array}{l}1621 \\
1623 \\
1663 \\
1602 \\
1570 \\
1786\end{array}$ & $\begin{array}{l}\text { libro } 733 \\
\text { libro } 734 \\
\text { libro } 734 \\
\text { libro } 731 \\
\text { libro } 730 \\
\text { leg. } 2.174\end{array}$ & $\begin{array}{l}\text { reprendido } \\
\text { reprendido } \\
\text { suspenso } \\
+ \text { en estatua } \\
\text { multado } \\
-\end{array}$ \\
\hline $\begin{array}{l}\text { Colomer, Barnar; labrador } \\
\text { Colomer, Joan (s) } \\
\text { Confinat, Jean (f) } \\
\text { Cros, Jacques (f); cocinero } \\
\text { Castelló Juan; militar }\end{array}$ & $\begin{array}{l}\text { Ventallo } \\
\text { Tárrega } \\
\text { Perpignan }\end{array}$ & $\begin{array}{l}1631 \\
1581 \\
1553 \\
1575 \\
1725\end{array}$ & $\begin{array}{l}\text { libro } 733 \\
\text { libro } 730 \\
\text { leg. } 1592 / 28 \\
\text { libro } 730 \\
\text { leg. } 2.161\end{array}$ & $\begin{array}{l}\text { suspenso } \\
\text { multado } \\
\text { azotado }\end{array}$ \\
\hline $\begin{array}{l}\text { Dalmau, Francesc; labrador } \\
\text { Dencros, Françoise ( } f \text { ) } \\
\text { Deugerma, Jean }(\mathfrak{f}) ; \text { apotecario }\end{array}$ & $\begin{array}{l}\text { ¿Mosabrio? } \\
\text { Granollers } \\
\text { Barcelona }\end{array}$ & $\begin{array}{l}1665 \\
1590 \\
1561\end{array}$ & $\begin{array}{l}\text { libro } 735 \\
\text { libro } 731 \\
\text { libro } 730\end{array}$ & $\begin{array}{l}\text { suspenso } \\
\text { absuelto } \\
\text { absuelto }\end{array}$ \\
\hline $\begin{array}{l}\text { Faix, Didac (om) } \\
\text { Felipe Esteban; carnicero } \\
\text { Ferran, Bernard (f); labrador } \\
\text { Feu, Pere; labrador }\end{array}$ & $\begin{array}{l}\text { Vic } \\
\text { Barcelona } \\
\text { Corro }\end{array}$ & $\begin{array}{l}1637 \\
1659 \\
1662 \\
1613\end{array}$ & $\begin{array}{l}\text { libro } 734 \\
\text { libro } 734 \\
\text { libro } 752 \\
\text { libro } 731\end{array}$ & $\begin{array}{l}\text { reprendido } \\
\text { suspenso } \\
\text { reprendido }\end{array}$ \\
\hline $\begin{array}{l}\text { Garrich, Dionis (f); (s) } \\
\text { Gerbes (s) } \\
\text { Gibert, Joan; labrador } \\
\text { Glauset, Guillen (s) }\end{array}$ & $\begin{array}{l}\text { Tremp } \\
\text { Puigcerdá } \\
\text { Figuerola }\end{array}$ & $\begin{array}{l}1639 \\
1571 \\
1658 \\
1575\end{array}$ & $\begin{array}{l}\text { libro } 734 \\
\text { libro } 730 \\
\text { libro } 734 \\
\text { libro } 730\end{array}$ & $\begin{array}{l}\text { - } \\
\text { absuelto } \\
\text { reprendido } \\
\text { azotado y } 3 \text { años } \\
\text { en galeras }\end{array}$ \\
\hline $\begin{array}{l}\text { Graells, Miquel; zurrador } \\
\text { Granie, Antoine (f); serrador } \\
\text { Guiamet, Francisco; militar }\end{array}$ & Cervera & $\begin{array}{l}1629 \\
1570 \\
1817\end{array}$ & $\begin{array}{l}\text { libro } 733 \\
\text { libro } 730 \\
\text { leg. } 3.722 / 87\end{array}$ & $\begin{array}{l}\text { reprendido } \\
\text { suspenso } \\
\text { - }\end{array}$ \\
\hline $\begin{array}{l}\text { Joseph de la Ascensión (f) (oc) } \\
\text { José de San Buenaventura (osa) } \\
\text { Juan, Pere } \\
\text { Juncas, Miguel }\end{array}$ & $\begin{array}{l}\text { Reus } \\
\text { Barcelona }\end{array}$ & $\begin{array}{l}1668 \\
1656 \\
1579\end{array}$ & $\begin{array}{l}\text { libro } 735 \\
\text { libro } 750 \\
\text { libro } 730\end{array}$ & $\begin{array}{l}\text { - } \\
\text { azotado y } 6 \text { años } \\
\text { en galeras } \\
\text { absuelto }\end{array}$ \\
\hline $\begin{array}{l}\text { Labernia, Godefroy }(f) \\
\text { Laboria, François }(f) \text {; blanqueador } \\
\text { Labat, Guillaume }(f) \text {; cirujano } \\
\text { Lera, Damien }(f)\end{array}$ & $\begin{array}{l}\text { Cervera } \\
\text { Os } \\
\text { Perafort }\end{array}$ & $\begin{array}{l}1612 \\
1571 \\
1595 \\
1611\end{array}$ & $\begin{array}{l}\text { libro } 732 \\
\text { libro } 730 \\
\text { libro } 731 \\
\text { libro } 732\end{array}$ & $\begin{array}{l}\text { reprendido } \\
\text { penitenciado } \\
\text { reprendido } \\
\text { reprendido }\end{array}$ \\
\hline $\begin{array}{l}\text { Lledó, Joan (cm) } \\
\text { Llorach, Gaspar; labrador } \\
\text { Malamosca, Guirau (f); labrador }\end{array}$ & $\begin{array}{l}\text { Girona } \\
\text { Pontils } \\
\text { Perpignan }\end{array}$ & $\begin{array}{l}1675 \\
1575 \\
1575\end{array}$ & $\begin{array}{l}\text { libro } 735 \\
\text { libro } 730 \\
\text { libro } 730\end{array}$ & $\begin{array}{l}\text { suspenso } \\
\text { absuelto } \\
\text { penitenciado }\end{array}$ \\
\hline
\end{tabular}




\begin{tabular}{|c|c|c|c|c|}
\hline Apellidos y nombre; profesión & Localidad & Fecha & Fuente & Sentencia \\
\hline $\begin{array}{l}\text { Mas, Jean (f); zapatero } \\
\text { Mato, Mathieu (f); labrador } \\
\text { Miró, Jaume; labrador } \\
\text { Molner, Jaume; pelaire } \\
\text { Moransol, Antón; militar } \\
\text { Munt, Vicenç; médico }\end{array}$ & $\begin{array}{l}\text { Perpignan } \\
\text { Perpignan } \\
\text { Barberá } \\
\text { Alcover } \\
\text { Barcelona }\end{array}$ & $\begin{array}{l}1575 \\
1578 \\
1623 \\
1620 \\
1752 \\
1638\end{array}$ & $\begin{array}{l}\text { libro } 730 \\
\text { libro } 730 \\
\text { libro } 733 \\
\text { libro } 732 \\
\text { leg. } 2167 \\
\text { libro } 734\end{array}$ & $\begin{array}{l}\text { azotado } \\
\frac{1}{\text { desterrado }} \\
\text { reprendido } \\
\text { reprendido }\end{array}$ \\
\hline $\begin{array}{l}\text { N } \\
\text { Nolla, Miquel; labrador } \\
\text { Nollas, Gaspar (s) }\end{array}$ & $\begin{array}{l}\text { Barcelona } \\
\text { Cambrills } \\
\text { Prats de Rei }\end{array}$ & $\begin{array}{l}1632 \\
1667 \\
1682\end{array}$ & $\begin{array}{l}\text { libro } 733 \\
\text { libro } 735 \\
\text { libro } 735\end{array}$ & $\begin{array}{l}\text { falleció } \\
\text { suspenso } \\
\text { suspenso }\end{array}$ \\
\hline $\begin{array}{l}\text { Ordento, Antoine (f); labrador } \\
\text { Orderts, Maria }\end{array}$ & $\begin{array}{l}\text { Perpignan } \\
\text { Reus }\end{array}$ & $\begin{array}{l}1565 \\
1730\end{array}$ & $\begin{array}{l}\text { libro } 730 \\
\text { leg. } 2.162\end{array}$ & azotado \\
\hline $\begin{array}{l}\text { Palou, Francesc (s) } \\
\text { Paris, Miquel; labrador } \\
\text { Pas, Jeroni del } \\
\text { Pas, Raimond del } \\
\text { Pasanau, Pierre (f); serrador } \\
\text { Patau, Jacint; pasamanero } \\
\text { Payaroli, Jeroni; escribano } \\
\text { Peyret, François (f); labrador } \\
\text { Peyro, Jaume } \\
\text { Pinos, Pere Joan; zurrador } \\
\text { Poncos, Francesc; labrador } \\
\text { Prats, Pau; sastre } \\
\text { Puig, Joan (om) } \\
\text { Puigferrer, Domenec; tejedor } \\
\text { Rebentos, Jacint (s) } \\
\text { Rellat, Jean (f); molinero } \\
\text { Roger, Jaume (osb) } \\
\text { Ros, Alexandre (s) } \\
\text { Rovira, Mateu; zapatero }\end{array}$ & $\begin{array}{l}\text { Agramunt } \\
\text { Vallclara } \\
\text { Barcelona } \\
\text { Perpignan } \\
\text { Barcelona } \\
\text { Palafrugell } \\
\text { Vilamajor } \\
\text { Cervera } \\
\text { Alcover } \\
\text { Barcelona } \\
\text { Vic } \\
\text { Avellanes } \\
\text { Canyelles } \\
\text { Stes Creus } \\
\text { Barcelona } \\
\text { Cervera }\end{array}$ & $\begin{array}{l}1639 \\
1631 \\
1617 \\
1638 \\
1570 \\
1638 \\
1665 \\
1582 \\
1574 \\
1629 \\
1674 \\
1632 \\
1637 \\
1609 \\
1637 \\
1569 \\
1694 \\
1638 \\
1629\end{array}$ & $\begin{array}{l}\text { libro } 734 \\
\text { libro } 733 \\
\text { libro } 732 \\
\text { libro } 734 \\
\text { libro } 730 \\
\text { libro } 734 \\
\text { libro } 735 \\
\text { libro } 730 \\
\text { libro } 730 \\
\text { libro } 733 \\
\text { libro } 735 \\
\text { libro } 733 \\
\text { libro } 734 \\
\text { libro } 732 \\
\text { libro } 734 \\
\text { libro } 730 \\
\text { libro } 760 \\
\text { libro } 734 \\
\text { libro } 733\end{array}$ & $\begin{array}{l}\text { reprendido } \\
\text { desterrado } \\
\text { desterrado } \\
\text { suspenso } \\
\text { suspenso } \\
- \\
\text { rerprendido } \\
\text { absuelto } \\
\text { absuelto } \\
\text { reprendido } \\
\text { absuelto } \\
\text { suspenso } \\
\text { reprendido } \\
\text { absuelto } \\
\text { suspenso } \\
\text { absuelto } \\
\text { desterrado } \\
\text { reprendido } \\
\text { reprendido }\end{array}$ \\
\hline $\begin{array}{l}\text { Sillant, Joan (s) } \\
\text { Sorbes, Jean (f) }\end{array}$ & Montbui & $\begin{array}{l}1570 \\
1594\end{array}$ & $\begin{array}{l}\text { libro } 730 \\
\text { libro } 731\end{array}$ & $\begin{array}{l}\text { suspenso } \\
\text { desterrado }\end{array}$ \\
\hline Termens, Pere & $\begin{array}{l}\text { Pont de Ar- } \\
\text { mentera }\end{array}$ & 1594 & libro 731 & multado \\
\hline $\begin{array}{l}\text { Toca, Josep (si) } \\
\text { Torrent, Joan (om) } \\
\text { Trahifach, Pierre (f); labrador }\end{array}$ & $\begin{array}{l}\text { Barcelona } \\
\text { Vic } \\
\text { Vilamitjana }\end{array}$ & $\begin{array}{l}1638 \\
1637 \\
1631\end{array}$ & $\begin{array}{l}\text { libro } 734 \\
\text { libro } 734 \\
\text { libro } 733\end{array}$ & $\begin{array}{l}\text { reprendido } \\
\text { reprendido } \\
\text { suspenso }\end{array}$ \\
\hline Ucos, Jean (f); labrador & & 1628 & libro 733 & suspenso \\
\hline $\begin{array}{l}\text { Valeri, Francesc (s) } \\
\text { Vernia, Pau; albañil }\end{array}$ & Barcelona & $\begin{array}{l}1632 \\
1610\end{array}$ & $\begin{array}{l}\text { libro } 733 \\
\text { libro } 732\end{array}$ & $\begin{array}{l}\text { reprendido } \\
\text { azotado y } 3 \text { años } \\
\text { en galeras } \\
\text { suspenso }\end{array}$ \\
\hline
\end{tabular}


Catálogo de los procesos inquisitoriales del Tribunal del...

\begin{tabular}{|c|c|c|c|}
\hline Apellidos y nombre; profesión & Localidad & Fecha Fuente & Sentencia \\
\hline
\end{tabular}

\section{CENSURA}

\section{Libros prohibidos}

\begin{tabular}{|c|c|c|c|c|}
\hline Barrera Valdés, Juan (s) & Barcelona & 1807 & ${ }_{3.731 / 4}^{\text {leg. } 2.177} \mathrm{y}$ & $1-$ \\
\hline $\begin{array}{l}\text { Barberi, Gabriel; mercader } \\
\text { Bordiu, Jean (f); (s) }\end{array}$ & Barcelona & $\begin{array}{l}1569 \\
1569\end{array}$ & $\begin{array}{l}\text { libro } 730 \\
\text { libro } 730\end{array}$ & $\begin{array}{l}\text { penitenciado } \\
\text { penitenciado }\end{array}$ \\
\hline Caramany, Salvador & Barcelona & 1780 & leg. 2.169 & suspenso \\
\hline $\begin{array}{l}\text { Ferrer, Miquel Andreu } \\
\text { Francisco de San Agustín (osa) }\end{array}$ & $\begin{array}{l}\text { Barcelona } \\
\text { Barcelona }\end{array}$ & $\begin{array}{l}1571 \\
1667\end{array}$ & $\begin{array}{l}\text { libro } 730 \\
\text { libro } 735\end{array}$ & $\begin{array}{l}\text { multado } \\
\text { suspenso }\end{array}$ \\
\hline Graciliano Alfonso & & 1815 & leg. 2.177 & - \\
\hline $\begin{array}{l}\text { Magarola, Antoni; boticario } \\
\text { Marqués, EI } \\
\text { Minguella, Juan Antonio }\end{array}$ & $\begin{array}{l}\text { Barcelona } \\
\text { Torrenti } \\
\text { Verdú }\end{array}$ & $\begin{array}{l}1571 \\
1819 \\
1759\end{array}$ & $\begin{array}{l}\text { libro } 730 \\
\text { leg. } 2.177 \\
\text { leg. } 2.169 \\
3.724 / 22\end{array}$ & multado \\
\hline N., Esteban; militar & & 1819 & leg. 2.177 & - \\
\hline Olboyle, Narciso; militar & Tarragona & 1817 & leg. 2.177 & - \\
\hline $\begin{array}{l}\text { Pagés, Joan; médico } \\
\text { Peralada, Conde de } \\
\text { Preuser (a) }\end{array}$ & $\begin{array}{l}\text { Palafrugell } \\
\text { Barcelona } \\
\text { Barcelona }\end{array}$ & $\begin{array}{l}1819 \\
1780 \\
1782\end{array}$ & $\begin{array}{l}\text { leg. } 2.177 \\
\text { leg. } 3.724 / 30 \\
\text { leg. } 3.724 / 31\end{array}$ & - \\
\hline $\begin{array}{l}\text { Raymond (f); librero } \\
\text { Rogun, Louis (f) } \\
\text { Royench, Louis (s) }\end{array}$ & $\begin{array}{l}\text { Girona } \\
\text { Barcelona }\end{array}$ & $\begin{array}{l}1557 \\
1744 \\
1743\end{array}$ & $\begin{array}{l}\text { leg. } 1295 / 23 \\
\text { leg. } 2.164 \\
\text { leg. } 2.164 \text { y } \\
3.724 / 160\end{array}$ & E \\
\hline $\begin{array}{l}\text { Sartine, Antón; militar } \\
\text { Senderio, Tomi de }\end{array}$ & Barcelona & $\begin{array}{l}1735 \\
1565\end{array}$ & $\begin{array}{l}\text { leg. } 2.162 \\
\text { libro } 730\end{array}$ & absuelto \\
\hline Tolet, Jean de $(f)$ & & 1569 & libro 730 & absuelto \\
\hline $\begin{array}{l}\text { Valantin, Jean }(f) ;(s) \\
\text { Vilajoana, Tomás; abogado } \\
\text { Vilana, Antonio; militar }\end{array}$ & $\begin{array}{l}\text { Barcelona c. } \\
\text { Barcelona }\end{array}$ & $\begin{array}{l}1562 \\
1750 \\
1735\end{array}$ & $\begin{array}{l}\text { libro } 730 \\
\text { leg. } 2.168 \\
\text { leg. } 2.162\end{array}$ & $\begin{array}{l}\text { desterrado } \\
\text { desterrado } \\
-\end{array}$ \\
\hline Dona, Jean $(f)$; comerciante & Barcelona & 1565 & libro 730 & multado \\
\hline Laparra, Pierre (f); comerciante & Barcelona & 1565 & libro 730 & multado \\
\hline
\end{tabular}


JUAN BLÁZQUEZ MIGUEL

\begin{tabular}{llcll}
\hline Apellidos y nombre; profesion & Localidad & Fecha Fuente & Sentencia \\
\hline Narro, Francisco; militar & & 1819 leg. 2.177 & ireprendido? \\
Olsina, Antoni; estudiante & Cardona & 1687 leg. 2156 & desterrado \\
Peinsot, Jean (f); comerciante & Barcelona & 1565 libro 730 & multado \\
Roquer, Charles (f); comerciante & Barcelona & 1565 libro 730 & absuelto
\end{tabular}

\section{RELIGIOSOS CASADOS}

\begin{tabular}{|c|c|c|c|c|}
\hline Capella, José Simón (s) & Cambrils & 1658 & libro 734 & $\begin{array}{l}\text { suspenso } \\
3 \text { años en galeras }\end{array}$ \\
\hline $\begin{array}{l}\text { Caseres, Lluc de } \\
\text { Constanç (f) }\end{array}$ & & $\begin{array}{l}1573 \\
1561\end{array}$ & $\begin{array}{l}\text { libro } 737 \\
\text { libro } 730\end{array}$ & $\begin{array}{l}3 \text { años en galeras } \\
\text { ayunos y discipli- } \\
\text { nas }\end{array}$ \\
\hline Joan, Martín & & $\begin{array}{l}1570 \\
1753\end{array}$ & $\begin{array}{l}\text { libro } 730 \\
\text { lea } 2167\end{array}$ & absuelto \\
\hline Palmerola, Sebastiá (osb) & Ripoll & $\begin{array}{l}1 / 53 \\
1591\end{array}$ & $\begin{array}{l}\text { leg. } 2.168 \\
\text { libro } 730\end{array}$ & $\overrightarrow{\text { reclusión }}$ \\
\hline $\begin{array}{l}\text { Picassan, Agustin (i) (cap) } \\
\text { Segui, Antoni }\end{array}$ & Barcelona & $\begin{array}{l}1603 \\
1570\end{array}$ & $\begin{array}{l}\text { libro } 731 \\
\text { libro } 730\end{array}$ & $\begin{array}{l}\text { reclusión } \\
\text { devuleto a su Or- } \\
\text { den }\end{array}$ \\
\hline Solsona, Pau de (cap) & & 1680 & libro 735 & $\begin{array}{l}6 \text { años en un pre- } \\
\text { sidio }\end{array}$ \\
\hline Tello, Joaquín (s) & Barcelona & 1721 & leg. 2.159 & - \\
\hline Timoteo (i) (cap) & Barcelona & 1602 & libro 731 & - \\
\hline
\end{tabular}

\section{CELEBRANTES DE MISA SIN ESTAR AUTORIZADOS}

\author{
Bassols, Francesc \\ Benet, Francesc \\ Burgada, Josep (osa) \\ Burgada, Salvador (osm) \\ Cailua y Vinyals, Vicenç \\ Cardona, Frances Josep (s) \\ Colomer, Francesc (of) \\ Colomer, Joan (of) \\ Diego de San Antonio (sd) \\ Finestrat, Antoni (s) \\ Gallardo, Joan \\ Juan Bautista (om) \\ Rodriguez Hernández (om)
}

\begin{tabular}{|c|c|c|c|}
\hline $\begin{array}{l}\text { Olot } \\
\text { Gironella }\end{array}$ & $\begin{array}{l}1819 \\
1610 \\
1745\end{array}$ & $\begin{array}{l}\text { leg. } 2.177 \\
\text { libro } 732 \\
\text { leg. } 2.165 \text { y } \\
3.724 / 99\end{array}$ & absuelto \\
\hline Barcelona & 1690 & libro 735 & desterrado \\
\hline Barcelona & 1750 & leg. $3.729 / 210$ & - \\
\hline Barcelona & $\begin{array}{l}1602 \\
1665\end{array}$ & $\begin{array}{l}\text { libro } 731 \\
\text { libro } 735\end{array}$ & $\begin{array}{l}\text { azotado } \\
\text { azotes y galeras }\end{array}$ \\
\hline Puigcerdá & 1665 & libro 735 & $\begin{array}{l}\text { suspenso de orde- } \\
\text { nes }\end{array}$ \\
\hline $\begin{array}{l}\text { Montiro } \\
\text { Selva, La } \\
\text { Sorpe }\end{array}$ & $\begin{array}{l}1784 \\
1635 \\
1580\end{array}$ & $\begin{array}{l}\text { leg. } 2.174 \\
\text { libro } 734 \\
\text { libro } 730\end{array}$ & $\begin{array}{l}\text { recluido } \\
\text { azotes y } 7 \text { años } \\
\text { en galeras }\end{array}$ \\
\hline & $\begin{array}{l}1628 \\
1608\end{array}$ & $\begin{array}{l}\text { leg. } 2.158 \\
\text { libro } 732\end{array}$ & $\begin{array}{l}\text { suspenso } \\
\text { entregado a su Or- } \\
\text { den }\end{array}$ \\
\hline
\end{tabular}


Catálogo de los procesos inquisitoriales del Tribunal del...

\begin{tabular}{|c|c|c|c|c|}
\hline Apellidos y nombre; profesión & Localidad & Fecha & Fuente & Sentencia \\
\hline $\begin{array}{l}\text { Lluvia, Bernardi (osb) } \\
\text { Madamunt, François (f); (of) }\end{array}$ & Ripoll & $\begin{array}{l}1666 \\
1597\end{array}$ & $\begin{array}{l}\text { libro } 735 \\
\text { libro } 731\end{array}$ & $\begin{array}{l}\text { suspenso } \\
\text { azotado y } 5 \text { años } \\
\text { en galeras }\end{array}$ \\
\hline Mercante, Justo (osm) & & 1764 & $\begin{array}{l}\text { leg. } 2.170 \mathrm{y} \\
3.724 / 75\end{array}$ & desterrado \\
\hline $\begin{array}{l}\text { Marc Antoine de Saint Gervase (f) } \\
\text { Pascual Felipe (y) }\end{array}$ & & $\begin{array}{l}1737 \\
1654\end{array}$ & $\begin{array}{l}\text { leg. } 2.164 \\
\text { libro } 734\end{array}$ & reprendido \\
\hline Pérez, Felipe & Barcelona & 1779 & leg. $3.724 / 35$ & - \\
\hline Rigau, Joan (s) & $\begin{array}{l}\text { Castello } \\
\text { d'Empuries }\end{array}$ & 1617 & libro 732 & $\begin{array}{l}\text { azotado y } 5 \text { años } \\
\text { en galeras }\end{array}$ \\
\hline $\begin{array}{l}\text { Salvador, Mateu } \\
\text { Salvador Guerrero, Joan (om) } \\
\text { Sampietro Martorell, Gregori }\end{array}$ & $\begin{array}{l}\text { Balaguer } \\
\text { Barcelona }\end{array}$ & $\begin{array}{l}1628 \\
1628 \\
1791\end{array}$ & $\begin{array}{l}\text { libro } 733 \\
\text { libro } 733 \\
\text { leg. } 2.174 \quad y \\
3.724 / 40\end{array}$ & $\begin{array}{l}\text { suspenso } \\
\text { absuelto } \\
-\end{array}$ \\
\hline
\end{tabular}

\section{DELITOS EN LA CONFESIÓN Y COMUNIÓN}

Alcedar, Pere

Ballarón, Juan Bautista (om)

Cadena, Benito (s)

Carolt, Giralt (f); pastor

Clausel, Francesc (of?)

Derniles, Antoni (op)

Font, Jean (f); labrador

Griffol, Antonine (f); (s)

Leonard Philippe (f); agujetero

Mestre, Bartomeu; labrador

Pellicer, Bernard (f); molinero

Ratera, Joanot

Serra, Joan; labrador

\begin{tabular}{|c|c|c|c|}
\hline $\begin{array}{l}\text { Sellent } \\
\text { Barcelona }\end{array}$ & $\begin{array}{l}1654 \\
1610\end{array}$ & $\begin{array}{l}\text { libro } 734 \\
\text { libro } 732\end{array}$ & $\begin{array}{l}\text { suspenso } \\
\text { recluido }\end{array}$ \\
\hline St. Salvador & 1635 & libro 733 & suspenso \\
\hline & 1629 & libro 733 & suspenso \\
\hline Torá & 1796 & leg. $3.724 / 44$ & suspenso \\
\hline Puigcerdá & $\begin{array}{l}1619 \\
1624\end{array}$ & $\begin{array}{l}\text { libro } 732 \\
\text { libro } 733\end{array}$ & $\begin{array}{l}\text { desterrado } \\
\text { reprendido }\end{array}$ \\
\hline & 1601 & libro 740 & - \\
\hline Tarragona & 1637 & libro 734 & suspenso \\
\hline Argensola & 1665 & libro 735 & suspenso \\
\hline $\begin{array}{l}\text { St. Esteve de } \\
\text { Palau Tor- } \\
\text { dera }\end{array}$ & 1628 & libro 733 & reprendido \\
\hline Tárrega & 1571 & libro 730 & penitenciado \\
\hline Girona & 1626 & libro 733 & reprendido \\
\hline
\end{tabular}

\section{BAUTIZOS MÚLTIPLES}

Baste, Maria

Jadin, Gabriel (i); militar

Juan Miguel de Santa María (m)

Mongay, Manuel (s)
1746 leg. 2.165

1746 leg. 2.165

1659 libro 734

1666 libro 735 falleció

suspenso 
JUAN BLAZQUEZ MIGUEL

\begin{tabular}{lllll}
\hline Apellidos $y$ nombre; profesión & Localidad & \multicolumn{2}{l}{ Fecha Fuente } & Sentencia \\
\hline Roldona, Isabel & Barcelona & 1661 & libro 734 & desterrada \\
Taden, Gabriel (i); militar & Figueres & c. 1750 & leg. 3.724/106
\end{tabular}

\section{COMER CARNE EN DÍAS PROHIBIDOS}

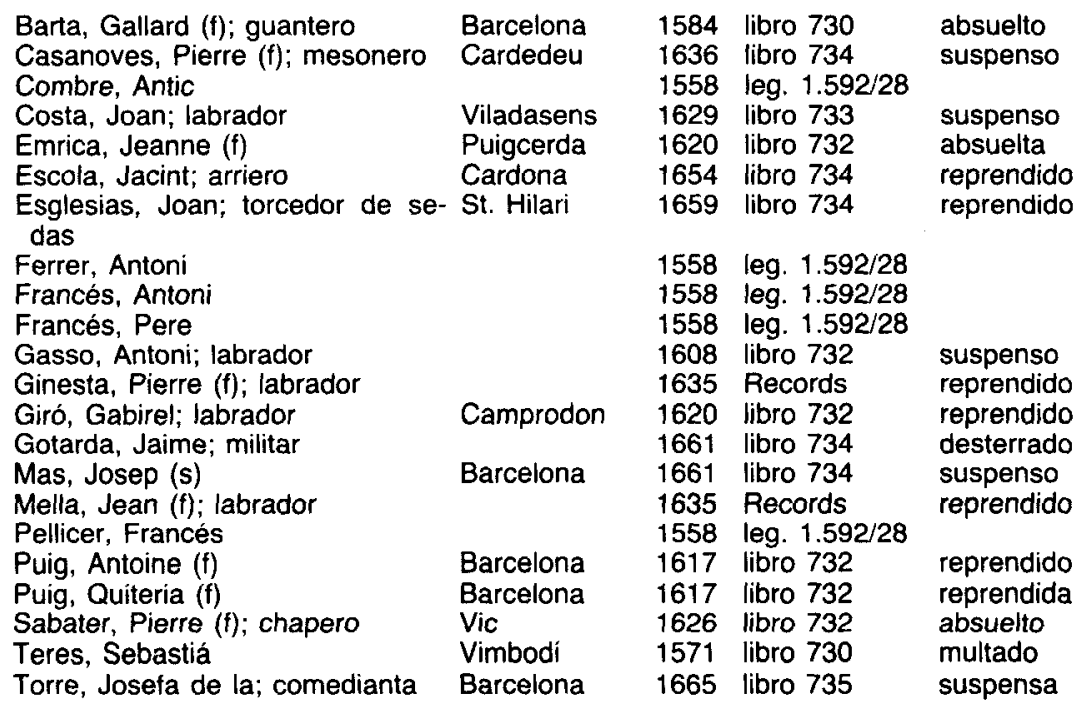

\section{DELITOS VARIOS}

Adan, Pere

Aguirre, Juan (of)

Artois, Guillaume (f); (cist)

Bareres, Pedro

Bisbe i Vidal, Orosia (of)

Cerdá, Bartolomé

Cristian, Felipe ( $r$ )

Drulla (f)

Duque, Maria

Faidella, Antonia María

Falico, Juan; albañil

Fontelles, Francesc

Geolar, Pablo; tintorero

Jacobi, Jacob (fl); militar

$\begin{array}{lll}1675 & \text { libro } 735 & \text { suspenso } \\ 1599 & \text { libro } 731 & \\ 1721 & \text { leg. } 2.159 & \\ 1675 & \text { libro } 735 & \text { suspenso } \\ 1636 & \text { libro } 734 & \text { absuelta } \\ 1666 & \text { libro } 735 & \text { suspenso } \\ 1674 & \text { libro } 735 & \text { absuelto } \\ 1797 & \text { leg. } 2.174 & \text { absuelto? } \\ 1662 & \text { libro } 734 & \text { suspensa } \\ 1665 & \text { libro } 735 & \text { desterrada } \\ 1662 & \text { libro } 735 & \text { suspenso } \\ 1662 & \text { libro } 734 & \text { suspenso } \\ 1622 & \text { libro } 733 & \text { reprendido } \\ & \text { leg. } 2.129 & \text { y }\end{array}$


Catálogo de los procesos inquisitoriales del Tribunal del...

\begin{tabular}{|c|c|c|c|c|}
\hline Apellidos y nombre; profesión & Localidad & Fecha & Fuente & Sentencia \\
\hline Jiménez de Cisneros, Francisco & Barcelona & 1738 & leg. 2.164 & \\
\hline Horts, Miquel (s) & Fiqueres & 1815 & leg. 2.177 & \\
\hline López de Aguilar, Jeronimo (osst) & & 1675 & libro 756 & absuelto \\
\hline Mauri, Tomás (op) & Barcelona & 1680 & libro 735 & suspenso \\
\hline March, Pere; labrador & Codony & 1639 & libro 748 & \\
\hline Mayoral, Francisco; militar & Barcelona & 1816 & leg. $3.725 / 85$ & suspenso? \\
\hline Melo Menedes, Rui de (p); (s) & & 1624 & libro 733 & suspenso \\
\hline Navel, Jeroni de & Barcelona & 1639 & libro 734 & reprendido \\
\hline Pablo de San Andrés (f) & & 1639 & libro 748 & absuelto \\
\hline Ripoll (op) & & 1680 & libro 735 & suspenso \\
\hline Rodrigo Fernando & & 1617 & libro 732 & \\
\hline Roger, José (cist) & Stes Creus & 1697 & libro 760 & \\
\hline Sabater, Tomás (op) & & 1680 & libro 735 & suspenso \\
\hline Sarrio, François (f) & & 1592 & leg. 2.158 & \\
\hline Serra, Rafael; labrador & Vendrell, $\mathrm{EI}$ & 1668 & libro 735 & \\
\hline Picar, Bartomeu; labrador & Tercui & 1629 & libro 733 & suspenso \\
\hline Sunyer, isidre (s) & Barcelona & 1682 & libro 735 & suspenso \\
\hline Tremol, Jacques $(f)$; marinero & & 1603 & libro 731 & \\
\hline Velas, Antón & & 1685 & libro 758 & \\
\hline Vidal, Pere (si) & & 1612 & libro 732 & reprendido \\
\hline Voltes, Armenter & Falset & 1666 & libro 735 & suspenso \\
\hline
\end{tabular}

\section{DELITO DESCONOCIDO}

Adrián (fl)

Agustín (s)

Alarcón, Alonso de; militar

Albertini, Elesio (i); militar

Alcedán, Pere (s)

Andreu, Josep; médico

Angelini, Santiago (i); (s)

Angelo del Santísimo

Sacramento (OC)

Antique, Joan

Arans, Francesc

Arau, Francesc (s)

Arreda, Gabriel; pastor

Arcos, María de los

Argelich, Macià (fraile)

Armengol, Josep (s)

Ascot, Bartomeu (s)

Asuar, Pere (osst)

Atanasio de Girona (cap)

Auger; sastre

Aulesa, Francesc de; baile

Aylla, Pere

Aznar, Pedro (osst)

$\begin{array}{lll}1553 & \text { leg. } 1.592 / 28 & - \\ 1539 & \text { libro } 730 & \text { penitenciado } \\ 1638 & \text { libro } 748 & - \\ 1741 & \text { leg. } 2.164 & - \\ 1653 & \text { libro } 749 & - \\ 1662 & \text { libro } 752 & - \\ & & \\ 1728 & \text { leg. } 2.161 & - \\ 1630 & \text { libro } 745 & - \\ & & \\ 1540 & \text { libro } 730 & \text { abjuró de levi } \\ 1556 & \text { leg. } 1.592 / 23 & - \\ 1632 & \text { libro } 746 & - \\ 1653 & \text { libro } 749 & - \\ 1640 & \text { libro } 748 & \text { suspensa } \\ 1634 & \text { libro } 747 & - \\ 1653 & \text { libro } 749 & - \\ 1629 & \text { libro } 745 & - \\ 1641 & \text { leg. } 2.158 & - \\ 1654 & \text { libro } 749 & - \\ 1540 & \text { libro } 730 & \text { abjuró de vehe- } \\ & & \text { menti } \\ 1552 & \text { libro } 730 & \text { penitenciado } \\ 1552 & \text { libro } 730 & \text { penitenciado } \\ 1658 & \text { libro } 751 & \end{array}$


JUAN BLÁZQUEZ MIGUEL

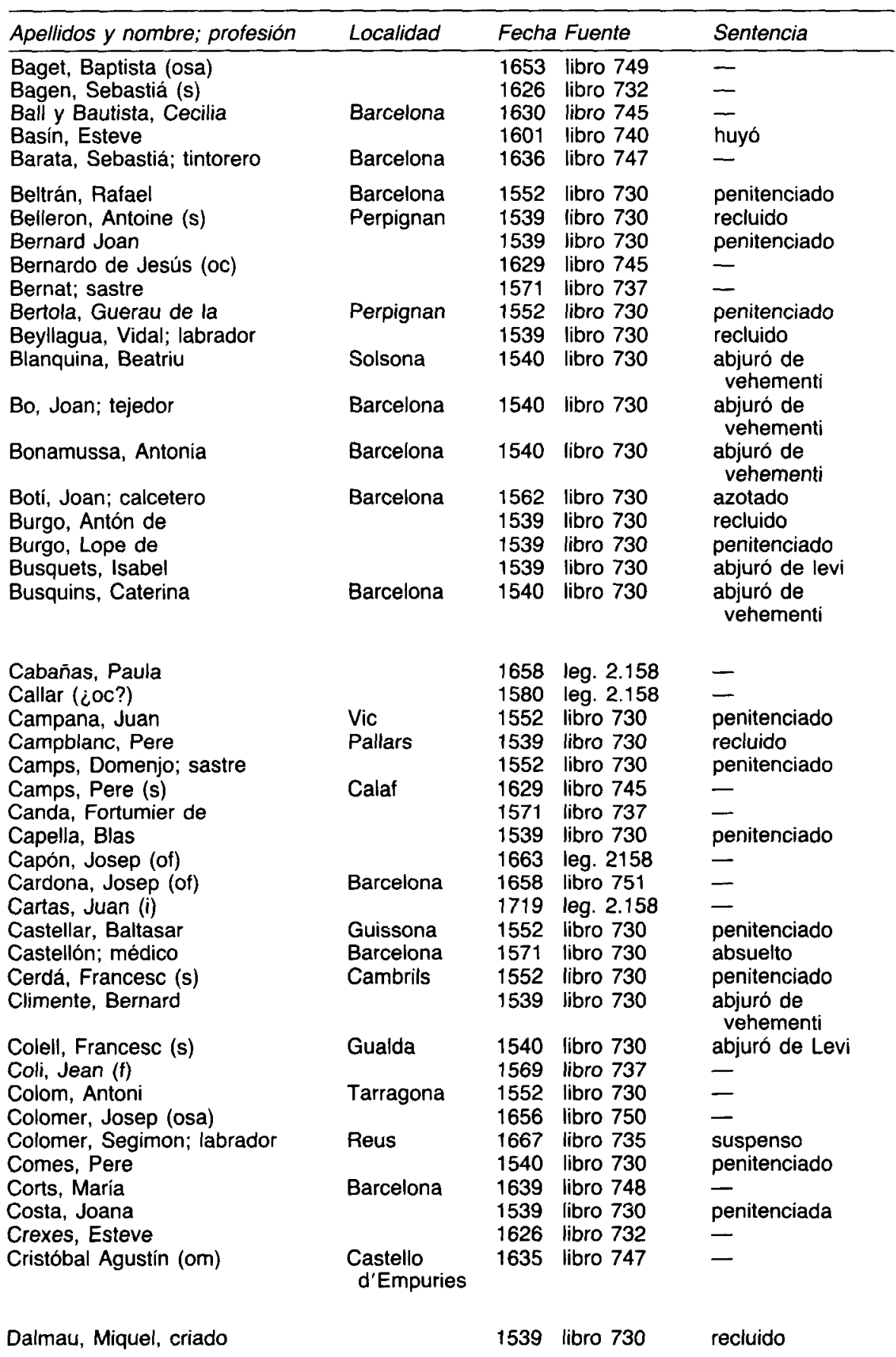


Catálogo de los procesos inquisitoriales del Tribunal del...

\begin{tabular}{l} 
Apellidos y nombre; pro \\
\hline Diaz, Juan \\
Donada, Caterina \\
Durán, Joan (s) \\
Esperanza \\
Fabricia, Ramón de la \\
Faix, Didac (om) \\
Ferris, Gaspar (jer) \\
Fierro, Joan \\
Floris, Joan; sastre \\
Fogas, Michel (i) \\
Forch, Amadora del \\
Forner, Josep \\
Forner, Onofre (s) \\
Fousán, Francesc \\
Francisco Pascual (s) \\
Fuster, Isabel
\end{tabular}

Gabriel de Jesús María (oc)

Garrich, Dionysos (f) (s)

Garrigella, Jaume; pelaire

Gausens, Agustí (s)

Gebelina, Isabel

Genesta, Juana

Gogenech, Arnau

Goig. Antoni; sastre

González, Juan

González, Leonor

González, Pedro; militar

Guillens-Nes, Bernat

Guitart, Juana

Heredia, Catalina

Huguet, Bernat

Jaume (s)

Jiménez, Isabel

Joliu, Bartomeu

Joan Alberte

Juana

Juglar, Pere

Localidad
Barcelo
Pallars

\begin{tabular}{|c|c|c|c|}
\hline & 1560 & libro 730 & - \\
\hline & 1638 & libro 748 & - \\
\hline & 1571 & libro 737 & - \\
\hline Seu d'Urgell & 1540 & libro 730 & abjuró de \\
\hline & 1539 & libro 730 & $\begin{array}{l}\text { abjuró de } \\
\text { vehementi }\end{array}$ \\
\hline & $\begin{array}{l}1606 \\
1626\end{array}$ & $\begin{array}{l}\text { libro } 732 \\
\text { libro } 732\end{array}$ & ¿+ en persona? \\
\hline & $\begin{array}{l}1626 \\
1634 \\
1539\end{array}$ & $\begin{array}{l}\text { libro } 732 \\
\text { libro } 747 \\
\text { libro } 730\end{array}$ & - \\
\hline Barcelona & 1705 & leg. 2.157 & - \\
\hline Barcelona & 1540 & libro 730 & $\begin{array}{l}\text { abjuró de } \\
\text { vehementi }\end{array}$ \\
\hline
\end{tabular}

$\begin{array}{lll} & 1646 & \text { leg. } 2.158 \\ \text { Tremp } & 1634 & \text { libro } 748\end{array}$

Perpignan 1540 libro 730 abjuró de

Solsona $\quad 1653$ libro 749

Reus $\quad 1540$ libro 730

1540 libro 730

1636 libro 747

1539 libro 730

1540 libro 730

Barcelona $\quad 1540$ libro 730

1722 leg. 2.159

1539 libro 730

1626 libro 732

Barcelona

1540 libro 730

$1657 \operatorname{leg} .2 .158$

Granollers

1628 libro 745

1539 libro 730

1539 libro 730

1539 libro 730

1540 libro 730

Castellfollit 1571 libro 730
Sentencia

abjuró de

vehementi

penitenciado

recluido

abjuró de

vehementi

vehementi

abjuró de

vehementi

abjuró de

vehementi

recluido

recluido

abjuró de

vehementi

recluido

-

abjuró de

vehementi

-

penitenciada

abjuró de levi

penitenciado

abjuró de

vehementi

desterrado 
JUAN BLÁZQUEZ MIGUEL

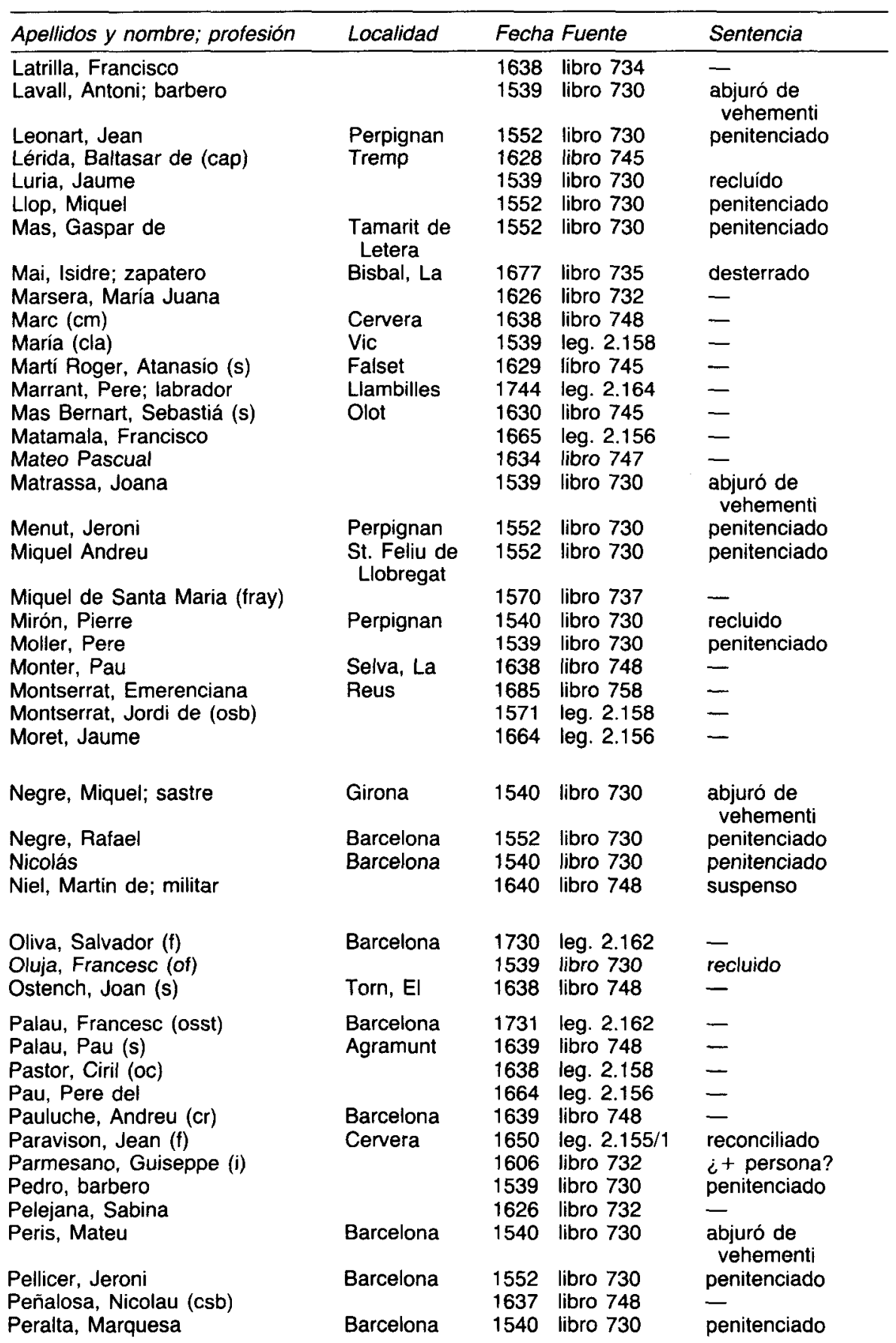


Catálogo de los procesos inquisitoriales del Tribunal del...

\begin{tabular}{|c|c|c|c|c|}
\hline \multirow{2}{*}{$\begin{array}{l}\text { Apellidos y nombre; profesión } \\
\text { Pou, Benet; pelaire }\end{array}$} & \multirow{2}{*}{$\frac{\text { Localidad }}{\text { Vic }}$} & \multicolumn{2}{|c|}{ Fecha Fuente } & \multirow{2}{*}{ 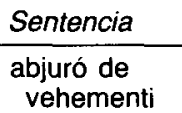 } \\
\hline & & 1540 & libro 730 & \\
\hline Preda, Josefa (p) & & 1740 & leg. 2.164 & - \\
\hline Provensal, Rafaela & Barcelona & 1540 & libro 730 & $\begin{array}{l}\text { abjuró de } \\
\text { vehementi }\end{array}$ \\
\hline Puiasola, Paula & & 1539 & libro 730 & $\begin{array}{l}\text { abjuró de } \\
\text { vehementi }\end{array}$ \\
\hline Puig, Antoni & Peralada & 1539 & libro 730 & penitenciado \\
\hline Puig, Joan & Perpignan & 1552 & libro 730 & penitenciado \\
\hline Puig, Joan (om) & & 1638 & libro 748 & - \\
\hline Puisegur, Joan; marinero & & 1766 & leg. 2.170 & - \\
\hline Pujalt, Miquel (si) & & 1730 & leg. 2.162 & - \\
\hline Rac, Pere $(\mathrm{cm})$ & Granollers & 1630 & libro 745 & - \\
\hline Rebollit, Pere, tejedor & Barcelona & 1540 & libro 730 & penitenciado \\
\hline Ribot, Joan; pelaire & & 1539 & libro 730 & $\begin{array}{l}\text { abjuró de } \\
\text { vehementi }\end{array}$ \\
\hline Rigalt, Mateu & & 1552 & libro 730 & penitenciado \\
\hline Rigalt, Pere; baile & $\begin{array}{l}\text { Vilafranca del } \\
\text { Penedés }\end{array}$ & 1639 & libro 748 & - \\
\hline Rio, Honorato (si) & Barcelona & 1638 & libro 748 & 一 \\
\hline Robledo, Benito; militar & & 1539 & libro 730 & abjuró de levi \\
\hline Robler, Antoni; mesonero & Girona & 1539 & libro 730 & abjuró de levi \\
\hline Roca, Tomás (op) & Barcelona & 1630 & libro 745 & - \\
\hline Rocaberti, Doulnis de & & 1539 & libro 730 & penitenciado \\
\hline Roger, Llorenç & Barcelona & 1552 & libro 730 & penitenciado \\
\hline Romagosa, Pere & $\begin{array}{l}\text { Prats de Rei, } \\
\text { Els }\end{array}$ & 1562 & libro 730 & falleció \\
\hline Ros i Llauger, Josep & Canet de Mar & 1797 & leg. 2.174 & - \\
\hline Rosell, Joan; blanquero & Vic & 1539 & libro 730 & $\begin{array}{l}\text { abjuró de } \\
\text { vehementi }\end{array}$ \\
\hline Rosell, Joan; cirujano & Barcelona & 1639 & libro 748 & - \\
\hline Rovira, Caterina & & 1539 & libro 730 & recluida \\
\hline Ruidor, Joan & Manresa & 1552 & libro 730 & penitenciado \\
\hline Ruiz, Juan & St. Llorenç & 1552 & libro 730 & penitenciado \\
\hline Saldon, Catalina & & 1540 & libro 730 & $\begin{array}{l}\text { abjuró de } \\
\text { vehementi }\end{array}$ \\
\hline Salvador, José; militar & & 1638 & libro 748 & - \\
\hline Salvat, Joan (s) & Riudoms & 1571 & libro 730 & absuelto \\
\hline Sampech, Isabel & St. Privat & 1647 & leg. $2.155 / 1$ & reconciliada \\
\hline Sampso, Pierre (f) & & 1539 & libro 730 & penitenciado \\
\hline Sanahuja de la Laguna, Juan & & 1552 & libro 730 & + estatua \\
\hline Segalos, Andreu (s) & Moncada & 1540 & libro 730 & abjuró de levi \\
\hline Sellay, Miquel & Valls & 1552 & libro 730 & penitenciado \\
\hline Sola, Joan & & 1626 & libro 732 & - \\
\hline Soler, Esteve (s) & & 1553 & leg. $1.592 / 28$ & - \\
\hline Soler, Jaume; apotecario & Manresa & 1552 & libro 730 & penitenciado \\
\hline Soler, Miquel (osa) & Barcelona & 1656 & libro 750 & - \\
\hline Spona, Mariano & & 1664 & leg. 2.156 & - \\
\hline Subies, Teodora (dom) & Barcelona & 1656 & libro 750 & - \\
\hline Sunyera, Eulalia & Barcelona & 1540 & libro 730 & penitenciada \\
\hline Tagarino, Pere & & 1540 & libro 730 & recluido \\
\hline
\end{tabular}


JUAN BLÁZQUEZ MIGUEL

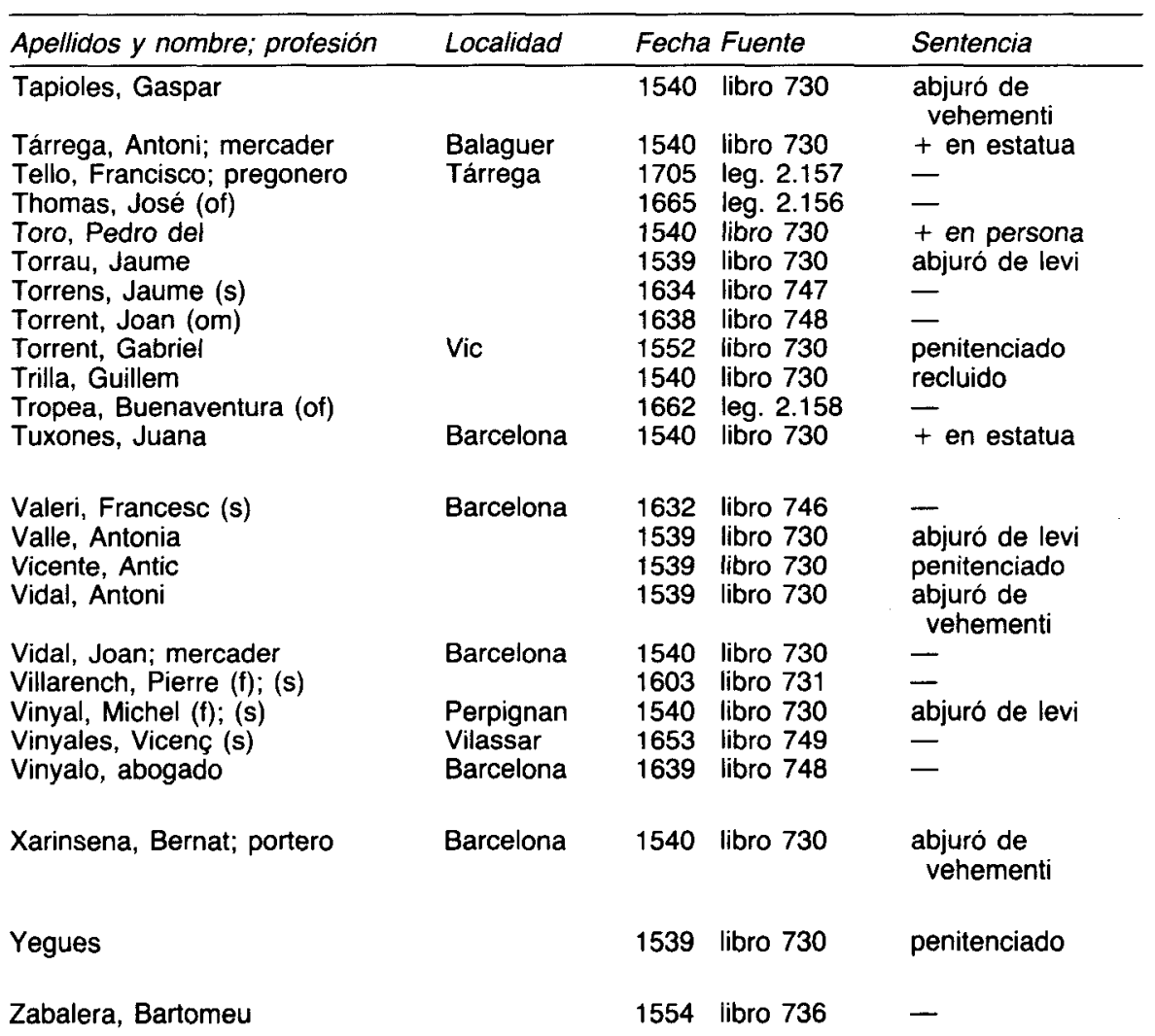


Catálogo de los procesos inquisitoriales del Tribunal del...

\section{PROCESOS CIVILES Y CRIMINALES}

\begin{tabular}{llll}
\hline Apellidos y nombre; profesión & Localidad & Fecha Fuente * & Sentencia \\
\hline
\end{tabular}

\section{BANDOLERISMO}

\begin{tabular}{|c|c|c|c|c|}
\hline Almao, Joan de; barbero & Calella & 1565 & libro 730 & desterrado \\
\hline $\begin{array}{l}\text { Barceló, Joaquín; labrador } \\
\text { Benajas, Antic; labrador } \\
\text { Bernat, Bartomeu Pere; ferrero } \\
\text { Bolla, Francesc } \\
\text { Bonmatí, Montserrat; labrador } \\
\text { Broguedos, Joan de; labrador } \\
\text { Bugatell, Narcis } \\
\text { Burguera, Jaume; labrador }\end{array}$ & $\begin{array}{l}\text { Sanauja } \\
\text { Constantins }\end{array}$ & $\begin{array}{l}1574 \\
1574 \\
1565 \\
1639 \\
1634 \\
1574 \\
1565 \\
1565\end{array}$ & $\begin{array}{l}\text { libro } 730 \\
\text { libro } 730 \\
\text { libro } 730 \\
\text { libro } 734 \\
\text { libro } 733 \\
\text { libro } 730 \\
\text { libro } 730 \\
\text { libro } 730\end{array}$ & $\begin{array}{l}\text { multado } \\
\text { multado } \\
\text { multado } \\
\text { multado } \\
\text { multado } \\
\text { multado } \\
5 \text { años en galeras } \\
\text { multado }\end{array}$ \\
\hline $\begin{array}{l}\text { Cala, Bartomeu; labrador } \\
\text { Camps, Bernat Jaume; labrador } \\
\text { Canales, Bartomeu; labrador } \\
\text { Canet, Joan Josep (s) } \\
\text { Caselles, Miquel; labrador } \\
\text { Cata, Bernat; labrador } \\
\text { Coll, Perot; labrador }\end{array}$ & Sallent & $\begin{array}{l}1565 \\
1574 \\
1574 \\
1635 \\
1565 \\
1574 \\
1574\end{array}$ & $\begin{array}{l}\text { libro } 730 \\
\text { libro } 730 \\
\text { libro } 730 \\
\text { libro } 733 \\
\text { libro } 730 \\
\text { libro } 730 \\
\text { libro } 730\end{array}$ & $\begin{array}{l}\text { multado } \\
\text { multado } \\
\text { multado } \\
\text { reprendido } \\
\text { multado } \\
\text { multado } \\
\text { multado }\end{array}$ \\
\hline Escallar, Jordi (osb) & Ripoll & 1581 & libro 730 & recluido \\
\hline Ferrer, Joan; labrador & & 1565 & libro 730 & desterrado \\
\hline Joan Josep; labrador & & 1574 & libro 730 & multado \\
\hline Gravell, Joan; labrador & & 1574 & libro 730 & multado \\
\hline Llovera, Narcis; labrador & & 1574 & libro 730 & multado \\
\hline Maciá, Jaume & Canet & 1636 & libro 734 & reprendido \\
\hline
\end{tabular}




\begin{tabular}{|c|c|c|c|c|}
\hline Apellidos y nombre; profesión & Localidad & Fecha & Fuente * & Sentencia \\
\hline Mas Palau, Joan & $\begin{array}{l}\text { St. Juliá de } \\
\text { Vilamirosa }\end{array}$ & 1628 & libro 733 & desterrado \\
\hline $\begin{array}{l}\text { Mascaro, Bernat; labrador } \\
\text { Mijans, Tomi; labrador } \\
\text { Mincasas; labrador }\end{array}$ & Castellet & $\begin{array}{l}1574 \\
1565 \\
1565\end{array}$ & $\begin{array}{l}\text { libro } 730 \\
\text { libro } 730 \\
\text { libro } 730\end{array}$ & $\begin{array}{l}\text { multado } \\
\text { desterrado } \\
\text { multado }\end{array}$ \\
\hline Maner, Pau & $\begin{array}{l}\text { Sia. Coloma } \\
\text { de Farners }\end{array}$ & 1634 & libro 733 & multado \\
\hline Naves, Antoni & & 1574 & libro 730 & multado \\
\hline Oller, Bartomeu; labrador & & 1574 & libro 730 & multado \\
\hline $\begin{array}{l}\text { Pocollo, Rafael; labrador } \\
\text { Poncet, Antoni; comerciante }\end{array}$ & Canet & $\begin{array}{l}1565 \\
1623\end{array}$ & $\begin{array}{l}\text { libro } 730 \\
\text { libro } 733\end{array}$ & $\begin{array}{l}\text { absuelto } \\
\text { multado }\end{array}$ \\
\hline $\begin{array}{l}\text { Ribosa, Bernat; labrador } \\
\text { Riera, Francesc; labrador } \\
\text { Ripoll, Pere } \\
\text { Rocha, Feliu (s) } \\
\text { Rosea, Joan } \\
\text { Roure, Bartomeu }\end{array}$ & $\begin{array}{l}\text { Sanauja } \\
\text { St. Coloma } \\
\text { de Farners }\end{array}$ & $\begin{array}{l}1574 \\
1574 \\
1565 \\
1574 \\
1639 \\
1631\end{array}$ & $\begin{array}{l}\text { libro } 730 \\
\text { libro } 730 \\
\text { libro } 730 \\
\text { libro } 730 \\
\text { libro } 734 \\
\text { libro } 733\end{array}$ & $\begin{array}{l}\text { multado } \\
\text { multado } \\
\text { multado } \\
\text { multado } \\
\text { multado } \\
\text { desterrado }\end{array}$ \\
\hline $\begin{array}{l}\text { Sagimar, Pau; labrador } \\
\text { Sisa, Joan; barbero } \\
\text { Soler, Guerau; labrador }\end{array}$ & Calella & $\begin{array}{l}1574 \\
1565 \\
1574\end{array}$ & $\begin{array}{l}\text { libro } 730 \\
\text { libro } 730 \\
\text { libro } 730\end{array}$ & $\begin{array}{l}\text { multado } \\
\text { desterrado } \\
\text { multado }\end{array}$ \\
\hline $\begin{array}{l}\text { Terradas, Antoni; labrador } \\
\text { Tos, Jaume; labrador } \\
\text { Tosell, Joan; labrador }\end{array}$ & & $\begin{array}{l}1565 \\
1565 \\
1574\end{array}$ & $\begin{array}{l}\text { libro } 730 \\
\text { libro } 730 \\
\text { libro } 730\end{array}$ & $\begin{array}{l}\text { multado } \\
\text { multado } \\
\text { multado }\end{array}$ \\
\hline $\begin{array}{l}\text { Vilaformiu, Salvador } \\
\text { Vilar, Miquel; labrador }\end{array}$ & Berga & $\begin{array}{l}1638 \\
1574\end{array}$ & $\begin{array}{l}\text { libro } 734 \\
\text { libro } 730\end{array}$ & $\begin{array}{l}\text { multado } \\
\text { multado }\end{array}$ \\
\hline Zarodo, Antoni; labrador & & 1574 & libro 730 & multado \\
\hline
\end{tabular}

\section{PASAR CABALLOS A FRANCIA}

Buscal, Guillén; comerciante

Alemany de Queralt, Gera

Beltran, Perucho ( $f$ ); militar

Benavente, Antoni Arnau; labrador Gerri

Casademunt, Montserrat; labrador Brull, EI (familiar)

Conill, Antic

Escalas, Joan; labrador

Escallas, Jordi Joan (osb)
Olot

Gerri

Ripoll
1572 leg. 1.592/27 absuelto

1574 libro 730 ¿multado?

1575 libro 730 absuelto

1629 libro 733 multado

1583 libro 730 multado

1575 libro 730

1628 libro 733

1581 libro 730 multado

multado y recluido 
Catálogo de los procesos inquisitoriales del Tribunal del...

\begin{tabular}{|c|c|c|c|c|}
\hline Apellidos y nombre; profesión & Localidad & Fecha & Fuente & Sentencia \\
\hline $\begin{array}{l}\text { Ferrera, Joan (s) } \\
\text { Font de Leret, Joan; labrador } \\
\text { Fresca, Bernardi; labrador (fami- } \\
\text { liar) } \\
\text { Mallol, Pere; (familiar) } \\
\text { Nil, Antic } \\
\text { Parramon, Dominique (f); labrador } \\
\text { Perinesta, Endaldo } \\
\text { Rosell, Antoni (familiar) } \\
\text { Sisa, Arnau (familiar) } \\
\text { Terça, Guillen; comerciante }\end{array}$ & $\begin{array}{l}\text { Isavarre } \\
\text { Sort } \\
\text { Surri } \\
\text { Noris } \\
\text { Olot } \\
\text { Ripoll } \\
\text { Andorra } \\
\text { Isavarre }\end{array}$ & $\begin{array}{l}1629 \\
1575 \\
1627 \\
1596 \\
1574 \\
1581 \\
1593 \\
1633 \\
1578\end{array}$ & $\begin{array}{l}\text { libro } 733 \\
\text { libro } 730 \\
\text { libro } 733 \\
\text { libro } 731 \\
\text { libro } 730 \\
\text { libro } 730 \\
\text { leg. } 2155(\text { a) } \\
\text { libro } 731 \\
\text { libro } 746 \\
\text { libro } 730\end{array}$ & $\begin{array}{l}\text { desterrado } \\
\text { absuelto } \\
\text { multado } \\
\text { multado } \\
- \\
\overline{-} \\
\text { multado } \\
\text { multado } \\
-\end{array}$ \\
\hline $\begin{array}{l}\text { Apellidos y nombre; } \\
\text { cargo inquisitorial }\end{array}$ & Localidad & Fecha & Fuente & Sentencia \\
\hline
\end{tabular}

\section{PORTAR ARMAS PROHIBIDAS}

\begin{tabular}{|c|c|c|c|c|}
\hline Baher, Pere Pau; familiar & $\begin{array}{l}\text { St. Esteve de } \\
\text { Llavanera }\end{array}$ & 1634 & libro 733 & multado \\
\hline Barrufet, Francés; familiar & Bellpuig & 1631 & libro 733 & multado \\
\hline Borrel, Joan; familiar & Guardia, La & 1638 & libro 734 & multado \\
\hline Farell, Jacint; familiar & $\begin{array}{l}\text { St. Feliu de } \\
\text { Codines }\end{array}$ & 1656 & libro 734 & reprendido \\
\hline Lluch, Francesc; familiar & Angles & 1635 & libro 733 & multado \\
\hline Monras, Miquel; familiar & Talaixa & 1667 & libro & reprendido \\
\hline $\begin{array}{l}\text { Planes de Angles, Salvador; fami- } \\
\text { liar }\end{array}$ & Talaixa & 1667 & libro 736 & reprendido \\
\hline $\begin{array}{l}\text { Puig, Antoni; hijo de familiar } \\
\text { Roca. Joan: familiar }\end{array}$ & $\begin{array}{l}\mathrm{Pi} \\
\text { Portell }\end{array}$ & $\begin{array}{l}1635 \\
1634\end{array}$ & libro 733 & multado \\
\hline
\end{tabular}

\section{USURA-MONEDA FALSA}

\author{
Alamany, Carles \\ Alinya, Jaume; familiar \\ Blanco, Bartomeu; familiar \\ Carrover, Jaume; familiar \\ Font, Jaume; familiar \\ Isern, Pere; familiar \\ Moxi, Francesc; familiar \\ Ninou, Joan (s); notario \\ Palet, Francesc; familiar \\ Pellicer, Josep; familiar
}

$\begin{array}{lll}\text { Barcelona } & 1632 & \text { libro } 746 \\ \text { Solsona } & 1633 & \text { libro } 733 \\ \text { Vilavella } & 1569 & \text { libro } 730 \\ \text { Gerb } & 1631 & \text { libro } 733 \\ \text { Malla } & 1634 & \text { libro } 733 \\ \text { Crespiá } & 1631 & \text { libro } 746 \\ \text { Solsona } & 1633 & \text { libro 733 } \\ \text { Rialp } & 1634 & \text { libro } 733 \\ \text { Perpignan } & 1631 & \text { libro } 733 \\ \text { Selva, La } & 1667 & \text { libro } 736\end{array}$

\author{
multado \\ huyó \\ desterrado \\ multado \\ multado \\ multado \\ suspenso \\ multado
}




Apellidos y nombre; profesión Localidad $\quad$ Fecha Fuente $\quad$ Sentencia

5. RIÑAS-INSULTOS

\begin{tabular}{|c|c|c|c|c|}
\hline $\begin{array}{l}\text { Abella, Magín (familiar); mercader } \\
\text { Agramont, Jaume (familiar); mer- } \\
\text { cader }\end{array}$ & Figueres & $\begin{array}{l}1667 \\
1574\end{array}$ & $\begin{array}{l}\text { libro } 736 \\
\text { libro } 730\end{array}$ & $\begin{array}{l}\text { multado } \\
\text { multado }\end{array}$ \\
\hline $\begin{array}{l}\text { Agujo, Jacint; labrador } \\
\text { Aiguaviva, Ramón; tte. goberna- } \\
\text { dor }\end{array}$ & $\begin{array}{l}\text { Sta. Perpetua } \\
\text { Conca D'Ode- } \\
\text { na }\end{array}$ & $\begin{array}{l}1633 \\
1633\end{array}$ & $\begin{array}{l}\text { libro } 733 \\
\text { libro } 746\end{array}$ & suspenso \\
\hline $\begin{array}{l}\text { Alesen, Francesc (s); ¿comisario? } \\
\text { Andreu, Antoni Joan }\end{array}$ & $\begin{array}{l}\text { Anglesola } \\
\text { Espluga de } \\
\text { Francolí }\end{array}$ & $\begin{array}{l}1670 \\
1565\end{array}$ & $\begin{array}{l}\text { libro } 754 \\
\text { libro } 730\end{array}$ & desterrado \\
\hline Areny, Joan; (familiar) & & 1631 & libro 733 & deterrados \\
\hline Atid, Gabriel & & 1551 & leg. $1.592 / 28$ & - \\
\hline $\begin{array}{l}\text { Badia, Joan (s) } \\
\text { Baldiri (s) } \\
\text { Baldrich, Joan; labrador } \\
\text { Bardos, Bernat (f); músico } \\
\text { Barriflet, Francesc; (familiar) } \\
\text { Basa, Antoni Lluís } \\
\text { Biosca, Joan (familiar) } \\
\text { Boixes, Antoni Franc (familiar); } \\
\text { barbero } \\
\text { Bombas, Sebastiá (familiar) } \\
\text { Bon, Pere; notario } \\
\text { Borrás, Antoni; (familiar) } \\
\text { Borrás, Antoni (hijo) } \\
\text { Bosca, Guilarma (f) }\end{array}$ & $\begin{array}{l}\text { Arros } \\
\text { Cambrils } \\
\text { Bellpuig } \\
\text { lgualada } \\
\text { Bascara }\end{array}$ & $\begin{array}{l}1633 \\
1565 \\
1561 \\
1570 \\
1633 \\
1574 \\
1570 \\
1569\end{array}$ & $\begin{array}{l}\text { libro } 733 \\
\text { libro } 730 \\
\text { libro } 730 \\
\text { libro } 730 \\
\text { libro } 733 \\
\text { libro } 730 \\
\text { libro } 730 \\
\text { libro } 739\end{array}$ & $\begin{array}{l}\text { suspenso } \\
\text { penitenciado } \\
\text { multado } \\
\text { penitenciado } \\
\text { reprendido } \\
\text { multado } \\
\text { multado } \\
\text { multado }\end{array}$ \\
\hline $\begin{array}{l}\text { Caballer, Miquel (familiar) } \\
\text { Campo, Jaume; mercader } \\
\text { Calavero, Joan (s); comisario } \\
\text { Camillas, Matías } \\
\text { Cañamals, Pere } \\
\text { Carbonell, Pere }\end{array}$ & $\begin{array}{l}\text { Sta. María de } \\
\text { Llusa }\end{array}$ & $\begin{array}{l}1631 \\
1574 \\
1569 \\
1560 \\
1565 \\
1662\end{array}$ & $\begin{array}{l}\text { libro } 733 \\
\text { libro } 1281 \\
\text { libro } 730 \\
\text { leg. } 1.592 / 28 \\
\text { libro } 730 \\
\text { libro } 734\end{array}$ & $\begin{array}{l}\text { reprendido } \\
\overline{\text { desterrado }} \\
\overline{\text { multado }} \\
\text { reprendido }\end{array}$ \\
\hline $\begin{array}{l}\text { Casallach, Joan } \\
\text { Casas, Jaume (s) } \\
\text { Casses, Esteve; (familiar) } \\
\text { Castellet, Guillén } \\
\text { Codina, Jaume (familiar) }\end{array}$ & $\begin{array}{l}\text { Torrent, EI } \\
\text { Aiguaviva } \\
\text { Cambrils } \\
\text { Perpignan }\end{array}$ & $\begin{array}{l}1639 \\
1681 \\
1634 \\
1574 \\
1562\end{array}$ & $\begin{array}{l}\text { libro } 734 \\
\text { libro } 735 \\
\text { libro } 733 \\
\text { libro } 730 \\
\text { libro } 730\end{array}$ & $\begin{array}{l}4 \text { años en galeras } \\
\text { multado } \\
\text { multado } \\
\text { multado } \\
\text { desterrado }\end{array}$ \\
\hline $\begin{array}{l}\text { Deu, Francesc; notario } \\
\text { Domenech (¿familiar?) } \\
\text { Domenech, Jeroni } \\
\text { Domenech, Rafael (s) } \\
\text { Domingo, Pau (familiar) } \\
\text { Durán, Jaume (familiar); labrador }\end{array}$ & $\begin{array}{l}\text { Sallent } \\
\text { Barcelona } \\
\text { Vic } \\
\text { Armentera } \\
\text { Sta. Fe }\end{array}$ & $\begin{array}{l}1636 \\
1556 \\
1574 \\
1556 \\
1681 \\
1637\end{array}$ & $\begin{array}{l}\text { libro } 734 \\
\text { leg. } 1.592 / 23 \\
\text { libro } 730 \\
\text { libro } 1.281 \\
\text { libro } 735 \\
\text { libro } 734\end{array}$ & $\begin{array}{l}\text { multado } \\
\text { azotado } \\
\text { reprendido } \\
\text { multado }\end{array}$ \\
\hline $\begin{array}{l}\text { Joan Antoni (s) } \\
\text { s, Jaume; mercader }\end{array}$ & Besalú & $\begin{array}{l}1631 \\
1632\end{array}$ & $\begin{array}{l}\text { libro } 733 \\
\text { libro } 733\end{array}$ & $\begin{array}{l}\text { suspenso } \\
\text { multado }\end{array}$ \\
\hline
\end{tabular}


Catálogo de los procesos inquisitoriales del Tribunal del...

\begin{tabular}{|c|c|c|c|c|}
\hline Apellidos y nombre; profesión & Localidad & Fecha & Fuente & Sentencia \\
\hline $\begin{array}{l}\text { Ferrer, Gabriel (s) } \\
\text { Ferrer, Joan } \\
\text { Ferrer, Joan (familiar) }\end{array}$ & $\begin{array}{l}\text { Girona } \\
\text { Girona } \\
\text { Sta. Maria de } \\
\text { Arenys }\end{array}$ & $\begin{array}{l}1561 \\
1561 \\
1631\end{array}$ & $\begin{array}{l}\text { libro } 730 \\
\text { libro } 730 \\
\text { libro } 746\end{array}$ & $\begin{array}{l}\text { desterrado } \\
\text { desterrado } \\
-\end{array}$ \\
\hline $\begin{array}{l}\text { Ferrer, Miquel } \\
\text { Feu, Simó (s) } \\
\text { Flasquet, Jaume (s) } \\
\text { Foibas, Marc (familiar) } \\
\text { Font, Joan } \\
\text { Forner, Pere (s) } \\
\text { Frexas, Jeroni; notario } \\
\text { Fuente, Manuel } \\
\text { Fuster, T. }\end{array}$ & $\begin{array}{l}\text { Puigcerdá } \\
\text { Barcelona } \\
\text { Barcelona } \\
\text { Cervera }\end{array}$ & $\begin{array}{l}1574 \\
1632 \\
1565 \\
1624 \\
1574 \\
1557 \\
1633 \\
1752 \\
1550\end{array}$ & $\begin{array}{l}\text { libro } 730 \\
\text { libro } 733 \\
\text { libro } 730 \\
\text { libro } 733 \\
\text { libro } 730 \\
\text { leg. } 1592 / 23 \\
\text { libro } 746 \\
\text { leg. } 3.724 / 110 \\
\text { leg. } 1.592 / 28\end{array}$ & $\begin{array}{l}\text { multado } \\
\text { multado } \\
\text { multado } \\
\text { desterrado } \\
\text { multado } \\
- \\
- \\
-\end{array}$ \\
\hline $\begin{array}{l}\text { Garriga, Jaume; platero } \\
\text { Gaspar, pintor } \\
\text { Gazañola, Lluís (familiar); labrador } \\
\text { Girona, Pau de (cap) } \\
\text { Gibert, Antoni; labrador } \\
\text { Gostar, Jaume; labrador } \\
\text { Granja, Miquel Joan; baile } \\
\text { Gravelosa } \\
\text { Grimaldo, Joan de } \\
\text { Gros, Jaume (familiar) } \\
\text { Guardia, Josep (s); comisario } \\
\text { Guinart Josep; clavario }\end{array}$ & $\begin{array}{l}\text { Barcelona } \\
\text { Barcelona } \\
\text { Tarragona } \\
\text { Camallera } \\
\text { Figueres } \\
\text { Tirvia } \\
\text { Vic } \\
\text { Bisbal, La } \\
\text { Sta. María de } \\
\text { Pineda } \\
\text { Barcelona }\end{array}$ & $\begin{array}{l}1632 \\
1562 \\
1634 \\
1617 \\
1666 \\
1631 \\
1668 \\
1556 \\
1565 \\
1574 \\
1688 \\
1662\end{array}$ & $\begin{array}{l}\text { libro } 733 \\
\text { libro } 730 \\
\text { libro } 733 \\
\text { libro } 732 \\
\text { libro } 735 \\
\text { libro } 733 \\
\text { libro } 735 \\
\text { leg. } 1.592 / 23 \\
\text { libro } 730 \\
\text { libro } 730 \\
\text { libro } 735 \\
\text { libro } 752\end{array}$ & $\begin{array}{l}\text { multado } \\
\text { multado } \\
\text { multado } \\
\text { suspenso } \\
\text { desterrado } \\
\text { desterrado } \\
\text { suspenso } \\
- \text { desterrado } \\
\text { multado } \\
\text { reprendido } \\
\end{array}$ \\
\hline $\begin{array}{l}\text { Hortoneda, Rafael (s) } \\
\text { Huguet, Gabriel; herrero }\end{array}$ & $\begin{array}{l}\text { Tarragona } \\
\text { Vila-Rodona }\end{array}$ & $\begin{array}{l}1632 \\
1631\end{array}$ & $\begin{array}{l}\text { libro } 733 \\
\text { libro } 733\end{array}$ & $\begin{array}{l}\text { multado } \\
\text { suspenso }\end{array}$ \\
\hline Izern, Pere, (familiar) & Crespiá & 1632 & libro 733 & reprendido \\
\hline $\begin{array}{l}\text { Jaume Lluis; zapatero } \\
\text { Jerroja, Bernat } \\
\text { Josep Francesc } \\
\text { Joro, Pere; curtidor }\end{array}$ & $\begin{array}{l}\text { Granollers } \\
\text { Girona } \\
\text { Vila-Seca } \\
\text { Girona }\end{array}$ & $\begin{array}{l}1562 \\
1560 \\
1637 \\
1633\end{array}$ & $\begin{array}{l}\text { libro } 730 \\
\text { leg. } 1.592 / 28 \\
\text { libro } 734 \\
\text { libro } 733\end{array}$ & $\begin{array}{l}\text { multado } \\
\text { reprendido } \\
\text { suspenso }\end{array}$ \\
\hline Juan Rafael; estudiante & & 1636 & libro 734 & suspenso \\
\hline $\begin{array}{l}\text { Laguna, Francesc; familiar } \\
\text { Lamuza, Dominique (f); mercader } \\
\text { López, Tomás; marinero } \\
\text { Lupia, Rafael } \\
\text { Llavanera, Jeroni (familiar); } \\
\text { labrador }\end{array}$ & $\begin{array}{l}\text { Ripoll } \\
\text { Perpignan } \\
\text { Sitges } \\
\text { Girona } \\
\text { Lladó }\end{array}$ & $\begin{array}{l}1628 \\
1565 \\
1639 \\
1562 \\
1637\end{array}$ & $\begin{array}{l}\text { libro } 733 \\
\text { libro } 730 \\
\text { libro } 734 \\
\text { libro } 730 \\
\text { libro } 734\end{array}$ & $\begin{array}{l}\text { multado } \\
\text { desterrado } \\
\text { reprendido } \\
\text { desterrado } \\
\text { absuelto }\end{array}$ \\
\hline $\begin{array}{l}\text { Lledós, Pere; familiar } \\
\text { Lledós, Joan }\end{array}$ & $\begin{array}{l}\text { Tirvia } \\
\text { Tirvia }\end{array}$ & $\begin{array}{l}1632 \\
1632\end{array}$ & $\begin{array}{l}\text { libro } 733 \\
\text { libro } 733\end{array}$ & $\begin{array}{l}\text { reprendido } \\
\text { reprendido }\end{array}$ \\
\hline $\begin{array}{l}\text { Macia, Dimás (familiar) } \\
\text { Marimón, Onofre } \\
\text { Mascaró, Bernat; marinero } \\
\text { Mascaró, Rafael (familiar) }\end{array}$ & Maçanet & $\begin{array}{l}1658 \\
1570 \\
1565 \\
1636\end{array}$ & $\begin{array}{l}\text { libro } 734 \\
\text { libro } 730 \\
\text { libro } 730 \\
\text { libro } 734\end{array}$ & $\begin{array}{l}\text { multado } \\
\text { multado } \\
\text { absuelto } \\
\text { multado }\end{array}$ \\
\hline
\end{tabular}


JUAN BLÁZQUEZ MIGUEL

\begin{tabular}{|c|c|c|c|c|}
\hline Apellidos y nombre; profesión & Localidad & Fecha & Fuente & Sentencia \\
\hline $\begin{array}{l}\text { Maseras, Jaume; ministro de } \\
\text { Justicia }\end{array}$ & Barcelona & 1633 & libro 746 & - \\
\hline $\begin{array}{l}\text { Maymó, Ramón; familiar } \\
\text { Medina, Hernando de }\end{array}$ & Arbos & $\begin{array}{l}1661 \\
1565\end{array}$ & $\begin{array}{l}\text { libro } 734 \\
\text { libro } 730\end{array}$ & $\begin{array}{l}\text { multado } \\
\text { azotado y } \\
\text { desterrado }\end{array}$ \\
\hline $\begin{array}{l}\text { Miguel, Guerau } \\
\text { Milla i Renart, Jaume }\end{array}$ & $\begin{array}{l}\text { St. Cristofol } \\
\text { les Fonts }\end{array}$ & $\begin{array}{l}1574 \\
1639\end{array}$ & $\begin{array}{l}\text { libro } 730 \\
\text { libro } 734\end{array}$ & $\begin{array}{l}\text { multado } \\
\text { suspenso }\end{array}$ \\
\hline $\begin{array}{l}\text { Molins, Francesc; curtidor } \\
\text { Molleres, Benet (s) } \\
\text { Montarguel i Soldevila, Miquel de } \\
\text { Montaguet, Tomás (familiar) } \\
\text { Montant, Cris } \\
\text { Montelles, Jaume; comisario } \\
\text { Morer, Vicenç } \\
\text { Mur, Josep; notario }\end{array}$ & $\begin{array}{l}\text { Montagut } \\
\text { Oleta } \\
\text { Girona }\end{array}$ & $\begin{array}{l}1565 \\
1637 \\
1639 \\
1631 \\
1561 \\
1574 \\
1574 \\
1661\end{array}$ & $\begin{array}{l}\text { libro } 730 \\
\text { libro } 734 \\
\text { libro } 734 \\
\text { libro } 733 \\
\text { libro } 730 \\
\text { libro } 730 \\
\text { libro } 730 \\
\text { libro } 734\end{array}$ & $\begin{array}{l}2 \text { años en galeras } \\
\text { multado } \\
\text { reprendido } \\
\text { reprendido } \\
\text { desterrado } \\
\text { multado } \\
\text { multado } \\
\text { suspenso }\end{array}$ \\
\hline $\begin{array}{l}\text { Navarro de Heredia, Pedro } \\
\text { Napolita, Valenti (familiar) } \\
\text { Ninou, Joan (s) }\end{array}$ & Rialp & $\begin{array}{l}1574 \\
1574 \\
1633\end{array}$ & $\begin{array}{l}\text { libro } 730 \\
\text { libro } 730 \\
\text { libro } 733\end{array}$ & $\begin{array}{l}\text { multado } \\
\text { multado } \\
\text { multado }\end{array}$ \\
\hline $\begin{array}{l}\text { Oliver, Antoni } \\
\text { Oliver, Pere } \\
\text { Oliver, Vicenç } \\
\text { Ombert, Salvio } \\
\text { Orriola, Jacint (familiar) } \\
\text { Ospical, Josep (s) }\end{array}$ & $\begin{array}{l}\text { Granollers } \\
\text { Granollers } \\
\text { Granollers } \\
\text { Olot } \\
\text { Menarguens } \\
\text { Barcelona }\end{array}$ & $\begin{array}{l}1636 \\
1561 \\
1561 \\
1640 \\
1634 \\
1676\end{array}$ & $\begin{array}{l}\text { libro } 734 \\
\text { libro } 730 \\
\text { libro } 730 \\
\text { libro } 748 \\
\text { libro } 733 \\
\text { libro } 735\end{array}$ & $\begin{array}{l}\text { desterrado } \\
\text { desterrado } \\
\text { desterrado } \\
\overline{\text { multado }} \\
\text { multado }\end{array}$ \\
\hline $\begin{array}{l}\text { Paris, Jaume Joan } \\
\text { Parrull, Alexos; criado } \\
\text { Pelaires (3); pelaires (3) } \\
\text { Pelejana, Joana } \\
\text { Penyella, Antoni (familiar); } \\
\text { labrador }\end{array}$ & $\begin{array}{l}\text { Montmagastre } \\
\text { Esponella } \\
\text { Perpignan } \\
\text { Montarguil }\end{array}$ & $\begin{array}{l}1690 \\
1633 \\
1553 \\
1562 \\
1636\end{array}$ & $\begin{array}{l}\text { libro } 735 \\
\text { libro } 733 \\
\text { leg. } 1.592 / 28 \\
\text { libro } 730 \\
\text { libro } 734\end{array}$ & $\begin{array}{l}\text { multado } \\
5 \text { años en galeras } \\
- \\
\text { multada } \\
\text { reprendido }\end{array}$ \\
\hline $\begin{array}{l}\text { Perarnau, Pere; labrador } \\
\text { Pere, Enric; cirujano } \\
\text { Piolat, Joan } \\
\text { Pla, Antic } \\
\text { Pou, Pere; labrador } \\
\text { Prats, Miquel (familiar) } \\
\text { Predico, Gabriel (s) } \\
\text { Puig, Gabriel } \\
\text { Puig, Francesc (familiar) } \\
\text { Puig, Jaume } \\
\text { Pujadas, Joan (familiar) } \\
\text { Pujadas, Pere; tejedor } \\
\text { Pujol, Jaume }\end{array}$ & $\begin{array}{l}\text { Corça } \\
\text { Vic } \\
\text { Girona } \\
\text { Sarriá } \\
\text { Fontcoberta } \\
\text { Dorve } \\
\text { Granollers } \\
\text { Granollers }\end{array}$ & $\begin{array}{l}1636 \\
1639 \\
1574 \\
1556 \\
1665 \\
1632 \\
1633 \\
1639 \\
1690 \\
1565 \\
1680 \\
1562 \\
1565\end{array}$ & $\begin{array}{l}\text { libro } 734 \\
\text { libro } 734 \\
\text { libro } 730 \\
\text { leg. 1.592/23 } \\
\text { libro } 735 \\
\text { libro } 733 \\
\text { libro } 733 \\
\text { libro } 734 \\
\text { libro } 735 \\
\text { libro } 730 \\
\text { libro } 735 \\
\text { libro } 730 \\
\text { libro } 730\end{array}$ & $\begin{array}{l}\text { suspenso } \\
\text { multado } \\
\text { multado } \\
\text { reprendido } \\
\text { multado } \\
\text { multado } \\
\text { reprendido } \\
\text { reprendido } \\
\text { reprendido } \\
\text { reprendido } \\
\text { desterrado } \\
\text { multado }\end{array}$ \\
\hline $\begin{array}{l}\text { Rodajel, Bernat (familiar) } \\
\text { Ramis, Francesc } \\
\text { Reigg, Antoni; baile } \\
\text { Renau, Ramón }\end{array}$ & $\begin{array}{l}\text { Barcelona } \\
\text { San Celoni } \\
\text { Vilabertrán } \\
\text { Castello } \\
\text { d'Empuries }\end{array}$ & $\begin{array}{l}1562 \\
1740 \\
1561 \\
1638\end{array}$ & $\begin{array}{l}\text { libro } 730 \\
\text { leg. } 2.164 \\
\text { libro } 730 \\
\text { libro } 734\end{array}$ & $\begin{array}{l}\text { multado } \\
\text { desterrado } \\
\text { reprendido }\end{array}$ \\
\hline
\end{tabular}


Catálogo de los procesos inquisitoriales del Tribunal del...

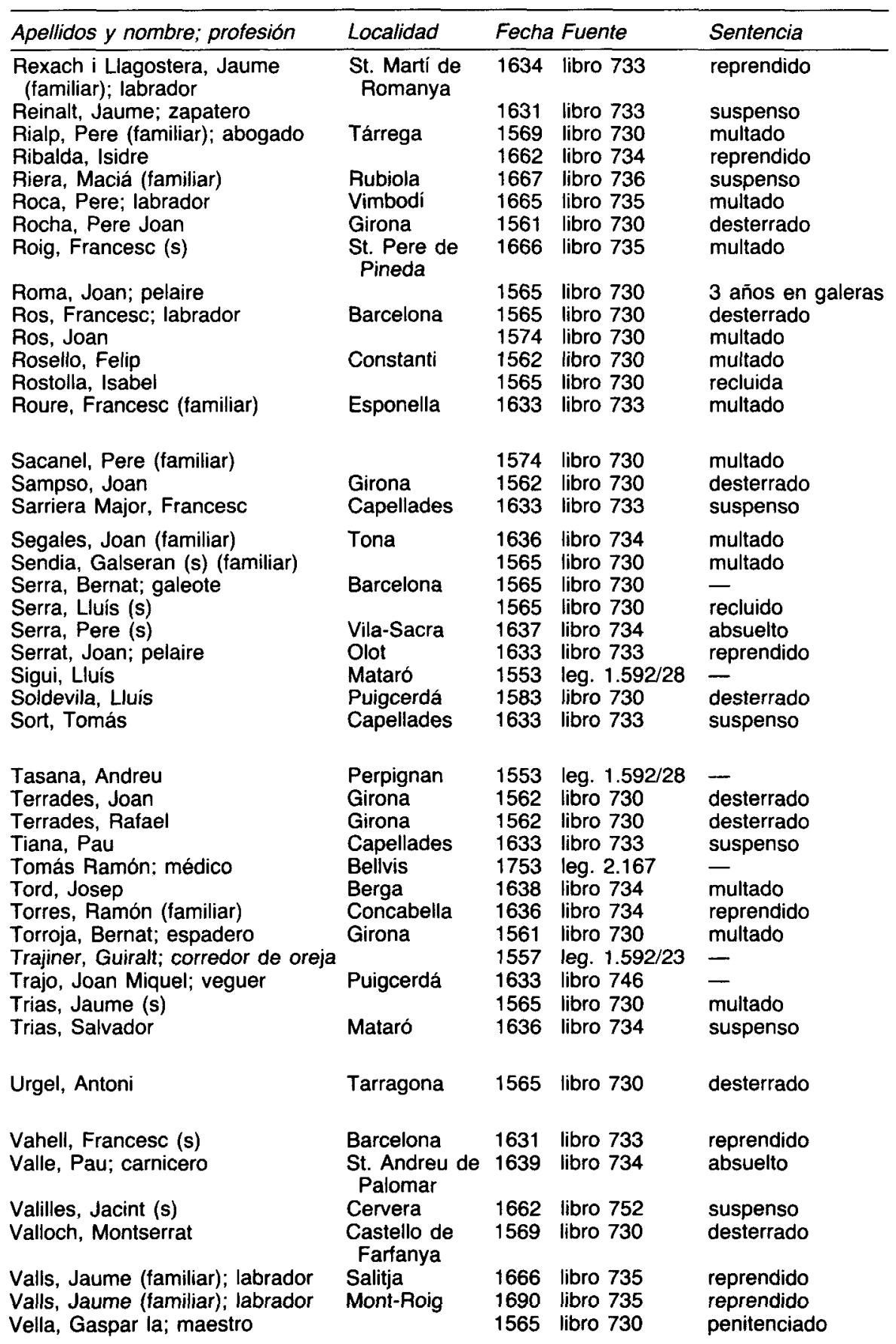


JUAN BLAZQUEZ MIGUEL

\begin{tabular}{lccll}
\hline Apellidos y nombre; profesión & Localidad & Fecha Fuente & Sentencia \\
\hline Vera, Bárbara & & 1574 libro 730 & multada \\
Vicens, Antoni (s) (familiar) & Finestres & 1569 libro 730 & - \\
Vila, Arnau (familiar) & & 1633 libro 733 & multado \\
Vives, Joanot & & 1574 libro 730 & multado \\
Zaporta, Jeroni & Tarragona & 1565 libro 730 & multado
\end{tabular}

\section{INCONTINENCIA SEXUAL}

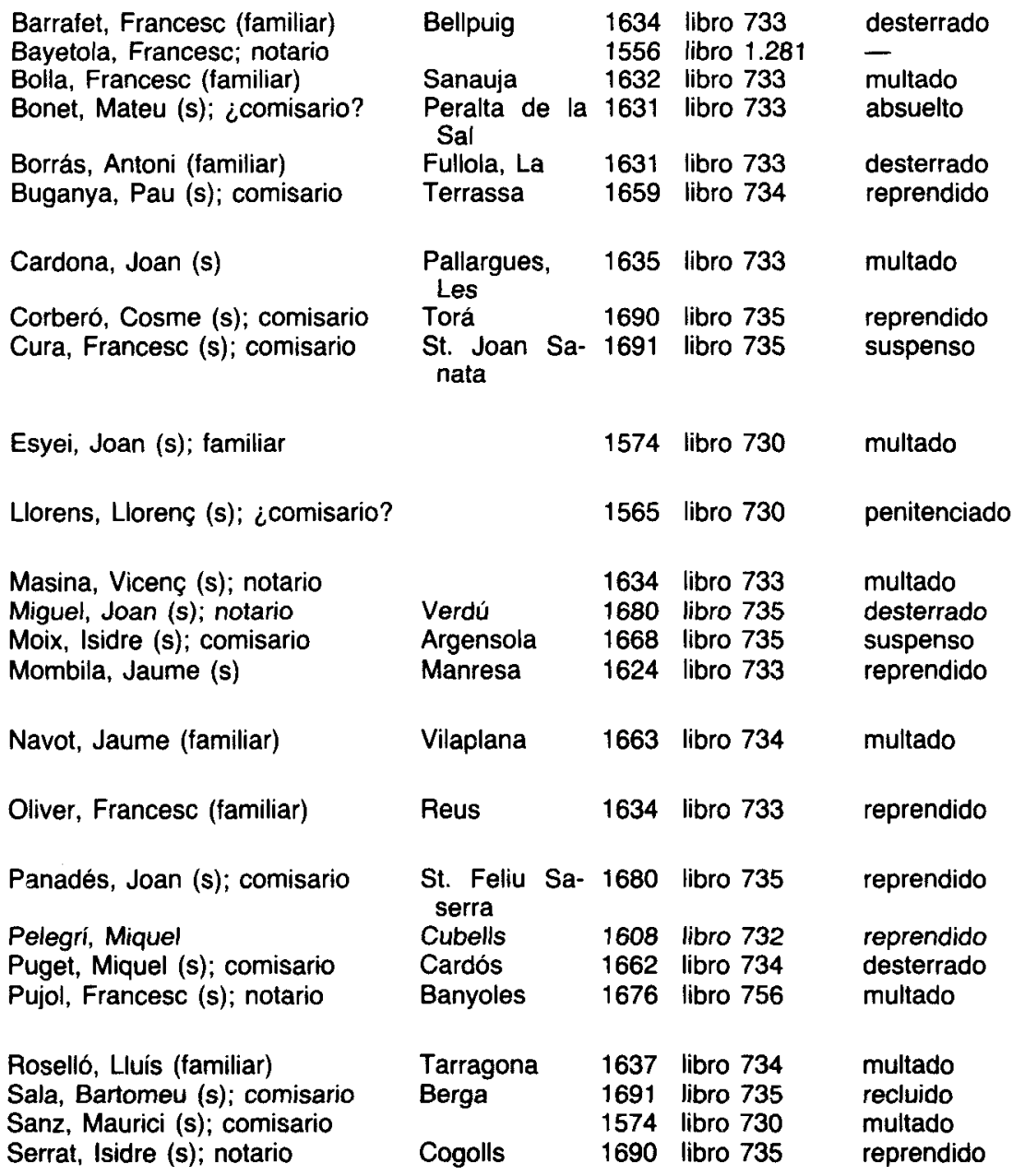


Catálogo de los procesos inquisitoriales del Tribunal del...

\begin{tabular}{lllll}
\hline Apellidos y nombre; profesión & Localidad & Fecha Fuente & Sentencia \\
\hline Torres, Oleguer (s); comisario & & 1716 leg. 2.161 & - \\
& & & & \\
& & 1636 libro 734 & absuelto \\
Vallovera, Gaspar & Tona & 1636 libro 734 & reprendido \\
Verdera, Jeroni (s); ¿comisario? & Vila-Sacra & 1672 libro 734 & -
\end{tabular}

\section{ASESINATOS}

Aguilar, Matias; gobernador

Arrufat, Bartomeu

Asolfa, Antoni

Avinyon, Pere Ramon

Brufat, Jaume

Casals, Francesc; pescador

Coma, Gabriel

Corco, Pau; abogado

Cusidor, Antoni

Espuer, Jeroni

Esquerra, Antoni

Estalella, Francesc

Feliu, Joan

Ferrer, Guillem; mercader

Foybas, Jaume; labrador

Foybas, Marc; labrador

Graells, Francesc

Forcadella, Jeroni; labrador

Lledós, Dimas

Mateu, Jacint

Moreig, Bernat; criado

Orteneda, Pau Joan; médico

Perantoni, Joan; labrador

Planas, Joan Miquel

\begin{tabular}{|c|c|c|c|}
\hline $\begin{array}{l}\text { Tragó } \\
\text { Claravalls } \\
\text { Brunyola }\end{array}$ & $\begin{array}{l}1627 \\
1636 \\
1570 \\
1603\end{array}$ & $\begin{array}{l}\text { libro } 733 \\
\text { libro } 734 \\
\text { libro } 730 \\
\text { libro } 731\end{array}$ & $\begin{array}{l}\text { reprendido } \\
\text { absuelto } \\
\frac{1}{\text { desterrado }}\end{array}$ \\
\hline Drumyora & 1003 & 1100ro 737 & desterrado \\
\hline $\begin{array}{l}\text { Tallada, La } \\
\text { Rocafort de } \\
\text { Queralt }\end{array}$ & $\begin{array}{l}1627 \\
1634\end{array}$ & $\begin{array}{l}\text { libro } 745 \\
\text { libro } 733\end{array}$ & $\begin{array}{l}\text { desterrado } \\
\text { absuelto }\end{array}$ \\
\hline $\begin{array}{l}\text { Santpedor } \\
\text { Balaguer } \\
\text { Crespiá }\end{array}$ & $\begin{array}{l}1633 \\
1628 \\
1636\end{array}$ & $\begin{array}{l}\text { libro } 733 \\
\text { libro } 733 \\
\text { libro } 734\end{array}$ & $\begin{array}{l}4 \text { años en galeras } \\
\text { desterrado } \\
\text { absuelto }\end{array}$ \\
\hline $\begin{array}{l}\text { Perpignan } \\
\text { Sta. Pau } \\
\text { Serra, La }\end{array}$ & $\begin{array}{l}1635 \\
1667 \\
1634\end{array}$ & $\begin{array}{l}\text { libro } 747 \\
\text { libro } 736 \\
\text { libro } 733\end{array}$ & $\begin{array}{l}\text { suspenso } \\
\text { desterrado }\end{array}$ \\
\hline $\begin{array}{l}\text { St. Feliu de } \\
\text { Guíxols }\end{array}$ & 1634 & libro 733 & absuelto? \\
\hline $\begin{array}{l}\text { Perpignan } \\
\text { Olvan } \\
\text { Olvan }\end{array}$ & $\begin{array}{l}1540 \\
1631 \\
1628\end{array}$ & $\begin{array}{l}\text { libro } 736 \\
\text { libro } 746 \\
\text { libro } 733\end{array}$ & $\begin{array}{l}+ \text { en persona } \\
\text { desterrado }\end{array}$ \\
\hline $\begin{array}{l}\text { Ntra. Sra. del } \\
\text { Pons }\end{array}$ & 1682 & libro 735 & multado \\
\hline Santpedor & 1636 & libro 734 & - \\
\hline Salas & 1658 & libro 751 & - \\
\hline $\begin{array}{l}\text { Vilanant } \\
\text { Tartareu }\end{array}$ & $\begin{array}{l}1636 \\
1585\end{array}$ & $\begin{array}{l}\text { libro } 734 \\
\text { libro } 730\end{array}$ & $\begin{array}{l}\text { multado } \\
+ \text { en persona }\end{array}$ \\
\hline Tarragona & 1634 & libro 733 & desterrado \\
\hline Llambilles & 1634 & libro 733 & 4 años en galeras \\
\hline Riudovelles & 1659 & libro 734 & absuelto \\
\hline
\end{tabular}


JUAN BLÁZQUEZ MIGUEL

\begin{tabular}{|c|c|c|c|c|c|}
\hline Apellidos y nombre; profesión & Localidad & & Fecha & Fuente & Sentencia \\
\hline $\begin{array}{l}\text { Riera, Joan } \\
\text { Robi, Jaume; comerciante } \\
\text { Robi, Joan; comerciante }\end{array}$ & $\begin{array}{l}\text { St. Steve } \\
\text { Puigcerdá } \\
\text { Puigcerdá }\end{array}$ & & $\begin{array}{l}1634 \\
1564 \\
1564\end{array}$ & $\begin{array}{l}\text { libro } 733 \\
\text { libro } 1.281 \\
\text { libro } 1281\end{array}$ & $\begin{array}{l}\text { multado } \\
\text { desterrado } \\
\text { desterrado }\end{array}$ \\
\hline $\begin{array}{l}\text { Sagoles, Joan } \\
\text { Sala, Francesc }\end{array}$ & $\begin{array}{l}\text { Tora } \\
\text { Arenys } \\
\text { Mar }\end{array}$ & de & $\begin{array}{l}1636 \\
1633\end{array}$ & $\begin{array}{l}\text { libro } 734 \\
\text { libro } 733\end{array}$ & $\begin{array}{l}\text { multado } \\
\text { absuelto }\end{array}$ \\
\hline Torres, Mariana de & & & 1608 & libro 732 & suspensa \\
\hline $\begin{array}{l}\text { Ventalada, Pau } \\
\text { Vinyales, Pere }\end{array}$ & Barcelona & & $\begin{array}{l}1594 \\
1554\end{array}$ & $\begin{array}{l}\text { libro } 731 \\
\text { leg. } 1.592 / 28\end{array}$ & $\begin{array}{l}+ \text { en persona } \\
\text { penitenciado }\end{array}$ \\
\hline
\end{tabular}

\section{DELITOS VARIOS DE FAMILIARES Y MINISTROS}

\begin{tabular}{|c|c|c|c|c|}
\hline $\begin{array}{l}\text { Badorch, Gabriel (familiar) } \\
\text { Bertus, Francesc (familiar) }\end{array}$ & $\begin{array}{l}\text { Vallbona } \\
\text { Conques }\end{array}$ & $\begin{array}{l}1569 \\
1667\end{array}$ & $\begin{array}{l}\text { libro } 730 \\
\text { libro } 736\end{array}$ & $\begin{array}{l}\text { multado } \\
\text { multado }\end{array}$ \\
\hline Campderós, Pau (familiar) & $\begin{array}{l}\text { St. Feliu de } \\
\text { Llobregat }\end{array}$ & 1634 & libro 733 & absuelto \\
\hline $\begin{array}{l}\text { Casas, Joan (s); notario } \\
\text { Fornelis, Pere Joan; militar } \\
\text { Fornes, Maciá (familiar) }\end{array}$ & $\begin{array}{l}\text { Coll de Nargo } \\
\text { Sanauja }\end{array}$ & $\begin{array}{l}1639 \\
1636 \\
1672\end{array}$ & $\begin{array}{l}\text { libro } 734 \\
\text { libro } 734 \\
\text { libro } 755\end{array}$ & $\begin{array}{l}\text { multado } \\
\text { multado } \\
-\end{array}$ \\
\hline $\begin{array}{l}\text { Greñón, Pere (familiar) } \\
\text { Guardia, Gabriel (familiar) } \\
\text { Gusol, Joan Guillem de (familiar) }\end{array}$ & $\begin{array}{l}\text { Vimbodí } \\
\text { Conques }\end{array}$ & $\begin{array}{l}1608 \\
1565 \\
1661\end{array}$ & $\begin{array}{l}\text { libro } 732 \\
\text { libro } 730 \\
\text { libro } 734\end{array}$ & $\begin{array}{l}\text { multado } \\
\text { multado } \\
\text { multado }\end{array}$ \\
\hline $\begin{array}{l}\text { Mijans, Pere (familiar) } \\
\text { Muntana, Domenech; abogado de } \\
\text { presos }\end{array}$ & Barcelona & $\begin{array}{l}1640 \\
1771\end{array}$ & $\begin{array}{l}\text { libro } 748 \\
\text { leg. } 2.170\end{array}$ & $\overline{-}$ \\
\hline $\begin{array}{l}\text { Oliveras, Antoni; sastre (hijo } \\
\text { de familiar) }\end{array}$ & Granollers & 1636 & libro 734 & multado \\
\hline $\begin{array}{l}\text { Ortigas, José; ayudante del alcai- } \\
\text { de }\end{array}$ & Barcelona & 1630 & libro 745 & - \\
\hline $\begin{array}{l}\text { Pastor, Juan; alcaide de la cárcel } \\
\text { Pons, Joan (familiar) } \\
\text { Postiel, Joan Francesc (familiar) } \\
\text { Prat, Salvador (familiar) } \\
\text { Pujalt, Joan (familiar) }\end{array}$ & Barcelona & $\begin{array}{l}1627 \\
1608 \\
1668 \\
1634 \\
1640\end{array}$ & $\begin{array}{l}\text { libro } 745 \\
\text { libro } 732 \\
\text { libro } 735 \\
\text { libro } 733 \\
\text { libro } 748\end{array}$ & $\begin{array}{l}- \\
\text { desterrado } \\
\text { multado } \\
-\end{array}$ \\
\hline $\begin{array}{l}\text { Ribot, Macià (familiar) } \\
\text { Roig, Joan (familiar) }\end{array}$ & $\begin{array}{l}\text { Andorra } \\
\text { Vilafranca del } \\
\text { Penedés }\end{array}$ & $\begin{array}{l}1593 \\
1593\end{array}$ & $\begin{array}{l}\text { libro } 731 \\
\text { libro } 730\end{array}$ & $\begin{array}{l}\text { absuelto } \\
\text { desterrado }\end{array}$ \\
\hline
\end{tabular}


Catálogo de los procesos inquisitoriales del Tribunal del...

\begin{tabular}{lllll}
\hline Apellidos y nombre; profesión & Localidad & Fecha Fuente & Sentencia \\
\hline Sala, Jaume; alcaide de la cárcel & Barcelona & 1682 & libro 735 & multado \\
& & & & \\
& Senet & 1611 libro 732 & suspenso \\
Tera, Ángel de (familiar) & & 1569 libro 730 & multado
\end{tabular}

\section{ROBOS A FAMILIARES Y MINISTROS}

\begin{tabular}{|c|c|c|c|c|}
\hline Bidorch, Arnaud (f) & Barcelona & 1639 & libro 734 & 5 años en galeras \\
\hline $\begin{array}{l}\text { Cabeza, Francisco } \\
\text { Costa, Francesc }\end{array}$ & Barcelona & $\begin{array}{l}1574 \\
1557\end{array}$ & $\begin{array}{l}\text { libro } 730 \\
\text { leg. } 1.592 / 23\end{array}$ & multado \\
\hline $\begin{array}{l}\text { Galera, Guillem; cochero } \\
\text { Gubies, Bernat; sastre }\end{array}$ & $\begin{array}{l}\text { Barcelona } \\
\text { Barcelona }\end{array}$ & $\begin{array}{l}1675 \\
1571\end{array}$ & $\begin{array}{l}\text { libro } 735 \\
\text { libro } 730\end{array}$ & $\begin{array}{l}2 \text { años en galeras } \\
\text { azotado }\end{array}$ \\
\hline Juan Bautista & & 1564 & libro 730 & $\begin{array}{l}\text { azotado y deste- } \\
\text { rrado }\end{array}$ \\
\hline Junyent, Jacint; labrador & Matadepera & 1633 & libro 733 & suspenso \\
\hline López, Juan & Barcelona & 1569 & libro 730 & $\begin{array}{l}\text { azotado y deste- } \\
\text { rrado }\end{array}$ \\
\hline Lleonart, Tomás; labrador & Tarragona & 1564 & libro 730 & absuelto \\
\hline $\begin{array}{l}\text { Porta, Josep; alcaide de la cárcel } \\
\text { Puig, Hereu del }\end{array}$ & Barcelona & $\begin{array}{l}1653 \\
1565\end{array}$ & $\begin{array}{l}\text { libro } 749 \\
\text { libro } 730\end{array}$ & multado \\
\hline Soler, Antoni & & 1574 & libro 730 & azotado \\
\hline Tinel, Pere & & 1574 & libro 730 & $\begin{array}{l}\text { azotado y deste- } \\
\text { rrado }\end{array}$ \\
\hline Varares, Pierre (f) & & 1555 & leg. $1.592 / 23$ & - \\
\hline
\end{tabular}

10. DESACATOS

$\begin{array}{lllll}\text { Aymar, Pere } & & 1574 & \text { libro } 730 & - \\ \text { Ballin, Jaume (s) } & \begin{array}{l}\text { Castello } \\ \text { d'Empuries }\end{array} & 1561 & \text { libro } 730 & \text { multado }\end{array}$




\begin{tabular}{|c|c|c|c|c|}
\hline Apellidos y nombre; profesión & Localidad & Fecha & Fuente & Sentencia \\
\hline Boter, Pere; mercader & Cervera & 1620 & libro 732 & desterrado \\
\hline Coll, Pau & & 1574 & libro 730 & - \\
\hline Costa, Josep (of) & Barcelona & 1663 & libro 734 & reprendido \\
\hline $\begin{array}{l}\text { Escardo, Pere Pau } \\
\text { Esprer, Joan (s) } \\
\text { Estier, Jeroni (s) }\end{array}$ & Ripoll & $\begin{array}{l}1574 \\
1562 \\
1574\end{array}$ & $\begin{array}{l}\text { libro } 730 \\
\text { libro } 730 \\
\text { libro } 730\end{array}$ & $\begin{array}{l}\text { penitenciario } \\
\text { multado } \\
\text { multado }\end{array}$ \\
\hline $\begin{array}{l}\text { Fabre, Antoni; baile } \\
\text { Fajardo (s) } \\
\text { Fere, N.; militar } \\
\text { Ferrer, Antic } \\
\text { Fornells, Pere Joan; labrador }\end{array}$ & Garriga, La & $\begin{array}{l}1562 \\
1559 \\
1654 \\
1574 \\
1636\end{array}$ & $\begin{array}{l}\text { libro } 730 \\
\text { leg. } 1592 / 28 \\
\text { libro } 749 \\
\text { libro } 730 \\
\text { libro } 734\end{array}$ & $\begin{array}{l}\text { absuelto } \\
\overline{-} \\
\text { desterrado } \\
\text { multado }\end{array}$ \\
\hline $\begin{array}{l}\text { Garriga, Josep } \\
\text { Guash, Jaume; platero } \\
\text { Guerris, Miquel; labrador } \\
\text { Guivert, Rafael (of) }\end{array}$ & $\begin{array}{l}\text { Sallent } \\
\text { Girona } \\
\text { Garriga, La } \\
\text { Barcelona }\end{array}$ & $\begin{array}{l}1638 \\
1635 \\
1636 \\
1663\end{array}$ & $\begin{array}{l}\text { libro } 734 \\
\text { libro } 747 \\
\text { libro } 734 \\
\text { libro } 734\end{array}$ & $\begin{array}{l}\text { desterrado } \\
\text { multado } \\
\text { suspenso }\end{array}$ \\
\hline Joan Alberte & Portella & 1574 & libro 730 & desterrado \\
\hline $\begin{array}{l}\text { Moneyrach; Pere Antoni } \\
\text { Moya, Esteve; criado }\end{array}$ & Barcelona & $\begin{array}{l}1574 \\
1564\end{array}$ & $\begin{array}{l}\text { libro } 730 \\
\text { libro } 730\end{array}$ & $\begin{array}{l}\text { desterrado } \\
\text { absuelto }\end{array}$ \\
\hline $\begin{array}{l}\text { Porta, Josep } \\
\text { Portabella, Joan } \\
\text { Prats, Antic } \\
\text { Prats, Martí }\end{array}$ & Barcelona & $\begin{array}{l}1654 \\
1562 \\
1574 \\
1553\end{array}$ & $\begin{array}{l}\text { libro } 734 \\
\text { libro } 730 \\
\text { libro } 730 \\
\text { leg. } 1.592 / 28\end{array}$ & $\begin{array}{l}\text { desterrado } \\
\text { multado } \\
-\end{array}$ \\
\hline $\begin{array}{l}\text { Reyes, Francisca de los } \\
\text { Rubi, Guillen } \\
\text { Rubies, Pere }\end{array}$ & Gerb & $\begin{array}{l}1574 \\
1574 \\
1562\end{array}$ & $\begin{array}{l}\text { libro } 730 \\
\text { libro } 730 \\
\text { libro } 730\end{array}$ & $\begin{array}{l}\text { azotada } \\
\overline{\text { multado }}\end{array}$ \\
\hline $\begin{array}{l}\text { Sardá, Narcís } \\
\text { Soler, Rafael }\end{array}$ & & $\begin{array}{l}1574 \\
1637\end{array}$ & $\begin{array}{l}\text { libro } 730 \\
\text { libro } 734\end{array}$ & $\begin{array}{l}\text { multado } \\
\text { reprendido }\end{array}$ \\
\hline Viejo, Jean (f) & & 1562 & libro 730 & $\begin{array}{c}\text { azotes y } 2 \text { años } \\
\text { en galeras }\end{array}$ \\
\hline Vilallongas, Antoni & & 1574 & libro 730 & - \\
\hline
\end{tabular}

\section{FINGIMIENTO DE CARGO INQUISITORIAL}

Aguilar, Francesc; maestro Aranés, Joan (s)

$\begin{array}{llll}\text { Riudoms } & 1602 & \text { libro } 731 & \text { desterrado } \\ \text { Castellterçol } & 1593 & \text { libro } 731 & \text { desterrado }\end{array}$


Catálogo de los procesos inquisitoriales del Tribunal del...

\begin{tabular}{|c|c|c|c|c|}
\hline Apellidos y nombre; profesión & Localidad & Fecha & Fuente & Sentencia \\
\hline $\begin{array}{l}\text { Barrota, Montserrat } \\
\text { Botella, Pere; zapatero }\end{array}$ & $\begin{array}{l}\text { Molins de Rei } \\
\text { Surp }\end{array}$ & $\begin{array}{l}1590 \\
1578\end{array}$ & $\begin{array}{l}\text { libro } 731 \\
\text { libro } 730\end{array}$ & $\begin{array}{l}\text { absuelto } \\
\text { azotado y galeras } \\
\text { perpetuidad }\end{array}$ \\
\hline $\begin{array}{l}\text { Castellar, Joan; labrador } \\
\text { Claramunt, Narcís; pintor }\end{array}$ & $\begin{array}{l}\text { Esponella } \\
\text { Vic }\end{array}$ & $\begin{array}{l}1563 \\
1637\end{array}$ & $\begin{array}{l}\text { libro } 730 \\
\text { libro } 734\end{array}$ & $\begin{array}{l}\text { desterrado } \\
\text { reprendido }\end{array}$ \\
\hline $\begin{array}{l}\text { Encinas, Lorenzo } \\
\text { Escales, Esteve } \\
\text { Estrabán, Luis }\end{array}$ & $\begin{array}{l}\text { Viladomiu } \\
\text { Girona }\end{array}$ & $\begin{array}{l}1570 \\
1562 \\
1595\end{array}$ & $\begin{array}{l}\text { libro } 730 \\
\text { libro } 730 \\
\text { libro } 731\end{array}$ & $\begin{array}{l}\text { multado } \\
\text { desterrado } \\
\text { desterrado }\end{array}$ \\
\hline $\begin{array}{l}\text { Figueres, Pere Joan; estudiante } \\
\text { Foix, Joanot } \\
\text { Font, Pau (s) }\end{array}$ & St. Cugat & $\begin{array}{l}1590 \\
1565 \\
1574\end{array}$ & $\begin{array}{l}\text { libro } 731 \\
\text { libro } 730 \\
\text { libro } 730\end{array}$ & $\begin{array}{l}\text { multado } \\
\text { multado } \\
\text { multado }\end{array}$ \\
\hline Ginebreda, Pedro; labrador & Molins de Rei & 1590 & libro 731 & multado \\
\hline Hernández, Juan & & 1565 & libro 730 & azotado \\
\hline $\begin{array}{l}\text { Lombart, Joan } \\
\text { Llompar, Bartomeu; labrador }\end{array}$ & Molins de Rei & $\begin{array}{l}1565 \\
1591\end{array}$ & $\begin{array}{l}\text { libro } 730 \\
\text { libro } 731\end{array}$ & $\begin{array}{l}\text { azotado } \\
\text { destarrado }\end{array}$ \\
\hline $\begin{array}{l}\text { Masot, Joan (s) } \\
\text { Marsal, Joan (s) } \\
\text { Mas, Bernat; albañil }\end{array}$ & $\begin{array}{l}\text { Lleida } \\
\text { Perpignan } \\
\text { Barcelona }\end{array}$ & $\begin{array}{l}1623 \\
1560 \\
1615\end{array}$ & $\begin{array}{l}\text { libro } 733 \\
\text { libro } 730 \\
\text { libro } 732\end{array}$ & $\begin{array}{l}\text { desterrado } \\
\text { destarrado } \\
\text { azotado y } 3 \text { años } \\
\text { en galeras }\end{array}$ \\
\hline $\begin{array}{l}\text { Miró, Nicolas ( } f \text { ) } \\
\text { Morera, Jaume; sastre }\end{array}$ & $\begin{array}{l}\text { Ger } \\
\text { Pons }\end{array}$ & $\begin{array}{l}1578 \\
1635\end{array}$ & $\begin{array}{l}\text { libro } 730 \\
\text { libro } 733\end{array}$ & $\begin{array}{l}\text { desterrado } \\
\text { multado }\end{array}$ \\
\hline $\begin{array}{l}\text { Negre, Jaume } \\
\text { Nicolás de Manuel; militar }\end{array}$ & Borrassa & $\begin{array}{l}1562 \\
1590\end{array}$ & $\begin{array}{l}\text { libro } 730 \\
\text { libro } 731\end{array}$ & $\begin{array}{l}\text { desterrado } \\
\text { azotado y } 3 \text { años } \\
\text { en galeras }\end{array}$ \\
\hline Quer, Pere (s) & Esponella & 1562 & libro 730 & desterrado \\
\hline Puig, Guillaume (f); (s) & & 1565 & libro 730 & desterrado \\
\hline $\begin{array}{l}\text { Ribadeulot, Bernart } \\
\text { Roca, Antoni } \\
\text { Roselló, Antic; labrador }\end{array}$ & $\begin{array}{l}\text { Valls } \\
\text { Molins de Rei }\end{array}$ & $\begin{array}{l}1565 \\
1602 \\
1590\end{array}$ & $\begin{array}{l}\text { libro } 730 \\
\text { libro } 731 \\
\text { libro } 731\end{array}$ & $\begin{array}{l}\text { multado } \\
\text { desterrado } \\
\text { desterrado }\end{array}$ \\
\hline $\begin{array}{l}\text { Salat, Joan; tejedor } \\
\text { Selva, Jaume; labrador } \\
\text { Selva, Pere (s) }\end{array}$ & $\begin{array}{l}\text { St. Climent } \\
\text { Sescebes }\end{array}$ & $\begin{array}{l}1585 \\
1591 \\
1581\end{array}$ & $\begin{array}{l}\text { libro } 730 \\
\text { libro } 731 \\
\text { libro } 730\end{array}$ & $\begin{array}{l}\text { absuelto } \\
\text { desterrado } \\
\text { multado }\end{array}$ \\
\hline Suzarello, Francesco (i) & & 1589 & libro 731 & $\begin{array}{l}\text { azotado y } 3 \text { años } \\
\text { en galeras }\end{array}$ \\
\hline Tomás, Francesc & & 1565 & libro 730 & absuelto \\
\hline
\end{tabular}




\begin{tabular}{lllll}
\hline Apellidos y nombre; profesión & Localidad & Fecha Fuente & Sentencia \\
\hline Valentín, Salvio (s) & Bisbal, La & 1677 libro 735 & multado
\end{tabular}

\section{DETENCIONES INDEBIDAS Y FUGAS}

\begin{tabular}{|c|c|c|c|c|}
\hline $\begin{array}{l}\text { Anglada, Joanot; mercader } \\
\text { Aragón, Guillén }\end{array}$ & $\begin{array}{l}\text { Manresa } \\
\text { Albons }\end{array}$ & $\begin{array}{l}1565 \\
1571\end{array}$ & $\begin{array}{l}\text { libro } 730 \\
\text { libro } 730\end{array}$ & $\begin{array}{l}\text { multado } \\
\text { penitenciado }\end{array}$ \\
\hline $\begin{array}{l}\text { Bas, Jaume } \\
\text { Blanco, Antón } \\
\text { Blanco, Juan } \\
\text { Borrell, Marc; baile } \\
\text { Botiller, Pere }\end{array}$ & Gornal, La & $\begin{array}{l}1570 \\
1570 \\
1570 \\
1562 \\
1570\end{array}$ & $\begin{array}{l}\text { libro } 730 \\
\text { libro } 730 \\
\text { libro } 730 \\
\text { libro } 730 \\
\text { libro } 730\end{array}$ & $\begin{array}{l}\text { desterrado } \\
\text { multado } \\
\text { multado } \\
\text { multado } \\
\text { desterrado }\end{array}$ \\
\hline $\begin{array}{l}\text { Codina, Jaume } \\
\text { Clot, Joan; labrador }\end{array}$ & & $\begin{array}{l}1565 \\
1565\end{array}$ & $\begin{array}{l}\text { libro } 730 \\
\text { libro } 730\end{array}$ & $\begin{array}{l}\text { multado } \\
\text { multado }\end{array}$ \\
\hline Ferrer, Bernat & & 1631 & libro 746 & - \\
\hline Guilla, Joan & & 1574 & libro 730 & desterrado \\
\hline $\begin{array}{l}\text { Horta, Miquel } \\
\text { Horta del Molí, Pere; baile }\end{array}$ & Brunyola & $\begin{array}{l}1570 \\
1666\end{array}$ & $\begin{array}{l}\text { libro } 730 \\
\text { libro } 735\end{array}$ & $\begin{array}{l}\text { desterrado } \\
\text { absuelto }\end{array}$ \\
\hline $\begin{array}{l}\text { March, Climent } \\
\text { Mascaró, Jaume } \\
\text { Miguel Trago, Joan; veguer } \\
\text { Moro, Joanot }\end{array}$ & $\begin{array}{l}\text { Arboç } \\
\text { Puigcerdá } \\
\text { Barcelona }\end{array}$ & $\begin{array}{l}1574 \\
1659 \\
1633 \\
1574\end{array}$ & $\begin{array}{l}\text { libro } 730 \\
\text { libro } 734 \\
\text { libro } 733 \\
\text { libro } 730\end{array}$ & $\begin{array}{l}\text { desterrado } \\
\text { reprendido } \\
\text { azotado y deste- } \\
\text { rrado }\end{array}$ \\
\hline Pere Joan Pasqual & $\begin{array}{l}\text { Arenys } \\
\text { Mar }\end{array}$ & 1658 & libro 751 & suspenso \\
\hline $\begin{array}{l}\text { Puignau, Agusti; veguer } \\
\text { Pujol, Jaume }\end{array}$ & & $\begin{array}{l}1633 \\
1574\end{array}$ & $\begin{array}{l}\text { libro } 733 \\
\text { libro } 730\end{array}$ & $\begin{array}{l}\text { absuelto } \\
\text { multado }\end{array}$ \\
\hline Romeu, Ramón; veguer & Barcelona & 1633 & libro 746 & - \\
\hline Sala, Joan & $\begin{array}{l}\text { St. Feliu Sa- } \\
\text { serra }\end{array}$ & 1569 & libro 730 & multado \\
\hline
\end{tabular}


Catálogo de los procesos inquisitoriales del Tribunal del...

\begin{tabular}{lllll}
\hline Apellidos y nombre; profesión & Localidad & Fecha Fuente & Sentencia \\
\hline Serra, Joan & 1633 libro 733 & multado \\
Torrent, Andreu & Barcelona & 1574 libro 730 & multado
\end{tabular}

\section{QUEBRANTAMIENTO DE DESTIERRO}

\begin{tabular}{|c|c|c|c|c|}
\hline $\begin{array}{l}\text { Barcetó, Miquel; cirujano } \\
\text { Beril, Guillamot }(f)\end{array}$ & & $\begin{array}{l}1668 \\
1573\end{array}$ & $\begin{array}{l}\text { libro } 735 \\
\text { libro } 737\end{array}$ & $\begin{array}{l}\text { desterrado } \\
+ \text { en estatua }\end{array}$ \\
\hline Cazañes, Antoine (f) & Macanet & 1600 & libro 731 & - \\
\hline $\begin{array}{l}\text { Estrany, Jeroni } \\
\text { Cardona, Francesc }\end{array}$ & & $\begin{array}{l}1659 \\
1606\end{array}$ & $\begin{array}{l}\text { libro } 734 \\
\text { libro } 732\end{array}$ & recluido \\
\hline Francés, Jean (s) & & 1573 & libro 737 & + en estatua \\
\hline Malafosa, Guillaume ( $f$ ) & & 1601 & libro 740 & - \\
\hline Mora, Jaime; labrador & Palafolls & 1654 & libro 734 & falleció \\
\hline Olivera, Mariana & Barcelona & 1658 & libro 734 & desterrada \\
\hline $\begin{array}{l}\text { Padu, Bernard }(f) \text {; carnicero } \\
\text { Pascual, Pere Joan }\end{array}$ & $\begin{array}{c}\text { Arenys } \\
\text { Munt }\end{array}$ & $\begin{array}{l}1573 \\
1662\end{array}$ & $\begin{array}{l}\text { libro } 737 \\
\text { libro } 734\end{array}$ & $\begin{array}{l}+ \text { en estatua } \\
\text { desterrado }\end{array}$ \\
\hline Rueda, Gabriel (f) & & 1573 & libro 737 & + en estatua \\
\hline Solans, Jean François (f) & Vila-Rubia & 1667 & libro 735 & - \\
\hline Torremira, José; pelaire & $\begin{array}{l}\text { St. Feliu Sa- } \\
\text { serra }\end{array}$ & 1659 & libro 734 & desterrado \\
\hline
\end{tabular}

\section{DELITOS VARIOS}

Arenas, Joana

Benavente, Ventura de

Bizcarri, Antón
Arenys de 1633 libro 733 multada
Mar

1574 libro 730

1570 libro 730 absuelto 
JUAN BLÁZQUEZ MIGUEL

\begin{tabular}{|c|c|c|c|c|}
\hline Apellidos y nombre; profesión & Localidad & Fecha & Fuente & Sentencia \\
\hline Cadena, Benet (s) & $\begin{array}{l}\text { St. Salvador } \\
\text { de Tolo }\end{array}$ & 1633 & libro 746 & - \\
\hline $\begin{array}{l}\text { Calvel, Jaume (s) } \\
\text { Capellades, Onofre } \\
\text { Carreras, Bartomeu } \\
\text { Caylo, Pierre (f); molinero }\end{array}$ & & $\begin{array}{l}1574 \\
1574 \\
1570 \\
1630\end{array}$ & $\begin{array}{l}\text { libro } 730 \\
\text { libro } 730 \\
\text { libro } 730 \\
\text { libro } 745\end{array}$ & $\begin{array}{l}\text { multado } \\
\text { desterrado } \\
\text { penitenciado } \\
-\end{array}$ \\
\hline Chacón, Juan & & 1555 & leg. $1.592 / 28$ & - \\
\hline Doria, Juan Ramón; marinero & $\begin{array}{l}\text { Sta. María del } \\
\mathrm{Pla}\end{array}$ & 1504 & libro 730 & multado \\
\hline Elías, Margarida & Guardia, La & 1632 & libro 733 & suspensa \\
\hline $\begin{array}{l}\text { Ferreray, Joan; trajinero } \\
\text { Follona, Margarida } \\
\text { Font, Raymond (f) (s) } \\
\text { Frexar, Esteve; tintorero }\end{array}$ & Olot & $\begin{array}{l}1574 \\
1565 \\
1564 \\
1627\end{array}$ & $\begin{array}{l}\text { libro } 730 \\
\text { libro } 730 \\
\text { libro } 730 \\
\text { libro } 745\end{array}$ & $\begin{array}{l}\text { absuelta } \\
\text { absuelto } \\
-\end{array}$ \\
\hline $\begin{array}{l}\text { Gámez, Diego de } \\
\text { Glauset, Guillem (s) } \\
\text { Guerris, Miquel } \\
\text { Gurri, Pere (of) }\end{array}$ & $\begin{array}{l}\text { Surp } \\
\text { Sanauja }\end{array}$ & $\begin{array}{l}1574 \\
1575 \\
1636 \\
1664\end{array}$ & $\begin{array}{l}\text { libro } 730 \\
\text { libro } 730 \\
\text { libro } 734 \\
\text { libro } 753\end{array}$ & - \\
\hline Llor, Jeroni & Barcelona & 1564 & libro 730 & desterrado \\
\hline $\begin{array}{l}\text { Marti, Antoni (osa) } \\
\text { Martir, Pere (s) } \\
\text { Maspons, Pau (osa) } \\
\text { Minguell, Joan (s) }\end{array}$ & $\begin{array}{l}\text { Barcelona } \\
\text { Barcelona } \\
\text { Barcelona }\end{array}$ & $\begin{array}{l}1622 \\
1589 \\
1622 \\
1722\end{array}$ & $\begin{array}{l}\text { libro } 733 \\
\text { libro } 730 \\
\text { libro } 733 \\
\text { leg. } 2.159\end{array}$ & $\begin{array}{l}\text { desterrado } \\
\text { multado } \\
\text { desterrado } \\
\text { _- }\end{array}$ \\
\hline $\begin{array}{l}\text { Pardin̄a, Francesc } \\
\text { Paz, Ramón } \\
\text { Pedro Marco } \\
\text { Pont, Pere; trajinero } \\
\text { Pujol, Sebastià; tejedor }\end{array}$ & $\begin{array}{l}\text { Barcelona } \\
\text { Reus } \\
\text { Barcelona }\end{array}$ & $\begin{array}{l}1627 \\
1638 \\
1608 \\
1574 \\
1631\end{array}$ & $\begin{array}{l}\text { libro } 745 \\
\text { libro } 748 \\
\text { libro } 732 \\
\text { libro } 730 \\
\text { libro } 746\end{array}$ & $\begin{array}{l}- \\
\text { suspenso } \\
\text { - }\end{array}$ \\
\hline Roig, Ramón (s) & $\underset{\text { Farfanya }}{\text { Castello }} \mathrm{de}$ & 1622 & libro 733 & - \\
\hline $\begin{array}{l}\text { Rosella, Caterina } \\
\text { Roure, Joan; labrador }\end{array}$ & $\begin{array}{l}\text { Barcelona } \\
\text { Figueres }\end{array}$ & $\begin{array}{l}1565 \\
1764\end{array}$ & $\begin{array}{l}\text { libro } 730 \\
\text { leg. } 2.170\end{array}$ & penitenciada \\
\hline Subirat, Joan & & 1663 & libro 746 & - \\
\hline Xammar, Ramón & & 1638 & libro 748 & - \\
\hline
\end{tabular}

